\title{
VII. Die Reparationen: Unvereinbare Interessen
}

Ausgeprägter als nach dem Ersten Weltkrieg war die Reparationsfrage zentraler Bestandteil der Konzeptionen zur Neuordnung des internationalen Mächtesystems, deren Reichweite über die Deutschlandfrage hinausgriff. Es galt nicht nur, den Fehler von 1918 zu vermeiden, als das vorrangige Interesse der Sieger an Reparationen und Produktivität eine strukturelle Abrüstung und Entmilitarisierung des Reiches verhindert hatte, und Deutschland keine neue Chance zur Revision der inneren wie der äußeren Kriegsfolgen zu gewähren; sondern die deutschen Reparationen waren zugleich ein zentrales Element der nationalen Rekonstruktionspläne und internationalen Neuordnungskonzepte der vier Alliierten, die mehr durch deren Verhältnis untereinander als durch ihr bilaterales Verhältnis zu Deutschland bestimmt waren ${ }^{1}$. Je näher der Frieden rückte, desto stärker trat der Aspekt der Rache bzw. der Wiedergutmachung hinter die globale Machtpolitik zurück. Der Wendepunkt war die Konferenz von Yalta, als dieses lauernde Konkurrenzkalkül gemeinsame Entscheidungen auch nur über Grundsätze unmöglich machte. Als nach der Potsdamer Konferenz besatzungspragmatische Sachzwänge hinzutraten, sanken die geringen Erfolgschancen des Kontrollrats weiter, der - in diesem Punkt eigentlich als technische Abwicklungsbehörde konzipiert - ohne politische Vorgaben hilflos blieb.

Am 23. Oktober 1943 unterbreitete der amerikanische Außenminister Hull auf der Moskauer Außenministerkonferenz einen detaillierten Vorschlag zur künftigen Behandlung Deutschlands. Dieses sollte verpflichtet werden, „die Wiedergutmachung des durch seine Streitkräfte der UdSSR und anderen alliierten und besetzten Ländern zugefügten materiellen Schadens zu sichern“. Zur Regulierung der Leistungen war eine Reparationskommission vorgesehen. Molotow, von seinen Kollegen gedrängt, „Kostenvoranschläge" für den Wiedergutmachungsbedarf einzureichen, wies diese bereitwillig darauf hin, „daß wir nicht nur Politiker, sondern in gewissem Maße auch Geschäftsleute sind“. Er nutzte die Gelegenheit, im Falle Italiens ein Präzedenz zu verankern und unter Hinweis auf die Bedürfnisse der Kriegführung das Prinzip von Vorab-Lieferungen einzuführen. Im Falle Deutschlands bekundete er lediglich „großes Interesse“ und umschrieb auf Rückfragen die sowjetischen Ziele pauschal, „Deutschland als einen aggressiven Staat maximal unschädlich zu machen“. Zugleich meldete er Ansprüche gegenüber allen deutschen Bündnispartnern an. Amerikanische Vorstellungen, die deutschen Reparationen weniger „als das Hauptkontrollinstrument über die deutsche Militärmacht“, sondern (wie schon die Lend-lease-Zahlungen) als „Beitrag [...] zur Errichtung der Art von Weltwirtschaft, wie sie die Vereinten Nationen anstreben“, einzusetzen, wies Molotow brüsk zurück ${ }^{2}$. Denn das hätte die weitergehenden Aspirationen der So-

1 Nübel, Reparationspolitik, bes. S. 43-67. Mai, Industrielle Abrüstung, S. 68 ff.

2 Moskauer Konferenz 1943, S. 29, 46, 158, 160 f., 217 ff., 239, 253 ff., 281 ff. 
wjetunion beeinträchtigt, wie sie Eugen Varga 1942 formuliert hatte: „Die Zahlung der Wiedergutmachungen wird ohne Zweifel die materielle Lage in den besiegten Ländern noch verschärfen, unter allen Umständen zu einer wachsenden Unzufriedenheit der Völker führen und eine revolutionäre Situation schaffen."3

In diesen Differenzen blitzte erstmals die Unvereinbarkeit der Positionen auf, die sich weiter verstärkte, je präziser die amerikanischen Vorstellungen für ihre „Welt-Reparationspolitik für Deutschland“ formuliert wurden ${ }^{4}$. Als deren Kernpunkt schälte sich heraus, daß die „Reparationszahlungen und -lieferungen auf den Prozeß der europäischen Rekonstruktion bezogen, wenngleich nicht eng beschränkt werden sollen. Diese Regierung plant ein Reparationsprogramm, das vorrangig weder ein Instrument der Strafe ist noch ein Mittel, Deutschland Sicherheitsmaßnahmen aufzuzwingen [...], sondern eine positive Serie von Maßnahmen auf seiten Deutschlands, um in den von ihm zerstörten Ländern die Grundlagen für ein stabiles und blühendes Wirtschaftsleben wiederaufzubauen. [...] Die Wirtschaftspolitik dieser Regierung gegenüber Deutschland als Ganzem [...] sollte so angelegt sein, daß neue Möglichkeiten für eine Verbesserung der Organisation der europäischen Wirtschaft insgesamt und die Entwicklung von umfassenden internationalen Institutionen im wirtschaftlichen Bereich eröffnet werden.“ Der Kontrollapparat sei „so zu gestalten, daß die technische Grundlage für verbesserte internationale wirtschaftliche Zusammenarbeit gelegt bzw. die Möglichkeit für eine solche erhalten wird“, z. B. durch „Organisationen mit dem Ziel der Vereinigung des europäischen Transportwesens, der Energie und Kommunikationseinrichtungen“. Wenn Deutschlands Wiederaufstieg zur Vormacht Europas verhindert, seine industrielle Autarkie gebrochen, ein landwirtschaftlicher Protektionismus ebenso wie diskriminierende Handelspraktiken unterbunden und sein Potential der „Rekonstruktion Europas“ zunutze gemacht werden sollten, dann schien es nur ein probates Mittel zu geben, um diesen anspruchsvollen Zielkatalog zu verwirklichen: die Reparationen ${ }^{5}$. Die Bedeutung der Reparationsfrage für die (gesamt)europäische Rekonstruktion sollte hervorgehoben werden, indem sie nicht einer alliierten Expertengruppe, sondern der von den Briten vorgeschlagenen „europäischen Hochkommission“ übertragen wurde ${ }^{6}$. Es war keineswegs die isolierte Auffassung eines Einzelnen, wenn Bernard Baruch im Frühjahr 1945 die Errichtung eines „Obersten Europäischen Rekonstruktionsrates“ vorschlug, um „Aspekte der europäischen Rekonstruktion mit der deutschen Reparationsregelung und anderen Fragen“ zu verknüpfen; die deutsche Vorherrschaft über Europa werde zerbrochen, „wenn viele deutsche Fabriken nach Ost und West zu befreundeten Nationen verlagert werden"7. Der Entschluß, „daß das Reparationsprogramm in erster Linie als ein Instrument genutzt werden sollte zur Reorientierung der europäischen Wirtschaft“, indem durch die ökonomische Entwaffnung Deutschlands Europa industriell entwickelt und seine Abhängigkeit von der deutschen Wirtschaft weitgehend abgebaut wurde ${ }^{8}$, leitete eine

3 Zitiert nach: Laufer, Reparationspolitik, S. 2.

4 FRUS, 1945/III, S. 1208 (Pauley, 7. 5. 1945). Vgl. FRUS, Malta and Yalta, S. 190-97 (Januar 1945).

5 NA, RG 107/McCloy, box 26 (WS-54c, 2. 3. 1944). FRUS, 1944/I, S. 278 ff. (14. 8. 1944). RG 59/ EAC, box 6, folder: General Correspondence (29. 4. 1945).

6 FRUS, 1944/l, S. 275 (Winant, 19. 8. 1944). Die Briten hatten im Juli 1943 die Bildung eines European Economic Committee angeregt. FRUS, 1944/II, S. $614 \mathrm{ff}$.

7 NA, RG 59, 740.00119 EAC/3-1745 (Annex); RG 59/Pauley Mission, box 11 (23.6. 1945).

${ }^{8}$ NA, RG 59/EAC, folder: USGCC (3.6. 1945; Bezug: JCS 1341, 10. 5. 1945). 
qualitativ neue Form von Reparationspolitik ein. Angesichts der Erfahrungen nach dem Ersten Weltkrieg durften nicht erneut „Rückzablung oder Rache“ die maßgeblichen Prinzipien sein, sondern „Sicherbeit für die Welt und Rekonstruktion der von den Deutschen verwüsteten Gebiete“" . Das aber implizierte, daß die deutschen Leistungen begrenzt werden mußten ${ }^{10}$. „Exporte aus Deutschland [...] im Wege von Reparationen“, sollten, das war die vorrangige Hoffnung, „die Notwendigkeit, Auslandskredite und andere Mittel zur Gewährleistung zusätzlicher Importe bereitzustellen“, reduzieren, die die europäischen Länder anders nicht finanzieren konnten ${ }^{11}$. Aber mancher sah bereits realistisch, daß ohne amerikanische Finanzhilfe der Wiederaufbau nicht gelingen würde. So riet Stimson in Potsdam, diese Hilfsgelder in den USA über „einen Mann und eine Behörde“ fließen zu lassen; ein „Wirtschaftsrat für Europa“, dessen amerikanischer Vorsitzender dem Präsidenten der USA unterstellt und aufgrund von Richtlinien der amerikanischen Behörde tätig werden sollte, würde „den europäischen Regierungen helfen, sich selbst $z u$ belfen bei der Wiederherstellung stabiler Verhältnisse "12.

Das nahm die Prinzipien des Marshall-Plans vorweg und ging weit über die Vorstellungen der Briten hinaus ${ }^{13}$. Deren Dilemma war 1944/45 in den Verhandlungen mit den USA formuliert worden: „Deutschlands Beitrag zur Wiederherstellung Europas, ob durch Reparationen oder anderes, darf diesem keine günstige Wettbewerbsposition im internationalen Nachkriegshandel geben.“ Bis zuletzt herrschte Unsicherheit, ob Reparationen und ökonomische Entwaffnung letztlich kompatibel seien, ob Deutschland zur „Normalität“ zurückgeführt oder durch „Umstrukturierung“ als Konkurrent ausgeschaltet werden sollte. Der Morgenthau-Plan wurde abgelehnt, selbst wenn er einen Nettogewinn „im sichtbaren Handel in der Größenordnung von $£ 30$ Millionen pro Jahr" erbringen würde. Deutschland wäre dann nicht zur Lieferung von Reparationen in der Lage, sondern England müßte im Gegenteil seine Vorkriegsinvestitionen in Deutschland abschreiben und dieses eventuell sogar noch zur Gewährleistung eines minimalen Lebensstandards finanziell unterstützen ${ }^{14}$. Wenn Deutschland - so versuchten die mehr an den Interessen der nationalen Industrie orientierten Kreise des Board of Trade beide Ziele zu vereinen - seine Entschädigungsleistungen anders als nach dem Ersten Weltkrieg nicht durch monetäre, sondern durch Sachlieferungen entrichtete, bestand die Möglichkeit, es in eine „Nation von Unterlieferanten“ umzuwandeln: die deutsche Wirtschaft als Ergänzung, nicht als Konkurrenz der britischen. Arbeitskräfte und Produktionspotentiale würden in Großbritannien für eine Exportoffensive freigesetzt, wenn Deutschland die erforderlichen Rohstoffe lieferte (Holz, Kali, Stahl und Papier, die auf dem britischen Binnenmarkt keine Konkurrenz bedeuteten),

9 NA, RG 59/Pauley Mission, box 19 (11. 9. 1945; Hervorhebung im Original).

10 Der Umfang der Reparationen dürfe, anders als nach 1918, nicht aus Geldleistungen bestehen, nur in Mengen geliefert werden, die die potentiellen Empfänger abzunehmen sich verpflichteten, zeitlich begrenzt und ohne innenpolitische Destabilisierung Deutschlands. FRUS, 1943/I, S. 740 (19. 10. 1943).

1 TL, Truman Papers, Confidential File, box 2, folder: Allied Reparations Commission (Pauley, 28. 5. 1945).

12 FRUS, Potsdam II, S. 808 f. (Hervorhebung im Original). Vgl. DBPO, I, 1, S. 172 ff.

13 Zur Malkin-Kommission, der auch Keynes angehörte, vgl. PRO, FO 942/52 (31.8. 1943). Cairncross, Price, S. 19 ff. Kettenacker, Krieg, S. 394 ff.

14 PRO, FO 942/96 (Somervell, 1. 7.; Chaplin, 4. 7.; Fleming, 7. 7. 1944); FO 371/46720 (APW(44)127, 27. 12. 1944); CAB 21/1873 (C.M.(45)31st Conclusion, 13.9. 1945, mit C.P.(45)160, 10.9. 1945). Cairncross, Price, S. 50. 
Kapitalgüter für die „Neuausstattung“ der heimischen Industrie, dazu Konsumgüter, die im Königreich knapp waren. Die Voraussetzungen für diese Leistungen sollte es auf Drittmärkten, z. B. in Osteuropa, erwirtschaften, an denen die Engländer weniger interessiert waren. Für eine Übergangszeit von zwei Jahren waren zudem Reparationen aus der laufenden Produktion vorgesehen, durch Veredelung von Rohstoffen, die England bereitstellen würde ${ }^{15}$. Doch die Expertenstäbe sprachen sich im Herbst 1944 aufgrund rein wirtschaftlicher Überlegungen gegen eine radikale Umstrukturierung Deutschlands aus. Dieses sollte sein Produktionspotential mit Ausnahme der Rüstungsindustrien behalten, aber unter dem Vorzeichen der „wirtschaftlichen Sicherheit“ jede Möglichkeit zu Autarkie und Wiederaufrüstung durch punktuelle Wirtschaftskontrollen (z. B. beim Import von Rohstoffen, der Herstellung synthetischer Produkte oder der industriellen Vorratshaltung) einbüßen. Die Experten befürworteten im Sinne der ökonomischen Effizienz die Errichtung einer zentralen Kontrollinstanz und lehnten ein Dismemberment ab, an dem die Politiker aus emotionalen Gründen bzw. aus Rücksichtnahme auf die Öffentlichkeit noch festhielten. Dieser Ansatz, Deutschland strukturell friedens- und lebensfähig („fett, aber impotent“) zu machen, ohne es durch De-Industrialisierung zum Agrarland werden zu lassen, schloß stets offen oder verdeckt die Überzeugung ein, daß eine extreme Belastung Deutschlands durch Reparationen oder ein wirtschaftliches Dismemberment sich in der Bilanz zum Nachteil des Königreichs auswirken müßte ${ }^{16}$.

Zwar waren sich die USA und Großbritannien seit 1943 einig, nicht die Fehler von 1918 zu wiederholen, von Deutschland Reparationen in einer Form zu verlangen, die erneut zu Handelskrieg, Zerrüttung des Weltmarkts, Zerstörung des internationalen Währungssystems führten und damit einen neuen Krisenzyklus provozierten. Doch hinter diesem prinzipiellen Konsens standen unterschiedliche nationale Interessen: Wenn die Briten mit Hilfe des deutschen Potentials ihre in zwei Weltkriegen verlorene Führungsposition gegen die USA zurückgewinnen wollten, konnten sie sich nicht durch den „integrativen“ Ansatz der amerikanischen „Welt-Reparationspolitik“ zu sehr in ihrer nationalen Autonomie binden lassen oder sich gar dem Führungsanspruch der USA unterstellen. Das galt noch ausgeprägter für Frankreich ${ }^{17}$ und für die Sowjetunion, deren Reparationspolitik unter deutschlandpolitischen Aspekten allein nicht zu verstehen ist. Beide Mächte, durch Kriegseinwirkungen erheblich stärker von Zerstörungen betroffen als ihre Alliierten, standen in der Gefahr, ihren Anspruch als gleichberechtigte Großmächte durch eine ökonomisch-strategische Abhängigkeit von den USA zu verlieren. Zwar hatte die Sowjetunion mit Hilfe von Lend-lease-Lieferungen zwei Drittel ihrer Rüstungsindustrie während des Krieges wiederaufbauen können, doch als die USA versuchten, diese Hilfe bzw. einen Wiederaufbaukredit in Höhe von \$ $6 \mathrm{Mrd}$. mit (wirtschafts)politischen Bedingungen zu verknüpfen, wurden die deutschen und osteuropäischen Reparationen zu einer Unabhängigkeit versprechenden Alternative ${ }^{18}$. Die Sowjetunion war zu unilateralem Handeln entschlossen,

15 PRO, BT 211/73 (20.11. 1945); FO 942/226 (APW(45)13, 26. 1. 1945; APW Committee, 1. 2. 1945); FO 943/206 (Ronald, 17. 5. 1946); PREM 8/214 (Cabinet, 21. 10. 1946)

16 PRO, FO 942/66 (EIPS/P(44)30(Final), 4. 9. 1944); FO 944/758 (EIPS/P(44)32, 27. 9. 1944); FO 371/46824 (ACAO/P(45)41, Appendix ,A', April 1945). Cairncross, Price, S. 38 ff., 49 ff., 73.

17 AMAE, Y 363, Bl. 99, 129 ff. (13.9. 1945). Monnet, Memoiren, S. 318.

18 Herring, Aid, S. 116, 144, 157 ff. In Yalta hatte Molotow noch eine Kombination von deutschen Reparationen und amerikanischen Krediten angestrebt. FRUS, Malta and Yalta, S. 610. 
sollte es anders nicht gelingen, „unseren Sieg zu verankern, [...] der den Weg zu einem neuen großen Aufstieg unseres Landes und zur weiteren Erhöhung des Lebensstandards unseres Volkes frei gemacht hat" ${ }^{\text {"19}}$. Für ein solches Vorgehen besaß sie bessere Voraussetzungen als Frankreich, das über eine wenig ertragreiche Zone in Deutschland verfügte und zugleich stärker in den westlichen Weltmarkt eingebunden war ${ }^{20}$. Frankreich wie die Sowjetunion schwankten zwischen Konzertierung mit einem (wie auch immer) zu integrierenden deutschen Restpotential, also Reparationen aus laufender Produktion, und rücksichtsloser Ausbeutung desselben zugunsten der eigenen Rekonstruktion durch radikale Demontagen. Zur Maximierung ihrer Bezüge hatten sie daher keine Einwände gegen eine international organisierte und institutionell verankerte „Bewirtschaftung“ der Reparationen. Da die USA und Großbritannien sich zwar über die Prinzipien deutscher Reparationen geeinigt, diese aber nicht in konkrete Vorstellungen umgemünzt hatten, ergriff die Sowjetunion in Yalta die Initiative. Sie erreichte die Einsetzung einer Alliierten Reparationskommission in Moskau und konnte einen erheblichen Teil ihrer inhaltlichen Positionen festschreiben.

In der Reparationskommission ${ }^{21}$, die infolge sowjetischer Widerstände gegen die sofortige Einbeziehung Frankreichs erst am 21. Juni 1945 ihre Arbeit aufnahm, prallten die auf der Moskauer Außenministerkonferenz 1943 und in Yalta erkennbaren gegensätzlichen Vorstellungen erneut aufeinander: Die Sowjetunion, die ihre Kriegsschäden mit 679 Milliarden Rubel (später 2,6 Billionen Rubel) bezifferte, forderte mit Nachdruck die Anerkennung ihrer Reparationsansprüche als „alles überragendes Prinzip“, im Grunde also eine Art „first-charge-principle“ für die vom Krieg am stärksten zerstörten Länder. Zugleich bestand sie - je mehr die USA von der „Diskussionsgrundlage“ der $\$ 20 \mathrm{Mrd}$. abrückten ${ }^{22}$ - auf der Festlegung präziser Summen, Termine, Quellen der Aufbringung und Anspruchsprioritäten im Rahmen eines „detaillierten Planes“, um neben einer völkerrechtlichen Absicherung ihrer Ansprüche feste Größen für die eigene Wirtschaftsplanung zu erhalten ${ }^{23}$. Demgegenüber implizierte das amerikanische und britische Beharren auf dem Primat der europäischen Rekonstruktion den Erhalt der deutschen Lebens- und Lieferfähigkeit und den Vorrang der

19 Tägliche Rundschau, 8. 11. 1945, S. 1 (Molotow). Slusser, Soviet Economic Policy, bes. S. 47 ff.

20 AMAE, Y 363, Bl. 98 ff., $153 \mathrm{ff}$.

21 Nübel, Reparationspolitik, S. 140-73. Cairncross, Price, S. 80-6. Die Abschlußberichte von Pauley und Lubin in: TL, Truman Papers, President's Secretary's File. Subject File, box 179, folder: German Reparations; Confidential File, box 2. NA, RG 59/Pauley Mission, box 19. Auszüge in: FRUS, Potsdam II, S. 940-49. Der britische Bericht in: DBPO, I, 1, S. 327 ff. Frankreich wurde aufgrund sowjetischen Widerstands erst nach Potsdam zugelassen. Der französische Bericht für die Zeit vom 10. 8.-6. 9. 1945 in: AMAE, Y 362, Bl. 95 ff. AO, Berlin/3275/4/704.

22 Am 2. 7. 1945 hatte das State Department Pauley noch mit auf den Weg gegeben, daß „the Department is not opposed to the discussion of an amount of reparations“, daß aber die Zahl von \$20 Mrd. als zu hoch erachtet wurde. "A figure approaching 12 or 14 billion dollars would be more appropriate, the 20 billion dollar figure may be adopted as a starting point for exploration and discussion." NA, RG 59/Pauley Mission, box 11 (Hervorhebung im Original).

${ }^{23}$ Baggaley, Reparations, S. 423 ff. FRUS, Malta and Yalta, S. 176 ff. (20. 1. 1945), 620 f. (5. 2. 1945), 633 (Stalin), 707, 808. Krim(Jalta)konferenz 1945, S. 24. Um „definitive“ Zahlen, d. h. „Mindestbeträge“, festlegen zu können, war Molotow in Potsdam bereit, die sowjetischen Ansprüche von $\$ 10$ auf $8 \mathrm{Mrd}$. zu reduzieren, dabei die Übertragungen an Polen und die „Kriegsbeute“ abrechnend; \$ 2-3 Mrd. Reparationsgüter sollten aus dem Ruhrgebiet kommen. DBPO, I, 1, S. 331 , 577 ff., 1014 , 1021 ff., 1051. NA, RG 59/Pauley Mission, box 19 (IX. Decisions Reached, Second Draft, Gulick, 12. 9. 1945) 
Importe vor den Reparationen ${ }^{24}$. Der schließlich gefundene Kompromiß kam den Forderungen der Sowjets prinzipiell entgegen, vermied aber konkrete Beschlüsse, weil die Angelsachsen im Interesse eines pragmatischen Zugriffs Festlegungen vermeiden wollten. Die Reparationskommission wurde beauftragt, einen Generalplan zu erarbeiten, der nach amerikanischen Vorstellungen vom Kontrollrat und einer speziellen Reparationsbehörde gemeinsam auszuführen war: Ersterer würde die Gesamtmenge wie die einzelnen Objekte festlegen, ebenso den zeitlichen Rahmen, letztere die Interessen der Reparationsgläubiger vertreten ${ }^{25}$. Das wertete den Kontrollrat gegenüber den Zonenbefehlshabern auf; doch richtete sich dieser Zentralisierungsansatz des State Department mehr gegen die Bestrebungen des eigenen Kriegsministeriums als gegen zonale Vorbehalte der Sowjetunion.

Die Reparationskommission vermochte lediglich, eine Formel für die Phase der "wilden“ Reparationsentnahmen vor Potsdam zu entwickeln und die unterschiedlichen Positionen herauszuarbeiten. Verärgert mußten die Westmächte zur Kenntnis nehmen, daß die Sowjetunion sich in Osteuropa mit „Kriegsbeute“ exzessiv bediente, die angeblich dem militärischen Einsatz gegen Japan zugute kommen sollte; vergeblich blieben ihre Versuche, diesem Vorgehen durch die restriktive Definition von „Kriegsbeute“ einen Riegel vorzuschieben. Angesichts ihrer eigenen Jagd auf deutsche Technologie und industrielles Know-how wurden ihre Definitionsansätze zunehmend flexibler ${ }^{26}$. Doch ließen sich weder Kriegsbeute, Vorab-Lieferungen, Restitutionen und Reparationen befriedigend trennen, noch eine Kontrolle dieser „Entnahmen“ bewerkstelligen, solange die Zonenkommandeure autonom handeln durften. Obwohl die USA zu dem Zeitpunkt eine Lösung ablehnten, nach der die Sowjetunion ihre Ansprüche aus Osteuropa und der SBZ unkontrolliert befriedigen konnte, plädierten sie zunehmend für eine geographische Trennung der Bezugsgebiete für Ost und West einerseits, für die Festlegung einer Gesamtmenge der "Entnahmen“ andererseits, die es unerheblich werden ließ, zu welchem Zeitpunkt und unter welchen Vorzeichen diese vorgenommen wurden ${ }^{27}$. Um ihren Primat der Rekonstruktion indirekt zu verankern, beharrten sie darauf, daß die Zonenbefehlshaber im Hinblick auf die Lebensfähigkeit ihrer Zone Reparationen zurückhalten durften. Dieser Vorbehalt mußte bei den Sowjets die Befürchtung bestätigen, eine derartige Regelung werde dem Zonenkommandeur das Recht geben, „die Reparationslieferungen aus seiner Zone zu suspendieren“, sofern er nicht durch eine (von ihm selbst mitzutragende) einstimmige Entscheidung des Kontrollrats anders gehalten war. In diesem Falle war es überflüssig, „in Moskau einen detaillierten Reparationsplan mit den Russen“ auszuarbeiten; dann reichte ein gemeinsamer Plan der drei Westmächte für ihre Zonen ${ }^{28}$.

${ }^{24}$ FRUS, 1945/III, S. 1181 ff. (24.3. 1945), 1222 ff. (18. 5. 1945).

25 NA, RG 107/McCloy, box 30 (27. 4. 1945). Das deckte sich mit britischen Vorstellungen, eine InterAllied Reparations Commission „on the flank“ des Kontrollrats zu errichten. RG 59/Pauley Mission, box 11 (Mai 1945).

${ }^{26}$ FRUS, Potsdam I, S. 522 f., 543 f. Zur sowjetischen Definition siehe FRUS, Potsdam II, S. 846 f., 852 ff., 888. Die für „Kriegsbeute“ zuständige „Trophäenabteilung“ der SMAD war noch weit nach Potsdam in der SBZ tätig. Scherstjanoi/Laufer, Erste Schritte, S. 173 f. Die Lieferungen wurden aus Moskau „bestellt“. Slusser, Soviet Economic Policy, S. $1 \mathrm{ff}$.

27 FRUS, Potsdam II, S. 521 (2. 7. 1945), 856 f. (23.7. 1945), 867 (24. 7. 1945), 895 f. (27. 7. 1945), 943 f. Am 2. 7. 1945 hatte sich das State Department noch gegen eine Teilung Europas in Reparationssphären ausgesprochen. NA, RG 59/Pauley Mission, box 11 (Byrnes an Pauley, 2. 7. 1945).

28 FRUS, Potsdam I, S. 508 f. DBPO, I, 1, S. 224, 618 f. 
Die Konflikte hatten sich derart zugespitzt, daß ein Scheitern der Potsdamer Konferenz und die wirtschaftliche Spaltung Deutschlands nur durch Formelkompromisse und Paketlösungen verhindert werden konnten. Das Potsdamer Abkommen führte lediglich die Formen der Reparationen auf, über die Einigung erzielt werden konnte: die deutschen Auslandsguthaben und das deutsche Gold, die Kriegs- und Handelsmarine sowie industrielle Ausrüstung „vor allem der metallurgischen, chemischen und Maschinenbau-Industrien, soweit sie für die deutsche Friedenswirtschaft unnötig" sei. Indirekt, durch Produktionsverbote, wurde die Demontage bzw. die Vernichtung reiner Rüstungsbetriebe vorgesehen. Ausgeklammert (aber nicht ausgeschlossen) wurden Entnahmen aus der laufenden Produktion und Arbeitsreparationen, die in Yalta faktisch gebilligt worden waren. Nur unvollkommen geklärt wurden die Zuständigkeiten für die Organisation der Demontagen. Die Bestimmung „des Umfanges und der Art der industriellen Ausrüstung, die für die deutsche Friedenswirtschaft unnötig ist und der Reparation unterliegt“, sollte vom Kontrollrat gemäß den Richtlinien der Alliierten Reparationskommission bestimmt werden. Zur Durchführung des Reparationsprogramms war ein Zeitraum von zwei Jahren angesetzt worden; „der Umfang der aus den westlichen Zonen zu entnehmenden Ausrüstung, der auf Reparationskonto geht, muß spätestens innerhalb sechs Monaten von jetzt an bestimmt werden.“ Das Programm war auf Deutschland als wirtschaftliche Einheit berechnet, doch war dieses in zwei Reparationsgebiete geteilt worden. Die komplizierend hinzutretende westliche Lieferverpflichtung von $10 \%$ der industriellen Ausrüstung ohne bzw. 15\% mit sowjetischer Gegenlieferungspflicht war inhaltlich, räumlich und zeitlich präzise fixiert: Die Lieferungen mußten „aus den westlichen Zonen“ erfolgen, aus Metallverarbeitung, Chemie und Maschinenbau. Die sowjetischen Gegenlieferungen waren erheblich vager festgelegt: Sie waren innerhalb von fünf Jahren ,im Austausch für einen entsprechenden Wert an Nahrungsmitteln, Kohle, Kali, Zink, Holz, Tonprodukten, Petroleumprodukten und anderen zu vereinbarenden Waren“ zu liefern.

Mit den Potsdamer Bestimmungen, die die unterschiedlichen Interessen der drei Mächte (z.T. durch Auslassung) widerspiegelten, waren neue Konflikte vorprogrammiert. Die Sowjetunion hatte für die folgenden Beratungen vertraglich deutlich besser abgesicherte Ansprüche gegenüber den Westzonen bzw. den Westmächten. Die Festlegung der aus den Westzonen zu liefernden Reparationen bzw. des in diesen zu belassenden Potentials ließ sich weder inhaltlich von der Bestimmung des künftigen gesamtdeutschen Friedensniveaus trennen, noch war es sinnvoll, die Planung durch die Alliierte Reparationskommission in Moskau und die Ausführung durch den Kontrollrat in Berlin institutionell und geographisch zu trennen, zumal die Zonenkommandeure ein Vetorecht gegen Einzelmaßnahmen besaßen. Nach längerem Sträuben akzeptierte dies auch die Sowjetunion, da die Reparationskommission in ihren Augen nicht sehr erfolgreich arbeitete ${ }^{29}$. Sie wurde von Moskau nach Berlin verlegt; schließlich wurden ihre Aufgaben dem Kontrollrat übertragen, der erst jetzt reale Kompetenzen in der Reparationsfrage erhielt. Durch die Vertagung definitiver Entscheidungen in Potsdam war dem Kontrollrat seitens der Regierungen die Verantwortung aufgebürdet worden, und die komplizierte Reparationsfrage wurde zum Test für dessen autonome Problemlösungsfähigkeit.

29 FRUS, Potsdam II, S. 922, 1486. Molotow hatte bereits in Potsdam die Arbeit der Reparationskommission „für nicht sehr effektiv“ gehalten. Potsdamer (Berliner) Konferenz 1945, S. 129, 172. 


\section{Der Industrieniveauplan vom März 1946}

„Wenn erst einmal die Reparationen aus dem Weg sind“, so hatte Maiski seine Kollegen in Potsdam gewarnt, „würde eine günstige Atmosphäre geschaffen. Wenn die Reparationsfrage nicht befriedigend gelöst werden sollte, würde die Lösung anderer Probleme viel schwieriger. “30 Das war zweifellos ein Schlüsselsatz. Und gerade deshalb bestand von Beginn an die Gefahr, daß der Reparationsplan ein Formelkompromiß werden würde, der den prinzipiellen Konsens reflektierte, Deutschland ökonomisch zu entwaffnen und sein Potential für den Wiederaufbau der kriegszerstörten Gebiete einzusetzen, im übrigen aber unter der prinzipiellen Differenz litt, daß die AngloAmerikaner den Plan als Festlegung des deutschen Mindestbedarfs, die Sowjets aber der maximalen Reparationsansprüche begriffen. Daß der „Plan für Reparationen und das Niveau der deutschen Nachkriegsindustrie ${ }^{\text {“31 }}$, dessen Name die widersprüchlichen Interpretationen reflektierte, am 26. März 1946 verabschiedet wurde, war ein wichtiger Erfolg des Kontrollrats. Doch was politisches Signal für die Kooperationsfähigkeit sein sollte, wurde zum Ausgangspunkt für die offene Ost-West-Konfrontation, da umstritten war, welcher der beiden Bereiche Vorrang hatte, wenn sie gleichzeitig nicht realisiert werden konnten.

In Präzisierung ihrer Forderungen von Yalta legte die Sowjetunion in Potsdam am 23. Juli den Entwurf für einen Reparationsplan vor ${ }^{32}$, nachdem ein solcher trotz wiederholter Ankündigungen der Reparationskommission in Moskau nicht unterbreitet worden war. Die einmaligen Entnahmen in Höhe von \$10-11,8 Mrd. sollten praktisch alle Bereiche der Industrie umfassen (6,1-6,9 Mrd.), die Auslandsinvestitionen (1,1-1,4 Mrd.), Aktien ${ }^{33}$, Devisen und Edelmetalle (1,9-2,3 Mrd.) und diverse kleinere Posten (0,9-1,2 Mrd.); dazu kamen jährliche Lieferungen in Höhe von \$10 Mrd. (Kohle, Chemikalien, Maschinen, Baustoffe, Lebensmittel usw.) und, das war in dieser Aufstellung (wie in anderen auch) nicht enthalten, 2-3 Mio. Arbeitskräfte ${ }^{34}$. Nach den Erläuterungen der sowjetischen Delegation war nicht Rache, sondern der eigene Wiederaufbaubedarf das Hauptmotiv für ihre Forderungen. Aufgrund der Kriegszerstörungen sei „Rußland nicht in der Lage, seine eigene Industrie ohne Hilfe wiederherzustellen. Die Hilfe, die es brauche, wäre die Entnahme entsprechender Industriebetriebe aus Deutschland“, vor allem aus dem Ruhrgebiet ${ }^{35}$. Wie in Yalta ging die

${ }^{30}$ DBPO, I, 1, S. 671 (24. 7. 1945).

31 Abgedruckt in: Ratchford/Ross, Reparations, S. $225 \mathrm{ff}$.

32 FRUS, Potsdam II, S. 863 f. Berechnungsgrundlage war Deutschland in den Grenzen von 1937, dazu die Preise von 1938 plus $15 \%$ bei Ausrüstungsgegenständen und plus $10 \%$ bei Rohstoffen und Endprodukten, bei einer Tauschrelation von 3,5 Reichsmark pro Dollar. Gegenrechnungen, die keine Globallösung, sondern regionale Aufschlüsselungen enthielten, ebenda, S. 877-85.

33 Eine Kontrolle der deutschen Industrie durch Aktienübertragung hatten die Briten 1943 diskutiert, u. a. weil eine solche Lösung der Sowjetunion eher zusagen werde als Demontagen! Kettenacker, Krieg, S. 407. Wie manches andere in den sowjetischen Reparationsvorschlägen fand sich auch das in den Plänen Morgenthaus. Morgenthau-Tagebuch, S. 110,173, 180. Offiziell entschieden sich die USA im Juni 1945 auf der Moskauer Reparationskonferenz gegen die Übertragung von Aktien als Reparationen, also deutlich vor den Sowjet AGs, die später Objekt der Kritik wurden. NA, RG 43/ WWII\&PWConf, box 147, folder: State Department Briefs (Memorandum No. 5: Post-Surrender Acquisitions in Germany). Vgl. S. 369 Anm. 273.

34 FRUS, Malta and Yalta, S. 177 (20.1. 1945).

35 DBPO, I, 1, S. 667. Eine Anlage präzisierte die Berechnungsgrundlagen und nannte pauschale Zahlen für die Entnahme aus 11 Branchen: $75 \%$ aus der Rüstungsindustrie, $65 \%$ aus der chemischen 
Sowjetunion von der Annahme aus, daß das deutsche Volksvermögen durch die Kriegszerstörungen gegenüber dem Vorkriegsniveau um $40 \%$ reduziert worden sei. Von dem Restbestand galten $30 \%$ als transferierbar; die Hälfte könne per Demontage abgezogen werden. Aus dem verbleibenden Volkseinkommen, das 30-35\% niedriger liegen werde als vor dem Krieg, ließen sich pro Jahr 5-6\% für laufende Reparationen abzweigen. „Für die Deckung des inneren, wirtschaftlich realen Bedarfs des Landes“ wurden $20 \%$ des industriellen Vorkriegsniveaus als ausreichend erachtet. Zugleich war eine internationale Kontrolle über die „verbleibenden Industrie-, Verkehrs- und anderen Betriebe, die vom Standpunkt der Möglichkeit eines Wiedererstehens des militärischen Potentials Deutschlands die größte Gefahr darstellen“, über die zehnjährige Reparationsphase hinaus vorgesehen. Damit signalisierte die Sowjetunion, daß sie sich im Interesse ihrer Reparations- und Sicherheitsansprüche auf eine lange Besatzungsund Kontrollperiode einrichtete ${ }^{36}$.

Für Moskau war die Festschreibung der Ansprüche in einem „detaillierten Plan“ um so drängender, als man dort - so sahen es selbst Mitglieder der amerikanischen Delegation in Potsdam ${ }^{37}$ - den Eindruck haben mußte, daß die USA von ihren Zusagen in Yalta abzurücken begannen und die Sowjetunion „betrogen“ werden solle. Hatte Pauley bislang in der Reparationskommission auf der Basis der sowjetischen Yalta-Formel deutsche Reparationen in Höhe von $\$ 20 \mathrm{Mrd}$. als Diskussionsgrundlage akzeptiert, distanzierten er und Byrnes sich davon in Potsdam offiziell: Die Zerstörungen, die Plünderungen im Okkupationsgebiet der Roten Armee und die Abtrennung Schlesiens ließen solches nicht mehr zu. Auch die Briten wurden noch zurückhaltender, je offenkundiger zu erkennen war, wie sehr die Sowjetunion in diesem Punkt unter Druck zu setzen war, erhoffte diese sich doch neben der Verabschiedung eines Reparationsplans auch die sofortige Aufnahme von „Vorab-Lieferungen“ als Vorschuß auf die noch festzulegenden Ansprüche ${ }^{38}$. Stalins Verdacht, die Westmächte wollten eine schnelle Erholung der sowjetischen Wirtschaft verhindern, verstärkte sich in Potsdam zu der Überzeugung, deren Pläne liefen darauf hinaus, „daß Deutschland keine Reparationen zahlen müsse“. „Die Engländer und Amerikaner wollen uns knebeln, aber keine Angst - wir haben den Bürgerkrieg durchgestanden, wir werden auch das überstehen." Die Sowjets, die seit Ende Juli nicht mehr auf Lend-lease-Zahlungen rechnen konnten, verzichteten daher in Potsdam darauf, die Frage eines amerikanischen Kredits zur Sprache zu bringen; sie hatten sich offenkundig darauf eingestellt, ihre Ansprüche auf anderem Wege abzusichern, vor allem durch Reparationen aus ganz Osteuropa, das zu diesem Zweck ihrer exklusiven Ausbeutung zu unterwerfen war ${ }^{39}$.

Amerikaner und Briten, vom Ausmaß der Zerstörungen in Deutschland ebenso schockiert wie von der sowjetischen „Beute“-Politik in ihrem Zugriffsbereich, waren

Industrie usw. bis hin zu $15 \%$ aus der Lebensmittelindustrie. Potsdamer (Berliner) Konferenz, S. 295.

36 Krim(Jalta)konferenz 1945, S. 65.

37 Library of Congress, Davies Papers, box 19, Diary, 28. 7. 1945 (Wischinski); ebenda, Journal, 28. 7. 1945 (Davies). NA, RG 59/EAC, box 3, folder: USGCC (3. 6. 1945). FRUS, Potsdam II, S. 900 f. (Clayton).

38 FRUS, 1945/III, S. 1186, 1191, 1212, 1233. DBPO, I, 1, S. 89, 302, 484.

39 Gromyko, Erinnerungen, S. 129 f., 156-61. Herring, Aid, S. 228 f., 240. Die Sowjets hatten die amerikanische Position in Yalta als endgültige Festlegung verstanden. DBPO, I, 1, S. 931 (Molotow, 27. 7. 1945). Potsdamer (Berliner) Konferenz 1945, S. 11, 18, 173 f., 183. 
selbst auf umfangreiche Lieferungen nicht angewiesen. Sie fürchteten zunehmend die Besatzungskosten und wollten zunächst den industriellen Grundbedarf Deutschlands nach Maßgabe des europäischen Lebensstandards festlegen. Die Reparationsfrage schien auf die Formel „R $R=P-(O+K+I)^{\star}$ “ reduzierbar, wie Pauley seinem Kollegen Maiski vorrechnete: „Laufende Reparationen ist gleich deutsche laufende Produktion weniger die Summe der Okkupationskosten, des Minimums der wesentlichen deutschen Konsumption und der Importe, die erforderlich sind, um die von den Alliierten genehmigte Produktion zu gewährleisten. “40 Von dem verbleibenden Rest konnte, solange dessen Größenordnung unbestimmt war, der Sowjetunion bestenfalls ein gewisser Prozentsatz, aber kein quantitatives Fixum zugesagt werden ${ }^{41}$. Auf Vorschlag von Byrnes enthielt das Potsdamer Abkommen daher die Garantie für ein deutsches Existenzminimum, das einem „mittleren Lebensstandard“ in Europa entsprechen sollte. Für Reparationen stand nur „die Menge und Art der industriellen Ausrüstung“ zur Verfügung, „die für die deutsche Friedenswirtschaft nicht benötigt wird“. Die Ausarbeitung eines entsprechenden Plans bedeutete zwangsläufig eine erneute zeitliche Verzögerung; diese kam den Westmächten nicht ungelegen, um die Forderungen der kleinen Nationen nicht dem „first-charge“-Anspruch der Sowjetunion opfern zu müs$\operatorname{sen}^{42}$. Frankreich, das hinsichtlich der Priorität der Reparationen für die kriegszerstörten Länder mit der Sowjetunion einig ging, stand jedoch in der (Selbst-)Verpflichtung zur Sicherung eines deutschen Überlebensminimums zweifellos der Position der Westmächte näher ${ }^{43}$.

Die Sowjetunion, wollte sie ihren Anspruch auf Reparationen aus den Westzonen nicht gefährden, nahm den Vorschlag an, nachdem ihr Vorab-Lieferungen zugestanden und dem Kontrollrat eine Frist von sechs Monaten zur Erarbeitung eines Reparationsplans gesetzt worden waren. Offenkundig begann sie zu befürchten, daß die SBZ nicht in der Lage sein werde, ihre Reparationserwartungen zu erfüllen. Ohne ein gemeinsames Reparationsprogramm würden sie keinen Zugang zum Ruhrgebiet erhalten. Doch als sich die SMAD später im Kontrollrat auf den Standpunkt stellte, die Reparationsformel von Potsdam sehe für die Westzonen ein anderes Verfahren als für die SBZ vor ${ }^{44}$, wirkte das für die Westmächte wie die Aufkündigung des Konsenses,

40 FRUS, Potsdam I, S. 547 (Hervorhebung im Original).

${ }^{11}$ DBPO, I, 5, S. 519 ff. Die amerikanischen und sowjetischen Vorstellungen über die voraussichtlich verfügbare Reparationsmenge klafften mit \$5-6 bzw. 20 Mrd. weit auseinander. Im März 1944 hatte das State Department, um den sowjetischen Forderungen entgegenzukommen, Summen zwischen \$10 und 50 Mrd. genannt und bewegte sich zuletzt - wie das Kriegsministerium - bei \$ 5-6 Mrd. FRUS, Potsdam II, S. 892. Nübel, Reparationspolitik, S. 72, 75 f., 151. Der britische Malkin-Report hatte eine Reparationssumme von $\$ 4$ Mrd. vorgeschlagen, die Anweisungen für die Delegation bei der Reparationskommission lagen bei \$6-9 Mrd. Cairncross, Price, S. 29, 77-80. Eine Liste des Board of Trade für "civil requirements from Germany“ sah „equipment and plant“ in Höhe von $£ 84$ Mio., Rohstoffe und Halbfabrikate in Höhe von $£ 208$ Mio. sowie Fertigprodukte in Höhe von $£ 311$ Mio. vor, insgesamt eine Summe von $£ 693$ Mio. PRO, BT 211/73 (O.R.C.(45)12, 25. 7. 1945). Müller, Sicherheit, S. $67 \mathrm{f}$.

42 FRUS, 1945/III, S. 1252 f. (Pauley an Clay, 11. 8. 1945; meine Hervorhebung).

43 AO, Berlin/3275/4/704 (Rapport, S. 6, ca. September 1945).

44 Für ihre Interpretation, „in der Ostzone ist dieses Problem den sowjetischen Behörden und in den Westzonen den alliierten Behörden übertragen worden“, konnte die Sowjetunion Belege beibringen. FRUS, 1945/III, S. 1295 (18. 9. 1945; meine Hervorhebung). Nowikow erklärte in der Alliierten Reparationskommission, der Westen habe „no right in the Eastern Zone or information concerning it“; ebenda, S. 1254 (13. 8. 1945). In Potsdam hatte Byrnes am 30.7. 1945 als Vorteil seines Vorschlags erläutert, „that the determination of what was available in the Soviet zone would concern neither the 
obwohl erst die amerikanische Reparationsformel nach Auffassung der Briten diese Entwicklung heraufbeschworen hatte und die SBZ zum „Ausland“ zu machen drohte $^{45}$. Letztlich mußte die Sowjetunion die westliche Forderung (bzw. Interpretation des Potsdamer Abkommens) akzeptieren, der Kontrollrat solle entscheiden, „was für Reparationen zur Verfügung steht“: Wirtschaftliche Entwaffnung und Reparationen sowie die Entwicklung von Landwirtschaft und Friedensindustrien traten als Ziel des Industrieniveauplans gleichberechtigt neben die Garantie eines minimalen Lebensstandards und die Gewährleistung deutscher Selbstversorgung ohne auswärtige Hilfe („first-charge-principle“) ${ }^{46}$. Möglicherweise war das der Punkt, an dem sich die Sowjetunion darauf einzustellen begann, daß sie ihre Reparationspolitik von den einmaligen, gesamtdeutschen Leistungen auf die laufenden Lieferungen aus der eigenen Zone umstellen müsse, um in absehbarer Zeit überhaupt Leistungen aus Deutschland beziehen zu können. Gleichwohl war lange Zeit eine klare Linie in der sowjetischen Reparationspolitik nicht zu erkennen. In Yalta wie in Potsdam hatte die Sowjetunion ein duales Reparationsprogramm von einmaligen Kapitalgüterlieferungen und Entnahmen aus der laufenden Produktion verlangt. Seit Herbst 1945, nach dem Ende der ersten „Beute“- und Demontagewelle, setzte die Regierung in Moskau immer stärker auf Entnahmen aus der laufenden Produktion. Entsprechend schwankend war ihre Haltung in der Frage der deutschen Stahlproduktion. Der in Potsdam vorgelegte Entwurf sah die Absenkung auf ein Drittel des Vorkriegsstandes vor; im August wurde gegenüber den Franzosen eine Zahl von 2 Mio. $t$ (=10\% der Produktion von 1938) genannt; im Oktober stimmte der sowjetische Vertreter im Industrieniveaukomitee dem Vorschlag der USA zu, bis zur endgültigen Entscheidung eine Produktionskapazität von 10-11 Mio. $\mathrm{t}$ als vorläufige Obergrenze vorzusehen, und schlug eine Stahlproduktion von 5,56 Mio. $\mathrm{t}$ vor, während die offizielle Stellungnahme der Sowjetunion 4 Mio. $t$ als das maximale Zugeständnis ansah ${ }^{47}$.

Hinter diesen widersprüchlichen Positionen standen zwei Fraktionen, die bis Anfang 1947 ihre Kämpfe austrugen ${ }^{48}$ : Die eine, geführt von Eugen Varga, befürworte „die De-Industrialisierung soweit wie möglich“. Dieser hatte bereits 1943 in einem nach ihm benannten Plan als Ziel „die dauernde Verminderung der Kriegsmacht Deutschlands“ definiert und zu diesem Zweck dessen Umwandlung ,von einem hochindustrialisierten Land der Schwerindustrie in ein Agrar-Industrieland mit Überwiegen der Leichtindustrie" vorgesehen ${ }^{49}$. Obwohl die Sowjetunion den MorgenthauPlan im September 1944 ausdrücklich verwarf, weil er Reparationen aus laufender Produktion nicht zugelassen hätte, hielt sie in Yalta an den Grundvorstellungen des

British, French nor the United States and they would not, therefore, be interfering in that determination“. FRUS, Potsdam II, S. 487. Nach dem britischen Protokoll war die UdSSR ,free to exercise its discretion as to removals of equipment from the Russian zone, without interference from the United States, Great Britain or the French“. DBPO, I, 1, S. 1022. Dem entsprach die Formel vom 1. 8. 1945, die in das Potsdamer Abkommen einging: "The amount of equipment to be removed from the $W e$ stern Zones on account of reparations must be determined within six months from now at the latest." FRUS, Potsdam II, S. 931 (meine Hervorhebung).

45 DBPO, I, 1, S. 1070 f., 1257 ff. DBPO, I, 5, S. 521.

46 BA, Z 45 F/OMGUS, 2/118-1/17-21 (CORC/P(46)46 und 83).

47 BA, Z 45 F/OMGUS, 2/133-3/8 (SCMT(M)45/2, 5. 10. 1945). AO, Berlin/3275/4/704 (Rapport, S. 30); 3269/1/2201 (10.10. 1945).

48 Karlsch, Reparationsleistungen, S. 64.

49 Zitiert nach: Laufer, Konfrontation, S. 61. 
„Varga-Plans“ fest. Die deutsche Wirtschaft solle „dazu angeregt werden, die landwirtschaftliche Produktion und ihre Leichtindustrien auszudehnen “50. Ein höherer Grad landwirtschaftlicher Selbstversorgung würde Produktionskapazitäten für die Lieferung von Reparationen aus laufender Produktion freisetzen; die „überschüssige“, weil weder ernährbare noch produktiv einsetzbare Bevölkerung könne zur direkten Wiederaufbauleistung in der Sowjetunion eingesetzt werden ${ }^{51}$. In diesem Sinne äußerte im Dezember 1945 der sowjetische Vertreter im Industrieniveaukomitee, Deutschland solle nicht „hochindustrialisiert“ bleiben, sondern „zu einem agrarischen Staat gemacht werden"; durch Unterdrückung ganzer Industriebranchen werde sich die Beschäftigung automatisch in den Agrarsektor verlagern. Das wichtigste Kriterium für die Definition des Lebensstandards seien die Nahrungsmittel: Würden die nach dem durchschnittlichen Kalorienwert der Zwischenkriegszeit bereitgestellt, sei eine Sonderversorgung mit Fleisch, Fett oder Zucker überflüssig und eine dementsprechend begrenzte Einfuhr von Lebensmitteln bzw. eine ebenso geringe Ausfuhr von Industriewaren erforderlich. Die Alliierten, so auch Sokolowski fast wörtlich in der Diktion des Morgenthau-Plans, „haben keine Verpflichtung, Deutschland zu ernähren, das arbeiten und sich selbst ernähren solle“ - auf der Basis des zugestandenen Lebenshaltungsniveaus, das durch die Bedürfnisse der Sieger, nicht der Deutschen definiert wurde ${ }^{52}$.

Die andere Fraktion, geführt von Saburow, dem Chef der Planungsbehörde Gosplan, wollte Deutschland „für jedes Produkt die Befriedigung seiner unbedingt nötigen Bedürfnisse durch seine eigene Produktion“ ermöglichen und damit leistungsbzw. lieferfähig erhalten ${ }^{53}$. Saburows Einbindung in die Verhandlungen der Moskauer Reparationskommission und der Potsdamer Konferenz unterstrich die enge Verzahnung der deutschen Reparationen mit dem sowjetischen Wiederaufbauprogramm, die ihren Niederschlag erneut bei der Erarbeitung des Fünfjahresplans im Frühjahr 1946 finden sollte ${ }^{54}$. Doch die für den Fünfjahresplan festgelegten Daten liefen faktisch ebenfalls auf eine De-Industrialisierung Deutschlands hinaus, wie die im Dezember 1945 in die Beratungen des Kontrollrats von eigens aus Moskau angereisten Gosplan-

${ }^{50}$ FRUS, Malta and Yalta, S. 176 ff., 622. So auch Stalin gegenüber Harry Hopkins am 28. 5. 1945. FRUS, Potsdam I, S. 49. Vgl. Moskauer Konferenz 1943, S. 220 (Molotow). DBPO, I, 1, S. 305, $751 \mathrm{ff}$., $818 \mathrm{ff}$.

51 Thomas, EAC, S. 133, 152.

52 BA, Z 45 F/OMGUS, 2/119-3/5-9 (LOIC/Misc(45)6, 11. 12. 1945: „agrarian nation“); 2/133-3/8 (SCMT/M(45)11, 3. 12. 1945); 2/120-2/8-13 (DECO/M(46)3, 19. 1. 1946); 2/132-2/13 (LOIC/ M(45)9, 10. 12. 1945). FRUS, 1946/V, S. 487 (Sokolowski, 18. 1. 1946). Da künftig Baumaßnahmen vor allem auf dem Lande stattfänden, wo Beton durch Holz ersetzt werden könne, hätten am Ende der Besatzungsphase, wenn „the movement from industry to agriculture“ abgeschlossen sei, die Gebäude nur ein oder zwei Stockwerke, und der Stahlverbrauch könne entsprechend gesenkt werden. AO, Berlin/3272/3/2731, I (Nowikow, 17. 11. 1945). Im Mai 1946 galt die Landwirtschaft als „Mittelpunkt" der deutschen Wirtschaft, von deren Erträgen die Deutschen "gut leben“ könnten, auch ohne Einfuhren von 2 Mrd. RM, die „einfach unmöglich“ seien. Tägliche Rundschau, 26. 5. 1946, S. 5. Erst am 10.7. 1946 distanzierte sich Molotow auf der Pariser Außenministerkonferenz ausdrücklich von der „Umwandlung in ein Agrarland“ und der „Vernichtung seiner wichtigsten Industriezentren“. Zitiert nach: Steininger, Deutsche Geschichte, Bd. 1, S. 211.

53 AO, Berlin/3275/4/704 (Rapport, S. 13).

54 Das ZK der KPdSU beriet über den Fünfjahresplan für die Jahre 1946-1950 am 14. 2. und 4. 3. 1946 parallel zu den Abschlußverhandlungen über das deutsche Industrieniveau. Priorität genossen der Maschinenbau, die chemische Industrie, Verkehr und Nachrichtenwesen; Schwerpunkte waren die Modernisierung der Rüstung und der bevorzugte Aufbau der Schwerindustrie. Geschichte der KPdSU, Bd. 5/2, S. 28 ff., 49, $150 \mathrm{ff}$. 
Experten hineingetragenen Forderungen erkennen ließen, die aufgrund ihrer Planvorgaben eine Revision der bisher erzielten Kompromisse bei den Beratungen über das deutsche Industrieniveau zu erzwingen suchten ${ }^{55}$. Seit Ende 1945 wurde Malenkows radikale Reparationspolitik, die unter dem Motto der „ökonomischen Entwaffnung“ stand, von Mikojan in Frage gestellt, da sie als unkoordinierte Beutepolitik sich als Fehlschlag erwiesen habe ${ }^{56}$. Je mehr seit dem Herbst 1945 sich die Hoffnung zerschlug, daß in absehbarer Zeit eine gemeinsame Kontrolle der Ruhr oder eine institutionalisierte Einflußnahme auf die Westzonen durch deutsche Zentralverwaltungen möglich sei, und je mehr sich angesichts der ausbleibenden positiven Effekte des Transfers deutscher Betriebe per Demontage in die Sowjetunion Ernüchterung breitmachte ${ }^{57}$, desto stärker wurde der Zwang, für die Reparationsfrage eine Lösung zu entwickeln, die einerseits den autonomen Zugriff auf das Potential der SBZ erhielt, die andererseits die maximale Ausbeutung des deutschen Industriepotentials ermöglichte, ohne ein Übermaß an Rüstungspotential zu erhalten. Einen Ausweg schien der vom Wirtschaftsexperten der SMAD, Kowal, um die Jahreswende 1945/46 entwikkelte Plan zu bieten, mit Hilfe von (als exterritorial geltenden) Sowjetischen Aktiengesellschaften (Sowjet AGs) zur systematischen Entnahme aus der laufenden Produktion überzugehen. Noch während der Verhandlungen über den Industrieniveauplan wurde dem Rat der Volkskommissare ein Paket von Entwürfen für eine solche Neuorientierung vorgelegt, die am 25. Januar 1946 mit vier Verordnungen zur entscheidenden Weichenstellung führten ${ }^{58}$.

Das waren keine guten Vorzeichen für die Bemühungen des Kontrollrats, die Details des Industrieniveau- und Reparationsplans zu erarbeiten. Obwohl das Wirtschaftsdirektorat am 15. August ein Industrieniveaukomitee eingesetzt hatte, dauerte es bis zum 14. September, bis alle Delegationen, als letzte die stets zur Eile drängende sowjetische, ihre Mitglieder benannt hatten ${ }^{59}$. Das Komitee einigte sich, zunächst vier Fragenkreise zu untersuchen: 1. die Bevölkerungszahl, 2. deren Bedarf an Gebrauchsgütern, 3. die erforderlichen Produktionsmittel (inkl. der Landwirtschaft), 4. die Bestimmung der benötigten Grundstoffindustrien. Damit war eine Arbeitsgrundlage geschaffen, zumal die USA ein Diskussionspapier vorgelegt hatten, das in seinen Grundzügen, wenngleich nicht in der Höhe seiner Ansätze, den späteren Vier-Mächte-Plan bestimmte ${ }^{60}$. Doch als das Komitee daran ging, diese abstrakten Parameter mit konkreten Daten aufzufüllen, erwies sich die Spannbreite der Definitionsansätze als so außerordentlich heterogen, daß die Grundsatzkonflikte von Potsdam sofort neu aufbrachen.

55 Hatten die Sowjets zunächst im Kontrollrat eine Reduktion um 25-30\% gegenüber dem Stand von 1938 akzeptiert, so forderte die aus Moskau kommende neue Gruppe 40\%. Cairncross, Price, S. 113.

56 Slusser, Soviet Economic Policy, S. $36 \mathrm{ff}$.

57 Vgl. AMAE, Y 290, Bl. 25 (Sokolowski gegenüber einem tschechischen Diplomaten).

58 Die Verordnungen betrafen 1. die Warenlieferungen aus der SBZ in die UdSSR, 2. die Gründung der Sowjet AGs, 3. die Versorgung der Roten Armee und 4. Fragen des Außenhandels der SBZ. Laufer, Auf dem Wege, S. 34. Die prinzipielle Entscheidung zugunsten von Sowjet AGs war viel früher gefallen, denn die Sowjetunion hatte Ähnliches bereits in Osteuropa praktiziert. Mitte November 1945 hatte Schukow den Ministerpräsidenten der SBZ die Errichtung der Sowjet AGs angekündigt. Scherstjanoi/Laufer, Erste Schritte, S. 174.

59 Ratchford/Ross, Reparations, S. 96 f. FRUS, 1946/V, S. 532 f. DBPO, I, 5, S. 527 ff.

60 BA, Z 45 F/OMGUS, 2/132-2/12 (LOIC/P(45)3 [Hoover-Report], 10. 9. 1945). Ratchford/Ross, Reparations, S. $73 \mathrm{ff}$. 
Das galt bereits für die Bestimmung der Bevölkerungszahl, die Ausgangspunkt aller Bedarfsrechnungen war. Nach Abtrennung der Gebiete östlich von Oder und Neiße strömten Flüchtlinge, Vertriebene und Ausgesiedelte in unbekannter Zahl in das erheblich verkleinerte deutsche Territorium, ohne daß es genaue Anhaltspunkte über die Kriegsverluste bei Wehrmachtsangehörigen und Zivilbevölkerung gab. Es war eine Schätzung erforderlich, die politischen Interessen offenstand. Trotz einer alliierten „Zwischenzählung“ vom Herbst 1945, die eine Wohnbevölkerung von 65,3 Mio. ergab, konnte der technische Stab des Komitees keine Einigung erzielen: Die USA und England nahmen für das Stichjahr 1949 eine Bevölkerung von „wahrscheinlich nicht unter 68 Millionen“ an, doch war das bereits ein Kompromißangebot, da sie von 70 Mio. und mehr ausgingen. Der sowjetische Vertreter begründete seinen Ansatz von lediglich 65-66 Mio. mit den Verlusten in der Zivilbevölkerung und den „weitgehend" abgeschlossenen Bevölkerungsumsiedlungen. Um den deutschen Mindestbedarf, der nach einem durchschnittlichen Pro-Kopf-Verbrauch berechnet wurde, im Interesse ihrer Reparationsforderungen möglichst niedrig ansetzen zu können, versuchte die sowjetische Delegation Ende November, gemäß neuen Instruktionen aus Moskau die Zahl auf 62 Mio. zu drücken. Nachdem das Koordinationskomitee wiederholt auf westliches Beharren die Zahl von 66,5 Mio. als Grundlage aller weiteren Berechnungen festgelegt hatte, kündigte Sokolowski am 8. März 1946 an, daß er keiner Revision des auf der Basis von 66,5 Mio. berechneten Inlandsbedarfs zustimmen werde, sollte sich die tatsächliche Bevölkerungszahl als höher erweisen ${ }^{61}$. Die Franzosen gingen von einer Bevölkerungsgröße von 70 Mio. aus, unterstützten aber aus ihren gleichgerichteten Reparationsinteressen heraus als Planungsgröße die sowjetische Zahl. Sie plädierten für eine flexible Handhabung dieser Größe, sollten sich die Schätzungen als zu niedrig erweisen, und empfahlen, als Weg zur Annäherung der Ist- an die SollWerte die Auswanderung der „überschüssigen“ Bevölkerung systematisch zu för$\operatorname{dern}^{62}$.

Weniger umstritten war im Ansatz die Definition des Lebenshaltungsniveaus. Ausgangspunkt war der Beschluß von Potsdam, daß die deutsche Lebenshaltung nicht über den europäischen Durchschnitt (ohne Großbritannien und die Sowjetunion) steigen dürfe. Der Hoover-Report, Grundlage der amerikanischen Vorlage, berechnete den europäischen Durchschnitt auf dem Niveau der Jahre 1930 bis 1938 . Um diesen Wert zu erreichen, mußte der deutsche Durchschnitt dieser Jahre um 26\% gesenkt werden. Das entsprach zufällig dem Stand des Jahres 1932, dem Tiefstpunkt der Wirtschaftskrise. Allerdings interpretierte die Sowjetunion diesen Grundkonsens dahingehend, daß die deutsche Lebenshaltung nur nach oben begrenzt sei und daß die industrielle Produktion nicht im gewogenen Mittel, sondern in jedem einzelnen Bereich

61 BA, Z 45 F/OMGUS, 2/98-3/9 und 10. Die Westmächte rechneten zu den 65,3 Mio. der „Zwischenzählung“ eine geschätzte Zahl von 6,55 Mio. Aussiedlern hinzu, so daß sich eine Gesamtzahl von 72 Mio. ergab (CORC/P(45)189, 7. 12. 1945). Das Direktorat für Kriegsgefangene ging von 72,3 bis 72,6 Mio. aus (DPOW/Misc(46)12, 4. 2. 1946). Die sowjetische Berechnung vom 29.11. 1945 $(\mathrm{DECO} / \mathrm{P}(45) 111)$ legte einen Zuwachs durch Geburten um 1,8 Mio. und Vertreibung um 10,8 Mio. zugrunde sowie Verluste durch Krieg (9,0 Mio.) und Emigration (1,1 Mio.). Die Volkszählung vom Oktober 1946 ermittelte 64,2 Mio. Einwohner, darunter 9,7 Mio. Umsiedler. Die Zählung von 1950 ergab 68,4 Mio., darunter 12,3 Mio. Aussiedler.

62 AMAE, Y 370, Bl. 43 ff. (GFCC, 7. 1. 1946); Y 651, Bl. 63 (MAE, Direction Economique, 14. 1. 1946). Zur De-Peuplierung Deutschlands vgl. FRUS, 1947/II, S. 415. AN, 457 (Bidault) AP 13/Moscou 1947 (Observations générales, S. 1-4). 
nicht über dem europäischen Durchschnitt liegen dürfe ${ }^{63}$. Das hätte den Spielraum für einmalige Reparationsleistungen durch Demontage drastisch erhöht, zugleich das deutsche Lebenshaltungsniveau weit unter das russische gedrückt, da die Sowjets die Grundstoff- und Produktionsgüterindustrien in den Lebensstandard mit hineinrechneten, von einer steigenden Landbevölkerung mit höherem Selbstversorgungsgrad ausgingen und zusätzlich pauschal einen militärischen Anteil von der Gesamtproduktion abzogen ${ }^{64}$. Wie sehr die Sowjetunion an raschen Beschlüssen, $d . h$. an raschen Lieferungen, interessiert war, zeigte sich an dem pauschalisierten Verfahren, das sie schließlich zur Bestimmung des Industrieniveaus vorschlug. Wenn das Limit für wirtschaftliches Kriegspotential definiert sei, also für Metallprodukte, Kohle, Strom, chemische Produkte und Schwermaschinenbau, dann erübrige es sich, den Bedarf anderer Industriezweige auch nur zu diskutieren; die Sowjets regten daher an, lediglich „das Niveau der wichtigsten Industrien“ festzulegen, „so daß die Last auf den Deutschen ruhe, ihre eigenen Bedürfnisse zu befriedigen, so gut sie können“. Die Hauptsorge müsse der „Begrenzung und Kontrolle“ gelten ${ }^{65}$.

Ein derartiges Verfahren hätte die Arbeit vereinfacht und drastisch verkürzt. In seiner Rigorosität war es jedoch für die Westmächte nicht akzeptabel, obwohl die Franzosen gleichfalls an der frühzeitigen, und sei es auch nur vorläufigen, Festlegung von Obergrenzen interessiert waren, um „sofort" Verfügungsmasse für Reparationslieferungen zu gewinnen ${ }^{66}$. Ein solches Verfahren hätte weder Exportmöglichkeiten (im Interesse des Importbedarfs der Nachbarstaaten, weniger der deutschen Devisenbeschaffung) belassen, noch in den volkswirtschaftlichen Kernbereichen (Kohle, Stahl) ein ausreichendes Produktionsniveau ermöglicht, das die deutsche Selbstversorgung bei Gebrauchsgütern ohne Fremdfinanzierung zugelassen hätte. Die Anglo-Amerikaner verlangten daher, zunächst die für das genehmigte Lebenshaltungsniveau (inkl. Importe) zulässige Konsumgüterproduktion festzulegen und von dieser Grundlage aus den Bedarf an Grundlagenindustrien zu bestimmen. Die Briten forderten zusätzlich, die Produktionskapazitäten für die SBZ nacb dem Ende der sowjetischen Demontagen zu berechnen und für die Westzonen als Bruttokapazität, „obne zukünftige Entfernungen in Rechnung zu stellen". Sie bezweifelten inzwischen, daß das vorhandene Restpotential noch Reparationen zulasse. Durch Abtrennung der Ostgebiete $(7 \%)$, Demontagen in der SBZ (50\% der Anlagen) und Kriegszerstörungen (20-25\% allein in den Westzonen) habe Deutschland bereits $35-40 \%$ seiner industriellen Kapazitäten verloren ${ }^{67}$. Mit ihrem Ansatz konnten sich die Westmächte zunächst in den unteren Gremien des Kontrollrats durchsetzen. Sie suchten nach einer flexibleren Formel, die trotz der wirtschaftlichen Entwaffnung an den Bedürfnissen Deutschlands orientiert war: „Wegen des Mangels an Land und anderen natürlichen Ressourcen im Verhältnis zur Bevölkerung“ müsse dieses höher industrialisiert bleiben als der euro-

${ }^{63}$ BA, Z 45 F/OMGUS, 2/132-2/13 (LOIC/M(45)9, 10. 12. 1945). Zu Vorläuferstudien des State Department vgl. Nübel, Reparationspolitik, S. 68 ff. Hammond, Directives, S. 404.

64 BA, Z 45 F/OMGUS, 2/132-2/13 (LOIC/M(45)3, 12. 10. 1945).

65 BA, Z 45 F/OMGUS, 2/132-2/13 (LOIC/M(45)4, 25. 10. 1945; M(45)11, 17. 12. 1945). AO, Berlin/ 3273/3/2731, I (Nowikow, 17. 11. 1945). Ratchford/Ross, Reparations, S. 89. AMAE, Y 651, Bl. 62 (MAE, Direction Economique, 14. 1. 1946).

66 AO, Berlin/3269/1/2001 (10. 10. 1945). Vgl. FRUS, 1945/II, S. 286 f. (20.9. 1945)

67 BA, Z 45 F/OMGUS, 2/132-2/13 (LOIC/M(45)3, 12. 10. 1945). DBPO, I, 5, S. 342 ff. (11. 11. 1945), 519 ff. (29. 11. 1945). 
päische Durchschnitt, zumal wenn man den Verlust der agrarischen Gebiete im Osten in Rechnung stelle. Sie beharrten daher, sollte Deutschland sich selbst versorgen können, auf einem erheblichen Außenhandel, den Sowjets und Franzosen übereinstimmend nur als untergeordnetes Hilfsmittel beim Endausgleich der volkswirtschaftlichen Gesamtbalance berücksichtigt wissen wollten ${ }^{68}$.

Nachdem die Westmächte die Erarbeitung eines detaillierten Industrieniveauplans durchgesetzt hatten, in dem jede Branche einzeln behandelt werden mußte, wurden nach einem Vorschlag Clays vom Oktober 1945 alle Kontrollratsdelegationen aufgefordert, bis zum 15. Januar 1946 einen eigenen Entwurf vorzulegen ${ }^{69}$. Das kostete Zeit und beschwor die Gefahr herauf, daß das Ergebnis keine lebensfähige Wirtschaftsstruktur ergab, sondern der politische Durchschnitt vielfältiger Einzelkompromisse war $^{70}$. In der Tat wichen die Vorschläge für das künftige industrielle Produktionsniveau stark voneinander ab. Während die Ansätze der drei Westmächte sich in der Regel in einer konsensfähigen Spannbreite bewegten, lag die Sowjetunion mit ihren regelmäßig um $20-60 \%$ darunter. Die Vorschläge der vier Alliierten ${ }^{71}$ offenbarten die Schwerpunkte, die sie hinsichtlich der künftigen deutschen Wirtschaftsstruktur bzw. ihrer Reparationspolitik anstrebten. Bezeichnend war die einheitliche Tendenz zur Re-Agrarisierung: Steigerung bei landwirtschaftlichen Maschinen gegenüber dem Vorkriegsstand; hohe Produktion von Kali, bei dem die Sowjetunion Höchstsätze vorsah; hohe Lebensmittelimporte auf Vorkriegsniveau, wie die Westmächte sie für nötig erachteten. Die Deutschen sollten Fahrrad fahren und, aus rüstungsstrategischen Gründen, bei Automobilen vollständig vom Import abhängig sein. Dabei spielten zwar handelspolitische Konkurrenzen eine Rolle; doch war den Briten klar, daß es keinen Plan ohne „eventuelle Interessenkonflikte mit britischen Exporteuren“ geben konnte, sofern eine ausgewogene Handelsbilanz für Deutschland Vorrang genoß. Sie hatten sich unter dem Einfluß von Keynes zu der Auffassung durchgerungen, daß eine den nationalen handelspolitischen Interessen angepaßte De-Industrialisierung Deutschlands weder kurz- noch langfristig von Vorteil sein werde ${ }^{72}$.

Nachdem sich die Diskussion im Industrieniveaukomitee auf die entscheidende Frage der Stahlproduktion zugespitzt hatte, waren die Verhandlungen Mitte Dezember so festgefahren, daß das Wirtschaftsdirektorat und das Koordinationskomitee bemüht werden mußten. Hauptvorwurf der Sowjetunion an die Adresse der Westmächte war, sie verstießen gegen das Potsdamer Abkommen, da ihre Produktionsziffern generell um das Doppelte über dem europäischen Durchschnitt lägen und Deutschland das höchste Industrieniveau in Europa beließen. Auch wenn sie das mit dem europäischen Wiederaufbaubedarf begründeten, so ergäbe sich die eigentliche Differenz zwischen den westlichen und den sowjetischen Vorschlägen allein aus dem vorgesehenen Inlandsverbrauch. Gleichwohl war die sowjetische Delegation bereit, für die Rekonstruktionsperiode ein höheres Produktionsniveau zuzulassen, das später abgesenkt

${ }^{68} \mathrm{BA}, \mathrm{Z} 45$ F/OMGUS, 2/118-1/2-4 (CORC/M(45)28, 21. 12. 1945); 2/132-2/13 (LOIC/M(45)9 und 12); 2/132-2/14 (LOIC/P(46)4, 9. 1. 1946). Gegenüberstellung der „fundamental differences of approach" in: $2 / 119-3 / 5-9$ (DECO/P(45)122, 21. 12. 1945).

69 BA, Z 45 F/OMGUS, 2/95-1/18.

70 NA, RG 59, $740.00119 \mathrm{EW} / 2-1246$.

71 Ratchford/Ross, Reparations, S. 145. Eine Teilübersicht mit z.T. abweichenden Angaben in: BA, Z 45 F/OMGUS, 2/132-2/14 (LOIC/P(46)4(Revise), 14. 1. 1946). Cairncross, Price, S. 117, $132 \mathrm{ff}$.

72 DBPO, I, 5, S. 81, $342 \mathrm{ff}$. 
werden könne. Indem sie zugleich auf die schematische Reduktion jedes einzelnen Industriezweigs auf europäisches Durchschnittsniveau verzichtete, bereitete sie ihr Nachgeben in der Stahlfrage vor, das sie sich teuer abkaufen ließ. Diese Zugeständnisse waren Ausdruck des Wunsches nach einer baldigen Einigung und einem entsprechend frühen Lieferbeginn. Sie waren aber mehr noch Ausdruck ihres beginnenden Positionswandels: nicht mehr De-Industrialisierung, sondern Entnahmen aus der laufenden Produktion.

In den nachfolgenden Verhandlungen suchte die Sowjetunion in augenfälliger Form die Unterstützung der Amerikaner für ihre Vorschläge, indem sie ihnen das de-industrialisierte Deutschland als Exportmarkt für Baumwollprodukte oder Automobile offerierte. Das war nicht ungeschickt, denn im State Department, das eigene Studien gegen den „weichen“ Hoover-Plan vorbereitete, hielt man umfassende Demontagen in den rüstungsrelevanten Industrien für möglich, da deren Kapazitäten während des Krieges erheblich ausgeweitet worden seien. Eine Beeinträchtigung des deutschen (wie des europäischen) Wiederaufbaus werde sich nicht aus fehlenden Produktionskapazitäten, sondern aus dem Mangel an Rohstoffen ergeben. Das State Department empfahl daher eine Reduktion der deutschen Einfuhren, die Steigerung der Exporte aus nicht rüstungsrelevanten Industrien sowie eine „Maximierung der Entnahmen" unter Belassung eines Mindestbedarfs an potentiellen Rüstungsbetrieben in der metallverarbeitenden und chemischen Industrie ${ }^{73}$. Auch Clay bestand darauf, „daß, wenn es einen Konflikt zwischen der Zerstörung von Kriegspotential und der Aufrechterhaltung des Lebensstandards gebe, das letztere zurückstehen müsse“. Aber ihm waren letztlich die „alliierte Entscheidung und Einheit [...] viel wichtiger als die Zahlen selbst“. Ohnehin lagen nach seiner Auffassung die amerikanischen Ansätze „,in der Mitte“ zwischen den britischen und sowjetischen Extremen; „durch geringfügige Kompromisse nach unten waren wir gewöhnlich in der Lage, uns mit den Sowjets zu einigen“. Er nahm keine Rücksicht auf die Warnung seiner Experten, daß das überdeutliche Bemühen um eine Einigung die USA erpreßbar mache ${ }^{74}$. Doch mehrten sich auf amerikanischer Seite längst die Stimmen, die sich gegen eine zu extreme DeIndustrialisierung aussprachen; das werde amerikanische Zuschüsse für Deutschland erforderlich machen und die (west)europäische Rekonstruktion beeinträchtigen ${ }^{75}$.

Die Briten richteten sich auf eine harte Auseinandersetzung mit den Sowjets ein, ohne von vornherein den Grundkonsens in der Reparationsfrage aufkündigen zu wollen. Wenn der Zerstörung des deutschen Kriegspotentials und der Gewährleistung eines minimalen Lebensstandards Priorität eingeräumt würden, seien Reparationen kaum mehr zu erwarten. Aus Sicht der britischen Interessen und angesichts der Erfahrungen nach dem Ersten Weltkrieg erschien die Umstrukturierung, nicht die De-Industrialisierung der deutschen Wirtschaft erfolgversprechender: In einer ersten Phase von zwei Jahren müsse die wirtschaftliche Abrüstung im Vordergrund stehen, während die übrige Wirtschaft auf „improvisierter Grundlage“ weitergeführt werde. In der zweiten Phase sei ein „konsequenteres Planen“ aufgrund der vorangegangen Erfah-

73 FRUS, 1945/III, S. 1341 ff. (12. 10. 1945). Nach Ratchford/Ross, Reparations, S. 133, gingen diese Planungen jedoch nicht mehr in die Verhandlungen des Kontrollrats ein.

74 CP, S. 112 f., 153. Ratchford/Ross, Reparations, S. 127, 129, 170. NA, RG 59, 740.00119 EW/21246 (James W. Angell).

75 Vgl. oben S. 59 mit Anm. 175. 
rungen angebracht, ehe dann in der dritten Phase die Neugestaltung abgeschlossen werden könne ${ }^{76}$. Diese Überlegungen liefen auf eine zurückhaltende Reparations- und Demontagepolitik hinaus. Selbst bei einer Stahlquote von 11,5 Mio. t, die das Kabinett beschloß, schien es zweifelhaft, „ob unser Plan, obwohl er ja auf einer liberalen Interpretation des Potsdamer Abkommens entwickelt worden ist, in der Praxis Deutschland als ein Subsistenzmittel dienen wird“. Für die CCG war der am 31. Dezember 1945 vorgelegte britische Entwurf das äußerste Limit dessen, was realistischerweise gegen die anderen Alliierten durchsetzbar schien; denn „nichts weniger Drastisches war unter den Bedingungen des Potsdamer Abkommens möglich“, nachdem sie entgegen ihren Anweisungen im Interesse der Kompromißfähigkeit nur 9 Mio. t Stahl eingesetzt hatte. Die Briten waren entschlossen, an ihrem Ansatz festzuhalten, wenngleich nicht „bis zu einem Punkt, wo wir uns in einer Minderheit von einer gegen die drei anderen Mächte wiederfänden“. Ihre Position hatte sich derart verfestigt, daß Sowjets und Amerikaner am 17. Januar 1946 „sehr bestürzt waren angesichts unserer entschlossenen Weigerung, uns auf irgendeine Zahl der jährlichen Stahlproduktion festzulegen, die so niedrig wäre, daß sie Deutschland zu einer Wüste machen würde“"77.

Frankreich spielte nur eine untergeordnete Rolle in diesen Verhandlungen. Erst zum Schluß legte die GFCC verschiedentlich ihr Veto ein, konnte die Debatten aber nicht entscheidend beeinflussen. Die französische Politik war unentschlossen und konzeptionslos. Infolge mangelhafter Koordination zwischen Paris, Baden-Baden und Berlin verfügte die GFCC über keinen Plan, sondern nur über „völlig unbrauchbare“ Anweisungen. Ihr Vertreter im Industrieniveaukomitee stellte daraufhin einige Zahlen zusammen, die er selbst als „lächerlich" und peinlich empfand ${ }^{78}$. Die Franzosen hatten erst seit dem Mai 1945 eine Reparationsstrategie zu entwickeln begonnen, doch war diese bis Ende des Jahres weder politisch endgültig beschlossen noch mit den Vorbereitungen des Monnet-Plans abgestimmt worden ${ }^{79}$. Zum einen sollte Deutschland kostenlos Kapitalgüter als einmalige Reparationsleistungen bereitstellen, ergänzt durch mehrjährige Lieferungen aus der laufenden Produktion, die von den Empfängern nur zu $80 \%$ in Devisen bezahlt würden, während der Rest als Reparationen abgeschöpft würde ${ }^{80}$. Zum zweiten wollte Frankreich bis zur Wiederherstellung der deutschen Lieferfähigkeit die notwendigen Importe nach Deutschland vorfinanzieren

76 PRO, FO 1034/17 (CCG/Economic Division, 19.9. 1945).

77 PRO, FO 371/55597/C425 (9.1. 1946); FO 371/55423 (CORC, 17. 1. 1946); CAB 21/1873 (C.P.(46)1 14, 16.3. 1946). DBPO, I, 2, S. 715. AO, Berlin/3269/1/2201 (11. 2. 1946). Zu den Versuchen, über Washington auf höchster Ebene eine Änderung der amerikanischen Haltung zu erreichen, vgl. Müller, Sicherheit, S. $72 \mathrm{ff}$.

78 AO, Berlin/3269/1/2201 (Comité d'Industrie, 18. 1. 1946). AMAE, Y 370, Bl. 74 f. (GFCC, 27. 2. 1946).

79 Da der Monnet-Plan (Plan de Modernisation et d'Equipement) erst im Januar 1946 vorlag, kamen die Detailplanungen für die Beratungen im Kontrollrat zu spät. Er war als mittelfristiger Wiederaufbauplan für die sechs wichtigsten Wirtschaftssektoren konzipiert: Kohle, Strom, Stahl, Zement, Transport und landwirtschaftliche Maschinen; Öl, chemische Produkte, Dünger, Kunstdünger, Kunstfasern und Schiffbau wurden später hinzugefügt. Die Liste macht die Bedeutung deutscher Reparationen (neben amerikanischen Krediten) für das ehrgeizige Ziel deutlich, durch Verdoppelung des Nationaleinkommens bis 1948 den Höchststand von 1929 wieder zu erreichen und bis 1950 um ein Viertel zu übertreffen. Monnet, Memoiren, S. $297 \mathrm{ff}$.

${ }^{80} \mathrm{AO}$, Berlin/3273/3/2731, I (Note, 26.6. 1945). AMAE, Y 278, Bl. 269 ff. (28. 11. 1944); Y 363, Bl. 153 ff. (Sous-Commission Economique, 13. 10. 1945); Y 650, Bl. 132 ff. (31. 10. 1945). Insgesamt sind einige Anleihen bei dem Seydoux-Plan der zwanziger Jahre erkennbar. 
und später mit der Bezahlung der deutschen Exporte verrechnen. Weiterentwickelt wurde diese Linie Anfang Juli 1945: Ökonomische Entwaffnung und Reparationen, gesichert durch eine langfristige Kontrolle der Alliierten in Deutschland, seien zu koppeln mit Maßnahmen, die Frankreich wieder „zu einer industriellen Großmacht“ werden ließen: „Auf französischer Seite wünscht man soweit als möglich die französische Industrie von der Konkurrenz der deutschen Industrie zu befreien und deren Demontage auszunutzen, um die industrielle Macht Frankreichs beträchtlich zu steigern. ${ }^{81}$ Frankreich war daher an umfassenden und baldigen Reparationsleistungen interessiert, darin den Sowjets folgend, benötigte aber langfristige Austauschbeziehungen mit einem industriell leistungsfähigen Deutschland und neigte in der Hinsicht den anglo-amerikanischen Vorstellungen zu. Das Land bemühte sich daher, wie Großbritannien, widersprüchliche Ziele auf einen Nenner zu bringen: die deutsche Handelskonkurrenz zu reduzieren, ohne Deutschland die Fähigkeit zur Selbstversorgung durch den Export von Industriewaren zu nehmen. Die Demontage der Schwerindustrie werde der angestrebten Modernisierung der französischen Wirtschaft förderlich sein, die Verlagerung der Industrieproduktion auf Leichtindustrie und Konsumgüter stelle jedoch eine „direkte Bedrohung“ der eigenen Industrie dar. Die Abhängigkeit der Drittländer von deutschen Exporten - das sei kein „egoistisches“, sondern ein „Ziel der Sicherheit“ - müsse gebrochen werden, da die Beibehaltung der exportorientierten Produktionskapazitäten hohe Importe erfordere und die rasche Wiedererlangung der Autarkie ermögliche. Gleichwohl wurde eine übertriebene industrielle Entwaffnung, wie die Sowjets sie propagierten, infolge der zu erwartenden Verelendung Deutschlands und seines vollständigen Ausfalls als Lieferant für den europäischen Rekonstruktionsbedarf nicht befürwortet: „Indem man eine militärische Gefahr eliminiert, schafft man eine nicht weniger bedrohliche Situation.“ Es galt einen prekären Mittelweg zu finden, der eine Kurskorrektur erforderlich machte: Die Abtrennung von Territorien im Westen, also von Ruhr, Rheinland und Saar, mochte „politische Sicherheit“ bieten; „sie wäre aber für sich allein nicht ausreichend, um das wirtschaftliche Problem zu lösen.“ Die Internationalisierung der Ruhr schien den Ausweg aus diesem Dilemma zu bieten, indem sie eine dauerhafte Kontrolle einerseits, einen minimalen Lebensstandard andererseits garantierte ${ }^{82}$.

Der Durchbruch im Kontrollrat erfolgte zum Jahreswechsel 1945/46. Sokolowski hatte am 21. Dezember die Wende eingeleitet, als er die Felder der Übereinstimmung herausstrich. Die Grundsatzerklärung, daß die Sowjetunion unnachgiebig auf „genuiner" Abrüstung beharre, mochte die Tatsache überdecken, daß das wachsende Interesse an Reparationen aus laufender Produktion eine Umkehr ihrer Ausgangsposition bewirkt hatte. Mit seiner Vorleistung, daß einige Leichtindustrien oberhalb des europäischen Durchschnitts liegen dürften, um Importbedürfnisse abzudecken ${ }^{83}$, hatte er Bewegung in die Verhandlungen gebracht und gleichzeitig die Westmächte zu Gegenleistungen gezwungen. Die Einigung im Koordinationskomitee über die Produktionsziffern für Stahl und Strom, also die volkswirtschaftlichen Eckdaten, verschob zugleich die Entscheidungen von der wirtschaftlichen auf die politische Ebene. Denn

\footnotetext{
81 AMAE, Y 363, Bl. 98 ff. (Document No. 183; Direction Economique, 7. 7. 1945); Y 433, Bl. 7 (14. 4. 1945).

82 AMAE, Y 370, Bl. 43 (GFCC, 7. 1. 1946); Y 651, Bl. 59 ff. (MAE, 14. 1. 1946).

83 BA, Z 45 F/OMGUS, 2/118-1/16 (CORC/P(45)212, Appendix ,A', 20. 12. 1945).
} 
der Kontrollrat stand unter Zeitdruck, da es absehbar war, daß der im Potsdamer Abkommen vorgegebene Termin für den Abschluß der Arbeiten am 2. Februar 1946 nicht einzuhalten war. Da sich alle Delegationen der politischen Bedeutung eines Erfolges bewußt waren, begann ein hartnäckiges Feilschen, in dem der unbedingte Einigungswille Clays und Murphys den Ausschlag zugunsten der Sowjetunion gab. Aber auch die Sowjets machten, wie Sokolowski am 7. März betonte und die Briten bestätigten, im Interesse einer raschen Einigung (und baldiger Reparationslieferungen) erhebliche Zugeständnisse, „manchmal selbst im Widerspruch zu einigen Beschlüssen der Potsdamer Konferenz“. Als Gegenleistung verlangte Dratwin am 20. März, daß eine Revision des Industrieniveaus erst nach Abwicklung des Reparationsplans erfolgen und eine Revision nur zu Lasten Deutschlands, nicht aber der Alliierten gehen dürfe; bis zum 10. April 1946 (bzw. zu einem „baldmöglichsten“ verbindlichen Termin) müsse die Liste der für Reparationen verfügbaren Betriebe verabschicdet werden. Damit war die Revision der Potsdamer Bestimmungen von den Sowjets eingeleitet worden. Auf der Pariser Außenministerkonferenz sollte Molotow im Juli 1946 davon Gebrauch machen.

Nach dem ersten Zugeständnis bei der Leichtindustrie erhöhte die Sowjetunion am 29. Dezember auch bei Stahl ihren extrem niedrigen Grundansatz und gab der britischen Forderung im Prinzip nach, zur Gewährleistung der festgelegten Produktionsmenge einen Kapazitätsüberhang von 10-20\% zuzugestehen. Zuletzt stimmten sie dem amerikanischen Vermittlungsangebot von 5,8 Mio. $t$ realer Produktion, aber 7,5 Mio. $t$ technischer Produktionskapazität zu. Doch waren damit keineswegs alle Probleme ausgeräumt, da bei den Abschlußberatungen im Wirtschaftsdirektorat die Briten die 7,5 und die Sowjets die 5,8 Mio. $t$ als „Planungszahl“ für die Bestimmung aller anderen Produktionsziffern zugrunde zu legen forderten ${ }^{84}$. Während für Clay die Zahl von 5,8 Mio. $t$ eine Untergrenze war, die den Kompromiß ermöglichte, aber vorsichtshalber doch der jährlichen Überprüfung unterliegen sollte, war sie für die Sowjets die Obergrenze; die Briten interpretierten die Zahlen dagegen als eine Begrenzung auf 5,8 Mio.t „für den Augenblick“, während die Kapazitäten für eine künftige Produktion von 7,5 Mio. t erhalten bleiben sollten, was eine technische Produktionskapazität von 8,62 Mio. t bedeutete ${ }^{85}$. Sokolowski akzeptierte am 10. Januar $1946 \mathrm{im}$ Kontrollrat die britische Untergrenze, die er bislang als unzumutbar abgelehnt hatte. Es dauerte kein Jahr, bis alle Mächte auf der Moskauer Außenministerkonferenz sich dem britischen Ansatz anschlossen und eine Kapazität befürworteten, die für die Produktion von 11,5 Mio. $t$ Stahl ausgelegt war $^{86}$.

Nachdem Clay durch seine Unterstützung der sowjetischen Positionen den Durchbruch herbeigeführt hatte, drängte er am 8. März auf die Verankerung der amerikani-

84 CP, S. 154 f. (31. 1. 1946). FRUS, 1946/V, S. 484-87.

${ }^{85}$ Die Ruhrfrage 1945/46, S. 574.

${ }^{86}$ Der sowjetische Vorstoß, die deutsche Stahlproduktion zu erhöhen und bei einer verbleibenden Kapazität von $12 \mathrm{Mio}$. $t$ in den Westzonen Produktionskapazitäten in Höhe von 13 Mio. $t$ zu demontieren, hatte keine Aussicht auf Erfolg; und nicht nur, weil Frankreich an der Stahlquote des ersten Industrieniveauplans in Höhe von 7,5 Mio. t, einschließlich der Saar, zugunsten der eigenen Stahlindustrie festhielt. AMAE, Y 371, Bl. 43 ff. (Général Juin), 65 ff. (Commissariat Général du Plan de Modernisation et d'Equipement, 7. 2. 1947); Y 293, Bl. 186 (Bidault, 18. 3. 1947). In den Verhandlungen über den bizonalen Industrieniveauplan forderte Clay 13,2 Mio. t Kapazität und 12 Mio. $t$ Produktion; die Briten wollten $11 \mathrm{Mjo}$. $\mathrm{t}$ Gesamtproduktion für ganz Deutschland akzeptieren. PRO, FO 371/64551/C9191 (ORC(47)32, 1. 7. 1947). 
schen Interessen, die ihn bei den parallelen Beratungen der Export-Import-Frage erstmals bewogen hatten, einen Demontagestopp in Erwägung zu ziehen. Der Industrieniveauplan sei ,in erster Linie eine Schätzung der Produktion, die genutzt werden soll, um die aus Deutschland zu entfernenden Reparationskapazitäten zu bestimmen. Wir sehen ihn nicht als einen Plan an, der Produktionsbegrenzungen für die Zukunft festlegt." Die Stahlquote, die Produktionsverbote im Rüstungsbereich und andere Begrenzungen zur wirtschaftlichen Entwaffnung seien auf lange Sicht berechnet; doch bei den Leichtindustrien müsse, z. B. aufgrund der Nachfrage am Weltmarkt, mit „erheblichen" Veränderungen gerechnet werden. Das zielte, wie er Mitte Januar 1946 intern äußerte, auf die langfristige Aufhebung aller Beschränkungen in diesem Sektor und auf den weitgehenden Verzicht auf Demontagen ${ }^{87}$. Den Franzosen, die am 1. Februar Alternativplanungen für den Fall einer Abtrennung der Saar verlangt hatten, drohte er am 20. März eine Fundamentalrevision an, wenn die wirtschaftliche Einheit durch Errichtung von Zentralverwaltungen nicht hergestellt werde oder Grenzveränderungen im Westen vorgenommen würden. Nach britischem Eindruck meinte Clay mit dieser Warnung aber die Sowjets. Seine Mitarbeiter hatten am 12. März die Franzosen zur Aufgabe kleinlicher Bedenken gedrängt, um die Sowjetunion vor den entscheidenden Test ihrer Kooperationswilligkeit zu stellen. Vorrangig sei es, „rasch ein Vier-Mächte-Abkommen abzuschließen, um dann zu prüfen, ob die sowjetische Delegation dieses Abkommen effektiv in die Praxis umsetzt oder sich von den anderen Alliierten deutlich isoliert. Wenn sich die letztere Hypothese bestätigt, werden die Angelsachsen im wirtschaftlichen Bereich neue Dispositionen treffen." ${ }^{\text {"88 }}$

Während Clay seine Revisionsdrohung öffentlich machte, arbeiteten die Briten noch hinter verschlossenen Türen - wie aber den Franzosen und den Sowjets ${ }^{89}$ gleichwohl nicht völlig entging - bereits an einem neuen Plan, „dem zufolge Deutschland eine große Produktionsfreiheit belassen werden wird“. Die britische Regierung diskutierte intern seit September 1945 allgemein über eine „drastische Revision unserer Politik“, d. h. eine „Revision“ des Potsdamer Abkommens. Nachdem aber die Sowjets im Wirtschaftsdirektorat „ziemlich überraschende Konzessionen“ gemacht hatten, „beinahe immer [...] erheblich größer als die der drei anderen Mächte“, war es weder nötig, noch angesichts der amerikanischen Haltung möglich, den Industrieniveauplan zur Erzwingung weitergehender Ziele abzulehnen. Die Briten rechneten es sich als Erfolg an, daß sie in der stahlverarbeitenden, chemischen und Bauindustrie derart hohe Zahlen durchgesetzt hatten, daß die Stahlproduktion automatisch nach oben getrieben wurde. Auch wenn damit die Sowjetunion indirekt die britische Interpretation des Potsdamer Abkommens akzeptiert habe, so mußte das Königreich ebenfalls seine $\mathrm{Zu}$ stimmung zu dem Abkommen erneuern, das selbst ,in seiner großzügigsten Interpretation als Verkörperung einer restriktiven und gefährlichen Politik für Deutschland, Europa und uns selbst" betrachtet wurde. Nachdem London vergeblich die USA zu bewegen versucht hatte, gemäß dem Vorbild der Stahlregelung in allen anderen Branchen ebenfalls ein höheres Niveau der zurückzuhaltenden Kapazitäten festzulegen, die als technische Reserven über die erlaubte Produktionsmenge hinausgingen, akzeptierte die CCG schließlich den Plan, allerdings unter zahlreichen Vorbehalten, die die

${ }^{87}$ FRUS, 1946/V, S. $490 \mathrm{f}$.

88 AMAE, Y 364, Bl. 85

89 Laufer, Reparationspolitik, S. 7 (Semjonow, 26. 5. 1946; Kudrjawzew, 25. 6. 1946). 
Wirtschaftseinheit, die Westgrenzen und die Bevölkerungszahl betrafen. Vor allem aber bestanden sie auf regelmäßigen und „verbindlichen “ Überprüfungen im Hinblick auf die „Modifikation oder Aufhebung“ von Kontrollen bzw. Beschränkungen der Friedensindustrien ${ }^{90}$.

In seiner endgültigen Form war der Industrieniveauplan erheblich unbestimmter als die ursprünglichen Entwürfe. Neben zahlreichen Produktionsverboten, die zum Teil durch zeitlich begrenzte Übergangsregelungen im Interesse der Finanzierung von Importen (und der Bedürfnisse der Besatzungsmächte) ausgehöhlt waren, wurden verschiedene Kategorien vorgesehen: 1. eingeschränkte und kontrollierte, weil potentiell kriegswichtige Branchen, in denen nur die Kapazität, weniger die Produktionsmenge selbst, in Prozent von 1936/38 festgelegt wurde; 2. „andere“ Industrien, für die keine starren Begrenzungen galten, in denen teilweise die vorhandenen Kapazitäten überschritten werden durften, so daß nach Auffassung der USA, die sich gegen den Widerstand Frankreichs und der Sowjetunion durchsetzten, die festgesetzten Werte „Schätzungen und keine Begrenzungen“ darstellten; 3. nicht eingeschränkte „friedliche“ Industriezweige, in denen auf amerikanisches und britisches Beharren hin gar keine Demontagen vorgenommen werden sollten. Der Plan war relativ einfach konstruiert, ließ prinzipiell Flexibilität zu, sofern der Kontrollrat bei den vorgesehenen Überprüfungen sich darauf einigen konnte. Er regelte zumeist das Verhältnis von Inlandsverbrauch und Export, wenngleich oft nur als arithmetischen Kompromiß zwischen den britischen und sowjetischen Extrempositionen, und reduzierte das Produktionsniveau auf $70-80 \%$ des Standes von $1936^{91}$; doch angesichts der bei Stahl, Strom und chemischen Grundstoffen geschaffenen Engpässe schien keineswegs gewährleistet, ob dieses Niveau erreicht werden konnte.

Mit der Einigung am 26./28. März 1946 schien ein entscheidender Stolperstein auf dem Weg zur Vier-Mächte-Einheit beiseite geräumt, da nun das Wirtschaftsdirektorat beauftragt werden konnte, bis zum 20. April eine erste Reparationsliste vorzulegen. Die Stimmung blieb gleichwohl bei allen Beteiligten gedämpft, die offiziellen positiven Urteile klangen nicht sehr überzeugend. Das britische Kabinett bewertete den Plan, trotz mancher Vorbehalte, als ,eine weder drastische noch großzügige Interpretation des Potsdamer Abkommens, sondern eine, die als fair betrachtet werden kann". Draper und andere Mitglieder von OMGUS hatten Bedenken, ob das Kunstprodukt selbst bei gutem Willen in der Praxis funktionieren könne ${ }^{92}$. Zwar hatten sich die Westmächte mit der Sowjetunion noch einmal auf einen gemeinsamen Plan zur Umgestaltung Deutschlands geeinigt, doch die Verhandlungen hatten in schonungsloser Deutlichkeit die Unvereinbarkeit der Besatzungsziele zwischen Ost und West ebenso offengelegt wie die der dahinterstehenden politisch-ideologischen Grundauffassungen. Sicherheit durch ökonomische Entmilitarisierung Deutschlands, das war der gemeinsame Nenner, auf dem die Einigung möglich war. Doch während die Sowjetunion eine ebenso radikale wie pauschale Abschöpfung von Reparationen verlangte, ohne die ökonomische Abrüstung anders als durch Transformation zu gestalten, verlangten

90 PRO, FO 942/475 (Robertson, 21. 2.; COGA, 27. 2.; COGA an Bevin, 7. 3. 1946); CAB 21/1873 (25. 1. 1946; C.P.(46)114, 16. 3. 1946; Extract C.M.(46)25, 18. 3. 1946). DBPO, I, 2, S. 713.

91 Cairncross, Price, S. 132. FRUS, 1947/II, S. 978 (50-55\% von 1938), 990 (70-75\% von 1936). Bei Werkzeugmaschinen waren es 11,4\%, im Schwermaschinenbau 31\% des Standes von 1938.

92 PRO, CAB 21/1873 (Hynd, C.P.(46)114, 12. 3. 1946). Ratchford/Ross, Reparations, S. 188 f. 
die Westmächte (wenngleich die französische Haltung zwiespältig war) die enge Verknüpfung von Destruktion und Rekonstruktion. Die Folgenabschätzung, das Nachdenken über die Wirkungen einer Vernichtung deutscher Produktionskapazitäten für Deutschland, Europa und die Weltwirtschaft ging bei den Westmächten weit über das hinaus, was in den Kriegsplanungen absehbar und notwendig erschienen war. Die langfristige Rekonstruktionsperspektive löste den kurzfristigen Rache- bzw. Sicherheitsgedanken ab. Das mußte, aus westlicher Perspektive, unter den gegebenen Umständen eine Entscheidung für Deutschland und gegen die Sowjetunion sein, auch wenn das viele sich noch nicht eingestehen wollten.

Die zahlreichen Vorbehalte, die jede der vier Delegationen geltend gemacht hatte, und die bis zur letzten Minute anhaltenden Revisionsversuche ließen eine allgemeine Unzufriedenheit mit dem Ergebnis erkennen, obwohl das Mißbehagen nur die Tatsache unterstrich, daß der Plan ein politischer Kompromiß im Geiste Potsdams war. Eben dadurch widersprach er aber den aktuellen Interessen der Besatzungsmächte; nicht De-Industrialisierung, sondern Ausdehnung der Produktion unter ihrer Kontrolle besaß inzwischen Priorität: im Hinblick auf ihre Import- oder ihre Reparationspläne. Es war absehbar, daß alle vier Alliierten bei der Umsetzung des Plans versuchen würden, ihre Vorstellungen nachträglich doch noch durchzusetzen. Gelegenheit dafür gab es reichlich. Zum einen wartete die Sowjetunion noch immer auf die ihr im Potsdamer Abkommen zugesagten Vorab-Lieferungen von Reparationen. Zum zweiten waren im Kontrollrat die Modalitäten der Demontagen und Reparationslieferungen zu entscheiden, deren Ausführung - zum dritten - in den Händen der Zonenkommandeure lag. Zum vierten war die Verknüpfung mit der Export-Import-Problematik einerseits, der Zentralverwaltungsfrage andererseits ein politisches Minenfeld, auf dem ein rasches Vorankommen nicht zu erwarten war. In diesen Verhandlungen hatten die Vertreter der Westmächte alle Trümpfe in der Hand, als Kontrollratsmitglieder wie als Zonenkommandeure, da die Sowjetunion als Berechtigter und Bedürftiger von ihrer Zustimmung abhängig war. Die Gelegenheit war verlockend, diese zur Kooperation oder zum Offenbarungseid zu zwingen.

\section{Vorab-Lieferungen, Reparationsstopp und Demontagen}

In Yalta war die Frage nach dem Beginn der deutschen Reparationslieferungen nur beiläufig behandelt worden. Doch angesichts des Vordringens der alliierten Armeen in die industrialisierten Kernregionen des Deutschen Reiches war den Westmächten daran gelegen, bis zur Verabschiedung bzw. bis zur organisierten Abwicklung eines gemeinsamen Reparationsprogramms Richtlinien für einseitige Entnahmen im Rükken der kämpfenden Truppen zu entwickeln. Damit sollten einerseits erste Schritte eingeleitet werden, „um die frühestmögliche Unterstützung der verwüsteten Gebiete in den Vereinten Nationen zu erzielen" ${ }^{\text {“93; }}$; andererseits mochte eine solche Übereinkunft verhindern helfen, daß sich einzelne Mächte unter dem Deckmantel der „Kriegsbeute“ exzessiv bedienten. Bezeichnenderweise konnte die Moskauer Reparationskommission, die seit dem Frühsommer 1945 über diese Fragen diskutierte, keine

93 FRUS, Potsdam I, S. 522-48 passim, Zitat S. 544. 
Einigkeit erzielen, ob und inwieweit die Vorab-Lieferungen später in der Reparationsgesamtbilanz verrechnet werden sollten. Das machte die Reparationen frühzeitig zur politischen Waffe.

Angesichts des ausgeprägten Interesses der Sowjetunion an einem raschen Beginn der Reparationslieferungen waren die Briten frühzeitig entschlossen, die Vorab-Lieferungen als den praktisch einzigen "Joker in unserem Spiel“, als „Verhandlungswaffe“ gegenüber der Sowjetunion einzusetzen, vor allem im Hinblick auf den Status der Gebiete östlich von Oder und Neiße. Mehr als Rohstoffe oder Konsumgüter mochten sie nicht anbieten ${ }^{94}$. Demgegenüber waren die USA bereit zuzugestehen, daß jede Besatzungsmacht aus ihrer Zone „Betriebe, Ausrüstung und Materialien (einschließlich laufender Produktion) “ entfernen durfte, soweit das dem Plan der Reparationskommission nicht entgegenstand und der Kontrollrat, dem ein Vetorecht gegen gewisse Entnahmen einzuräumen war, entsprechend informiert wurde; dabei sollte jeder der vier Mächte gestattet sein, ,jede andere“ Nation an den Entnahmen partizipieren zu lassen. Alle vorläufigen Maßnahmen standen unter dem Vorbehalt, daß über die Entnahmen Buch geführt wurde und diese „ohne Präjudizierung der endgültigen Zuteilung der Reparationsanteile“ erfolgten"s. Solchen Entnahmen wollte London jedoch nur gegen Bezahlung in „akzeptabler Währung“ zustimmen, solange nicht die „Umrisse“ des Reparationsplans festgelegt und die Definition der „Kriegsbeute“ vereinbart waren, auch wenn der britischen Regierung selbst eine Pauschallösung am Herzen lag, die die sofortige Eintreibung von 5\% ihres voraussichtlichen Anteils an den Reparationen in genau definierten Fällen erlaubt hätte. Mit ihrem Veto in der Reparationskommission trug die britische Regierung dazu bei, daß die Sowjetunion ihre Beutepolitik forcierte ${ }^{96}$.

Erwartungsgemäß drängte die Sowjetunion in Potsdam seit dem 23. Juli auf eine Regelung, die ihr angesichts „der Dringlichkeit des Bedarfs“ den Vorrang ihrer Ansprüche auf Lieferungen von Kapitalgütern wie aus laufender Produktion zusicherte. Maiski hatte gehofft, die Reparationskommission werde innerhalb weniger Tage festlegen, welche Industrien in Deutschland ganz oder teilweise zu verbieten seien. Wenn die Liste noch in Potsdam gebilligt werde, könnten die ersten Lieferungen bereits Anfang September einsetzen. Doch weder in der Moskauer Reparationskommission noch auf der Potsdamer Konferenz waren die Westmächte gewillt, auf dieses Druckmittel zu verzichten. Indem die Sowjetunion, an die amerikanischen Entwürfe in der Reparationskommission anknüpfend, die Streitfrage ausklammerte, ob diese Lieferungen „als Reparationen oder Restitutionen oder auf Wareneingangskonto“ zu verbuchen seien, gelang es ihr immerhin, das Prinzip von Vorab-Lieferungen im Abschlußprotokoll zu verankern. Auf dieser Grundlage drängte sie in der Moskauer Reparationskommission am 11. August auf rasche Beschlüsse und ließ dabei erkennen, daß sie vor allem am Bezug von Kapitalgütern, weniger von Lieferungen aus laufender

94 DBPO, I, 1, S. 88 f., 302, 309, 335, $483 \mathrm{f}$.

95 FRUS, 1945/III, S. 1184. Zu den Instruktionen für die Delegation der USA bei der Reparationskommission vom 18. 5. $1945 \mathrm{vgl}$. ebenda, S. $1222 \mathrm{ff}$. Der Assistant Secretary of the Treasury hatte vorgeschlagen, daß jede Besatzungsmacht für ein Jahr aus ihrer Zone alles als Reparationen entfernen dürfe, ,which it desires, up to a certain maximum amount to be fixed by the Reparations Commission“. NA, RG 59/EAC, box 16, folder: EAC. General Correspondence (10.4. 1945).

96 Vgl. FRUS, 1947/II, S. 264 (Molotow, 9. 3. 1947). 
Produktion interessiert $\mathrm{sei}^{{ }^{97}}$. Eine Woche später, am 18. August, erließ die SMAD ihren ersten Demontagebefehl. Wieder fünf Tage später legte sie dem Kontrollrat eine Wunschliste für Vorab-Reparationen vor, die 30 Betriebe aus der britischen, neun aus der amerikanischen und zwei aus der französischen Zone enthielt. Abermals vier Tage später verlangte Sokolowski im Koordinationskomitee die sofortige Bedienung dieser Liste. Doch Clay, unterstützt von Robertson, forderte deren Verweisung an die Reparationskommission, dann an das Wirtschaftsdirektorat: Ehe nicht der Friedensbedarf der deutschen Industrie festgelegt sei, könne eine abschließende Behandlung nicht erfolgen ${ }^{98}$. Daraufhin entschloß sich die Sowjetunion Anfang September endgültig für den Alleingang in ihrer Zone. Auf Anweisung aus Moskau ordnete die SMAD am 8. September die Ausarbeitung eines „Plans der Reparationslieferungen aus der Sowjetischen Besatzungszone in die UdSSR“ an. Bis zum 15. November war eine Bestandsaufnahme der Industrie in der SBZ zu erstellen, auf deren Grundlage bis zum 1. Dezember ein Plan vorgelegt werden mußte, dessen Durchführung vor dem Ende der Verhandlungen über das deutsche Industrieniveau im Kontrollrat abgeschlossen sein sollte ${ }^{99}$ ! Während sie längst zu einer unilateralen Reparationspolitik in ihrer Zone übergegangen war, forderte die Sowjetunion, taktisch ungeschickt, auf der alliierten Ebene Maßnahmen, die den Westmächten Argumente für neuerliche Verzögerungen boten. Sie verlangte nicht nur den Primat der Reparationskommission gegenüber dem Kontrollrat, sondern zielte, indem sie die Arbeit der ersteren ausschließlich auf die $25 \%$ ige Lieferpflicht der Westzonen begrenzen wollte, offenkundig auf eine weitgehend unbeschränkte zonale Autonomie. Zusätzlich verlangte sie eine Entscheidung bis zum 15. Oktober, um mit dem Abtransport der Vorab-Lieferungen am 1. Januar 1946 beginnen zu können. Auf der Londoner Außenministerkonferenz nahm Molotow letzteres zurück, nachdem erkennbar geworden war, daß die Westmächte, trotz gewisser Veränderungen in den französischen und britischen Positionen, nicht bereit waren, diesen Zeitplan zu akzeptieren ${ }^{100}$. Mit Befehl Nr. 128 vom 1. November zog die SMAD ihre Konsequenzen und ging zur systematischen Entnahme aus laufender Produktion über.

Die Westmächte, verärgert über die Konflikte mit der Sowjetunion in Österreich und Osteuropa, wandten sich gegen deren Anspruch auf bevorzugte Belieferung vor allen anderen Gläubigernationen. Sie verknüpften ihrerseits seit September die VorabLieferungen mit der Behandlung Deutschlands als Wirtschaftseinheit ${ }^{101}$. Wieder waren es die Briten, die „starke Einwände“ gegenüber den sowjetischen Forderungen anmeldeten und auf Zeit spielten. Erstmals wurde in London über ein Aussetzen oder doch Verzögern der Reparationslieferungen diskutiert, um die Sowjetunion zum Einlenken in Deutschland und Osteuropa zu zwingen; auch wenn das gegen die Verein-

97 AN, 457 (Bidault) AP 63/Conférence des Réparations (Sowjetisches Memorandum: Tâches immédiates, 11. 8. 1945). Vgl. FRUS, Potsdam II, S. 864 f. (23./24. 7. 1945). Potsdamer (Berliner) Konferenz 1945 , S. $296 \mathrm{f}$.

$98 \mathrm{BA}, \mathrm{Z} 45$ F/OMGUS, 2/118-1/5-16 (CORC/P(45)20, 23. 8. 1945; P(45)109(Revise), 8. 10. 1945).

99 Slusser, Soviet Economic Policy, S. $47 \mathrm{ff}$. Zu den Verhandlungen zwischen SMAD und deutschen Zentralverwaltungen um die Ausführung der ersten „Bestellung“ im November 1945 vgl. BAP, G-2/1023. Die KPD drängte im Januar/Februar 1946 in Moskau mit Rückendeckung der SMAD auf eine Revision der radikalen De-Industrialisierungsvorstellungen. SAPMO, ZPA, NI 36/631, B1. 33 (Bericht von Walter Ulbricht, 6. 2. 1946). Badstübner, Beratungen, S. 106.

100 FRUS, 1945/III, S. 1295 ff., 1309, 1325. FRUS, 1945/II, S. 175 f., 325 f., 372 ff. DBPO, I, 2, S. 311 f.

101 FRUS, 1945/III, S. 1284. AO, Berlin/3276/1/2007. 
barungen von Potsdam verstieß, und selbst auf die Gefahr hin, daß es die Arbeit des Kontrollrats erheblich belasten könne ${ }^{102}$. Die westlichen Militärkommandeure, von deren Ermessen jede Lieferung abhing, beharrten auf der vorherigen Lösung aller „Grundsatzfragen“ und machten Fortschritte von der Klärung der Frage abhängig, ob die Reparationskommission oder der Kontrollrat zuständig sei. Die Angelsachsen waren lediglich bereit, bis zur Festlegung des Industrieniveaus vereinzelte Vorab-Lieferungen aus reinem Kriegspotential als "Zeichen des guten Willens“ zu tätigen; Anfang Oktober stellte Clay (mit Billigung mehr des War als des State Department) zwei Betriebe aus seiner Zone für die Sowjetunion zur Verfügung. Es dürfte den Briten und dem State Department nicht unliebsam gewesen sein, daß die Franzosen mit der Forderung nach dem Vorrang der Restitutionen zusätzliche Hindernisse errichteten. Ebenso kamen ihnen Reibungen innerhalb der IARA nicht ungelegen, um unter Hinweis auf die Interessen anderer Gläubigernationen neue Verzögerungen zu bewirken $^{103}$. Erst Ende Oktober nahm das Koordinationskomitee ernsthaft die inhaltliche Diskussion auf, auch wenn zwischenzeitlich im Wirtschafts- und Reparationsdirektorat bzw. im Industriekomitee detaillierte Vorarbeiten durchgeführt worden waren.

Angesichts dieser Verzögerung lag jetzt im Kontrollrat neben der sowjetischen Liste auch eine französische vor, die, anders als erstere, in der britischen und amerikanischen Zone bereits bearbeitet wurde, obwohl sie im Kontrollrat offiziell noch nicht behandelt worden war ${ }^{104}$. Seine Ansprüche auf Vorab-Lieferungen hatte Frankreich erstmals auf der Londoner Außenministerkonferenz angemeldet, nachdem es bislang diesen Schritt als formelle Anerkenntnis der Potsdamer Beschlüsse vermieden hatte. Nach erheblichem Feilschen kam am 6. Dezember im Koordinationskomitee eine Einigung zustande, nachdem die Sowjetunion im Interesse rascher Lösungen von ihrer Forderung abgegangen war, daß ihr alle oder doch wenigstens drei Viertel der VorabLieferungen zufließen müßten. Jetzt gestanden Briten und Franzosen ihr die Hälfte zu, unter der Bedingung, daß möglichst rasch der Lieferanteil auf das ihr zustehende Viertel zurückgeschraubt werde. Die Sowjets akzeptierten zudem, daß verschiedene Demontagebetriebe, darunter einige Krupp-Werkstätten, für die Briten weiterarbeiteten, erhielten dafür aber die Zusage von weiteren Vorab-Reparationen in Höhe von 111 Mio. RM, während den westlichen Gläubigernationen Lieferungen in Höhe von 120 Mio. RM vorbehalten wurden ${ }^{105}$. Doch waren damit keineswegs alle Hindernisse aus dem Weg geräumt. Obwohl das Wirtschaftsdirektorat Anfang Januar 1946 angewiesen wurde, die Arbeit der Inspektions- und Bewertungsteams zu forcieren und das Verfahren von Demontage, Verpackung und Transport vorzubereiten, geschah zunächst nichts. Es begann ein erneutes Feilschen um die Bewertungs- und Verrechnungskriterien ${ }^{106}$.

102 FRUS, 1945/III, S. 1273 f. Der Vertreter der USA bei der IARA, James W. Angell, warnte, die Reparationsfrage als "pressure weapon“ einzusetzen; ,inadequate implementation of objectives of reparation chapter of Potsdam Declaration would seriously prejudice our relations with Russia“; ebenda, S. 1369.

103 FRUS, 1945/III, S. 1330 f., 1337, 1349 f. CP, S. 86 f. (28. 9. 1945), 104 ff. (13. 10. 1945).

104 AO, Berlin/3269/1/2001 (22. 12. 1945).

105 BA, Z 45 F/OMGUS, 2/118-1/2-4. FRUS, 1945/III, S. 1447 f. Die Anteile der IARA ebenda, S. 1464. AMAE, Y 363, Bl. 88 (19. 11. 1945).

106 Die Westmächte waren verärgert, weil die Sowjetunion für ihre Bezüge besonders vorteilhafte Bewertungsmaßstäbe verlangte, während sie bei ihren Gegenlieferungs-Verpflichtungen extrem hohe Preise anzusetzen versuchte. PRO, FO 371/55423/C1653 (12. 2. 1946). Keine Einigung wurde er- 
Die Verabschiedung des Industrieniveauplans hatte keine positiven Auswirkungen auf die Vorab-Lieferungen. Sokolowski klagte die Briten am 2. April in scharfer Form an, durch „alle Arten von Ausflüchten und Verzögerungen“ bislang jede Reparationslieferung aus ihrer Zone verhindert zu haben. Diese wiesen alle Anschuldigungen zurück, sondern sahen - wie die USA - die Verantwortung für die Verzögerungen in personellen und organisatorischen Problemen bei den Sowjets selbst ${ }^{107}$. Nachdem die Zusage, die Lieferungen im April aufzunehmen, nicht eingehalten wurde, wiederholte Sokolowski am 6. Mai seinen Vorwurf der „künstlichen Verzögerung“; noch immer sei aus der britischen Zone keine Lieferung eingegangen. Robertson versprach abermals eine Beschleunigung der Arbeiten, doch blieb die geringe Demontage- und Liefergeschwindigkeit der britischen Zone auf Monate hinaus ein Dauerthema im Koordinationskomitee. Robertsons Einwand, ihre Erwartungen seien unrealistisch, begegneten die sowjetischen Vertreter mit dem Hinweis, daß es entsprechende Probleme in den beiden anderen Westzonen nicht gab ${ }^{108}$.

Hatten bis dahin die Franzosen durch ihre Restitutionsansprüche und die Briten durch ihre Verzögerungstaktik jede Vorab-Lieferung von Reparationen erfolgreich verhindert, so schloß sich dem nach Verabschiedung des Industrieniveauplans Clay mit seinem Demontagestopp an. Nachdem die USA am 1. April 1946 in den Gremien des Kontrollrats den Vorsitz übernommen hatten, drängte Clay energisch auf die Umsetzung des Planes. Damit stieß er bei seinen drei Alliierten auf allseitigen Widerstand: Die Briten verweigerten ein koordiniertes Reparationsprogramm, die Franzosen die Zentralverwaltungen und die Sowjets einen gesamtdeutschen Export-Import-Plan. Damit brachen sofort die mühsam überdeckten Konflikte wieder auf. Clays Demontagestopp traf sämtliche Reparationsgläubiger gleichermaßen, doch politisch begründet wurde er nur mit dem Verhalten der Sowjets. Als diese sich am 8. April auf den Standpunkt stellten, die Export-Import-Balance sei erst für die Zeit nach Abschluß der Reparationen vorgesehen, sah Clay den Grund für die Revision des Industrieniveauplans gegeben und drohte mit der Einstellung der Reparationslieferungen: „Sollten wir

zielt, ob die Empfängerländer das Recht hatten, bei der Lieferung von ganzen Betriebseinheiten einzelne Teile zurückzuweisen. Wohl durften für keine Lieferung weniger als $22 \%$ des Zeitwertes von 1938 bezahlt werden, aber die Sowjets wollten nur bezahlen, was sie behielten. Die Angelsachsen akzeptierten nach anfänglichem Widerstand gegen Versuche, sich die „Rosinen herauszupikken“, die französische Forderung nach einer „Zurückweisungs-Marge“ von $10 \%$, die den Mindesterstattungssatz auf $19,8 \%$ drückte; aufgrund sowjetischer Vorbehalte zog sich eine Einigung bis September hin. AO, Berlin/3273/1/2706 (31. 12. 1945). BA, Z 45 F/OMGUS, 2/118-2/8-20 (CORC/P(46)172, 3rd Revise, 29. 8. 1946); 2/116-1/17-22 (DRDR/Memo(46)15, 23. 3. 1946).

$107 \mathrm{Vgl}$. FRUS, 1946/V, S. $532 \mathrm{ff}$. Intern hieß es bei den Briten: "It is true that we have been one against three in the Control Council and to that extent can be held responsible for the delay in determining the amount of reparation available. But we would also have reached agreement much sooner, if the Russians had from the outset been more reasonable." PRO, FO 371/55379/C3392 (8. 3. 1946).

108 Nach einer UUbersicht vom 17. 5. 1946 schätzten die Briten, daß in ihrer Zone ca. 1500 Betriebe für Reparationen in Frage kamen, von denen 450 als „verfügbar" deklariert worden waren; Ende Mai könnten weitere 340 als „verfügbar" deklariert, in weiteren zwei Monaten das Programm abgeschlossen werden. Dafür standen 77 deutsche Bewertungsteams zur Verfügung, die ca. drei Wochen für einen Betrieb benötigten. Bei 350 Betrieben galt zusätzlich eine Vier-Mächte-Bewertung als erforderlich. Für die Bewertung von 1000 Betrieben wurden 34 und für den Schriftverkehr bei Angebot und Deklaration sechs Wochen angesetzt, so daß der erste Betrieb nach frühestens zehn, der letzte nach 40 Wochen bereitgestellt werden könne; bei den IARA-Ländern wurden Fristen von 18 bzw. 48 Wochen angenommen. Da nicht mehr als 100 Betriebe gleichzeitig demontiert werden könnten, wurde mit einer Gesamtdemontage- und -lieferzeit von nicht unter vier Jahren gerechnet. Angesichts der Fristen bei den IARA-Ländern werde das Reparationsprogramm sechs Jahre dauern. PRO, FO 1034/33. 
nicht in der Lage sein, uns auf einen gemeinsamen Import-Export-Plan zu einigen, wird die amerikanische Delegation zu einem geeigneten Zeitpunkt in der nahen $\mathrm{Zu}$ kunft die Klausel heranziehen, die ein ausgeglichenes Import-Export-Programm fordert, und auf einer Revision des Reparationsplans bestehen." Da sich am 26. April die Briten und, zur Überraschung der Sowjets, die Franzosen dieser Auffassung anschlossen, wich Dratwin zurück, beharrte aber im Kern auf seinen Positionen, indem er auf der Berücksichtigung „lokaler“, d. h. zonaler, Gegebenheiten bestand. Sein Kompromißangebot vom 3. Mai lief abermals auf eine Vertagung bis 1949 hinaus, so daß Clay die Demontagen in der amerikanischen Zone für vorläufig eingestellt erklärte, mit Ausnahme der Bedienung der inzwischen beschlossenen ersten Reparationsliste. Die Planungen zur Ausführung des Industrieniveauplans würden weitergeführt, an ihre Umsetzung sei indes nicht zu denken, ehe nicht die amerikanischen Bedingungen erfüllt seien ${ }^{109}$. Die Briten, von Sokolowski erneut beschuldigt, „die ganze Reparationslösung zu sabotieren“, schlossen sich diesem demonstrativen Schritt nicht an; die sowjetische Weigerung, einen gemeinsamen Export-Import-Plan zu akzeptieren, bot ihnen jedoch die unverhoffte Möglichkeit, ,unsere Rücktrittsklauseln in der Industrieniveau-Vereinbarung früher geltend zu machen als zu erwarten war “110.

Die Westmächte nutzten diese neuerliche Verzögerung zur Gegenoffensive und verlangten Planungen für den Erhalt der Friedensindustrien. Da CCG und OMGUS die Fortsetzung der Bewertungsarbeiten und selbst die Zuteilung (aber nicht die Auslieferung) von Reparationsbetrieben als „Geste“ weiterlaufen ließen, konnte die SMAD nicht verhindern, daß der Kontrollrat das Industriekomitee beauftragte, mit den Vorarbeiten zur Umsetzung des Industrieniveauplans zu beginnen: nämlich einen Schlüssel für die zonale Aufteilung des künftigen Produktionsniveaus zu erarbeiten, der indirekt ein Maximum an zonalen Demontagen festgelegt hätte, und Listen der in Deutschland „verbleibenden“ Betriebe aufzustellen, die eine Auskunftspflicht für die SMAD implizierten ${ }^{111}$. Diese Arbeiten wirkten angesichts der prinzipiellen Differenzen zwischen den Alliierten unwirklich, zumal das Feilschen um technische Details einen riesigen Arbeitsaufwand erforderte, ohne in irgendeiner Form die Lösung zu beschleunigen. Bei den Beratungen der Liste mit den Stahlbetrieben brachen die unüberbrückbaren Differenzen wieder auf, als Frankreich es ablehnte, daß die Betriebe des Saargebiets selbst unter Vorbehalt in den Listen aufgeführt wurden ${ }^{112}$. Daraufhin verlangte das Koordinationskomitee vom Wirtschaftsdirektorat eine vollständige Liste aller in Deutschland „vorhandenen“ Betriebe; doch bedeutete das nur eine Vertagung des Problems, solange die Saarfrage auf der politischen Ebene nicht geklärt war.

109 Vgl. FRUS, 1946/V, S. 545 ff. PRO, FO 371/55423/C3909 (Steel, 8. 4. 1946); FO 371/55424 (26. 4. 1946).

110 PRO, FO 371/55423 (CORC, 2. 2. 1946; C1653, 12. 2. 1946); 55424 (CORC, 2. und 8. 4. 1946). Die Ruhrfrage 1945/46, S. 649. Cairncross, Price, S. $136 \mathrm{ff}$.

11 Die Arbeiten auf Komitee-Ebene, Listen mit den in Deutschland verbleibenden Betrieben zu erarbeiten, gediehen nicht weit. Das Unterkomitee für Maschinen und optische Geräte legte als einziges bis Anfang 1947 eine Liste vor. Demnach bestand in der britischen Zone, gemessen an den Vorgaben des Industrieniveauplans, ein Kapazitätsüberhang von $35 \%$, in der amerikanischen von $84 \%$, in der französischen von $21 \%$ und in der SBZ von $31 \%$. Im Industriekomitee bestanden die USA und England auf einer Korrektur der Expertenschätzung; die Zahlen wurden auf 13, 67, 17 bzw. 25\% revidiert. BA, Z 45 F/OMGUS, 2/118-3/10-21 (CORC/P(47)161, Appendix ,A').

112 AMAE, Y 364, Bl. 193 ff. (Protokolle der Kommission zur Vorbereitung der Reparationslisten, 7. bis 9. 4. 1946). 
Jetzt erst begann der Reparationsstopp wirklich zu greifen, weil das französische Veto jede Maßnahme verhinderte, die über die bisherigen symbolischen Vorab-Lieferungen hinausreichte. Koenig sah sich am 10. Mai 1946 veranlaßt, in Paris anzufragen, ob das Bekenntnis zur deutschen Wirtschaftseinheit - abgesehen von den Vorbehalten in der Ruhr-bzw. der Saarfrage - noch uneingeschränkt gültig sei: vor allem im Hinblick auf den Außenhandel und die Reparationen. Da die Angelsachsen ihre eigenen Wege zu gehen drohten und die handels- und währungspolitische Aufspaltung Deutschlands „in vier oder eventuell zwei Zonen“ sich abzeichnete, hielt er es angesichts der wirtschaftlichen Abhängigkeit seiner Zone von der Kooperation mit den anderen Zonen für verfehlt, sich der Taktik der SMAD anzuschließen, „notfalls den Angelsachsen im Prinzip einige Genugtuung zuteil werden zu lassen, ohne sich jedoch faktisch der Vorteile einer unilateralen Verwaltung ihrer Zone zu berauben“. Sehr vorsichtig begann sich Noiret (GFCC) im Sommer 1946 der anglo-amerikanischen Argumentation anzuschließen, daß bei einer Verhinderung der Wirtschaftseinheit durch die Sowjetunion der Reparationsplan zu überprüfen, wenn nicht zu revidieren sei. Im September wiederholte Koenig seine Bedenken, das Festhalten an Potsdam sei nicht ohne „Nachteile und selbst Gefahren“; eine unilaterale Politik berge aber noch größere Risiken. Die Wiederaufnahme einseitiger Entnahmen würde nicht nur die alten Probleme neu beleben, „sowohl mit den Besatzungsmächten als auch mit den neutralen Mächten der IARA. Sie riskiert ebenso, Frankreich und die Zone gewisser Kategorien von Ausrüstung, die es in der französischen Zone nicht gibt, zu berauben und uns von den Reparationen der IARA auszuschließen.“ Er kam zu dem Schluß, daß eine unilaterale Politik „momentan inopportun ist, die nicht eher eingeschlagen werden kann, ehe wir eine Bestätigung haben, daß es unmöglich ist, den vorgesehenen Reparationsplan durchzuführen“113.

Die Reaktionen der Sowjetunion auf Clays Reparationsstopp demonstrierten eine gewisse Verunsicherung. Sokolowski erklärte am 6. Mai intern, am 21. Mai offiziell die Demontagen für beendet ${ }^{114}$. Der Reparationsstopp sei „ein Mittel der Druckausübung auf uns“, mit dem die USA ,jonglierten“; dem könne man „mit einer Reihe von positiven Vorschlägen zur Lösung des Außenhandelsproblems unter interzonalen Bedingungen“ begegnen und den Angelsachsen „eine entschiedene Abfuhr im Kontrollrat“ erteilen $^{115}$. Am 14. Mai äußerte Sokolowski gegenüber Robertson Verständnis für die „vorübergehende“ Einstellung der Reparationslieferungen aus den Westzonen, um für sich daraus das Recht auf die Entnahme von "gewissen“ Reparationen aus der laufenden Produktion als Kompensation abzuleiten. Einerseits zeigte er sich versöhnlich, indem er eine Initiative für eine interimistische Export-Import-Regelung ankündigte; andererseits betonte er nachdrücklich, „es sei zwecklos, der Sowjetunion mit der Reparationsfrage zu drohen“" ${ }^{116}$. Im Juni 1946 wurde der Reparationsstopp als der „geeignete Vorwand“ interpretiert, um der Sowjetunion Reparationen aus den Westzonen vorzuenthalten und sie ,am Erhalt von Warenlieferungen aus der sowjetischen Besat-

113 AO, Berlin/3276/5/2019 (10. 5. 1946); 3273/3/2731, I (27.6. und 18. 9. 1946).

114 Karlsch, Reparationsleistungen, S. 66. Die Sequesterbetriebe, die nicht für Reparationen vorgesehen waren, wurden bereits am 29.3. 1946, einen Tag nach Inkrafttreten des Industrieniveauplans, deutschen Verwaltungskommissionen übergeben; am 4. 4. schuf die Landesverwaltung Sachsen die Rechtsgrundlage für den Volksentscheid zur Sozialisierung dieser Betriebe.

115 Zitiert nach: Laufer, Reparationspolitik, S. 6 (Arkadjew an Wischinski, 30. 4. 1946).

116 PRO, FO 943/308; FO 942/324. 
zungszone zu hindern und somit sogar die Reparationslieferung aus der sowjetischen Besatzungszone zu gefährden" ${ }^{117}$. Der Reparationsstopp zeigte also offenbar die beabsichtigte Wirkung; dem konnte die Sowjetunion nicht tatenlos zusehen. Sie reagierte im Juni mit einer neuen Demontagewelle ${ }^{118}$, sodann mit der systematischen Überführung deutscher Betriebe in Sowjet AGs. Mittelfristig hat Clays Demontagestopp die Sowjets zur endgültigen Reorientierung ihrer gesamten Reparations- und Deutschlandpolitik veranlaßt, obwohl sie mit den Sowjet AGs, die sie als exterritorial erklärten, ein Instrument gefunden zu haben glaubten, die Produktionsbegrenzungen des Industrieniveauplans zu umgehen ${ }^{119}$. Sie hielten sich aber die Hintertür offen, über eine Revision des Plans doch noch zu einer Einigung mit den Westmächten in der Frage der Reparationen aus laufender Produktion zu kommen.

Clay sah durch die sowjetische Reaktion den Reparationsstopp so entwertet, daß er kurzzeitig überlegte, mit Rückendeckung aus Washington, diesen für 60 bis 90 Tage auszusetzen, um den Sowjets - und den Franzosen! - Gelegenheit zu geben, die Behandlung Deutschlands als politische, verwaltungsmäßige und wirtschaftliche Einheit zu akzeptieren ${ }^{120}$. Zugleich begannen die USA, wie die Briten schon Ende 1945, der Sowjetunion die Gegenrechnung aufzumachen. Sie führten in Moskau Beschwerde, die Sowjetunion demontiere in der SBZ ohne Rücksprache mit dem Kontrollrat auch Eigentum der Alliierten, und machten vorsorglich Regreßansprüche geltend ${ }^{121}$. Clay hatte für diesen Kurs von Beginn an Robertsons Unterstützung gefunden, dieser erhielt jedoch aus London keine Erlaubnis, sich dem Reparationsstopp anzuschließen: Die Regierung habe „den amerikanischen Standpunkt niemals offiziell gebilligt, aber ihm stillschweigend zugestimmt ${ }^{\text {“122 }}$. Durch Fortsetzung ihrer bisherigen Verzögerungstaktik verschaffte sich jedoch die CCG indirekt die Grundlage für einen faktischen Demontagestopp. Im Wirtschaftsdirektorat band ihr Vertreter am 20. April 1946 die Freigabe der 462 als „lieferbar“ bezeichneten Betriebe seiner Zone an mehrere Vorbehalte. Er werde deren Übergabe verhindern: 1. wenn sich die Grenzen Deutschlands änderten, z. B. durch Abtrennung der Ruhr; 2. wenn Betriebe für „wichtige Bedürfnisse“ der Besatzungsmächte gebraucht würden (Bergbau, Transport); 3. wenn sie ganz oder teilweise Angehörigen der Siegermächte gehörten; 4. wenn Teile der Betriebe unter die Restitutionen fielen, was (im französischen Sinne) durch Inspektionen zu verifizieren sei; und 5. - der wichtigste Punkt - solange nicht der Umfang feststehe, in dem das Produktionsvolumen des Industrieniveauplans auf die einzelnen Zonen aufgeteilt werde. Andernfalls, das war die unausgesprochene Warnung, sei die britische Zone gezwungen, im Alleingang ihre Überlebensfähigkeit sicherzustellen. Anfang Juni 1946 verlieh Robertson dieser Erklärung Nachdruck, in-

117 Zitiert nach: Laufer, Reparationspolitik, S. 7 f. (Bericht Kudrjawzew, Stellvertreter Semjonows, 25. 6. 1946).

118 NA, RG 59, 740.00119 Control(Germany)/6-1546.

119 Die Sowjets umgingen den Industrieniveauplan, indem sie Betriebe, die über die zulässigen Kapazitätsgrenzen hinausgingen, in Sowjet AGs umwandelten, die Betriebe aber unter deutscher Leitung beließen. Badstübner, Restauration, S. 180. BA, Z 45 F/OMGUS, 2/120-2/8-13 (DECO/M(46)42).

${ }^{120}$ FRUS, 1946/V, S. 549 ff. (Acheson/Hilldring an Byrnes, 9. 5. 1946).

121 FRUS, 1946/V, S. 568 ff. (17.6. 1946). Die sowjetische Antwort vom 1.9. 1945, die Gesprächs-, aber kaum Kompromißbereitschaft ankündigte, ebenda, S. 600 f. Den Briten hatte die Regierung in Moskau im Februar/März 1946 eine Bestandsaufnahme und den Schutz des britischen Eigentums zugesagt. Die USA und Frankreich hatten den britischen Vorstoß zu der Zeit nicht unterstützt. PRO, FO 371/55636.

122 FRUS, 1946/V, S. 545 f. (Robertson, 26. 4. 1946), 565 f. (Bevin, 6. 6. 1946). AMAE, Y 455, Bl. 4. 
dem er für alle Betriebe, die für die Reparationslisten des Kontrollrats gemeldet wurden, den Vorbehalt geltend machte, daß sie im Falle der fehlenden Wirtschaftseinheit für Besatzungszwecke zurückgehalten würden. Dennoch zögerten die Briten weiterhin, sich Clays Reparationsstopp offiziell anzuschließen. Erst nach dem Scheitern der Pariser Konferenz zeichnete sich ab, wie Bevin am 25. Juli 1946 dem Kabinett erklärte, daß die Gründung der Bizone das faktische „Abrücken von dem Abkommen über das deutsche Industrieniveau“ bedeutete; jeder Versuch zur Rehabilitation der eigenen Zone würde diese Konsequenz haben, die wiederum, das wußte er schon Anfang Juni, den „vollständigen Bruch mit Rußland“ implizierte, den er (noch) zu vermeiden suchte ${ }^{123}$.

Nicht zu Unrecht warf der sowjetische Vertreter den Briten vor, ihre Vorbehalte entwerteten die Vereinbarungen vollständig. Obwohl das Wirtschaftsdirektorat angewiesen worden war, bis zum 20. April 1946 einen Vorschlag für die Demontagen bzw. Reparationslieferungen vorzulegen, und obwohl das Reparationsdirektorat ein Ständiges Sekretariat zur Beschleunigung der Sacharbeiten eingerichtet hatte, waren bis Mitte Mai nur wenige Vorschläge erarbeitet worden: im wesentlichen für Zementund Stahlbetriebe der amerikanischen Zone ${ }^{124}$. Die Sowjetunion drängte auf allen Ebenen zur Eile und schlug am 16. Mai die Entsendung von Inspektions- und Bewertungsteams in die Betriebe vor, sobald diese nach Aufhebung des amerikanischen Demontagestopps für „lieferbar“ erklärt seien. Die Briten forderten am 23. Mai und 6. Juni alle interessierten Mächte zur Entsendung von Expertenteams auf, reagierten dann aber auf sowjetische Anmeldungen auf Wochen hinaus nicht. Als die Sowjets schließlich zugelassen wurden, erschienen die britischen Experten nicht; die Originaldokumente, Grundlage der Bewertungsarbeiten, fehlten; in anderen Fällen hatten die Deutschen die Vorarbeiten nicht abgeschlossen. Die Franzosen stellten so wenige Experten zur Verfügung, daß der Bewertungsprozeß sich erheblich in die Länge zog. Neue Verzögerungen ergaben sich aus inhaltlichen Differenzen; teilweise klafften die Schätzungen des Demontageguts zwischen britischen und sowjetischen Experten um 50 bis 60, zwischen Sowjets und Amerikanern um bis zu 40 Prozentpunkte auseinander. Einzelne Betriebe wurden einvernehmlich als wertlos von den Reparationslisten zurückgezogen, andere erwiesen sich als von zweifelhaftem Wert oder nicht mehr existent. Die Briten gaben zu, 1945 während der Kampfhandlungen ganze Betriebe als „Kriegsbeute“ entfernt zu haben, die sie noch 1946 als Reparationsbetriebe deklarierten. Andere seien als Kriegspotential vernichtet worden. Wieder andere in der britischen und amerikanischen Zone waren bei der Ankunft der Sowjets leer oder enthielten nur Einzelstücke mit Schrottwert, so daß letztere annehmen mußten, „daß die Ausrüstung [...] geplündert, entfernt oder verkauft worden war"125. Ihr Vertreter be-

123 PRO, FO 943/325. Sir Cecil Weir erläuterte im November 1946 dem Zonenbeirat der britischen Zone, daß ,wir das Recht hätten, ihn [den Industrieniveauplan] zu revidieren“. Er plädierte für eine Stahlproduktion von 11 Mio. t. AVBRD, Bd. 1, S. 1060. PRO, FO $371 / 55588$ (21.6. 1946). Zu den Vorbehalten Bevins gegenüber einer Erhöhung des Industrieniveaus vgl. FO 800/Ger/46/44 (1. 11. 1946). Die Diskussion über einen Reparationsstopp kam erneut auf für den Fall, daß die Moskauer Außenministerkonferenz scheitern sollte. FO 371/64476/C3952 (Strang, 8. 3. 1947); 65001/ CE1031 (Meeting COGA, 2. 4. 1947).

124 BA, Z 45 F/OMGUS, 2/118-2/8-20 (CORC/P(46)169-172).

125 BA, Z 45 F/OMGUS, 2/116-2/1-10 (DRDR/P(46)77, 4. 7. 1946; P(46)98); 2/118-2/8-20 (CORC/ $\mathrm{P}(46) 238,19.7$. 1946). Zu ökonomischer Entwaffnung, alliierten Kontrollen und Produktionsverbo- 
hauptete am 23. Juli 1946 im Koordinationskomitee unwidersprochen, daß aus einem Reparationsbetrieb der amerikanischen Zone Maschinen sogar an deutsche Firmen verkauft worden waren. Indem er insinuierte, „daß diese Vorkommnisse ein Glied in der Kette von Maßnahmen bildeten, die auf einen gezielten Stopp der Reparationslieferungen aus einer der westlichen Zonen hinausliefen“, warf er den USA einen Verstoß gegen die Entmilitarisierungsbestimmungen des Potsdamer Abkommens vor und unterstellte ihnen zugleich, Rüstungsgüter in Deutschland gegen die Sowjetunion zu produzieren $^{126}$. Clay und sein britischer Kollege Erskine dementierten die konkreten Einzelvorwürfe der Sowjetunion nicht, sondern verschoben "geschickt“ die Diskussion auf die politische Ebene, indem sie verlangten, durch eine Kontrolle der Entmilitarisierung in allen vier Zonen auch Zugang zur SBZ zu erhalten ${ }^{127}$.

Mißtrauisch geworden, mit dem Byrnes-Plan sollte die „Beseitigung des Rüstungsindustriepotentials umgangen, die Kontrolle der vier Mächte über die Entwicklung der Industrie ignoriert und die Demokratisierung des Landes“ vermieden werden ${ }^{128}$, stimmte die Sowjetunion im Juni 1946 im Wirtschaftsdirektorat der Einsetzung alliierter Inspektionsteams zu. Diese sollten in allen vier Zonen im Lichte des Industrieniveauplans die Betriebe nach ihrer Eignung für Reparationen bzw. für die deutsche Friedensproduktion klassifizieren und „eine Schätzung der Gesamtkapazität der anderen, in der Zone zurückbehaltenen Betriebe“ erarbeiten. Jede Delegation wurde verpflichtet, einen „vollständigen“ Bericht über Demontagen und "Transfers“ in der eigenen Zone vorzulegen, „der den Namen des Betriebs, seine Lage, seinen Industriezweig und seine Kapazität angibt“. Damit hätten die Westmächte einen sehr weitreichenden, wenngleich nur in Teilen („25 bis 50\%“, wie sie meinten) überprüfbaren Einblick in die sowjetische Reparationspolitik erhalten. Doch weigerte sich die Sowjetunion zunächst, den Vier-Mächte-Inspektionsteams auch die Betriebe der Konsumgüterindustrie zu öffnen ${ }^{129}$. Versuche des Kontrollrats, einschlägige Informationen direkt bei den Behörden der SBZ einzuholen, wurden von der SMAD unterbunden ${ }^{130}$. Doch am 12. August stimmte die Sowjetunion überraschend dem ursprünglichen Plan $\mathrm{zu}^{131}$.

ten gemäß Gesetz Nr. 23 und 43 vgl. 2/118-3/10-21 (CORC/P(47)169); 2/118-2/8-20 (CORC/ P(46)308: Direktive Nr. 39, 2. 10. 1946).

126 Übersichten über die Entwicklung der „Prohibited Industry temporarily retained in Germany“ gemäß Direktive Nr. 39 in: 2/93-1/16 und 17 (CORC/P(47)187 und 232). Zur Ersparnis von Importkosten war die Fortführung der Produktion von (prinzipiell rüstungsrelevanten) synthetischem Benzin, synthetischem Kautschuk und Kugellagern gestattet. 2/118-1/17-21 (CORC/P46)43, 13. 2. 1946). Man verschloß sich in London den möglichen Folgen nicht: „We should not hide from ourselves the fact that this action is bound to make it more difficult to destroy the plant later should we think it desirable to do so. The will to destroy industry is bound to prove weaker as time goes on." PRO, FO 371/55625/C10340 (Troutbeck, 25. 1. 1946); CAB 21/1873 (FO an COGA, 29. 1. 1946). Die Ruhrfrage 1945/46, S. 495 (Harvey, 12. 2. 1946). Am 9. 11. 1945 hatte Maiski ebenfalls gewarnt, wenn man nicht sofort handele, werde die ,industrial disarmament" Deutschlands später nicht mehr durchzusetzen sein. DBPO, I, 6, S. 195. Die Prophezeiung, daß die Import-Ersparnis obsiegen werde, sollte sich bei Kugellagern, optischen Instrumenten oder Aluminium bestätigen. PRO, FO 1049/752; FO 1036/662.

127 FRUS, 1946/V, S. $581 \mathrm{f}$.

${ }_{128}$ Geschichte der KPdSU, Bd. 5/2, S. 133.

129 BA, Z 45 F/OMGUS, 2/120-1/1-22 (DECO/P(46)206(Revise), 20.6. 1946).

${ }^{130} \mathrm{Zu}$ Anfragen des Unterkomitees für Elektrizität und Gas des Wirtschaftsdirektorats vom Juni und Dezember 1946 vgl. BAP, G-2/1044, Bl. 165; G-2/1066. Bereits im Oktober 1945 wurden die Deutschen durch SMAD-Offiziere angewiesen, keine Zahlen an „Ausländer“, $d$. h. amerikanische oder britische Offiziere, zu geben. L-1/996, Bl. 28.

131 BA, Z 45 F/OMGUS, 2/120-2/8-13. 
Einerseits drängte sie mit Erfolg auf verbindliche Kontrollratsbeschlüsse zur wirtschaftlichen Entmilitarisierung ${ }^{132}$. Andererseits suchte sie bei den Beratungen über den Bericht an die Moskauer Außenministerkonferenz von ihrer Zustimmung zu den Inspektionen wieder abzurücken; der Beschluß habe, da weder durch Kontrollrat oder Koordinationskomitee gebilligt, keine „Gesetzeskraft“ und sei daher für sie nicht bindend. Als die USA antworteten, es gehe nicht um die Reparationsleistungen der SBZ, sondern um die Feststellung der über den Industrieniveauplan hinausgehenden Kapazitäten (was auf das gleiche hinauslief), waren die Sowjets hilflos. Sie gingen zum Gegenangriff über, da sie sich selbst eine Falle gestellt hatten: In den Westzonen seien noch über 1500 Reparationsbetriebe weder zugeteilt noch gar demontiert; ehe die Westmächte Zahlen aus der SBZ verlangten, seien sie ihrerseits verpflichtet zu erklären, warum diese Betriebe weiterarbeiteten ${ }^{133}$.

Ein erstes Inspektionsteam des Kontrollrats, das im Januar 1947 die vier Zonen besichtigt hatte, meldete erhebliche Verzögerungen bei der Zerstörung der Rüstungsbetriebe in den Westzonen, weil die Westmächte die Betriebseinrichtungen, aber nicht die Gebäude zerstört hatten ${ }^{134}$. Die Westmächte gerieten erheblich unter Druck, da sie weder willens noch in der Lage waren, diese Zerstörung konsequent in Angriff zu nehmen. Sie begründeten das mit Problemen bei der Zuteilung durch die IARA und mit technischen Schwierigkeiten; es sei ökonomisch widersinnig, auch die Gebäude zu zerstören. Draper hatte im Mai 1946 den Demontagestopp sogar auf Rüstungsbetriebe ausgedehnt ${ }^{135}$, so wie in der amerikanischen Zone viele Betriebe dieser Kategorie nicht demontiert, sondern lediglich „neutralisiert“ wurden ${ }^{136}$. Gleichzeitig ermu-

132 BA, Z 45 F/OMGUS, 2/118-2/8-20 (CORC/P(46)308). Die Materialien des Liquidation of German War Potential Committee in: $2 / 130-2 / 15$ bis $2 / 130-3 / 8$. Die Sowjetunion forderte seit April 1947 zwei getrennte Untersuchungskommissionen, eine des Militärdirektorats zur Kontrolle der Produktion (in den Betrieben), eine des Wirtschaftsdirektorats zur Überwachung des Verbleibs der Produkte. Das entsprach der bisherigen Praxis. Die Zuständigkeit lag im Falle der Direktiven Nr. 22 (Zerstörung von Befestigungsanlagen, 20.11. 1946) und 28 (Berichterstattung über Zerstörung und Verwendung deutschen Kriegsmaterials in Deutschland, 26.4. 1946) beim Militärdirektorat, bei den Direktiven Nr. 39 (Liquidation des Kriegspotentials, 2. 10. 1946) und 47 (Liquidation der deutschen Kriegsforschungseinrichtungen) sowie beim Gesetz Nr. 43 (Herstellung, Lagerung, Einfuhr und Ausfuhr von Militärgerät, 20. 11. 1946) beim Wirtschaftsdirektorat. Im Juni 1947 einigte man sich darauf, daß die Direktorate ihre eigenen Kontrollen und Berichte weiterführen, aber auf gemeinsamen Sitzungen eine wechselseitige Koordination herstellen sollten. $\mathrm{Zu} \mathrm{dem} \mathrm{Zweck} \mathrm{wurde}$ eine Working Party eingerichtet. 2/118-3/10-21 (CORC/P(47)127/1, 28.6. 1947). Ein französischer Antrag, eine dem Koordinationskomitee unterstellte Kommission zur Kontrolle der Einhaltung der Entmilitarisierung, in all its aspects“ einzurichten und durch Unterkomitees regelmäßig durchzuführen, fand keine Zustimmung (CORC/P(47)127, 23. 5. 1947). Eine Zusammenstellung der Materialien, inkl. der US-Briefs, in: 2/93-3/13.

133 BA, Z 45 F/OMGUS, 2/121-1/9-12 (DECO/M(47)4, 31. 1. 1947).

134 BA, Z 45 F/OMGUS, 2/130-3/1-2 (CLWP/M(47)15, 21. 7. 1947). Beschwerden der Sowjets über das anglo-amerikanische Vorgehen wurden von der GFCC geteilt, die „schwere“ Verstöße gegen die Direktive Nr. 39 und das Gesetz Nr. 43 in der amerikanischen Zone monierte, ohne sich über die Zustände in der SBZ Illusionen zu machen. AMAE, Y 372, Bl. 28 ff. (GFCC, 27. 11. 1947), $158 \mathrm{ff}$. (Saint-Hardouin, 6.3. 1948). Zu französisch-sowjetischen Gesprächen im Juni 1947 vgl. Y 371, Bl. 173.

135 BA, Z 1/506, Bl. 228. Als Zeichen des guten Willens kündigte Clay im Koordinationskomitee am 7. 10. 1946 die Wiederaufnahme dieser Demontagen an.

136 Am 20. 2. 1947 teilten die Angelsachsen im Koordinationskomitee mit, daß 70 der 88 reinen Kriegsbetriebe in der amerikanischen und $95 \%$ in der britischen Zone vollständig demontiert bzw. „neutralisiert" seien. „Die amerikanische Art der Demontage“ sah nur „das Herausziehen von Bolzen und das Abklemmen des Stroms" vor; da aber weder die Einrichtung abtransportiert noch die Gebäude vernichtet wurden, „sollte es leicht möglich sein, sie in kurzer Zeit und mit geringem Ar- 
tigte OMGUS die Deutschen, auf eine Revision des gesamten Plans wie der einzelnen Listen zu drängen ${ }^{137}$. Die deutschen Proteste wurden dabei von regionalen Militärdienststellen unterstützt ${ }^{138}$. Zwar überlegte die SMAD seit dem November 1946, ob sie die Praxis der Westmächte kopieren sollte; doch um ihren Propagandaerfolg abzusichern, verschob sie derartige Maßnahmen, hielt sich aber im Kontrollrat alle diesbezüglichen Möglichkeiten offen ${ }^{139}$. Sie stimmte zu, daß nur 60 Rüstungsbetriebe der Kategorie I bis auf die Grundmauern zerstört wurden, um eine Re-Konversion wie nach dem Ersten Weltkrieg zu verhindern; dafür verlangte sie, die alliierte Kontrolle auf die Betriebe zumindest der Kategorie II auszudehnen ${ }^{140}$. Ihre Forderung, die Westmächte sollten nicht nur die Gründe für die ausgebliebene Zerstörung der Rüstungsbauten angeben, sondern eine Erhaltung für zivile Zwecke von der Genehmigung des Kontrollrats abhängig machen, wurde von diesen als Eingriff in die Zonenautonomie abgelehnt! Sie konnte lediglich erreichen, daß Anfang Juni ein zweites Inspektionsteam zu einer neuen Bestandsaufnahme in allen vier Zonen aufbrach ${ }^{141}$. Die Entsendung eines dritten Inspektionsteams verhinderten die Westmächte. Es ge-

beitsaufwand wieder in Betrieb zu nehmen“. FRUS, 1948/II, S. 822 f. Nach britischen Angaben waren von 198 Rüstungsbetrieben der Kategorie I ihrer Zone im September 1947 nur 29 vollständig demontiert und abtransportiert, 20 vollständig demontiert, aber nicht abtransportiert, 27 vollständig demontiert bis auf die Gebäude; in 45 waren die Spezialwerkzeuge und Maschinen zerstört, das Reparationsgut noch vorhanden, aber der Abbruch hatte bereits begonnen; 34 standen für die Zuteilung an die IARA bereit, 43 wurden für Besatzungszwecke weitergenutzt. PRO, FO 371/65240/ CJ1314.

137 BA, Z 1/506, Bl. 98, 106, 119, 131, 169 ff., 210, 224 und passim. Gemäß Pollocks Empfehlung erarbeitete der Wirtschaftsrat durch einen Unterausschuß einen Gegen-Industrieniveauplan. Die USA signalisierten den Deutschen, sie hätten drei Monate Zeit für ein solches Vorhaben. Der Länderrat bat OMGUS, beim Kontrollrat gegen die Demontageliste zu protestieren und dahingehend vorstellig zu werden, daß die Demontagen in der SBZ gegen den Industrieniveauplan verstießen und „unabsehbare Folgen" für die Wirtschaft der Westzonen und die Wirtschaftseinheit hätten.

138 Die Militärregierung von Hessen (OMGH) engagierte sich für den Erhalt von Buderus als dem einzigen eisenerzeugenden Betrieb des Landes. Sie lehnte im April 1946 die Demontage des mangels eines zweiten Hochofens ineffizienten Zementwerks ab, sondern befürwortete im Gegenteil ein Hochfahren der Produktion. BA, Z 45 F/OMGUS, 8/80-1/10; 8/92-2/1 (Historical Report Metal Section OMGH, 14. 6. 1946); 8/189-1/1 (Chief OMGH, Reparations Historical Report 1945-1949). Die Regierung des Landes Hessen erreichte, daß die Zahl der nach dem revidierten Industrieplan zu demontierenden Betriebe von 108 auf 51 reduziert wurde. Von diesen waren 27 reine Rüstungsbetriebe, die seit Kriegsende stillgelegt waren. Von 24 Betrieben mit ziviler Produktion wurden 9 ohne Unterbrechung ihrer Tätigkeit und ohne Umsatzeinbußen durch Ersatzmaschinen ,remontiert“. Wenn Hessen bei der Demontage "mit einem blauen Auge davongekommen" sei, so verdanke es das der OMGH, die "für unsere Wünsche stets Verständnis gehabt" habe. HStA-WI, 507/ 1408 (Magnus, 30. 8. 1948).

139 Prinzipiell ließ Direktive Nr. 39 ,im Falle dringender Notwendigkeit" den vorübergehenden Erhalt von Gebäuden „für Besatzungszwecke“ zu. Im Dezember 1946 lag eine Liste mit 100 zu erhaltenden Betrieben in der SBZ vor; eine zweite mit 150 war angekündigt. Die SMAD vertröstete die SBZ-Behörden im Januar 1947 auf die Ergebnisse der Moskauer Konferenz, „weil die Untersuchungskommission der Alliierten dies [...] als Verstoß gegen die Potsdamer Beschlüsse auslegen könnte“. Allerdings hatte die SMAD weiter "starke Bedenken“ und wollte nur Betriebsgebäude erhalten bzw. in Wohngebäude, Verwaltungen, Schulen etc. umwandeln lassen, deren Deckenkonstruktion den Einbau schwerer Kräne nicht erlaubte. BAP, G-2/1044, Bl. 56, 86, 92, 100.

140 BA, Z 45 F/OMGUS, 2/118-2/8-20 (CORC/P(46)308). Gemäß Direktive Nr. 39 mußten dem Kontrollrat Berichte über die Rüstungsbetriebe nach 4 Kategorien vorgelegt werden: I. reine Rüstungsbetriebe, die nach Reparationsplan zu verbieten waren; II. Rüstungsbetriebe, die zu kontrollieren waren, III. Betriebe gemäß dem noch zu verabschiedenden Gesetz Nr. 43 vom 29.12. 1946, IV. Friedensbetriebe, in denen Produktionsanlagen der Kategorien I und II installiert worden waren.

141 BA, Z 45 F/OMGUS, 2/118-3/2-9 (CORC/M(47)24, 27, 28). Zu den Debatten über Entsendung und Aufgaben des zweiten Inspektionsteams vgl. 2/118-3/10-21 (CORC/P(47)129, 23. 5. 1947; dessen Bericht in: $C O R C / P(47) 234,29.11$. 1947). 
lang ihnen, die Sowjetunion zum Veto zu zwingen, indem sie die völlige Inspektionsfreiheit auch in der SBZ forderten ${ }^{142}$.

Auf diese Weise verhinderten alle vier Mächte eine vom Kontrollrat organisierte, systematische Demontage. Denn trotz der Verabschiedung des Industrieniveauplans hatten sich längst die Optionen verschoben. Auch der amerikanische Demontagestopp war keineswegs nur ein Pressionsversuch gegenüber der Sowjetunion, sondern entsprach zugleich der Einsicht, daß angesichts der deutschen Importbedürfnisse wie des europäischen Wiederaufbaubedarfs der De-Industrialisierungsansatz des Industrieniveauplans wirtschaftlich völlig verfehlt war. Da der Demontagestopp auf eine Begünstigung der Westzonen hinauslief, sahen sich die USA Protesten auch der westeuropäischen Reparationsgläubiger ausgesetzt, so daß im Sommer 1946 eine innerwestliche Diskussion um die Wiederaufnahme der Reparationen und eine Rückkehr zum Industrieniveauplan entbrannte ${ }^{143}$. Um der Sowjetunion die Gelegenheit für Propaganda-Attacken zu nehmen, die USA verhinderten die Entmilitarisierung Deutschlands, und allen Forderungen nach laufenden Reparationen aus den Kapazitätsüberhängen entgegenzutreten, überlegte das State Department Anfang Oktober, ob eine Zwischenlösung möglich sei, „die die Wiederaufnahme von begrenzten Reparationsentnahmen zuließe und gleichzeitig den Standpunkt gegen Lieferungen an Sowjets und Franzosen [!] aufrechterhielte, solange sich diese der Potsdamer Politik der Wirtschaftseinheit widersetzen“. Angesichts der erheblichen politischen Nachteile für die Glaubwürdigkeit des Reparationsstopps und für das Verhältnis zu Frankreich riet Clay von einer solchen Lösung ab. Er favorisierte die Fortsetzung der bereits zugesagten Kapitalgüterlieferungen aus reinen Rüstungsbetrieben, um nicht die Türe ganz zufallen zu lassen, und er war bereit, auf den sowjetischen Wunsch nach Lieferung aus laufender Produktion einzugehen. Letzteres hätte die Kapazitäten in Deutschland erhalten und zugleich Zeit für eine Entscheidung geboten, ob die Lieferungen an die UdSSR endgültig gestoppt oder an westeuropäische Länder umgeleitet werden sollten $^{144}$. Es gelang Clay, seine westlichen Kollegen zu bewegen, wenigstens der Bewertung der in Frage stehenden Betriebe zuzustimmen und die Bereitstellung für Demontagezwecke von der Lösung der Grundsatzfragen, nämlich Herstellung der Wirtschaftseinheit und Abtrennung der Saar, abhängig zu machen. Auf der Basis waren im

142 BA, Z 45 F/OMGUS, 2/118-3/2-9 (CORC/M(47)34, 48, 49, 50); 2/118-3/10-21 (CORC/P(47)103, $127,127 / 1,234,240)$.

143 PRO, FO 943/2, 28, 206, 272 und 314. Die Besatzungsmächte verschafften sich Vorteile, indem sie in ihren Zonen "Reparation Disposal Teams“ und Technical Missions (BIOS, FIAT usw.) einsetzten, die aus Vertretern der interessierten Firmen bestanden. In England wurden diese über die Federation of British Industrialists angeworben. Sie erhielten zwar keine Uniformen, wurden aber auch nicht wie normale Geschäftsleute in ihrer Bewegungsfreiheit eingeschränkt. Vgl. FO 935/51 (80seitige FIAT accession list, No. 6, 30.11. 1945). Während Großbritannien auf die Weise sich vor Anmeldung seiner Ansprüche bei der IARA die interessantesten Objekte heraussuchte, beschwerten sich die anderen IARA-Mitglieder, sie erhielten keine präzisen Informationen über die verfügbaren Reparationsgüter. Die Lieferverzögerung verminderte den Nutzen für die Berechtigten. Die IARA, die nur durch das Reparationsdirektorat Zugang zum Kontrollrat hatte und seit Mitte 1946 auf einen direkten Kanal zu den Zonenkommandeuren und eine Vereinfachung des Verfahrens zusteuerte, sah im März 1947 das gesamte „Potsdam reparation system“ als gescheitert an und forderte die Wiedereinsetzung der Alliierten Reparationskommission, unabhängig vom Kontrollrat. FRUS, 1947/II, S. 391 ff. NA, RG 59, 740.00119 Council/3-3047.

144 FRUS, 1946/V, S. $611 \mathrm{ff}$. (Acheson, 11. 10. 1946), $621 \mathrm{ff}$. Vgl. unten S. $345 \mathrm{ff}$. Clay bekräftigte wiederholt den Reparationsstopp; auf sowjetisches Befragen ließ er jedoch im November 1946 erkennen, daß er gegen die Fortsetzung der Lieferungen aus der britischen und französischen Zone zwar protestieren, aber kein Veto einlegen werde. 
Juni und Oktober 1946 zwei weitere Reparationslisten vom Koordinationskomitee zur Bewertung an die Direktorate freigegeben worden.

Die erste Liste enthielt die 414 Betriebe, die bis zum 1. April 1946 für „lieferbar“ erklärt worden waren, darunter auch die 75 der beiden ersten Vorab-Listen. Es handelte sich im wesentlichen um Rüstungsbetriebe, dazu Werften, chemische und Elektrobetriebe: 130 aus der amerikanischen Zone (davon 24 von den Vorab-Listen), 262 (39) aus der britischen und 23 (12) aus der französischen ${ }^{145}$. Die zweite Liste umfaßte 167 Betriebe, darunter 37 stahlerzeugende mit einer Kapazität von 17,6 Mio. t, sowie Zementfabriken, Flugzeug- und Munitionsbetriebe: 14 aus der amerikanischen, 130 aus der britischen und 23 aus der französischen Zone. Sie stand jedoch unter dem Vorbehalt, daß einige Betriebe im Interesse der Besatzungsmacht und im Bereich von Bergbau und Transport von den Zonenkommandeuren vorläufig zurückgehalten wurden ${ }^{146}$. Die dritte Liste mit 109 Betrieben (88 der nicht-eisenverarbeitenden Metallindustrie und 21 der verbotenen synthetischen Industrien) befand sich noch in einem vorläufigen Bearbeitungsstadium und war mit zahlreichen Einzelvorbehalten versehen. In Vorbereitung war eine weitere Liste mit 814 Betrieben der Maschinen- und der optischen Industrie, dazu 27 der chemischen Industrie, während 110 Kraftwerke bereits die Direktoratsebene passiert hatten; 182 Betriebe, vor allem der chemischen Industrie, wurden als mögliche Reparationsbetriebe angekündigt ${ }^{147}$. Bis zum Herbst 1946 waren die Betriebe der beiden ersten Listen und die der nicht-eisenverarbeitenden Metallindustrie der dritten Liste vom Koordinationskomitee wegen des Demontagestopps nur zur Bewertung freigegeben worden, mit Ausnahme der 75 Betriebe der Vorab-Zuteilungen. Von diesen 75 Betrieben waren der IARA 65,75 und der Sowjetunion 9,25 zugesprochen worden. 41 waren endgültig bewertet worden, von denen wertmäßig $15 \%$ der Sowjetunion zustanden; aber geliefert worden waren an diese bis Anfang September 1946 nur 3,5-4\%, nach sowjetischen Angaben 1\% ${ }^{148}$.

Um Demontagen und Lieferungen zu beschleunigen, beantragte die Sowjetunion, alle Bewertungsarbeiten bis zum 15. Dezember 1946 abzuschließen ${ }^{149}$. Anfang November 1946 waren in der amerikanischen Zone nur noch zwei von 137 Betrieben zu bewerten, so daß die Arbeiten bis zum 30. November abgeschlossen sein könnten. In der französischen Zone waren es 13 von 55 Betrieben; hier galt der 15. Januar 1947 als voraussichtlicher Abschlußtermin, falls nicht nachträglich Betriebe des Saarlandes einbezogen wurden. Dagegen erklärten sich die Briten außerstande, einen Abschlußtermin zu nennen, da angeblich die Deutschen alles taten, um die Arbeiten zu verzögern und die Werte zu verfälschen. In ihrer Zone waren noch 268 von 436 Betrieben zu

145 BA, Z 45 F/OMGUS, 2/118-2/8-20 (CORC/P(46)194, 24. 5. 1946); 2/120-1/1-22 (DECO/ $\mathrm{P}(46) 183)$. Die Vorab-Listen in: CORC/P(45)183 und $\mathrm{P}(46) 116$.

146 BA, Z 45 F/OMGUS, 2/118-2/8-20 (CORC/P(46)199(Revise), 18. 6. 1946). Briten und Franzosen zogen 1,4 bzw. 1,2 Mio. $t$ „zeitweise“ zurück, so daß die Liste 14,5 Mio. $t$ für „verfügbar“ erklärte.

$147 \mathrm{BA}, \mathrm{Z} 45 \mathrm{~F} / \mathrm{OMGUS}, 2 / 120-1 / 1-22$ (DECO/P(46)193, 194, 273, 410). Eine Übersicht über alle drei Listen, nach Zonen, Industriebranchen und Bearbeitungsstand gegliedert, in: 2/118-2/8-20 (CORC/P(46)327, 12. 10. 1946); 2/120-1/1-22 (DECO/P(46)273, 2nd Revise). BA, Z $1 / 626$.

148 FRUS, 1946/II, S. 886 f. FRUS, 1946/V, S. 601, 630 (Anm. 87). Im November 1945 waren 13 Betriebe für Vorab-Reparationen bewertet worden, davon wertmäßig $55 \%$ für die Sowjetunion. Von den 21 noch nicht bewerteten stand dieser nur einer zu, so daß ihr Anteil auf 38,5\% (nach Wert) anzusetzen war. BA, Z 45 F/OMGUS, 2/118-2/8-20 (CORC/P(46)271(Revise), 31. 8. 1946). Eine Liste der der IARA angebotenen 54 Vorab-Betriebe in: 2/102-1/1-10 (DECO/P(46)5, 27. 12. 1945).

14 BA, Z 45 F/OMGUS, 2/118-2/8-20 (CORC/P(46)336, 19. 10. 1946). 
bewerten, von denen sie 45 bis Ende November abschließend zu bearbeiten versprachen. Da sie in der Folgezeit 60 Betriebe pro Monat zu bewerten gedachten, hätten die Arbeiten weitere vier Monate in Anspruch genommen ${ }^{150}$. Trotz neuerlicher Versprechungen, die Bewertungen zu beschleunigen, hatten die Briten erkannt, „daß die Schwierigkeit, eine einvernehmliche Vier-Mächte-Bewertung zu erreichen, die gesamten Reparationen schon bei der Geburt ersticken könnte“. Mit Hilfe der technischorganisatorischen Probleme ließ sich ein „Engpaß“ künstlich herbeiführen, auch wenn höhere Verwaltungskosten und Exportverluste sie selbst betrafen ${ }^{151}$. Am 6. August 1947 gestand Robertson im Koordinationskomitee ein, daß das langsame Voranschreiten in der Absicht geschehe, die Durchführung des Industrieniveauplans zu verhindern. Er erklärte es als „sinnlos“, weitere Zeit mit der Erstellung und Beratung von Listen, mit der Erfassung und Bewertung von Betrieben zu verschwenden, die ohnehin nie als Reparationen geliefert würden, da die Freigabe der Listen mit den zu bewertenden Betrieben durch das Koordinationskomitee den Zonenkommandeur nicht band, wann und in welchem Tempo er die Bewertungen durchführen ließ. Zwar wurden die Arbeiten im Industriekomitee und in den Zonen nie eingestellt, sie zogen sich aber bis zum Herbst 1947 hin $^{152}$. Von den 727 Betrieben, die das Koordinationskomitee billigte, wurden bis Anfang 1948 nur 577 (=80\%) abschließend bewertet ${ }^{153}$. Zur gleichen Zeit waren, teilweise nach einer Demontagezeit von zwei Jahren, von den 293 zugeteilten Vorab-Betrieben nur 50 vollständig demontiert: zwölf in der britischen, 37 in der amerikanischen und einer in der französischen Zone; bei den anderen wurde das Ende der Arbeiten für 1949 oder gar 1950 avisiert ${ }^{154}$.

Ähnlich schleppend gestaltete sich die Lieferung bei den sonstigen Demontageund Reparationsprogrammen, die überhaupt zur Durchführung gelangten. Von November 1946 bis November 1947 konnte das Wirtschaftsdirektorat auf Anweisung des Koordinationskomitees vom 24. Oktober 1946 aus insgesamt 219 westzonalen Rüstungsbetrieben der ersten Kategorie sog. „general purpose equipment“ im Wert von 133.840.366 RM zuteilen, nachdem Clay diese als Zeichen des guten Willens wie die Vorab-Reparationen aus dem Reparationsstopp seiner Zone herausgenommen hatte $^{155}$. Bis zum November 1947 waren aus der amerikanischen Zone von den 200.000 t Demontagegut nur 102.602 geliefert worden (davon 68.420 an die Sowjetunion, also $67 \%$, deren Ansprüche damit fast erfüllt waren), aus der britischen Zone 158.304 der $257.386 \mathrm{t}$ (76,5\% an die Sowjetunion), aus der französischen Zone nur 2612 der 28.562 t (71\%). Demnach wäre die Sowjetunion mit 72,61\% aller aus den Westzonen gelieferten Reparationsgüter gemäß ihren Ansprüchen bedacht worden, da

150 BA, Z 45 F/OMGUS, 2/116-2/1-10 (DRDR/P(46)149(Revise), 9. 11. 1946). Zum Progress Report der Sowjetunion für die Stichtage vom 1. 1. und 1. 5. 1947 vgl. 2/118-3/10-21 (CORC/P(47)174, Appendix ,A', 31. 7. 1947).

151 PRO, FO 943/28 (Dakin/Knight, Report, Juli 1946).

152 BA, Z 45 F/OMGUS, 2/108-3/4 (CONL/M(47)18, 11. 8. 1947).

153 BA, Z 45 F/OMGUS, 17/8211/31 (PRSec(48)1/1, Annex ,E).

154 BA, Z 45 F/OMGUS, 2/118-3/10-21 (CORC/P(48)26, Appendix ,B‘, 27. 2. 1948).

$155 \mathrm{BA}, \mathrm{Z} 45$ F/OMGUS, 2/118-3/10-21 (CORC/P(47)68, 122, 146, 154, 188, 198, 224; P(48)3). Von der ersten Tranche erhielten die Sowjetunion und Polen $24,98 \%$, von der zweiten $21,84 \%$ und von der dritten $15,14 \%$; bei der vierten, sechsten und neunten wurde ausschließlich die IARA bedacht; bei der fünften erhielten Sowjetunion und Polen wieder $27 \%$, bei der siebten $3,84 \%$, bei der achten 19,2\%. - Zur Wiederaufnahme der Kontrollratszuteilung von ,general purpose equipment remaining in war plants after the specialized equipment was destroyed“, vgl. NA, RG 59/CED, box 2 (Department of State, The German Reparations Program, 28. 12. 1948, S. 7). 
ihr nur $25 \%$ aller Vorab-Reparationen zustanden ${ }^{156}$. Die Sowjetunion berechnete den Wert der bis zum 1. Januar 1947 aus den Westzonen bezogenen Reparationsgüter auf $\$ 12,5$ Mio., von denen $\$ 7,5$ Mio. durch Gegenlieferungen auszugleichen waren ${ }^{157}$.

Leidtragende der Verzögerungen waren indes nicht nur die Sowjets oder die kleineren westeuropäischen Gläubigerländer. Die Briten waren von $6 \mathrm{Mrd}$. RM bzw. $£ 500$ Mio. an deutschen Reparationen ausgegangen, von denen $£ 100$ Mio. auf sie selbst entfallen würden, dazu der Anteil von $£ 75$ Mio. an den sowjetischen Gegenlieferungen. Bis Ende 1947 hatten sie lediglich Schiffe im Wert von $£$ 6,192 Mio., IARAZuteilungen von $£ 0,370$ Mio. sowie ca. 1900 Tonnen Material aus der eigenen und der amerikanischen Zone erhalten ${ }^{158}$. Sie sahen sich - auch infolge von Clays Reparationsstopp ${ }^{159}$ - selbst als Opfer und leiteten daraus den Anspruch auf unilaterale Maßnahmen $a^{160}$ ! Seit Juli 1946 gab es in London Überlegungen, sich in der eigenen Zone die „Rosinen“ aus den Reparationsgütern herauszupicken, die nur ein Fünftel des Volumens, aber vier Fünftel des Wertes ausmachen würden ${ }^{161}$. Nur die deutschen Lieferungen, das war das Argument, könnten im britischen Rekonstruktionsprozeß sinnvoll eingesetzt werden, die innerhalb der ersten 18 Monate bereitgestellt wurden. „Wenn Schnelligkeit nicht die Grundlinie unserer Aktivitäten ist, wird der Hauptwert unserer Reparationen verlorengehen. Bereits jetzt werden aufgrund übermäßiger Verzögerungen Betriebe, die uns wertvolle Devisen erbracht und Exportmärkte erobert hätten, zu spät ankommen, wenn sie überhaupt ankommen, um uns noch von großem

156 BA, Z 45 F/OMGUS, 2/98-1/5 (DRDR/CIV/Memo(47)58, Appendix ,A').

157 Belezki, Politik, S. 39. Stalin nannte im April 1947 die Summe von \$2 Mrd., ,including assets in Eastern Europe and some reparations from current production“. FRUS, 1947/II, S. 343.

158 NA, RG 43/WWII\&PWConf, box 177, folder: U.K. Papers. Danach hatten die Briten 88 Mio. RM an Schiffen, 18 Mio. RM an Kapitalgütern sowie \$80 Mio. an deutschen Auslandsguthaben erhalten, die USA bis Anfang 1947 \$275 Mio., vor allem deutsche Auslandsguthaben; ebenda, box 193, folder: Misc. Reparations Germany (USDel Working Papers, 5th Draft, 22. 3. 1947).

159 PRO, FO 371/64451/C9191 (ORC(47)31, 1. 7. 1947).

160 Im Dezember 1945 entnahmen die Briten einseitig Maschinen aus Deutschland. London gestattete zusätzlich pauschal Entnahmen bis $£ 1$ Mio., gleich ob die Entnahmen als Vorab-Lieferungen oder „normale“ Exporte zu werten waren. PRO, FO 1046/343 (CCG/Financial Division, 10. 12. 1945); FO 371/55379/C100 (13. 12. 1945). Die USA entnahmen 1000 Werkzeugmaschinen ohne Genehmigung der IARA über FIAT-Listen. Als Großbritannien protestierte, es sei vereinbart, keine FIAT-Entnahmen mehr zu tätigen, bot Clay den Briten an, sie sollten als Ausgleich die gleiche Zahl von Maschinen entnehmen. NA, RG 59/OWEA, Misc. German Files, box 4, folder: Memoranda (Kirk, 19. 9. 1946). Clay zog die FIAT-Entnahmen von den Reparationslisten zurück (CORC/ $\mathrm{P}(46) 169$, 9. 5. 1946) und holte sich, ais Frankreich Ähnliches eingestand, nachträglich Absolution bei der IARA, sagte zugleich die Beendigung der einseitigen Praxis zu. RG 59, 740.00119 Control(Germany)/6-2446. Als die IARA gegen die Selbstbedienung der Besatzungsmächte protestierte, erschrak Botschafter Kirk angesichts der Summe von \$10 Mio. einseitiger Entnahmen, die ihm „much too high" erschien. Nachdem England $£ 90.000$ zugegeben hatte, würden solche Entnahmen einen ,highly unfortunate impression“ hinterlassen. Eine interne Bestandsaufnahme ergab, daß ohne FIAT-Entnahmen ca. \$12 Mio. entnommen worden waren, auch noch nach der offiziellen Einstellung. War und Navy Departments hatten zusätzlich \$4 Mio. entnommen, weitere $\$ 3,75$ Mio. waren "doubtful“" aber das State Department hielt es für „very possible that complete report will reveal considerable additional removals beyond those presently known". RG 59, 740.00119 Council/3-2847 und /4-747. Im Februar 1947 schätzten britische Stellen, daß BIOS Werte von $£ 100.000$ entnommen hatte, die USA von $\$ 500.000$ „or more“. PRO, FO 371/65012/ C31. Frankreich hielt sich mit solchen Maßnahmen zurück, um keine Repressalien bei den Reparationslieferungen zu riskieren. AMAE, Y 364, Bl. 121.

161 PRO, FO 943/28 (Dakin/Knight, Report, Juli 1946). Frankreich, Jugoslawien und Griechenland erhielten mehr Einzellieferungen als Großbritannien, doch reservierte dieses die höherwertigen Maschinen für sich seibst. 
Wert zu sein.“ Der Bedarf war so dringend, daß Bevin dafür plädierte, im Falle des Scheiterns der Moskauer Außenministerkonferenz die Kategorien von demontagewürdigen Rüstungsbetrieben zu erweitern, um den Bedürfnissen Englands und der Westeuropäer entgegenkommen zu können; notfalls müsse das Königreich „einseitige Maßnahmen“ ergreifen. Die Briten suchten daher nach einer Lösung, die die Verweigerung der Lieferungen an die Sowjetunion nicht zum eigenen Nachteil werden ließ; entweder, so die Überlegungen im März 1947, indem sie Potsdam offiziell aufkündigten oder sich, wie die Sowjetunion in ihrer Zone, stillschweigend selbst bedienten ${ }^{162}$. Das geeignete Instrument dazu erschien ihnen der „Multilaterale Lieferplan“, um „wenigstens die wichtigeren Werkzeugmaschinen und einzelne Ausrüstungsteile zu bekommen, im Unterschied zu ganzen Betrieben oder Betriebseinheiten, die wir zum Ersatz für die durch übermäßigen Gebrauch während des Krieges abgenutzten brauchen, um die Lücken in unserer Ausrüstung aufzufüllen und den Bedürfnissen unserer Rekonstruktionspläne und Exportprogramme nachzukommen“. Zur politischen Absicherung ihrer Aktion beteiligten die Briten auch andere Reparationsgläubiger über die IARA. Das Programm, in dessen Rahmen zunächst 2250 Werkzeugmaschinen geliefert werden sollten, kam nur schwer in Gang, wegen interner, aber auch deutscher Widerstände, so daß sein Abschluß sich hinauszögerte. Im März 1947 waren erst 198 Maschinen in England angekommen, 35\% waren jedoch von den Empfängern zurückgewiesen worden. Bis September 1947 waren 4082 Maschinen ausgewählt und 3295 zugeteilt worden. Der Gesamtwert dieser Entnahmen belief sich auf 23 Mio. RM, enttäuschend angesichts der erhofften 75 bis 100 Mio. RM. 34 Betriebe waren ganz oder teilweise vom Ministry of Supply als besonders erwünscht eingestuft worden, darunter praktisch alle Eisen- und Stahlwerke der britischen Zone; doch wurden diese nie geliefert. Die USA kritisierten die Aktion zwar öffentlich, aber „haben uns privat wissen lassen, daß sie die Gründe dafür verstehen, die uns dazu bewogen haben“. Die Sowjets protestierten heftig und weigerten sich, die ihnen angebotenen $25 \%$ der Lieferungen anzunehmen. Angesichts dieser Kritik stellten die Briten im Oktober 1947 die einseitigen Entnahmen ein und verbuchten sie nachträglich auf das Reparationskonto ${ }^{163}$.

Bei der Beschlagnahme von Maschinen war Frankreich erfolgreicher, weil rücksichtsloser. Nach deutschen Angaben waren in der französischen Zone nicht nur 30 Betriebe vollständig demontiert worden, zu denen zehn Rüstungs- und 58 andere Betriebe hinzukamen. Dazu waren 20.000 „neue“ Maschinen im Wert von 100 Mio. RM konfisziert worden, 1947 nochmals 3000 Werkzeugmaschinen im Wert von 110 Mio. RM. Angesichts der starken Vermehrung von Werkzeugmaschinen im Bereich der drei Westzonen um 610.000 von 1936 bis 1945 hatte Paris keine Bedenken, trotz der angestrebten Restitution von 40.000 und Demontage von 234.200 Maschinen einen Überhang von 375.000 Stück anzunehmen und als „einen unentbehrlichen und sehr dringenden Beitrag für den Wiederaufbau, im Rahmen der europäischen Rekonstruktion“ im Namen der westeuropäischen Nachbarstaaten Deutschlands einzu-

162 PRO, PREM 8/791 (C.P.(47)68, 20. 2. 1947).

163 PRO, FO 1049/752 (18. und 20. 3. 1947); FO 371/65012/CE669 (25. 3. 1947); PREM 8/791 (Bevin, C.P.(47)68, 20. 2. 1947). BA, Z 45 F/OMGUS, 2/118-3/7-9 (CORC/M(47)41, 12. 9. 1947; CORC/ P(47)198). AVBRD, Bd. 3, S. 693 (Anm. 15), 696. Kramer, Demontagepolitik, S. 188-220. Die britischen Lieferungen (an 14 Länder) erreichten 20,5 Mio. RM, die französischen (an 15 Länder) 12,3 Mio. RM. Piettre, Economie, S. 567. 
fordern ${ }^{164}$. Da nach eigenen Angaben bis zum April 1947 von den Reparationsgütern, die die IARA Frankreich im Werte von 16,2 Mio. RM (1938) zugeteilt hatte, erst Lieferungen von 2 Mio. RM eingegangen waren, war Paris ebenfalls dazu übergegangen, angesichts der ,skandalösen Unzulänglichkeit des Systems der Kapitalgüter-Reparationen" ${ }^{165}$ sich in seiner Zone mit einseitigen Entnahmen von 26 Mio. RM (1938) schadlos zu halten, die angeblich später auf Reparationskonto verrechnet werden sollten. Dazu kamen Schiffe ( $£$ 1,88 Mio.) und deutsches Eigentum in Frankreich (5 Mrd. Francs). Aber selbst in der französischen Zone wurden nur 33 von ursprünglich $88 \mathrm{Fa}$ briken ganz oder teilweise demontiert, mit einem Restwert von 103 Mio. RM ${ }^{166}$.

Nachdem infolge politischer Vorbehalte und taktischer Verzögerungen das gesamte Programm der Vorab-Lieferungen praktisch gescheitert bzw. zu mehr oder minder verdeckten zonalen Einzelmaßnahmen verkommen war, drohte die ökonomische Entwaffnung Deutschlands durch Demontagen zu scheitern. Das konnte auch nicht im Interesse der Westmächte liegen, zumal nachdem sie seit Gründung der Bizone, dann vor allem mit dem Marshall-Plan den Industrieniveauplan endgültig aufgegeben und ihre Besatzungspolitik von Reparationen auf Rekonstruktion, von Begrenzung auf Wachstum umgestellt hatten. Briten und Amerikaner wollten daher aus sicherheitspolitischen Rücksichten in ihren Zonen das Demontageprogramm abschließen, ehe politischer Druck seitens des amerikanischen Kongresses eine Wiederbelebung der deutschen Wirtschaft ohne Rücksicht auf deren strukturelle Konversion erzwang. Obwohl OMGUS und CCG am 11. August 1947 zugestimmt hatten, daß die Bewertung der bereits freigegebenen Betriebe weitergeführt werde, kündigten sie am 30. August im Kontrollrat, am 5. September im Koordinationskomitee an, ihre endgültige bizonale Liste für die Bewertung von Betrieben zur „Prüfung“ durch die vier Mächte vorzulegen ${ }^{167}$. Nach Konsultationen mit den Deutschen veröffentlichten sie am 16. Oktober 1947 eine Liste mit 682 Betrieben, legten diese aber dem Kontrollrat „ausschließlich zur Information“ vor $^{168}$. Faktisch war, wie Clay dem Länderrat vertraulich offenbarte, auch deren Verwirklichung nicht mehr zu erwarten ${ }^{169}$.

Um sich endgültig freie Hand für eine solch weitreichende Revision der bisherigen Politik zu verschaffen, unterbreiteten Anfang Dezember 1947 die Briten im Kontrollrat ein Memorandum, das sie den Franzosen vorher zur Kenntnis gebracht hatten. Zur „Beschleunigung“ des Verfahrens schlugen sie vor, die Bewertung der Reparationsbetriebe zukünftig vom Zonenbefehlshaber vornehmen und vom Kontrollrat unbesehen

164 AMAE, Y 372, Bl. 28 ff. (21. 11. 1947), 68 (5. 12. 1947), 154 ff. (19. 2. 1948).

165 AN, 457 (Bidault) AP 60/IV (MAE, 25. 2. 1947).

$166 \mathrm{AO}$, Berlin/3275/4/701 (CMAE(47) (M)131, 15. 4. 1947). Ludmann-Obier, Chemische Industrie, S. 99.

167 BA, Z 45 F/OMGUS, 2/118-3/10-21 (CORC/P(47)191, 2. 9. 1947); 2/108-2/3-7 (CONL/P(47)49). PRO, FO 371/64451/C9191 (ORC(47)31, 1. 7. 1947)

168 Gimbel, Besatzungspolitik, S. 232 ff. Die Deutschen durften innerhalb von 14 Tagen Alternativen und Austauschvorschläge unterbreiten. AVBRD, Bd. 3, S. 693 (Anm. 13). Die CDU/CSU-Fraktion im Wirtschaftsrat erachtete die Demontageliste ,nur als politisches Alibi der Londoner Konferenz“. Die CDU/CSU im Frankfurter Wirtschaftsrat, S. 93. Möglicherweise war das ein Grund dafür, daß die Ministerpräsidenten sich auf keine einheitliche Stellungnahme zu einigen vermochten. Troeger, Interregnum, S. 46 ff. Die französische Demontageliste umfaßte 234 Betriebe, so daß in den Westzonen 916 Betriebe zur Demontage ins Auge gefaßt waren, etwa die Hälfte der ursprünglich benannten. NA, RG 59, 862.60/9-2848.

169 AVBRD, Bd. 3, S. 745 (3./4. 11. 1947). Gleichwohl befürwortete Clay im Januar 1948 vor dem Senat weitere Demontagen im Interesse des europäischen Wiederaufbaus. Baade, Demontagen, S. 569. 
übernehmen zu lassen. „Dem Zonenkommandeur steht es frei, wenn er es möchte, Betriebe sofort nach der Bewertung zu demontieren." ${ }^{170}$ Nachdem Frankreich Ende November 1947 den revidierten Bizonenplan mit Vorbehalten akzeptiert hatte, stimmte es auch diesem Vorschlag in der Erwartung zu, daß er eine Beschleunigung der Reparationslieferungen bringen (und in der eigenen Zone freie Hand geben) werde, solange die Möglichkeit der Verifikation der zonalen Bewertungen erhalten blieb. Das bedeutete eine neuerliche „Reduktion der Kompetenzen des Kontrollrats“, nachdem bereits die Ankündigung der Angelsachsen, ihre bizonale Liste sei endgültig, dem Kontrollrat auch in diesem Bereich die Entscheidungskompetenz entzogen hatte ${ }^{171}$. Nicht zu Unrecht attackierten die Sowjets dies am 17. März 1948 in der letzten Sitzung des Koordinationskomitees als Wiederaufnahme der einseitigen Reparationslieferungen zugunsten der westlichen Reparationsgläubiger.

Bei der abschließenden Regelung der Vorab-Lieferungen seitens der BizonenMächte sollten lediglich die früheren Verpflichtungen gegenüber der Sowjetunion abgewickelt werden, zumal deren Ansprüche nur noch Restlieferungen im Schätzwert von 150 Mio. RM (1938) betrafen. Nach Clays Vorschlag würden auch Rüstungsbetriebe im Rahmen der Potsdamer 15-Prozent-Klausel weitergeliefert werden, soweit die Sowjetunion dafür die vorgesehenen Gegenlieferungen leistete. Im Hinblick auf den bizonalen Industrieplan und den Marshall-Plan beschlossen die USA im September 1947, daß es außer Vorab-Lieferungen von Kapitalgütern und Einzelstücken aus Rüstungsbetrieben bis zur nächsten Außenministerkonferenz keine weiteren Reparationen für die Sowjetunion geben werde; sollte sich die Konferenz nicht auf die Herstellung der Wirtschaftseinheit einigen, sollten alle Lieferungen an die Sowjetunion „auf unbestimmte Zeit ausgesetzt werden“172. Gegen massive Widerstände in den Westzonen ${ }^{173}$, im Kongreß ${ }^{174}$, im Kabinett ${ }^{175}$ und in Großbritannien ${ }^{176}$ suchte das State Department Mitte Februar 1948 eine Fortsetzung der Lieferungen damit zu begründen, daß sie ökonomisch und strategisch für die Sowjetunion relativ bedeutungslos, aber für das „einheitliche westliche Vorgehen“ im Kontrollrat unabdingbar seien. Während die Demontagen in der amerikanischen Zone weitgehend abgeschlossen seien, so daß keine großen Zugeständnisse an deutsche Proteste und Widerstände in Kongreß und Regierung gemacht werden mußten, lägen etwa 300 Betriebe, deren vollständigen oder teilweisen Erhalt der Kongreß forderte, in der britischen und fran-

170 BA, Z 45 F/OMGUS, 2/188-3/10-21 (CORC/P(47)242). Die Briten begründeten letzteres mit Verzögerungen bei der Entsendung von Expertenteams der IARA-Länder, nicht der Sowjetunion.

171 NA, RG 335, box 49, folder: 463.3/Germany (Draper an Clay, 22. 11. 1947). AO, Berlin/3275/4/701 (3. 12. 1947; 4. 3. 1948).

172 FRUS, 1947/II, S. 1123 (Marshall an Clay und Murphy, 11. 9. 1947). Dabei wurde zunächst offengelassen, ob dieser Lieferstopp auch für die osteuropäischen IARA-Länder gelten würde. Vgl. AMAE, Y 296, Bl. 11 (Saint-Hardouin, 15. 9. 1947). Vgl. unten S. 354 und $437 \mathrm{f}$.

173 BA, Z 4/17.

174 CP, S. 446 (27. 10. 1947), 464 ff. (1. 11. 1947). NA, RG 59/ASSOA, box 3 (Bericht des State Department an den Kongreß, 24.1.1948).

175 Federführend war Handelsminister Averell Harrimann, der drei Punkte hervorhob: 1. den Widerspruch zwischen Demontagen und deutschem Wiederaufbau, 2. die strategische Verweigerung von hochwertigen Industriegütern gegenüber der Sowjetunion, 3. den Marshall-Plan. Begonnen hatte der Widerstand gegen eine Wiederaufnahme der Lieferungen an die Sowjetunion im Frühjahr 1947. Library of Congress, Harriman Papers, box 241.

176 PRO, FO 800/460/Eur/47/12 (12.6. 1947). NA, RG 59/CED, box 2, folder: G 400 Reparations (3. 10. 1947). 
zösischen Zone. Da Briten und Franzosen nicht bereit seien, sich einem totalen Reparationsstopp anzuschließen, um sich die Tür zum Handel mit der SBZ und der Sowjetunion offenzuhalten, würde ein amerikanischer Alleingang wenig wirksam sein, sondern eher „den Vier-Mächte-Reparations-Apparat zerstören“. Doch solche Mahnungen verhallten ungehört. Mit der Drohung, im Falle einer Fortsetzung des Demontageprogramms für beide Zonen keine Gelder aus dem Marshall-Plan bereitzustellen, wurden die beiden Westalliierten gegen den Einspruch des State Department im Oktober 1948 gezwungen, der Reduzierung der Demontagelisten zuzustimmen ${ }^{177}$.

Auf französische und sowjetische Verhandlungsforderungen konnten und wollten Engländer und Amerikaner zu diesem Zeitpunkt keine Rücksicht mehr nehmen. Die Erfahrungen im Kontrollrat und die Zwänge des Marshall-Plans sprachen dagegen. Ein französischer Vorstoß, aus Gründen der „ökonomischen Sicherheit“ Produktionsverbote über die bisherigen Regelungen hinaus zu erlassen, französisch-sowjetische Proteste gegen die „künstliche“ Reduzierung der Liste der Rüstungsbetriebe in Kategorie I um 86 Betriebe in der britischen Zone sowie ihre Forderungen nach Beratung der Liste der Rüstungsbetriebe in Kategorie II (ganz zu schweigen von den Kategorien III und IV) wurden von den Briten z.T. rüde, aber mit amerikanischer Rückendeckung, zurückgewiesen ${ }^{178}$. Wenn auf dem Londoner Außenministerrat „ein letzter Versuch, die sowjetische Zustimmung zur amerikanischen Interpretation“ des Potsdamer Abkommens zu erreichen, unternommen werden sollte, allerdings nur im Rahmen der in Moskau „eng definierten Kompromißvorschläge“, so war das Folge des Drucks der westeuropäischen Länder, inkl. Frankreichs und Englands, die Reparationslieferungen wieder aufzunehmen. Reparationen aus laufender Produktion waren in der neuen amerikanischen Position noch immer nicht völlig ausgeschlossen, allerdings nur, soweit sie, das war eine neue Hürde, mit dem Marshall-Plan koordiniert würden. Da deutsche Reparationen an die Sowjetunion und Osteuropa zu Lasten der Lieferungen an die ERP-Länder gehen mußten, waren solche Reparationsleistungen nur akzeptabel, ,wenn die Sowjetunion (und möglicherweise andere osteuropäische Länder) Deutschland als Teil der Regelung Nahrungsmittel, Kohle und Rohstoffe lieferten, die anders nicht zu haben gewesen wären oder die sonst zu Bedingungen, die viel ungünstiger für die ERP-Länder gewesen wären, hätten eingetauscht werden müssen“. Das galt jedoch als „höchst unwahrscheinlich“. „Ein entsprechend abgesicherter Versuch, der sowjetischen Forderung nach Zugang zur industriellen Produktion

177 FRUS, 1948/II, S. 732 f., 810 f., 816 f., 823-52. In zähen Verhandlungen im Dezember 1948 konnten Briten und Franzosen die extremen Forderungen der ECA abwehren, mußten aber im revidierten Reparations-Abkommen vom 13.4. 1949 erhebliche Zugeständnisse machen, die den faktischen Reparationsstopp im Petersberg-Abkommen vom 22. 11. 1949 vorbereiteten. AMAE, Y 372, Bl. 68. PRO, FO 371/71093. FRUS, 1948/II, S. 778-88 (Final Report on Dismantling of Industrial Plants located in the three Western Zones of Occupation of Germany, Juli 1948, den eine Technical Mission der Departments for Agriculture, Commerce and Interior, unter Rückkoppelung mit OMGUS und State Department, erarbeitet hatte). NA, RG 59/OWEA, Miscellaneous German Files, box 3, folder: Germany-Dismantling; RG 59, 862.60/9-2848. PRO, FO 371/71093/CJ1692 (3. 4. 1948). Zum Washingtoner Abkommen vom 13.4. 1949, das weitere 159 Betriebe von der Demontageliste absetzte, vgl. EA, 1949, S. 2113 f., 2165 ff. Zum Petersberger Abkommen vgl. AAPD, Bd. 1, S. 10 f., 16, 23 f., 30 ff., 467 ff.

178 BA, Z 45 F/OMGUS, 2/118-3/10-21 (CORC/P(47)110, 166, 169). PRO, FO 1036/748 (The Future Level of German Industry). Schließlich stimmten die Anglo-Amerikaner den französischen Forderungen zu. In dem trilateralen Abkommen über das Militärische Sicherheitsheitsamt und das westzonale Industrieniveau vom Januar bzw. April 1949 wurden Produktionskontrollen, -beschränkungen und -verbote z.T. unter Bezug auf die Kontrollratsgesetze verhängt. EA, 20. 5. 1949, S. 2163 ff. 
Westdeutschlands entgegenzukommen, sollte gleichwohl gemacht werden, als ein letzter Versuch, eine Regelung der Reparationsfrage zu erreichen“, entweder für eine begrenzte Summe in Höhe von ca. \$120 Mio. durch Veredelungsarbeiten oder ein Handelsabkommen „als ein Ersatz für laufende Reparationen“. Derartige Angebote würden kaum auf sowjetische Gegenliebe stoßen, wie man in der amerikanischen Delegation wohl wußte. Das konnte kein ernsthafter Versuch mehr sein, geschah eher aus taktischen Rücksichten, wie auch die Pro-forma-Bereitstellung von Reparationen für die Sowjetunion vom State Department bis zum Beginn der Berlin-Blockade Ende Juni 1948 aufrechterhalten wurde ${ }^{179}$.

Da die Demontagen in erster Linie das deutsche Rüstungs- und Kriegspotential betrafen, fiel dieser Teil der vorgesehenen Reparationsleistungen seit Ende März 1948 automatisch unter das Embargo gegen die Sowjetunion. Nach dem Putsch in Prag wurden alle Reparationslieferungen an die Tschechoslowakei, Jugoslawien und Albanien mit der Begründung von Transportproblemen eingestellt. Nach Protesten dieser Länder wurden die Lieferungen Anfang Juni wieder aufgenommen, jedoch durfte gemäß den Embargobestimmungen nur „general purpose equipment“ übergeben werden; militärisch sensible Spezialausrüstungen mußten unter Vorwand zurückgehalten und zerstört werden ${ }^{180}$. Ein Motiv für dieses behutsame Vorgehen gegenüber der Sowjetunion und den osteuropäischen IARA-Ländern war, daß die USA die Vereinbarungen nicht offen und einseitig aufkündigen wollten: einmal um eine Legitimation für die fortgesetzte Bedienung der westeuropäischen IARA-Staaten zu haben, zum anderen um eine Wiederbelebung des Kontrollrats zu vermeiden ${ }^{181}$. Da die Sowjetunion eben mit den Reparations-Gegenlieferungen begonnen hatte und zur Aufrechterhaltung ihrer Ansprüche offenkundig gewillt war, ihre Verpflichtungen zu erfüllen, hatten die Westmächte keinen Anlaß bzw. Vorwand, die Reparationen, die auf den Potsdamer Beschlüssen und Vereinbarungen im Kontrollrat beruhten, einseitig aufzukündigen.

\section{Restitutionen}

Daß Güter, die Deutschland sich in den besetzten Gebieten unrechtmäßig angeeignet hatte, zurückgegeben werden mußten, war seit der Londoner Deklaration vom 5. Januar 1943 Konsens zwischen den Alliierten ${ }^{182}$. Der Entwurf, den die Briten am 15. Januar 1944 der EAC vorlegten, definierte die Verpflichtung in aller Breite als „Restitution, Wiedereinsetzung, Restauration“ und bezog sich auf „Immobilien, Vermögen, Rechte, Besitztitel und Beteiligungen in Deutschland, die zu irgendeiner Zeit nach dem 1. Januar 1935 irgendeiner der Vereinten Nationen oder einem ihrer Staatsbürger gehören oder gehörten“" ${ }^{183}$. Sie drängten Ende 1944 auf eine grundsätzliche Lösung dieser Frage durch Einsetzung einer Restitutionskommission, „selbst wenn die Dis-

179 NA, RG 43/WWII\&PWConf, box 177, folder: Position Papers (CFM 3, Annex 5: Reparation). Vgl. FRUS, 1948/II, S. 754,772 ff., 796 ff.

180 FRUS, 1948/II, S. 703-46, 751, 758 f.

181 FRUS, 1948/II, S. 756, 764, 768. Vgl. unten S. 474 und ff.

${ }^{182}$ FRUS, 1943/I, S. 443 f. Vgl. PRO, FO 942/52 (Sommer 1942).

183 FRUS, 1944/I, S. 130 f. (EAC(44)1). 
kussion allgemeiner wirtschaftlicher Fragen noch nicht möglich ist “184. Erst auf der Potsdamer Konferenz näherten sie sich zögernd der amerikanischen Auffassung, die Restitutionen auf „identifizierbare“ Güter zu begrenzen und alle anderen Ansprüche als Teil der Reparationen zu behandeln; sie weigerten sich aber, die Rückgabeverpflichtung auf wenige, eng definierte Bereiche oder gar nur Kunstwerke zu beschränken. Schließlich verhinderten sie einen Kompromiß auf der Ebene der Regierungschefs mit dem Argument, daß die französische Provisorische Regierung in Potsdam nicht vertreten sei $^{185}$.

Die USA forderten die Rückgabe von „identifizierbarem gestohlenem Eigentum“ in Deutschland und von Eigentum, das in den besetzten Gebieten durch „Nötigung oder Betrug“ erworben worden war. Im Interesse des raschen Wiederaufbaus der zerstörten Gebiete und einer baldigen Rückkehr zu normalen Handelsbeziehungen schienen die Restitutionen (neben den Vorab-Lieferungen von Reparationen) besonders geeignet, die dringendsten Engpässe in einer Übergangszeit zu beseitigen. Aufgrund dieser engen Verknüpfung mit der Reparationsproblematik machten die USA eine Reihe von Vorbehalten geltend. Der Anspruch auf Rückgabe sollte nicht „absolut“ sein: „Die alliierten Behörden haben das unumschränkte Recht, die Restitution von hochwichtigen Gegenständen (wie z. B. von rollendem Material) zu verhindern oder zu verschieben, wenn solche Gegenstände als notwendig und hilfreich für die Wiederherstellung eines gefährlich desorganisierten Landes angesehen werden.“ Daher tendierten die USA immer stärker dazu, Restitution nur für Kunstwerke vorzusehen, da die Rückgabe von Maschinen oder rollendem Material die Reparationslieferungen ebenso erschweren würde wie die Gewährleistung der deutschen Selbstversorgung. Insofern war Restitution auch nicht als „Ersatz“ gedacht, sondern als Rückgabe im Ist-Zustand; ob und inwieweit der eingetretene Wertverlust durch zusätzliche Reparationen ausgeglichen werden sollte, blieb offen. Des weiteren sollten Angehörige der Vereinten Nationen für ihren Vorkriegsbesitz in Deutschland, soweit er der Demontage oder ,anderen, ihren Wert beeinträchtigenden Maßnahmen“ unterworfen wurde, „angemessen“ entschädigt werden, ohne daß die Besitzansprüche die Lieferung von Reparationen behinderten. Zur Erleichterung der technischen Abwicklung sollte die Kompensation von Verlusten jeglicher Art im wesentlichen pauschal über die jeweiligen Regierungen geregelt werden. Schon im Vorfeld der Potsdamer Konferenz suchte Pauley daher nach Maßgabe dieser Einschränkungen zu erreichen, daß im Interesse des Wiederaufbaus die Restitution von schwerindustriellen und agrarischen Maschinen, Werkzeugmaschinen und Transportmitteln durch Vorab-Reparationen kompensiert werden durfte; doch waren derartige Lieferungen als „untrennbar miteinander verknüpft“ später mit dem Reparationskonto zu verrechnen. Früh erkannte er die Gefahr, daß die Restitutionen zur Selbstbedienung geeignet waren, wenn sie „einen Vorrang vor den als Reparationen angesetzten Beträgen und über diese hinaus“ begründeten, und zur Bevorzugung privater Interessen führen könnten ${ }^{186}$.

184 NA, RG 59/EAC, box 3. FRUS, 1944/I, S. 334, 413. FRUS, 1944/II, S. 1048.

185 FRUS, Potsdam I, S. 553. FRUS, Potsdam II, S. 848. DBPO, I, 1, S. 301.

186 FRUS, 1944/I, S. 234 f., 295. FRUS, Malta and Yalta, S. 196. FRUS, 1945/III, S. 1172 ff., 1193, 1198 f. FRUS, Potsdam I, S. 513 ff., 549 ff. FRUS, Potsdam II, S. 818 f., 833 f., 848, 860, 934 f. TL, Truman Papers, President's Secretary's File, box 179, folder: German Reparations (Pauley, 11. 6. 1945). NA, RG 59/Pauley Mission, box 11 (Pauley, 29.6. 1945; Byrnes an Harriman, 30. 6. 1945). CP, S. $45 \mathrm{f} ., 68 \mathrm{f}$. 
Aus den amerikanischen Vorbehalten, an der Reduzierung der Besatzungskosten und der Rückkehr zum freien Welthandel orientiert, entwickelte sich Anfang 1945 in der EAC der Grundsatzkonflikt mit Frankreich, denn dieses verlangte „den Ersatz von verlorenen oder zerstörten Objekten durch ähnliche und gleichwertige Güter, die in Deutschland zur Zeit der Kapitulation vorgefunden wurden “187. Damit wäre das Prinzip der Reparationen, Kriegsfolgen pauschal zu entschädigen, ausgehöhlt worden, indem nicht nur ein Anspruch auf Einzelfallregelung, sondern auch auf eine Art von „first-charge-principle“ zugunsten der von Deutschland besetzten Staaten erhoben wurde. Neben der Forderung nach „identischen“ oder „äquivalenten“ Gegenleistungen für zerstörte Werte wurde eine weitgefaßte Definition des Begriffs „Spoliation“ vorgetragen, die den „Kauf“ durch „Bezahlung in Landeswährung, die von der Besatzungsmacht gewaltsam abgepreßt wurde“, und „Anweisung auf ein nicht ausgeglichenes Clearingkonto“ ebenso einschloß wie die „in welcher Art auch immer“ erfolgte Aneignung alliierter Auslandsguthaben ${ }^{188}$. Frankreich bestand auf einer getrennten Behandlung von Restitutionen und Reparationen: zum einen, um für sich ein Vetorecht gegen die Potsdamer Reparationsbeschlüsse zu gewinnen, zum anderen, weil es sich auf dem Feld eine raschere Erfüllung seiner Forderungen erwartete ${ }^{189}$. „Die Restitutionen sind für uns zur Zeit interessanter als jemals zuvor. Der Umfang der Reparationen, die wir uns erhoffen, ist ungemein geschrumpft, und die Restitutionen, selbst wenn sie sich auf einen Teil der uns geraubten Objekte reduzieren, haben eine Bedeutung, die denen der Reparationen vergleichbar ist." ${ }^{190}$ Diese Einschätzung konnte nicht erstaunen, da Frankreich die deutschen Entnahmen auf 34 Mrd. Mark (1938) schätzte ${ }^{191}$. Allerdings, so warnte Rueff, der französische Vertreter bei der Alliierten Reparationskommission, aus Moskau seine Regierung weitsichtig, eine Verlagerung der Restitutions- und Reparationsfrage in den Kontrollrat werde sich nachteilig auswirken, weil dieser, „aus der Logik der Sache heraus, von dem Bemühen bestimmt werden wird, die ungeheueren Schwierigkeiten zu lindern“, und daher auf eine $\mathrm{Re}$ duktion der Belastungen für Deutschland drängen müsse ${ }^{192}$.

Die Sowjetunion zeigte zunächst wenig Interesse, da sie sich rücksichtslos Kompensationen über die „Kriegsbeute“ verschaffte, durch „äquivalente“ Restitutionen auch technologisch keinen Vorteil gezogen hätte und daher diese als Teil der Reparationen regeln wollte ${ }^{193}$. Noch im Frühjahr 1945 schien sie keine konkreten Vorstellungen zu haben, sondern wurde erst durch die französischen Vorstöße in der EAC aufmerksam. In Potsdam legte sie eine „drastisch abweichende“ Definition vor, die jede Form des Besitztums, einschließlich der produzierten Güter, vor und während der Besatzungszeit einschloß, „ungeachtet der Art, wie sie dem Feind in die Hände fielen“. Wenn die Ersatzpflicht für „Eigentum, das vom Feind zerstört oder benutzt wurde oder das infolge feindlicher Aktivitäten an Wert verloren hat", sich neben

187 FRUS, Malta and Yalta, S. 197.

188 FRUS, 1945/III, S. 1170 f., 1196.

189 FRUS, 1945/III, S. 1243 f. TL, Truman Papers, President's Secretary's File, box 179, folder: German Reparations (Pauley, 11.6. 1945).

$190 \mathrm{AO}$, Berlin/3273/2/2730, I (Glasser an Koeltz, 14. 11. 1945); 3273/3/2731, I (SGAAA, 10. 8. 1945).

AMAE, Y 134 (Commission des Réparations, Délégation Française, 3. 10. 1945).

191 AO, Berlin/3273/2/2730, III (8. 10. 1947).

192 AN, 457 (Bidault) AP 61/III (2. 8. 1945). FRUS, 1945/III, S. 1243 ff., 1263.

193 FRUS, 1944/I, S. 234, 236, 426. FRUS, 1945/III, S. 1196, 1244. 
Kunstwerken auch auf „einzigartige“ wirtschaftliche Objekte erstreckte, so waren den Ansprüchen keine Grenzen gesetzt ${ }^{194}$. Da das Land die stärksten Kriegszerstörungen erfahren hatte, war eine derartige Regelung besser geeignet, den Primat der sowjetischen Forderungen durchzusetzen als die von den Westmächten abgelehnte Pauschalforderung nach $\$ 10 \mathrm{Mrd}$. an Reparationen, zudem unabhängig von einem Dismemberment Deutschlands oder anderen territorialen Veränderungen. Das anhaltende Desinteresse der Sowjetunion an konkreten Lösungen legt nahe, daß sie diesen Punkt vor allem unter verhandlungstaktischen Aspekten betrachtet zu haben scheint ${ }^{195}$.

Nachdem die Sowjetunion in der EAC die Einsetzung einer Restitutionskommission verhindert hatte und die Restitutionsproblematik aus dem Potsdamer Protokoll ausgeklammert worden war, verlangte Frankreich (unterstützt von den Niederlanden) Anfang August von den anderen Mächten die sofortige Aufnahme der Restitutionslieferungen. Noch bevor der Kontrollrat zusammengetreten war, schlug Koeltz für die Westzonen eine Drei-Mächte-Kommission als Ersatz für die Alliierte Restitutionskommission bzw. die Ernennung von französischen Attachés bei den britischen und amerikanischen Hauptquartieren vor. Byrnes und Acheson lehnten eine innerwestliche Lösung nicht grundsätzlich ab, und Clay erklärte gegenüber Koeltz seine Bereitschaft zur informellen Kooperation auf unterer Expertenebene, schränkte das am 2. August 1945 aber dahingehend ein, er halte sofortige Restitutionen für ,inopportun“. Damit schien die innerwestliche Lösung gefährdet ${ }^{196}$. Da Clay Ende August noch keine Instruktionen erhalten hatte und in der Reparationskommission kein Durchbruch erzielt worden war, ergriffen die Briten die Initiative. Anfang September brachten sie im Koordinationskomitee eine Resolution ein, nach der „leicht zu identifizierende“ Restitutionen in „kleiner Stückzahl“ entnommen werden durften, soweit die Empfängerländer diese dringend brauchten, die Verlagerung ohne großen Aufwand $\mathrm{zu}$ bewerkstelligen war und eine endgültige Regelung nicht präjudiziert wurde ${ }^{197}$. Doch Sokolowski blockierte im Koordinationskomitee gegen das Votum des sowjetischen Vertreters im Reparationsdirektorat einen Beschluß, indem er zunächst eine Definition des Begriffs ,Restitution“ verlangte.

$\mathrm{Da}$ die Angelsachsen trotz der neuerlichen Verzögerung gestatteten, daß mit der Rückgabe von Kulturgütern aus ihren Zonen begonnen wurde, war es für Frankreich ohne großes Risiko, sich in der Reparationskommission und im Kontrollrat für einen Blockadekurs zu entscheiden. Denn trotz aller Verärgerung blieben die USA bemüht, den französischen Ansprüchen entgegenzukommen. Sie ließen seit September 1945 französische und belgische Expertenkommissionen in ihre Zone einreisen, forderten Listen von Restitutionsgütern an, stimmten im November der Erweiterung der Restitutionskategorien für diese Missionen zu und begannen, Maschinen an Belgien und Rohstoffe an die Niederlande zurückzugeben. Bis zum April 1946 hatten sie Kunstwerke und Rennpferde, aber auch Industriegüter ,in einem bedeutsamen Maße“, insbesondere Werkzeugmaschinen, Schiffe und Kriegsmaterial im Werte von 1 Mrd. Francs zurückgegeben, die britische Zone im Werte von 300 Mio. Francs. In ihrer Zone suchten, erfaßten und sicherten die Franzosen seit September 1945 die Restitu-

194 FRUS, Potsdam I, S. $542 \mathrm{f}$.

195 FRUS, 1945/III, S. 1255, 1260, 1281, 1363. AO, Berlin/3273/3/2731, I (17. 11. 1945).

196 AN, 457 (Bidault) AP 63/Conférence des Réparations (11.8. 1945).

197 FRUS, 1945/III, S. 1273, 1279 f. BA, Z 45 F/OMGUS, 2/118-1/5-15 (CORC/P(45)36, 4. 9. 1945). 
tionsgüter systematisch und umfassend mit Hilfe eines in Berlin eingerichteten Restitutionsbüros ${ }^{198}$.

Um eine weitere Zuspitzung der Debatten über den Vorrang von Restitutionen oder Vorab-Reparationen zu verhindern, unterbreitete Clay im Kontrollrat einen Kompromiß, der indes noch restriktiver war, da er jegliche Restitutionen ablehnte, die eine "Minimalwirtschaft“ in Deutschland verhinderten, zu erhöhten Importen führten, die USA finanziell belasteten oder das Reparationsprogramm beeinträchtigten. Zwar erhielt er aus Washington Anweisung, Restitutionen („außer Gold, Wertpapieren und Devisen") auch ohne Rücksicht auf deutsche Bedürfnisse zuzulassen, notfalls nur auf der Ebene der drei Westmächte, aber nicht über die IARA; er setzte aber seine besatzungspraktische Linie im Kontrollrat durch. Der jeweilige Zonenkommandeur wurde zur zentralen Anlaufstelle für alle Vorab-Restitutionen, er prüfte die Ansprüche der Gläubigernationen und gab deren Anträgen statt, „außer wenn der Besitz aus Gründen militärischer Notwendigkeit zurückbehalten werden muß “199. Frankreich zeigte sich, um seine eigenen Ansprüche im Prinzip zu wahren, jetzt flexibler: Es stimmte Vorab-Reparationen zu, sofern dem keine Restitutionsansprüche entgegenstanden $^{200}$, lehnte es aber unter Berufung auf die alliierte Deklaration vom Januar 1943 weiterhin ab, nicht „identischen“ oder nicht „äquivalenten“ Ersatz für solche Maschinen zu akzeptieren, die als zentraler Teil einer Fabrik in Deutschland verbleiben oder als Vorab-Lieferung auf Reparationskonto an andere Gläubigernationen gehen sollten. Während die Sowjetunion jegliche Restitutionen aus Reparationsbetrieben ablehnte, die deren Demontage verzögert hätten, zeigten sich die Angelsachsen kompromißbereit, indem sie Einzelfallprüfungen nicht ausschließen wollten. Obwohl beide Vorschläge Kompensation vorsahen, beharrten die Franzosen auf sofortigen Inspektionen, um ihre Ansprüche geltend machen zu können: Die Suche nach äquivalentem Ersatz sei zu zeitaufwendig, sofern er bei Spezialmaschinen überhaupt möglich sei; bei der Verlagerung ganzer Fabriken sei eine Produktionsreife erst nach Jahren zu erwarten, während die Rückführung von Maschinen in ihre Ursprungsbetriebe zu sofortigen, spürbaren Produktionserfolgen führen werde ${ }^{201}$. Nachdem Bidault Anfang Oktober auf der Londoner Außenministerkonferenz an Molotows Verzögerungstaktik gescheitert war, verknüpfte er seine Zustimmung zur Lieferung von Vorab-Reparationen mit einer Lösung der Restitutionsfrage bis zum 1. November 1945. Die Sowjets, die auf den Beginn der Vorab-Lieferungen zum 1. Dezember gehofft hatten, antworteten mit der Blockade der Restitutionsfrage im Kontrollrat ${ }^{202}$.

198 AO, Berlin/3273/2/2730, I-III. Die SMAD, „reserviert“ gegenüber französischen Forderungen, ließ keine Expertentrupps in ihre Zone, erklärte sich aber zum Schutz der Güter bereit, deren Vorhandensein in der SBZ nachgewiesen würde. Das legte den Franzosen die Beweispflicht auf. Da aus der SBZ bis zum September 1946 keine Lieferungen, sondern nur vertröstende Hinweise auf die Probleme bei Erfassung und Sicherstellung eingegangen waren, stellten die Franzosen in der eigenen Zone für die Sowjetunion und die osteuropäischen Staaten ebenfalls nur Voruntersuchungen an.

199 FRUS, 1945/III, S. 1440 (4. 12. 1945); zu früheren Ansätzen dieser Art im September vgl. ebenda, S. 1282 f., 1293 f., 1444 . CP, S. 108 ff.

200 AO, Berlin/3273/3/2731, I (29. 10. 1945). AMAE, Y 363, Bl. 88.

201 BA, Z 45 F/OMGUS, 2/118-1/5-16 (CORC/P(45)89(Final); CORC/P(45)147). FRUS, 1945/III, S. 1353 ff., 1364 f. Von den nach Deutschland verbrachten ca. 60.000 Werkzeugmaschinen gelangten zwar $80 \%$ aus der eigenen Zone, aber kaum mehr als $10 \%$ aus der britischen und amerikanischen Zone zurück. AMAE, Y 653, Bl. 67 (CGAAA, 3. 5. 1946). AO, Berlin/3273/2/2730, III (23. 1., 26. 2., 10. 3., 8. 4., 15. 9. und 8. 10. 1947). NA, RG 59/CED, box 2 (5.12. 1947).

202 AO, Berlin/3273/2/2730, I-II; 3273/3/2731, I. FRUS, 1945/III, S. 1325 ff., 1345 ff., 1356 f., 1373 , 
In der Definitionsfrage waren im Laufe des Oktobers Fortschritte nicht zu erzielen. Das Reparationsdirektorat legte zwei Varianten vor, die vom Koordinationskomitee seit Ende November in fast jeder Sitzung beraten wurden. Der entscheidende Unterschied zwischen dem sowjetischen und dem westlichen Vorschlag war, daß gemäß ersterem nur die Güter zurückzugeben waren, die die Deutschen "gewaltsam“ entnommen hatten ${ }^{203}$, während letzterer sich dem französischen Verlangen anschloß, nicht nur alle Entnahmen von Vorkriegsbeständen einzubeziehen, „wie immer die Mittel der Enteignung gewesen sein mögen“, sondern auch alle Produkte der Besatzungszeit, „deren Aneignung durch einen Gewaltakt vollzogen wurde“, was auch den „legalen“ Kauf unter den Bedingungen der Besatzung einschloß. Ein amerikanischer Vermittlungsvorschlag versuchte, die Anspruchsvoraussetzung für Restitutionen auf einen "Gewaltakt“" zu reduzieren und auf ein Maß zu begrenzen, das „mit den Reparationen und dem Deutschland belassenen wirtschaftlichen Minimum vereinbar" sei. Die französische Regierung lehnte, unterstützt von kleineren IARA-Ländern, auch diesen Kompromiß ab, der einem partiellen Demontagestopp gleichkam; denn diese Regelung hätte sie denselben Einschränkungen bei den Restitutionen unterworfen wie die Sowjets bei den Reparationen im Falle der Export-Import-Regelung. Frankreich ließ sich auch durch Clays Drohung nicht beeindrucken, einen Restitutionsstopp zu verhängen ${ }^{204}$. Auf Vorhaltungen aus Washington rechtfertigte dieser seine Drohung: „Vier-Mächte-Regierung muß notwendigerweise eine Regierung durch Kompromiß sein. Die Russen haben sich sehr weit bewegt, um den Franzosen bei den Restitutionen entgegenzukommen“, die ihrerseits keine Kompromißbereitschaft zeigten. „Bisher ist ihr einziger Beitrag gewesen, auf der Übernahme ihrer Restitutionspolitik zu bestehen und sich einem zentralen Verwaltungsapparat zu widersetzen. Sie haben keinen konstruktiven Beitrag zur Vier-Mächte-Regierung gemacht. Es scheint mir, daß wir uns in einer Einbahnstraße befinden, in der wir Frankreich bis zum letzten unterstützen und absolut keine Unterstützung von Frankreich für die Politik erhalten, die wir in Potsdam verfochten haben und die dort übernommen wurde. ${ }^{\text {(205 }}$ Eine Verlagerung in den Kontrollrat brachte keinen Fortschritt, weil alle Delegationen an Vorgaben ihrer Regierungen gebunden waren. Da aber die USA und Großbritannien weiterhin Frankreich entgegenzukommen bereit waren und sich im Reparationsdirektorat mit diesem auf eine gemeinsame Definition geeinigt hatten, stieg bei ihnen erkennbar die Neigung, sich notfalls auf Drei-Mächte-Ebene zu arrangieren. Angesichts der „systematischen Obstruktion" der Sowjetunion sah auch die GFCC die Lage im Kontrollrat als aussichtslos an und empfahl ihrer Regierung, mit London und Washington Verhandlungen für eine westliche Lösung aufzunehmen ${ }^{206}$.

Ende Dezember unterbreitete die französische Delegation ein neues Angebot, das den sowjetischen Bedenken teilweise Rechnung trug, indem Kollaborateure von Re-

1391 ff. FRUS, 1945/II, S. 175 f., 285, 325 f., 372 ff., 394 ff., 421 ff. DBPO, I, 2, S. 362 ff., 379 ff., $400 \mathrm{ff} ., 421,431 \mathrm{f}$.

203 Dieses Argument richtete sich, taktisch ungeschickt, gegen Frankreich. Pétain, Laval und die französische Industrie kämen als Kollaborateure sonst in den Genuß von Restitutionen; Entnahmen aus der Sowjetunion seien dagegen per definitionem ausschließlich mit Gewalt erfolgt. FRUS, 1945/ III, S. 1336, 1345. BA, Z 45 F/OMGUS, $2 / 108-1 / 3$ (CONL/M(45)15, 10. 12. 1945).

${ }^{204}$ BA, Z 45 F/OMGUS, 2/118-1/5-16 (CORC/P(45)167). FRUS, 1945/III, S. 1422 f., 1426 f., 1441.

205 CP, S. 140 f. (29. 12. 1945).

${ }^{206} \mathrm{AO}, \mathrm{Berlin} / 3273 / 2 / 2730$, I (27. 11. und 4. 12. 1945). 
stitutionen ausgeschlossen wurden, doch sollten deren Ansprüche auf die jeweilige Regierung übergehen. Den USA kam sie entgegen, indem sie auf das Zerreißen ganzer Produktionsstraßen zugunsten einzelner Restitutions-Maschinen gegen Kompensation verzichtete. Die Sowjetunion versuchte noch einmal, ihre Version durchzusetzen. Doch als die drei Westmächte am 10. Januar 1946 im Kontrollrat empfahlen, den Regierungen die mangelnde Einigungsfähigkeit offiziell mitzuteilen, lenkten die Sowjets ein. Nach britischem Eindruck waren sie wie die Franzosen sehr um eine Einigung bemüht ${ }^{207}$, um die Verhandlungen über den Industrieniveauplan und den baldigen Beginn der Reparationslieferungen nicht zu gefährden. Auf der Grundlage des französischen Angebots wurde eine Einigung erzielt, die zwar, wie eine amerikanisch inspirierte „Interpretation“ des Koordinationskomitees unterstrich, die französischen Ansprüche wahrte, aber die Restitutionen doch den Reparationen nachordnete ${ }^{208}$. Mit dieser Einigung war der Durchbruch erzielt, die praktische Umsetzung ließ jedoch auf sich warten. Ein Restitutionskomitee wurde eingesetzt, das bis zum April 1946 brauchte, um Verfahrensnormen, Arbeitsrichtlinien, Modalitäten für den Ersatz von vernichteten Unikaten (Kunstwerke, Maschinen usw.) oder die Deklarationspflicht der Deutschen, die im Besitz von Restitutionsgütern waren, zu entwickeln.

Mit Hilfe der Restitutionen konnten Frankreich und die westeuropäischen Länder Clays Reparationsstopp teilweise durchbrechen, obwohl dieser versucht hatte, auch bei den Restitutionen Restriktionen einzuführen, da sie den deutschen Wiederaufbau behinderten und einen unverhältnismäßig hohen Aufwand erforderten. Am 19. Juni 1946 wies er seine Behörden an, nur Restitutionen anzuerkennen, die nachweisbar durch Gewalt entfernt worden seien und deren Rückgabe die deutsche Selbstversorgung nicht beeinträchtige. Einen entsprechenden Vorbehalt hatten er und Robertson bereits im Januar 1946 geltend gemacht, nämlich daß die Restitutionen nicht zur Erhöhung des Zuschußbedarfs ihrer Zonen führen dürften. Er scheiterte jedoch im August 1946 mit seinem Vorstoß, daß Anträge auf Restitutionen bis zum 31. Dezember vorliegen müßten, damit deren Lieferung zum 30. Juni 1947 abgeschlossen werden könne ${ }^{209}$. Während die Sowjetunion und Großbritannien zustimmten, legte Frankreich abermals sein Veto ein und verlangte, daß seine eigene Praxis auch auf die anderen Zonen übertragen werde: systematische Suche durch Expertenkommissionen, Verpflichtung der Deutschen zur Selbstdeklaration und Auswertung deutscher Archive. Die GFCC lehnte auch den sowjetischen Vorschlag ab, die Meldefrist um ein halbes Jahr zu verlängern, sondern bestand auf einer Regelung, wie sie in den Friedensverträgen mit einigen kleineren Nationen vorgesehen war, nämlich daß Ansprüche bis zu einem Jahr nach Abschluß des Vertrages geltend gemacht werden konn$\operatorname{ten}^{210}$. Frankreich wiederholte seinen Protest, als Clay Anfang Februar 1947 einen abermaligen Vorstoß unternahm, ein Enddatum für die Anmeldung der Ansprüche festzulegen, und schließlich erneut ein einseitiges Vorgehen androhte. Wieder wandte sich Paris auf diplomatischen Kanälen an Washington, das Clay zu mehr Rücksicht-

208 Zusammenfassend: BA, Z 45 F/OMGUS, 2/118-2/1-7 (CORC/P(46)143, 17. 4. 1946). FRUS, $1946 /$ V, S. 483, 488 f., 504 f.

${ }^{209}$ AO, Berlin/3273/2/2730, II (Les restitutions, April-September 1946).

210 BA, Z 45 F/OMGUS, 2/118-3/10-21 (CORC/P(47)25, 30. 1. 1947). AO Berlin/3273/2/2730, II (10. 10. 1946). 
nahme aufforderte. Der lehnte jedoch weiterhin den von Frankreich angestrebten Freibrief ab, da sonst das Reparationsprogramm modifiziert werden müsse ${ }^{211}$.

Danach ruhte die Frage bis zum Oktober 1947, als die USA nachdrücklich auf einen definitiven Beschluß drängten, um im Hinblick auf den Marshall-Plan auch diesen irritierenden Faktor für einen raschen Wiederaufbau Westeuropas und Westdeutschlands auszumerzen. Während OMGUS empfahl, an den vertraglichen Verpflichtungen grundsätzlich festzuhalten, verstärkten sich in Washington die Bedenken gegenüber solchen Lieferungen, vor allem soweit sie osteuropäische Länder betrafen. „Es ist nicht länger wahr“, so hieß es im Juli 1947, „daß sich unsere Bemühungen um jeden Preis darauf richten, den Aufschwung der deutschen und der österreichischen Wirtschaft zu verhindern. Wir stehen mitten in einer großen Anstrengung, diese Volkswirtschaften wieder aufzubauen." Güter, die in Deutschland dringend gebraucht würden, müßten an osteuropäische Staaten übergeben werden, in denen die ursprünglichen Besitzer längst enteignet seien oder die die Lieferungen an die Sowjets weiterleiteten. „Das stimmt kaum mit unserer Politik überein, Westeuropa zu helfen und die sowjetische Expansion einzudämmen.“" ${ }^{212}$ Kurz: Die ursprüngliche Regelung, die zur Verminderung des Verwaltungsaufwands gedacht war, nämlich die Restitutionen nicht an die Besitzer, sondern an die Regierungen zu übereignen, wandte sich in Osteuropa gegen die westlichen Interessen. Der Kongreß verlangte daher energisch, im Zuge des beginnenden Handelsembargos gegenüber der Sowjetunion neben den Demontagen für Reparationszwecke auch die Restitutionslieferungen einzustellen ${ }^{213}$.

Im Kontrollrat drängte Clay abermals darauf, den 30. April 1948 als Stichtag für die Anmeldung aller Ansprüche festzusetzen, sicherte aber die flexible Behandlung begründeter Ausnahmen zu; andernfalls werde er, so wiederholte er seine inzwischen übliche Drohung, einseitig vorgehen. Überraschend akzeptierte Frankreich jetzt, während die Sowjetunion ihren Protest damit begründete, daß im Frühjahr, als sie selbst eine zeitliche Begrenzung befürwortet hatte, nicht absehbar gewesen sei, wie schleppend die Lieferungen aus den Westzonen erfolgten ${ }^{214}$. Mit dieser Umkehrung der Fronten war auch in dieser Frage eine gemeinsame westliche Position erreicht, die Rücksichten im Kontrollrat nicht mehr erforderlich machte. Anfang März 1948 schloß sich Clay der in Washington vorherrschenden Meinung an und empfahl seinerseits die Einstellung aller Restitutionslieferungen an kommunistische Länder. Anlaß war eine Silbersendung an Jugoslawien, die nur dazu beitrage, Titos Unruhe stiftende Politik auf dem Balkan zu finanzieren. Noch hielten sich die USA pro forma an ihre vertraglichen Verpflichtungen, doch gab das Auseinanderbrechen des Kontrollrats Gelegenheit, am 2. April alle Lieferungen nach Osteuropa einzustellen, während sie im Westen weiterlaufen durften, soweit sie den Marshall-Plan nicht beeinträchtigten. Nachdem weder Briten noch Franzosen im Interesse ihres Osthandels bereit waren, das Embargo in der gewünschten Schärfe mitzutragen, nachdem Jugoslawien bei der IARA Protest gegen die Einstellung der Restitutionen eingelegt hatte, hoben die USA ihr Lieferverbot wieder auf, soweit vertragliche Verpflichtungen durch Kontrollratsbeschlüsse oder Friedensverträge mit den ehemaligen Feindstaaten vorlagen. Allerdings

211 CP, S. 336 ff. (14. 4. 1947).

212 NA, RG 59/CED, box 2 (Lightner an Matthews, 21. 7. 1947).

213 CP, S. 446, $464 \mathrm{ff}$. FRUS, 1948/II, S. $703 \mathrm{ff}$.

214 BA, Z 45 F/OMGUS, 2/118-3/10-21 (CORC/P(47)25/1, 11. 10. 1947). 
galt der prinzipielle Vorbehalt weiter, daß die Lieferungen nicht den amerikanischen Embargovorschriften widersprechen oder zu einer Beeinträchtigung der deutschen Wirtschaft führen dürften. Dieser dehnbare Vorbehalt bedeutete faktisch das Ende der Restitutionen. Clay wurde dementsprechend ermächtigt, den Gläubigernationen das Auslaufen der Lieferungen zum Ende des Jahres 1948 anzukündigen ${ }^{215}$.

Insgesamt hat gemäß den Meldungen an den Kontrollrat bis zum Juli bzw. August 1947 die amerikanische Zone Güter im Werte von 109,2 Mio. RM (1938) restituiert (an Frankreich: 37,6; Tschechoslowakei: 14,1; Niederlande: 27,4; Jugoslawien: 13,5 Mio.), die britische Zone 124,5 Mio. (Niederlande: 86,6; Belgien: 17,0; Frankreich: 15,8 Mio.), die französische Zone 53,2 Mio. (Frankreich: 35,9; Niederlande: 11,1 Mio.), die SBZ 35,8 Mio. (Sowjetunion: 16,5; Polen: 10,4; Niederlande: 7,2 Mio.). Demnach wurden an die Niederlande aus allen vier Zonen Restitutionen in Höhe von 132,3 Mio., an Frankreich von 89,3 Mio. RM (1938) geleistet ${ }^{216}$. Gleichwohl war Frankreich mit dem „beachtlichen Umfang“ der Lieferungen aus den Westzonen zufrieden. In der Tat scheint es, daß Paris aufgrund der Erfahrungen nach dem Ersten Weltkrieg die erfolgreichere Strategie gewählt hatte. Nach der amtlichen Schlußbilanz hatte Frankreich bis 1950 Reparationen von 65 Mrd. Francs (1950) oder 270 Mio. RM (1938), aber Restitutionen von 134 Mrd. Francs (1950) oder 558 Mio. RM (1938) bezogen $^{217}$, so daß die Summe der Restitutionen doppelt so hoch lag wie die der (offiziell) empfangenen Reparationen. Zuletzt war es für Frankreich ohnehin attraktiver, mit Hilfe des Marshall-Plans die Chance zur Modernisierung wahrzunehmen, als in Deutschland nach veralteten Werkzeugmaschinen zu suchen.

\section{Reparationen aus laufender Produktion: Eine verpaßte Chance?}

Die Reparationen aus laufender Produktion wurden zum zentralen Konfliktpunkt zwischen den Westmächten und der Sowjetunion. Letztere hatte wenig Mühe, im Abschlußprotokoll von Yalta eine Kombination von einmaligen Kapitalgüter-Lieferungen und regelmäßigen Sachleistungen für zehn Jahre „als Diskussionsgrundlage“ zu verankern, da das den westlichen Planungen und Vorstellungen während der Kriegs-

${ }^{215}$ CP, S. 565. FRUS, 1948/II, S. 212, 745, $794 \mathrm{ff}$.

216 BA, Z 45 F/OMGUS, 2/116-3/1-6 (DRDR/P(47)151-154). Während die Niederlande ihre Ansprüche rasch eintrieben, dabei auf kleinere Posten im Interesse der Effizienz verzichteten, zog sich die Arbeit der Franzosen immer weiter hinaus, da sie Vollständigkeit anstrebten. Bei Automobilen leugneten die drei anderen Mächte nicht nur ein praktisches Interesse der Ursprungsländer, sondern verlangten auch den Nachweis, daß sie definitionsgemäß „mit Gewalt“ genommen worden waren. Das gelang ihnen bei 60.000 Automobilen, während sie von „mehreren hunderttausend“ ausgegangen waren. Bei den Eisenbahnen schätzten die Franzosen ihre Ansprüche auf 980 Lokomotiven, 68.000 Güterwagen und 1950 Personenwaggons im Wert von insgesamt rund $20 \mathrm{Mrd}$. Francs. Die Angelsachsen verlangten im Gegenzug die Rückgabe deutscher Schiffe und Waggons, die sie nicht als Reparationen anerkannten, und gaben nur 40.000 beschädigte französische Waggons zurück. Die SBZ reagierte in der Regel überhaupt nicht oder bestritt den angegebenen Aufenthaltsort.

217 AO Berlin/3273/2/2730, III (Bilan des Restitutions, 29. 5. 1947; Résumé Général, 1. 10. 1946 bis 1. 10. 1947, S. 7). Piettre, Economie, S. 125. Die Ansprüche der Briten aus der eigenen Zone waren bis Ende 1947 mit 135 Mio. RM zu 33\% erfüllt, mit 121 Mio. RM aus der amerikanischen Zone zu $39 \%$, mit 58 Mio. RM aus der französischen Zone zu 56\% und aus der SBZ zu 6,5\%. BA, Z 45 F/ OMGUS, 2/118-2/8-20 (CORC/P(46)277, 305, 322); 2/118-3/2-9 (CORC/M(47)49, 8. 12. 1947). 
zeit entsprach ${ }^{218}$. Zwar ließ die allmähliche Erkenntnis des Grundwiderspruchs zwischen industrieller Entwaffnung und Dismemberment einerseits, Reparationen aus laufender Produktion und europäischer Rekonstruktion andererseits die Westmächte zurückhaltend auf die sowjetische Forderung reagieren, daß die Hälfte der deutschen Reparationen aus der laufenden Produktion zu bezahlen sei; doch bezogen sich die Bedenken mehr auf eine starre quantitative Festlegung als auf das Prinzip an sich.

Der britische Malkin-Report war 1943 ganz selbstverständlich von Reparationen aus der laufenden Produktion ausgegangen. Die Probleme, die sich für die Wiederanknüpfung normaler Handelsbeziehungen und den Schutz der nationalen Industrie daraus ergeben könnten, wurden nicht übersehen; doch wollte man sich gegenüber den anderen Mächten nicht in Nachteil begeben, indem man auf diese Möglichkeit verzichtete. Insgesamt schienen die Vorteile zu überwiegen, so daß eine zwei- bis fünfjährige Lieferverpflichtung Deutschlands vorgesehen wurde. Im Juni 1945 beschloß das Kabinett, sich auf den Bezug bestimmter Rohstoffe und Halbprodukte zu konzentrieren, z. B. Kohle, Kali, Holz, Zement, Ziegelsteine und Stahl. Um einem Konflikt mit dem Prinzip der „ökonomischen Sicherheit“ auszuweichen, wollte man nun laufende Reparationen erst nach zwei Jahren einsetzen lassen, wenn die Demontagen und die ökonomische Entwaffnung abgeschlossen, die wirtschaftliche Grundsubstanz Deutschlands gesichert war. Dafür sollten die Reparationen über einen Zeitraum von zehn Jahren geliefert werden; nach fünf Jahren sei der Modus zu überprüfen ${ }^{219}$.

Auch in den USA vertraten die Planungsinstanzen bis August 1944 die Auffassung, „daß über die gesamte Zeit die große Masse der Reparationslieferungen aus der laufenden Produktion kommen muß, weil die Reparationen, die durch den Transfer von Kapitalgütern gewonnen werden könnten, in jedem Fall relativ gering wären, verglichen mit den aus der laufenden Produktion verfügbaren“. Im Interesse der baldigen Wiederherstellung normaler Handelsbeziehungen sollten die Lieferungen zeitlich beschränkt werden und die zeitliche Begrenzung Vorrang vor der zu liefernden Menge haben. Dabei war nicht daran gedacht, zerstörte Produktionsanlagen für die Herstellung laufender Reparationen in „extensivem“ Umfang wiederaufzubauen, so daß Deutschland am Ende der Reparationsperiode über modernere Produktionsanlagen verfügte als seine Nachbarn; nicht ausgeschlossen wurde „die Konversion statt der Demontage der Industriebetriebe, die jetzt der Kriegsanstrengung Deutschlands dienen, aber zum Wiederaufbau einer Friedenswirtschaft in Deutschland und zur Rekonstruktion Europas beitragen könnten" ${ }^{\text {"220 }}$. Derartige Vorstellungen waren Anlaß und Ansatzpunkt der Kritik Morgenthaus an der gesamten deutschlandpolitischen Planung. Statt Deutschland die Produktionskapazitäten für Reparationen aus laufender Produktion zu belassen, sollten diese zerstört oder für Lieferungen von Kapitalgütern demontiert werden; der Ausfall der deutschen Produktion werde automatisch Ersatzindustrien in den Nachbarländern entstehen lassen. Als Kompensation für die ausbleibenden deutschen Lieferungen wollte er den Gläubigernationen neben Arbeitsrepara-

218 FRUS, Malta and Yalta, S. $630 \mathrm{ff} ., 707,937,979,982 \mathrm{f}$.

219 PRO, FO 952/96 (Juli 1944); FO 371/46729/C104 (12. 1. 1945); FO 942/226 (APW Committee, 1. 2. 1945; APW(45)13, 26. 1. 1945). FRUS, Malta and Yalta, S. 885 (10. 2. 1945). Cairncross, Price, S. $29 \mathrm{f} ., 75 \mathrm{f}$.

220 FRUS, 1944/I, S. 278-99 (ECEFP D-37/44, 12. 8. 1944). NA, RG 59/Pauley, box 19 (IX. Decisions Reached, Second Draft, Gulick, 12.9. 1945, S. 39). 
tionen die Abtretung von Gebietsteilen oder Märkten anbieten ${ }^{221}$. Der Widerstand Hulls und Stimsons, die Deutschland langfristig in die Weltwirtschaft reintegrieren wollten, ließ die Frage zunächst in der Schwebe. Das State Department setzte sich schließlich mit seinen Vorstellungen durch: Deutschland sei zur Garantie eines minimalen Lebensstandards eine entsprechende Produktionskapazität zu belassen. Um eine neue Abhängigkeit der Gläubiger von deutschen Lieferungen zu vermeiden, waren laufende Reparationen nur „für eine möglichst lange Reparationsperiode mit jährlichen, periodischen, möglichst geringen Zahlungen“ vorgesehen, die allmählich auslaufen würden. Die amerikanische Delegation bei der Alliierten Reparationskommission wurde angewiesen, Lieferungen aus laufender Produktion lediglich ,aus politischen Gründen“ zu akzeptieren, also aus Rücksicht auf die anderen Reparationsgläubiger. Die Marge für Reparationen aus laufender Produktion war insofern gering; und diese sollten nur „in geringstmöglichem Maße“ aus Fertigwaren, sondern vor allem aus Rohstoffen bestehen, wie Kohle, Erze, Kali oder Holz ${ }^{222}$.

Der Potsdamer Reparationskompromiß erlaubte es den Westmächten, einer klaren Entscheidung auszuweichen. Diese Vertagung stärkte jedoch die Kräfte in den USA, die Lieferungen aus laufender Produktion prinzipiell ablehnten. Die Briten bedauerten bald, sich unter dem Einfluß der USA im Potsdamer Reparationspoker faktisch gegen Lieferungen aus laufender Produktion festgelegt zu haben, zumal sie bereits jetzt entschlossen waren, der Sowjetunion bei einer zonalen Aufteilung der Reparationsentnahmen keine Lieferungen aus laufender Produktion aus den Westzonen zuzugestehen $^{223}$. In den dreiseitigen Reparationsverhandlungen der Westmächte in Paris und in den Kontrollratsberatungen über den Industrieniveauplan kehrten sie zu ihren Vorstellungen vom Mai/Juni 1945 zurück, laufende Reparationen aus der „ÜberschußProduktion“ entweder für zehn Jahre mit einer Revision nach fünf Jahren oder für sechs Jahre ohne eine Revisionsklausel vorzusehen ${ }^{224}$. Trotz der prinzipiellen Entscheidung gegen Entnahmen aus der laufenden Produktion Ende November 1945 willigten die USA auf der Pariser Reparationskonferenz noch einmal, wenngleich zögernd, in derartige Lieferungen für fünf Jahre ein, jedoch unter dem strikten Vorbehalt, daß gemäß dem „first-charge-principle“ zunächst die Importe nach Deutschland bezahlt, das inzwischen entstandene Importdefizit und dann die Besatzungskosten abgedeckt werden müßten. Angesichts der sowjetischen Haltung in diesen Punkten waren solche Lieferungen damit faktisch, aber nicht grundsätzlich ausgeschlossen ${ }^{225}$. In ihrem Vorschlag zum Industrieniveauplan legten sich die USA endgültig darauf fest, „daß keine industriellen Produktionskapazitäten in Deutschland für den spezifischen Zweck verbleiben werden, Reparationen aus laufender Produktion zu liefern“226.

Das Ausbleiben einer Vereinbarung im Kontrollrat hinderte keine der Mächte, Entnahmen aus der laufenden Produktion in ihren Zonen vorzunehmen. Frankreich, wenngleich ohne konkrete Vorschläge, war nicht minder an laufenden Reparationen,

221 Hammond, Directives, S. 345, 350 ff., 363 f. Mai, American Policy.

222 NA, RG 59/EAC, box 3, folder: USGCC (Knapp an Murphy, 3.6. 1945). BA, Z 45 F/OMGUS, POLAD-TS/34/1-3 (29. 4. 1945). FRUS, 1945/III, S. 1223 (18. 5. 1945). AO, Berlin/3273/3/2731, I (Note, 11. 9. 1945).

223 DBPO, I, 1, S. $1070 \mathrm{f}$.

224 FRUS, 1945/III, S. 1386 f. FRUS, 1946/II, S. 900.

225 FRUS, 1945/III, S. 1389.

226 BA, Z 45 F/OMGUS, 2/132-2/14 (DECO/P(46)50). 
besonders an Kohle, interessiert, obwohl auch Paris den Widerspruch zwischen den Reparationen und der wirtschaftlichen Entmilitarisierung erkannte ${ }^{227}$. Von Beginn an hatte Paris solche Leistungen aus dem nach Abzug der Restitutionen und der VorabReparationen verbliebenen Potential als unverzichtbar reklamiert und kritisierte daher die Radikalität der sowjetischen Demontagen; diese verhinderten langfristig die Lieferung von Reparationen aus laufender Produktion ${ }^{228}$. Durch eine Kombination von sofortigen Kapitalgüterlieferungen und nachfolgenden laufenden Reparationen hoffte man der Gefahr zu entgehen, daß Deutschland ein umfangreiches, zudem noch modernisiertes Produktionspotential behielt. Zudem würde die Demontage wichtiger Werke nach einer Übergangsphase von fünf bis zehn Jahren der Reparationsproduktion kaum mehr durchsetzbar sein. Um eine rasche Lösung realisieren zu können, war Frankreich 1947 sogar bereit, einer sonst vehement zurückgewiesenen zentralistischen Lösung zuzustimmen: Nach Ausarbeitung eines gemeinsamen Plans sollten der Kontrollrat auf dessen Exekution verpflichtet und die Zonenkommandeure ihres Vetorechts beraubt werden ${ }^{229}$. Bis dahin hatten die Franzosen jede Gelegenheit genutzt, sich unilateral zu bedienen. Zwar bestritten sie entsprechende Entnahmen, indem sie diese als Kriegsbeute, Requisitionen oder Restitutionen deklarierten, gewisse Formen des „Ausgleichs“ für die Schäden der deutschen Besatzung wurden dennoch zugegeben; die Entnahmen würden gemäß Vereinbarung des Kontrollrats in die Dollar-Außenhandelsbilanz eingestellt und dienten der Bezahlung zonaler Importe. Die „versteckten Reparationen“ summierten sich nach eigenen Angaben bis März 1948 auf $\$ 336,715$ Mio. $^{230}$

Die Sowjetunion hatte auf der Potsdamer Konferenz bis zuletzt versucht, die zonale Aufteilung der Reparationen auf die einmaligen Entnahmen zu beschränken: „Die Entnahme von jährlichen Warenlieferungen aus der laufenden Produktion erfolgt nicht nach Zonen, sondern im gesamtdeutschen Rahmen."231 Denn sie würde, wie Maiski bekannte, ihre Forderungen aus der eigenen Zone nicht befriedigen können ${ }^{232}$. Sie mußte jedoch die Verankerung der reparationspolitischen Teilung Deutschlands

$227 \mathrm{AO}$, Berlin/3273/3/2731, I (Note Générale sur le problème des réparations, o.D., ca. Juli 1945; Note, 11. 9. 1945). BA, Z 45 F/OMGUS, USGCC/44-45/23/15 (1. 9. 1945).

228 AO, Berlin/3273/3/2731, I (26.6., 10. 8., 11. 9. 1945). AMAE, Y 363, Bl. 153 ff. (13. 10. 1945).

229 AN, 457 (Bidault) AP 60/IV (MAE, 25. 2. 1947); AP 61/V (Situation actuelle des réparations, ca. Anfang 1947, S. 46 ff.).

230 PRO, PREM 8/791 (C.P.(47)68, 20. 2. 1947, S. 12). 1945/46 erfolgten „einseitige Requisitionen“ (die ca. $10 \%$ der Industrieausrüstung der Zone betrafen), 1947 eine zweite Welle. AO, Berlin/3276/6/ 2020, I (16. 8. 1946); 3276/5/2019D (GFCC, 15. 10. 1947, Annexe L). PRO, FO 371/47002/C6258 und C6469. AMAE, Y 434, S. 37 ff. FRUS, 1946/V, S. 570 f., 582 ff., 596 ff. Abelshauser, Wirtschaft und Besatzungspolitik, S. 119, 127. Hinzu kamen Abschöpfungen in Form von Dienstleistungen oder durch Direktverkauf deutscher Produkte. Das Institut für Besatzungsfragen berechnete, inkl. der irregulären Requisitionen, Sach- und Werkleistungen von 2,225 bzw. 5,1 Mrd. RM/DM. Dazu kamen mindestens 1,4 Mrd. RM haushaltsmäßig nicht erfaßte Leistungen, so daß die französische Zone bis 1948 Leistungen von 6,5 Mrd. RM erbracht hatte. Frankreich zahlte nur $80 \%$ des Preises in Devisen, bei Lebensmitteln $70 \%$, und akzeptierte daher den sowjetischen Vorwurf, die Westmächte entnähmen selbst Reparationen aus laufender Produktion, indem sie nur „einen Bruchteil der Weltmarktpreise“ bezahlten. BA, Z 45 F/OMGUS, 2/109-2/19-20 (DECO/M(47)25, 5. 6. 1947; US-Protokoll 129. DECO, 29. 11. 1947); 2/118-3/2-9 (CORC/M(47)37, 16. 7. 1947). In Baden machten die gewerblichen Lieferungen (ohne Handwerk und Handel) mindestens $14,5 \%$ der Gesamterzeugung aus, in Rheinland-Pfalz $11 \%$ und in Württemberg-Hohenzollern $25 \%$. BA, B 120/ vorl. 272a, Bl. 155-61. Ludmann-Obier, Chemische Industrie, S. 95 ff.

231 DBPO, I, 1, S. 1014. Potsdamer (Berliner) Konferenz 1945, S. 344, 359 f.

232 DBPO, I, 1, S. 668 ff. (24. 7. 1945). 
im Potsdamer Abkommen akzeptieren, das ihr zwar in der eigenen Zone freie Hand beließ, jedoch Entnahmen aus der laufenden Produktion als Reparationsform nicht erwähnte, gleichwohl prinzipiell - wie die Briten im Kontrollrat zugestanden ${ }^{233}$ - auch nicht ausschloß. Die SMAD ging mit Befehl Nr. 128 vom 1. November 1945 systematisch zu Entnahmen aus der laufenden Produktion über, bereits jetzt auf ihre Unabhängigkeit von westlichen Lieferungen hinsteuernd: „Grundsätzlich soll nicht mit Lieferung von Zubehör- oder Fertigteilen aus dem Westen gerechnet werden. Derartige Fertigungen sind in der Sowjetzone neu aufzuziehen“, außer wenn es absolut unumgänglich sei. Für diese Zwecke durften nicht nur alte Rüstungsbetriebe eingesetzt werden, sondern auch bereits demontierte Maschinen, die noch nicht abtransportiert waren, und sogar die „Trophäenläger“ beschlagnahmter Rohstoffvorräte. Da die Mehrzahl der für die spezifischen Aufträge benötigten Betriebe bereits demontiert worden war, mußte mit Hochdruck der Neu- bzw. Wiederaufbau betrieben werden ${ }^{234}$. Westliche Forderungen, die Besatzungskosten zu senken und dem „first-charge-principle“ Rechnung zu tragen, wies Molotow auf der Pariser Außenministerkonferenz brüsk zurück und betonte statt dessen den absoluten Primat der Reparationen; angesichts der in Potsdam festgelegten Beschränkung der sowjetischen Reparationsansprüche auf die eigene Zone sei ein Rückgriff auf die laufende Produktion unvermeidlich ${ }^{235}$. Aber wenn die Sowjetunion Reparationen aus der laufenden Produktion entnehmen mußte, um ihren Anspruch auf $\$ 10 \mathrm{Mrd}$. an Reparationen auch nur annähernd realisieren zu können, und das auch nur in der eigenen Zone, dann hatte sie, das war den Briten klar, keine andere Wahl, als sich auf eine lange Besatzungszeit einzurichten ${ }^{236}$. Schließlich mußte man im Sommer 1946 den Widerspruch zwischen den Maßnahmen zur Entmilitarisierung und den Befehlen zum Wiederaufbau auch in Moskau zur Kenntnis nehmen. Dort entwickelte das Ministerium für Außenhandel unter der Federführung von Mikojan und Kolpakow (letzterer war zugleich stellvertretendes Mitglied des Wirtschaftsdirektorats in Berlin) neue Überlegungen, wie die geforderte Reparationssumme von $\$ 10 \mathrm{Mrd}$. doch noch realisiert werden könne: Nach ersten Sondierungen Kolpakows bei seinem amerikanischen Kollegen im Wirtschaftsdirektorat, Don Humphrey, Ende Juli trat Mitte August 1946 Sokolowski informell an Clay wegen der „möglichen Beifügung eines Programms aus laufender Produktion zum deutschen Reparationsprogramm“ heran ${ }^{237}$.

Auch wenn diese Offerte, angesichts des Scheiterns der Pariser Außenministerkonferenz, Ende August durch die Umstellung der sowjetischen Reparationspolitik desavouiert wurde, als ohne vorherige Information der SMAD und gegen alle Proteste

233 BA, Z 45 F/OMGUS, 2/132-2/13 (LOIC/M(45)11, 17. 12. 1945).

234 Matschke, Entwicklung, S. 201, 204 ff. Auf einer Besprechung mit der SMAD wurden am 20.11. 1945 Einzelheiten für die Lieferung von (jährlich) 20-30.000 Eisenbahnwaggons, Flußkähnen, 300 bis 500 Elektro-Schmalspurlokomotiven, 2-3000 Abbauhämmern für den Bergbau, Portalkränen, 500-1000 Automobilkränen sowie 30-50 Zementfabriken „mittlerer Größe“ und Siemens-MartinÖfen festgelegt. Gegen die Einwände der Ostdeutschen, weder über die Konstruktionszeichnungen noch über die Patente zu verfügen, teilte die SMAD diesen mit, die Zeichnungen aus dem Westen werde die Sowjetunion zur Verfügung stellen; „auf Patente braucht man keine Rücksicht zu nehmen“. BAP, G-2/1023 (1. und 27. 11. 1945).

235 FRUS, 1946/II, S. 846, 866.

236 PRO, FO 943/325 (Bevin, 17.6. 1946) und 308 (28. und 29. 8. 1946); FO 371/55843/C7729 (Franklin, 11. 7. 1946) und 55844/C7885 (12.7. 1946).

237 Laufer, Reparationspolitik, S. 12 f. FRUS, 1946/V, S. 593 f. Kindleberger, Letters, S. 6, 8, 10, 20, 57, 65 . 
der Ostdeutschen aus Moskau eine neue Demontagewelle angeordnet wurde ${ }^{238}$, so bewertete Clay das Angebot doch als das „ermutigendste Einzelereignis“ der bisherigen zwölfmonatigen Tätigkeit des Kontrollrats. „Wenn erst einmal eine grundsätzliche Übereinkunft erzielt ist, können die Sowjets wahrscheinlich dazu gebracht werden, der Beseitigung der meisten Hindernisse zuzustimmen, die jetzt die Wirtschaftseinheit verhindern.“ Die Überlegung, ob man „einen gewissen Preis“ bezahlen müsse, „um den gegenwärtigen toten Punkt mit den Sowjets in Berlin zu überwinden“, wurde akut $^{239}$. Nach westlicher Einschätzung war das Angebot weniger eine Reaktion auf die Bizone, als vielmehr Ausdruck der wirtschaftlichen Zwänge in der UdSSR, die ihren Bedarf aus der SBZ nicht zu decken vermochte ${ }^{240}$. Fast flehentlich beschwor Semjonow seinen Kollegen Heath, „daß die Frage der Einigung über die Wirtschaftseinheit eine relativ leichte sei, vorausgesetzt, daß die USA voll und ganz anerkennen, daß Rußlands großer Bedarf an Reparationen Vorrang vor allen Plänen einer wirtschaftli-

${ }^{238}$ PRO, FO 943/308. NA, RG 43/WWII\&PWConf, box 147, folder: State Department Briefs (Principal Economic Issues, 1st Revision; Memo \# 2). - Die SED protestierte im August 1946 gegen die Demontagen und Entnahmen, nachdem die Länder bzw. Provinzen vorstellig geworden waren. Ulbricht wurde nach Karlshorst mit der Forderung geschickt, die SMAD solle nur kontrollieren, sich aber aller Eingriffe in die Wirtschaft enthalten. ThHStA, MWA/420, Bl. $70 \mathrm{ff}$. Wenn die fortgesetzten Demontagen weiter als Kriegsbeute gewertet statt auf Reparationskonto verrechnet würden, müßten alle Länder und Provinzen in Karlshorst gemeinsam vorstellig werden. Falls die SMAD sich sperre, sei notfalls „die Angelegenheit dem Interalliierten Kontrollrat vorzulegen“. ThHStA, Büro des Ministerpräsidenten/1397, Bl. 7. Die SMAD gestand im September 1946 nach Protesten gegen die seit Frühjahr 1946 erfolgenden „Ersatzbeschlagnahmungen“ seitens regionaler SMAs (SAPMO, ZPA, IV/2/602/51) zu, sie habe sich "geirrt“ und die Reparationsauflagen „zu hoch“ angesetzt; sie versprach, die „Deckung für nicht erfülte Reparationsaufträge aus der zivilen Versorgung" für die Zukunft zu untersagen. BAP, G-2/1044, Bl. 121, 138, 158; G-2/8724, Bl. 150, 160 ff. Ende 1946 kamen neue Klagen. ThHStA, MWA/481, Bl. 196; 117, Bl. 49 f. Die sächsische SED protestierte gegen einen Befehl der SMA-Sachsen vom 16. 10. 1946, durch den zugunsten der sowjetischen Einkaufsorganisationen „die letzten leistungsfähigen Betriebe Sachsens für den zivilen Sektor" ausgeschaltet würden. In beiden Fällen wurde das ZK der SED aufgefordert, für die Aufhebung oder Modifizierung der Befehlsentwürfe Sorge zu tragen. SAPMO, ZPA, IV/2/602/8, Bl. 1, 39 ff. Daraufhin bemühten sich DWK und SED seit Herbst 1946, Einfluß auf die Gesamtplanung zu erhalten, die ihr erstmals Informationen über den „Bedarf“ der Sowjettruppen und die Sowjet AGs eröffnet hätte, die ihr bis dahin nach Äußerungen von SMAD-Offizieren ,auf keinen Fall zugänglich gemacht“ würden und sie „nicht zu bekümmern“ brauchten. BAP, G-2/8724, Bl. 97 (18. 12. 1946), 150 (24. 10. 1946); C-15/231, 510, 663, 664 und 665. Die Plandaten für 1947 waren von der SMAD durch Befehl Nr. 306 ohne Rücksprache mit den Deutschen nach Beratungen der zuständigen Abteilungen in Moskau festgelegt worden. SAPMO, ZPA, IV/2/602/53, Bl. 1-12. BAP, G-2/8724, Bl. 119. „Der Produktionsplan 1947 für die Eisen verarbeitende (Schwer-)Industrie stellt im wesentlichen einen Reparationsplan dar“; $82 \%$ der Planerzeugung im Maschinenbau, dem Fahrzeug- und Apparatebau, bei Eisen- und Metallwaren waren betroffen. BAP, G-2/1044, Bl. 58 (Hervorhebung im Original). Obwohl den Deutschen Zugeständnisse gemacht werden mußten, da die SAG-Betriebe in die Produktionspläne der Länder und Provinzen aufgenommen werden sollten, rissen die Debatten nicht ab. Bei der Vorbereitung der Pläne gab es „wesentliche Differenzen“ zwischen den deutschen und sowjetischen Vorstellungen, nicht zuletzt wegen der „verdeckten $\mathrm{Re}$ parationsleistungen in den einzelnen Ländern und Provinzen“, die "hohe Beträge“ ausmachten, aber nicht in das „Gesamtabführungssoll“ eingesetzt wurden. G-2/8724, Bl. 177; C-15/231 (11. 12. 1947). BAC, N-1/2079-5, Bl. 6 (DZFV und Länderregierungen, 29. 1. 1947). Vergeblich versuchten die Deutschen im Sommer 1947, Sokolowski auf seine öffentliche Erklärung vom 13.1. 1947 festzulegen, die Entnahmen seien „erheblich“ herabgesetzt worden. L-1/301, Bl. $1 \mathrm{f}$. Obwohl die SMAD den Forderungen nach einem Gesamtplan entgegenzukommen versprach, waren die Auseinandersetzungen um die „Verteilungszuständigkeiten“ noch Anfang 1948 nicht ausgeräumt. BAP, G-2/1090.

239 Krieger, Clay, S. $192 \mathrm{f}$.

240 AO, Berlin/3273/3/2731, I (29. 7. 1946); 3276/5/2019 (Humbert-Rudenko, 27. 1. 1947). Krieger, Clay, S. $189 \mathrm{f}$. 
chen Wiederbelebung Deutschlands haben müsse“241. Nur vereinzelt sahen amerikanische Stimmen in dem Angebot einen Versuch der Sowjetunion, über die zehnjährige Lieferverpflichtung einen indirekten Einfluß auf die westdeutsche Industrie zu gewinnen; doch auch ihnen schienen die Vorteile für den Westen zu überwiegen. Sehr schnell erhielt Clay die Zustimmung von Byrnes, mit den Sowjets in Gespräche einzutreten, „vorausgesetzt, daß die Gesamtsumme nicht zu hoch sei“. In dem Sinne verhandelten Draper und sein Stellvertreter Humphrey mit ihren Kollegen Kowal und Kolpakow vom Wirtschaftsdirektorat, an deren Ende letztere ein Angebot vorlegten, das OMGUS als „vernünftige Diskussionsgrundlage“ akzeptierte ${ }^{242}$.

Gemäß dem sowjetischen Vorschlag sollte das Grundprinzip des Industrieniveauplans erhalten bleiben, doch könnten die Demontagen für zehn Jahre ausgesetzt werden, um die Kapazitäten für Reparationen aus laufender Produktion zu nutzen. Voraussetzung sei, daß sie aus dem gesamtdeutschen Potential erbracht und zwischen der Sowjetunion und Polen einerseits, den IARA-Ländern andererseits unter Verrechnung der Auslandsguthaben und Kapitalgüterlieferungen aufgeteilt würden; daß die Empfänger die Rohstoffe zur Verfügung stellten, „bis Deutschland eine positive Handelsbilanz hat und diese selbst bereitstellen kann"; daß der Kontrollrat die Liefermenge bestimmte und entsprechend den Industrieniveauplan anpaßte; daß deutsche Zentralverwaltungen errichtet würden, „besonders eine, die für die Ausführung der Vereinbarung über Reparationen aus laufender Produktion verantwortlich ist“ (deren Errichtung sie eben noch selbst verhindert hatte ${ }^{243}$ ); daß ,jede zonale Kontrolle in wirtschaftlichen Fragen beseitigt wird, außer daß die Zonenkommandeure weiterhin für die Entnahme von Kapitalgüter-Reparationen verantwortlich sind“; daß ein gemeinsames Import-Export-Programm für ganz Deutschland aufgestellt werde; daß die Westmächte den Lieferstopp für Kapitalgüter aufhöben ${ }^{244}$. Das war ein weitreichendes Angebot, das Stalin im Vorfeld der Moskauer Konferenz auch der SED annoncierte und das die wichtigsten Hindernisse der Wirtschaftseinheit ausgeräumt hätte soweit nicht in den Verhandlungen neue Hemmnisse aufgetaucht wären, etwa im Hinblick auf die kaum vermeidbare Öffnung der SBZ. Aber, das hatten die Westmächte zur Kenntnis genommen: „Ein Wirtschaftsplan, der Reparationen aus laufender Produktion einschließt, ist eine sowjetische Bedingung für die Einigung." ${ }^{245}$

Die sowjetische Offerte traf sich mit amerikanischen Überlegungen. Washington sah sich vor der Grundsatzentscheidung, ob man der Sowjetunion ein Angebot machen sollte, das deren wirtschaftlichen Bedürfnissen wie ihrem Prestigebedürfnis entgegenkam, oder ob man ihre Abhängigkeit von den Reparationen, ihre Erpreßbarkeit nutzen sollte, um abermals einen Versuch zu unternehmen, sie zur Kooperation zu zwingen. Es war Clay, dessen Reparationsstopp im Mai 1946 für eine Verhärtung der Lage gesorgt hatte, der nun dafür plädierte, der Sowjetunion (und Frankreich) die Wiederaufnahme der Reparationslieferungen anzubieten, wenn diese in der Frage der Wirtschaftseinheit zu Zugeständnissen bereit waren. In Washington wurden solche

241 NA, RG 59, 740.00119 Control(Germany)/11-1246.

242 FRUS, 1946/V, S. 602 f., 622 (Zitat).

243 Vgl. oben S. $109 \mathrm{ff}$.

244 TL, Tenenbaum Papers, box 5, folder: currency reform (8), (Reparations from current production and present economic policy, 31. 10. 1946). FRUS, 1946/V, S. 621-25.

245 BA, Z 45 F/OMGUS, 2/102-3/5 (CONL/M(47)2, Appendix ,B', 20. 1. 1947; CORC/P(47)1/3, Tab ,A': US-Brief, 27. 1. 1947). PRO, PREM 8/791 (C.P.(47)68, 20. 2. 1947, S. 11). 
Überlegungen nicht rundweg abgelehnt, ob die USA in dieser Frage durch eine „konstruktivere" Politik auf die sowjetischen Wünsche eingehen sollten, zumal die Gefahr bestand, daß sich bei einem anhaltenden Stopp der Kapitalgüterlieferungen die kleinen Gläubigerländer der sowjetischen Forderung nach Reparationen aus laufender Produktion anschließen würden ${ }^{246}$. Auf diesem Gebiet schien der deutschlandpolitische Durchbruch möglich: Konnte die Sowjetunion durch Zugeständnisse in der Reparationsfrage zur Kooperation bewegt werden, dann würde sich auch Frankreich einer pragmatischen Lösung nicht länger entziehen können. Bemerkenswerterweise sah Clay die Sowjet AGs nicht als gravierendes Hindernis an ${ }^{247}$. Er und Draper waren noch nicht bereit, das Potsdamer Abkommen und den Industrieniveauplan aufzukündigen und damit „die Tür zur Einigung“ zuzuwerfen, sie glaubten sich angesichts des Bedarfs der anderen Reparationsgläubiger allerdings auch in einer guten Verhandlungsposition. Das Zugeständnis von laufenden Reparationen hätte die Schwierigkeit überwinden können, die Vier-Mächte-Einheit trotz Bizone aufrechtzuerhalten. Doch Clay wollte die Wirtschaftseinheit bzw. die Anerkennung des „first-charge-principle“ als Gegenleistung einhandeln, während Murphy noch immer hoffte, mit Hilfe der Reparationen aus laufender Produktion die SBZ westlichem Einfluß öffnen und die Wiederzulassung der SPD, Pressefreiheit oder andere politische Grundrechte für die SBZ eintauschen zu können. Beide suchten daher nach Wegen, Garantien für die uneingeschränkte Umsetzung einer möglichen Vereinbarung einzubauen: ein gemeinsames Budget für Besatzungskosten; Währungsreform; politische Freiheiten im westlichen Sinne für die SBZ, darunter die Wiederzulassung der SPD. „So sollten wir versuchen“, drängte Murphy seit Mitte Oktober wiederholt, „zusätzlich zur wirtschaftlichen und finanziellen Einheit zugleich auch wichtige politische Ziele zu erreichen. Das könnte unsere letzte Gelegenheit sein, solch eine machtvolle Verhandlungsposition in Deutschland für diese Zwecke zu nutzen.“248 Zumindest aber schien ein Arrangement auf diesem Gebiet als Lockmittel oder Trumpfkarte in dem Verhandlungspoker auf der bevorstehenden Moskauer Außenministerkonferenz geeignet. Obwohl Clay sich Ende Oktober 1946 optimistisch über die Kompromißchancen äußerte und Anfang November Byrnes in einem Privatbrief warnte, ein Scheitern der Verhandlungen werde „die Spaltung Deutschlands bedeuten “249, machten das Mißtrauen gegenüber der Sowjetunion und die Überschätzung der eigenen Position, also politisch-taktische Überfrachtung, den prekären Ansatz zu einer pragmatischen Minimallösung von vornherein zur Illusion. Denn auch bisher hatte die Sowjetunion es stets vorgezogen, lieber im Inneren ökonomisch zurückzustecken, als sich nach außen politisch durch Verflechtung zu binden.

Das reparationspolitische Angebot der Sowjetunion stellte die USA vor eine Grundsatzentscheidung, da die Zustimmung zu Reparationen aus der laufenden Produktion nicht nur eine völlige Neuorientierung der eigenen Politik, sondern auch „die Ausweitung und mögliche Neuformulierung des Potsdamer Abkommens" bedeutet

246 NA, RG 59/OWEA, Misc. German Files, box 2, folder: Germany, Basic Papers (Claxton an Hilldring, 10. 10. 1946).

247 NA, RG 59, 740.00119 Control(Germany)/11-146 und /1-947.

248 NA, RG 59, 740.00119 Control(Germany)/11-1446 (Anlage: Murphy an Byrnes, 25. 10. 1946); RG 43/WWII\&PWConf, box 43, folder: Germany II (Murphy, 16. 10. 1946; Acheson an Marshall, 9. und 10.12. 1946). FRUS, 1946/V, S. $624 \mathrm{f}$.

249 CP, S. 282. 
hätte. Die Aufhebung der Zonengrenzen konnte erst auf lange Sicht zu gesteigerter Produktivität und Selbstversorgung führen, so daß die Westmächte zwischenzeitlich die Überbrückungsfinanzierung für die deutschen Importe und damit für die Reparationslieferungen an die Sowjetunion hätten übernehmen müssen. Ob das wünschenswert oder innenpolitisch durchsetzbar sei, schien zweifelhaft. Mißtrauen bestimmte insofern auch das Verhalten der USA in den folgenden Gesprächen, zumal die Prioritätensetzung zwischen Washington und OMGUS umstritten blieb. Die von Clay und Murphy entwickelten Vorstellungen fanden in Washington eine positive Resonanz bei denen, die im Interesse der Einheit eines neutralen, selbstversorgenden Deutschland der Sowjetunion entgegenzukommen empfahlen. Nur wenn man deren deutschlandpolitische Prioritäten, nämlich Sicherheit und Reparationen, ernst nehme, werde man zu einer tragfähigen Lösung gelangen. Claxton schlug vor, die Sowjets sollten zwei bis drei Jahre ihre Ansprüche aussetzen, bis Deutschland eine ausgeglichene Handelsbilanz erreicht habe. Humphrey erarbeitete einen Entwurf, der Lieferungen im Wert von \$ 7,5 Mrd., verteilt auf zehn Jahre, vorsah; Leistungen im großen Stil seien erst nach fünf Jahren möglich, und auch nur dann, wenn der Industrieniveauplan revidiert, die Importe vorfinanziert und die Demontagen reduziert würden ${ }^{250}$. Dagegen sprach sich das von Byrnes eingesetzte Deutschlandkomitee prinzipiell gegen laufende Reparationen aus, sondern empfahl Ersatzlösungen, wie erweiterte Kapitalgüterlieferungen, Streichung der sowjetischen Gegenlieferungen, im äußersten Fall ein Programm von Veredelungsarbeiten ${ }^{251}$. Der inoffizielle Gegenvorschlag, der der SMAD am 11. Oktober übermittelt wurde, enthielt keine politischen Bedingungen im Sinne Clays oder Murphys, aber Moskau blieb mißtrauisch, nachdem Byrnes in seiner Stuttgarter Rede Reparationen aus laufender Produktion in Frage gestellt hatte. Beide Seiten entschieden sich, die Verhandlungen auf der inoffiziellen Ebene zu belassen und auf den Rat der Außenminister im November zu vertagen. Während Semjonow und Smirnow den USA die Absicht unterstellten, die Potsdamer Reparationsbeschlüsse revidieren zu wollen, riet in Berlin Sokolowski zur Fortsetzung der Sondierungen, da ,wir aus unserer Zone, infolge von ernsthaften Schwierigkeiten und Unzulänglichkeiten der Produktionskapazität, nicht Lieferungen im notwendigen Umfang finden können “252

Die Briten waren alarmiert von der Aussicht eines deutschlandpolitischen Arrangements mit der Sowjetunion. Nachdem sie von Clay am 17. August eingeweiht worden waren, hatte die Regierung in London sich binnen vier Tagen entschieden, daß der Plan ,inakzeptabel“ sei $^{253}$. Sie hoffte, durch eine Verweisung dieser Frage an die Außenminister die seit langem angestrebte Revision des Potsdamer Abkommens einleiten zu können. Das Mißtrauen gegenüber der langfristigen Kompromißbereitschaft der Sowjetunion war so groß, daß die Wiederzulassung der SPD in der SBZ kein erheblicher Gewinn schien ${ }^{254}$. Zeitweise befürchtete auch die französische Regierung eine Übereinkunft zwischen den USA und der Sowjetunion, so daß sie durch gezielte Indiskretionen die Verhandlungen in die Öffentlichkeit zu bringen und dadurch zu

250 NA, RG 59, 740.00119 Control(Germany)/11-446. Krieger, Clay, S. 192 f.

251 NA, RG 59, 740.00119 Control(Germany)/9-1546 (Report, S. 32 ff.).

252 Zitiert nach: Laufer, Reparationspolitik, S. 16 f., 20.

253 Ebenda, S. 14. PRO, FO 371/55590/C9966.

254 FRUS, 1946/V, S. 650 f. NA, RG 59, 740.00119 Control(Germany)/12-546. PRO, CAB 129/17 (C.P.(47)68, 20. 2. 1947). 
torpedieren versuchte ${ }^{255}$. Doch angesichts der amerikanischen Vorbehalte und Vorbedingungen hielten die Franzosen bereits Anfang November die Chancen eines „russisch-amerikanischen Abkommens" für nicht sehr groß, wenngleich sie mit Bedenken den prinzipiellen Konsens ihrer drei Partner im Hinblick auf eine Erhöhung des Industrieniveaus zur Kenntnis nahmen ${ }^{256}$.

Gleichwohl wurde das sowjetische Angebot in Washington und London als so weitreichend erachtet, daß Robertson und Clay sowie die Politischen Berater angewiesen wurden, eine Stellungnahme zu erarbeiten, unter welchen Bedingungen ein Kompromiß akzeptabel sei. In ihrem Bericht vom 5. Dezember 1946 listeten diese neben ökonomischen Fragen (Export-Import-Programm, Währungsreform, Besatzungskosten, Aufhebung der Handelsschranken zwischen den Zonen) auch politische Bedingungen auf (Pressefreiheit, Reisefreiheit, freie Wahlen, Zentralverwaltungen, deutsche Zentralregierung). Auf dieser Grundlage sowjetischer Vorleistungen sollte das Arrangement für laufende Reparationen entwickelt werden, das der Sowjetunion die Zustimmung zur Erhöhung des Industrieniveaus abverlangte, die Offenlegung der ,industriellen Situation" der SBZ, eine Begrenzung der Besatzungstruppen und damit der Besatzungskosten, bis eine leistungsfähige und ,ausgewogene“ Wirtschaft in Deutschland wiederhergestellt sei. Das kam der Aufforderung zur Kapitulation gleich, zumal die Autoren des Berichts mißtrauisch blieben und lediglich eine Prüfung der sowjetischen Vorschläge im Kontrollrat empfahlen, „ohne sich hinsichtlich ihrer Annahme zu verpflichten. [...] Erst wenn eine solche Prüfung abgeschlossen ist, wäre es möglich, die Kosten abzuschätzen, die die sowjetischen Angebote mit sich bringen, und demzu-

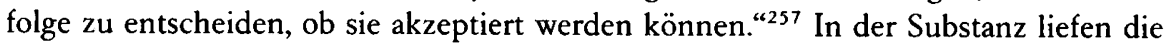
anglo-amerikanischen Forderungen darauf hinaus, daß die Sowjetunion zunächst faktisch auf alle Ansprüche verzichten und sich im Gegenteil an den Kosten beteiligen müsse; erst wenn Deutschland saniert und leistungsfähig gemacht worden sei, würde sie Reparationen aus laufender Produktion erhalten. Das mochte ökonomisch sinnvoll sein, soweit es die wohlhabenden Amerikaner betraf, doch bedeutete es für die ausgeblutete Sowjetunion eine nicht akzeptable Zumutung, sofern nicht zwischenzeitlich andere Finanzierungsquellen, also westliche Kredite, bereitgestellt wurden.

In den nachfolgenden Sondierungsgesprächen blieben die Reparationen aus der laufenden Produktion für die USA als deutschlandpolitisches Handelsobjekt interessant, zumal nachdem Kowal am 19. Dezember 1946 gegenüber seinem Kollegen Draper hatte durchblicken lassen, daß bei einer Einigung nicht nur die Import-Export-Frage gelöst werden könne, sondern auch eine Globallösung für die Wirtschaftseinheit, inkl. Zentralverwaltungen und Revision des Industrieniveauplans, möglich sei. Bei einer Fortsetzung der Gespräche am 21. Januar 1947 bestätigte Kowal das Angebot mit Rückendeckung seiner Vorgesetzten. Zwar glaubte er, daß „die Zeit für deutsche Zentralverwaltungen vorbei sei und daß sie allein nicht genügen würden“, sondern daß „die provisorische Regierung aus reiner Notwendigkeit geschaffen werden wird“, allerdings „unter der Kontrolle der Alliierten Kontrollbehörde“; doch blie-

255 AO, Berlin/3273/3/2731, I (Glasser-Kolpakow, 7. 10. 1946); 3282/4/2120B (26. 10. 1946). AMAE, Y 288, Bl. 391 ff.; Y 289, Bl. 45, 84 f.; Y 377, Bl. 358 ff. Backer, Clay, S. 178 f. Ende Oktober, Anfang November 1946 berichtete die New York Times über die Kontakte. Krieger, Clay, S. 193.

256 AMAE, Y 289, Bl. 66 ff. (Chauvel, 6. 11. 1946), 130 (Saint-Hardouin, 15. 11. 1946); Y 378, Bl. $1 \mathrm{f}$ (Bonnet, 17. 11. 1946).

257 NA, RG 43/WWII\&PWConf, box 187, folder: Economic Unity. 
ben in Kowals Position die sowjetischen Vorbehalte erkennbar. Drapers Programm für die Herstellung der wirtschaftlichen und politischen Einheit in etwa drei Monaten schien ihm einerseits „Zu kühn“; andererseits erklärte er die Zeit der kleinen Schritte für überwunden. Hier kündigte sich bereits die sowjetische Verhandlungsposition wenig später auf der Moskauer Außenministerkonferenz an. Offenkundig wollten die Sowjets erst die ökonomische Einheit herstellen, d. h. ihre Reparationsansprüche gesichert sehen, ehe sie einer provisorischen Regierung zustimmten. Das hielt die Befürchtungen wach, die Sowjets wollten ihre Interessen „in der gegenwärtigen Konstellation", also bei separater Zonenverwaltung, realisieren, und verstärkte zugleich die Überzeugung, diese seien so verzweifelt auf Reparationen angewiesen, daß sie um fast jeden Preis Zugeständnisse machen müßten ${ }^{258}$.

Die Entscheidung mußte auf der Moskauer Außenministerkonferenz im März 1947 fallen. In informellen Gesprächen am Rande der Konferenz zeigte sich Marshall bereit, „einen Preis für die Einheit Europas zu zahlen. [...] Marshall schien zu denken, daß es möglich sei, mit den Russen einen Handel zu machen, indem er laufenden Reparationen zustimmte gegen Konzessionen hinsichtlich der polnische Westgrenze. ${ }^{\text {259 }}$ Trotz aller Hoffnungen des amerikanischen Außenministers auf einen allgemeinen Ausgleich waren die amerikanischen (und britischen) Überlegungen mit derart weitreichenden Vorbehalten versehen, daß an eine Zustimmung der Sowjetunion kaum zu denken war $^{260}$. Marshalls Konzept, zunächst die Wirtschaftseinheit zu realisieren, auf dieser Grundlage ein Export-Import-Programm zu entwickeln, dazu den Industrieniveauplan zu revidieren, um erst im letzten Schritt Reparationen in Betracht zu ziehen, kehrte die politischen wie die ökonomischen Akzente des sowjetischen Vorschlags um. Clay warnte vor übereilten, rein ökonomisch motivierten Entschlüssen; ein Scheitern der Verhandlungen über laufende Reparationen könne dazu führen, „unseren Einflußbereich an der Elbe enden zu lassen statt an der Oder-Neiße“. Auch angesichts des westeuropäischen Rekonstruktionsbedarfs sei zu erwägen, ob nicht zumindest ein Reparationsprogramm in Form von Veredelungsarbeiten denkbar sei. Clay trug seine Empfehlung, „im Laufe der Verhandlungen könnte es nötig sein, in dieser Frage Kompromisse zu schließen, um die sowjetische Zustimmung in anderen Fragen zu gewinnen“, am 5. März 1947 zwar mit „größter Zurückhaltung“ vor, diese beruhte aber auf dem Eindruck, daß eine Revision der sowjetischen Reparationspolitik eingesetzt habe ${ }^{261}$. Noch traf Clay in Washington auf offene Ohren, weil das State Department im Hinblick auf die westeuropäische Rekonstruktion zu der Überzeugung gelangt war, daß der Industrieniveauplan auf eine „planmäßige permanente Depression“ in Deutschland hinauslaufe und „der derzeitige niedrige Umfang des deutschen AuBenhandels einer der wichtigsten Faktoren für die heutige Wiederbelebung autarker

258 NA, RG 43/WWII\&PWConf, box 187, folder: Misc., Economics.

259 Zitiert nach: Deighton, Impossible Peace, S. 148 (Dixon diary, 23. 3. 1947). PRO, FO 800/466/Ger/ $47 / 2$ und 12 (21.3. 1947); 502/SU/47/36 (8. 4. 1947) und 38 (15.4. 1947); PREM 8/702 (23.3. 1947).

260 Nach britischen Informationen riet die SMAD ihrer Regierung, die Frage der laufenden Reparationen auf der Moskauer Außenministerkonferenz nicht vorzutragen, da keine Erfolgsaussicht bestehe. PRO, FO 371/64305 (An Appreciation of the Economic Position in the Soviet Zone). Moskau hatte bei der SMAD Auskunft über die bisherigen Entnahmen (\$ 3 Mrd.) angefordert, um auf der Konferenz westlichen Informationsforderungen nachkommen zu können. Kessel, Westeuropa, S. 173.

261 NA, RG 43/WWII\&PWConf, box 186, folder: Analysis of the German Problem and Comments on State Department Working Papers (OMGUS, 5. 3. 1947). 
Tendenzen in ganz Europa“ sei. Obwohl prinzipiell laufenden Reparationen abgeneigt, zeigte man sich zögernd bereit, diese „als einen letzten Ausweg“ zu akzeptieren $^{262}$. Dagegen herrschte in der amerikanischen Delegation auf der Moskauer Außenministerkonferenz die Überzeugung vor, die Sowjetunion könne sich ein Scheitern der Konferenz wegen der Reparationsfrage nicht leisten. Da diese einen „taktischen Rückzug"von ihren bisherigen Positionen zu suchen schien, glaubte man, daß ein Entgegenkommen nicht erforderlich sei: „Die Sowjets sind mit dem Dilemma konfrontiert, daß sie, wenn Deutschland gespalten bleibt, keine Reparationen aus dem Westen erhalten werden; aber wenn Deutschland auf der Grundlage eines Generalabkommens vereinigt wird, werden sie ihre Forderung nach ausgedehnten Reparationen aus laufender Produktion aufgeben und der Beteiligung am nationalen Defizit zustimmen müssen.“263

Angesichts der verhärteten Fronten auf der Moskauer Außenministerkonferenz sowie angesichts der Zusammensetzung der amerikanischen Delegation sanken die Chancen für die Vorstellungen Clays, die Außenminister sollten den Kontrollrat anweisen, die Folgekosten verschiedener Modelle von Lieferungen aus laufender Produktion durchzurechnen. Clay erlitt in Moskau mit seinem Vorstoß, „daß wir den Russen einige laufende Reparationen geben sollten, um die Wirtschaftseinheit zu erkaufen“, eine „krachende Niederlage“. Er war so verärgert, daß er sich unter vier Augen selbst gegenüber Sokolowski darüber beschwerte. Letztlich waren die USA unter dem Einfluß von Dulles, Bohlen und Kindleberger nicht bereit, von ihrer prinzipiellen Linie abzuweichen, das Potsdamer Abkommen gestatte keine laufenden Reparationen bzw. nicht unter den von den Sowjets verschuldeten Bedingungen in Deutschland. Das sowjetische Angebot, das Industrieniveau zu erhöhen, falls dafür Reparationen aus laufender Produktion geliefert würden, lehnte Marshall zwar nicht rundweg ab; aber die Anweisung Trumans vom 1. April, keine laufenden Reparationen zu akzeptieren, ließ seinen Verhandlungsspielraum sehr eng werden. Marshalls Einverständnis, den Nexus von Industrieniveau und laufenden Reparationen unter gewissen Bedingungen (Ausgleich der Zahlungsbilanz, keine Kohlelieferungen, kein Hinauszögern der Rückkehr zur Selbstversorgung) wenigstens in einigen Teilbereichen als eine Art Entschädigung für die entfallenden Kapitalgüterlieferungen zu akzeptieren, erfolgte nur noch in der Erwartung, daß die Sowjetunion das als ungenügend ablehnen werde; denn die hatte unmißverständlich erklärt, „die Billigung von Reparationen aus laufender Produktion ist eine kategorische Bedingung dafür, daß die sowjetische Delegation das Prinzip der wirtschaftlichen Einheit Deutschlands akzeptiert“264. Schließlich wich Marshall einer Entscheidung aus und schob diese den Briten bzw. Washington $\mathrm{zu}^{265}$. Daß die Entscheidung der USA letztlich negativ ausfiel, war besonders dem Argument zu verdanken, Lieferungen aus laufender Produktion würden nicht nur die Gefahr der indirekten amerikanischen Finanzierung heraufbeschwören, sondern auch

262 TL, Papers of Paul A. Porter, box 1, folder: Criticism (The German Problem in the Light of Soviet Policy, 22. 8. 1946; Notes of some economic consequences of Allied occupation policy in Germany, o.D.). NA, RG 59, 740.00119 Control(Germany)/10-146. CP, S. 283.

263 NA, RG 43/WWII\&PWConf, box 191, folder: Moscow Misc. (19. 3. 1947).

264 NA, RG 59/CED, box 2 (Department of State, The German Reparations Program, 28. 12. 1948, S. 8). FRUS, 1947/II, S. 301-06. PRO, CAB 21/1874 (Bevin aus Moskau, 8. 4. 1947). Kindleberger, Letters, S. 154.

265 Kindleberger, Letters, S. 153, 157 f., 160, 169, 179 f., 184, 190 f. 
die Dauer des Reparationsprogramms ausdehnen und eine Rückkehr zum normalen Handel unerträglich verzögern. Mehr und mehr setzte sich die Überzeugung durch, daß das gesamte Reparationsprogramm für Deutschland und Europa ein wirtschaftlicher Fehlschlag sei und eine Wiederaufnahme nur das sowjetische Rüstungspotential stärken werde. Diesen falschen Weg abzubrechen, war vielversprechender als neue Experimente einzugehen ${ }^{266}$. Auch kann nicht ausgeschlossen werden, daß das amerikanische Nein angesichts der eigenen Ratlosigkeit der einfachste Ausweg war, neue komplizierte Verhandlungen zu vermeiden und innenpolitisch Pluspunkte zu sammeln. In jedem Fall konnte man die Sowjets für ihre mangelnde Kooperationsbereitschaft bestrafen. Zwar wollten sich die USA, solange sie sich trotz aller Vorbehalte an das Potsdamer Abkommen gebunden fühlten, Reparationen nur an Ost und West gleichermaßen liefern, doch wurden dafür gegenüber der Sowjetunion Bedingungen formuliert, die diese nicht akzeptieren konnte. Man kann sich des Eindrucks nicht erwehren, daß die Unvereinbarkeit mit den politischen und den wirtschaftlichen Bedürfnissen der Sowjetunion, die diese Bezüge fest in ihre Wirtschaftspläne eingebaut hatte, nicht unbeabsichtigt war, in jedem Fall aber in Kauf genommen wurde.

Denn bemerkenswerterweise wollten die USA bei den frühen Beratungen des Marshall-Plans Lieferungen aus der laufenden Produktion an die kleineren westeuropäischen Staaten keineswegs prinzipiell ausschließen. Dort machten sich gegen die Einstellung der Reparationslieferungen erhebliche Vorbehalte bemerkbar. Dem suchten die USA Rechnung zu tragen, indem sie einerseits das durch den Reparationsstopp vom Mai 1946 unterbrochene Lieferprogramm reiner Rüstungsbetriebe abzuschließen ankündigten und andererseits im Rahmen des Marshall-Plans ein „begrenztes“ Programm von Lieferungen aus der laufenden Produktion in Erwägung zogen. Derart sollte der Wiederaufbau Westeuropas durch eine Mischung aus deutschen Reparationen und amerikanischem Kapital beschleunigt werden: aus Kostengründen ebenso wie aus Rücksicht auf die politische Psychologie. Bei einer endgültigen Einstellung der Kapitalgüterlieferungen war zu befürchten, daß die Gläubigernationen verstärkt auf laufende Reparationen drängten, „ohne Rücksicht auf die Kosten für die deutsche Wirtschaft und indirekt für die USA“267. Die Westeuropäer waren längst zu der Überzeugung gelangt, daß ihnen die Lieferung von Kapitalgütern nur geringe Vorteile bot, da der Zeitverlust von zwei bis fünf Jahren durch Demontage und Wiederaufbau wirtschaftlich unvertretbar war, zumal geschätzte $50-80 \%$ der Kapitalgüter nach der Demontage nur noch Schrottwert hatten. Demgegenüber schienen, wie Außenminister Marshall am Rande der Moskauer Außenministerkonferenz zu bedenken gab, laufende Reparationen nicht nur eine Soforthilfe in der akuten Not zu versprechen, sondern auch die Forderungen nach amerikanischen Krediten zumindest zu begrenzen ${ }^{268}$. Der Hauptteil der Reparationen aus der laufenden Produktion

266 TL, Papers of Paul A. Porter, box 1, folder: Criticism (Notes of some economic consequences of Allied occupation policy in Germany, o.D.). NA, RG 59, 740.00119 Control(Germany)/8-2247 (Edelstein an Saltzman). FRUS, 1947/II, S. 265, 977-82, 1055. NA, RG 335, box 42, folder: 091.3 Germany/Rehabilitation (State Department, 21. 9. 1948). PRO, FO 371/71093.

267 NA, RG 59/ASSOA, box 1, folder: Germany Place (Hilldring an Claxton, 18.6. 1947); ebenda, box 5, folder: 8031.2 (Pauley an Marshall, 14. 2. 1948). FRUS, 1947/II, S. 110, $391 \mathrm{ff} ., 1116 \mathrm{f}$. PRO, FO 942/476 (8. 4. 1946).

268 Mai, American Policy, S. $91 \mathrm{f}$. 
sollte jedoch in der Form von Veredelungsarbeiten erfolgen; die Reparationsgläubiger hätten Rohstoffe, Brennstoffe und Lebensmittel zur Verfügung stellen, Auskunft über ihre bisherigen Entnahmen geben und sich mit einer fixen Restsumme einverstanden erklären müssen.

Überzeugt, daß das Potsdamer Reparationsprogramm gescheitert sei, waren längst die Briten. Es gab daher für sie keinen Grund, durch einen neuen Reparationskompromiß die Agonie zu verlängern. Noch im Januar 1947 hatte Bevin befürchtet, die USA könnten durch Zugeständnisse bei den laufenden Reparationen ein sowjetisches Entgegenkommen in der Frage der wirtschaftlichen Einheit erkaufen, obwohl er selbst noch schwankend war und im Interesse einer Vier-Mächte-Regelung sowohl dem bizonalen Alleingang im Hinblick auf die Erhöhung des Industrieniveaus als auch unter gewissen Bedingungen der kompensatorischen Wiederaufnahme der Reparationslieferungen an die Sowjetunion zustimmte. Doch auf der Moskauer Konferenz erklärte er unmißverständlich, er werde einen solchen Handel nicht akzeptieren. Er war lediglich bereit, wenngleich mehr aus diplomatischen Rücksichten, die Möglichkeit von Reparationen aus laufender Produktion nach einer Stabilisierung Deutschlands vorläufig noch nicht endgültig auszuschließen. Während Frankreich und die Sowjetunion „Gewinn" aus ihren Zonen zögen, die USA die Kosten ihrer Zone relativ leicht verkraften könnten, sei England verhältnismäßig am härtesten betroffen, wenn Deutschland, statt zu exportieren, Reparationen aus laufender Produktion zahlen müsse und sich nicht selbst ernähren könne. England habe nur eine „geringe Chance, das zurückzubekommen, was wir vorgelegt haben; aber unsere beste Chance besteht in den ersten Jahren, nachdem Deutschland selbstversorgend geworden ist (in den frühen fünfzigern), wenn wir wahrscheinlich noch immer eine ziemlich umfassende Kontrolle ausüben werden. Die Erholung zu verschieben, heißt wahrscheinlich, sie ganz aufzugeben und sicherlich auf einen Beitrag für unsere Zahlungsbilanz in voraussichtlich immer noch kritischen Jahren zu verzichten.“ Mit der Bizone stand eine Alternative zur Verfügung, die zumindest nicht teurer werden würde: „Die Wirtschaftseinheit war tot, ist tot und wird für viele Monate tot bleiben, und das Bizonen-Abkommen ist die einzige bestehende Alternative. ${ }^{\text {269 }}$ Die britische Regierung war daher bereit, das Programm für Kapitalgüterlieferungen möglichst rasch durch den Kontrollrat abschließen zu lassen und als Kompensation für die bizonale Erhöhung des Industrieniveaus nur noch die bereits zugesagten Lieferungen an die Sowjetunion abzuwickeln, sofern diese die Gegenlieferungen bereitstellte. Man wußte in London, daß die UdSSR eine solche Regelung „fast unvermeidlich als Zeichen für den endgültigen Bruch zwischen Ost und West betrachten“ werde. Aus grundsätzlichen wie aus ökonomisch-praktischen Gründen waren die Briten an einer Gesamtlösung nicht mehr interessiert: „Alles hängt von der russischen Reparationspolitik ab, sowohl hinsichtlich der Demontagen wie hinsichtlich der Reparationen aus laufender Produktion. Wenn die Reparationen eingestellt werden, wird die russische Zone ein wirtschaftlicher Aktivposten sein; wenn Reparationen wie bisher weitergehen“, und anderes war kaum zu erwarten, „kann die

269 PRO, PREM 8/791 (C.P.(47)68, 20. 2. 1947, Appendix ,A', S. 13 f.); FO 371/65052 (Hall-Patch an Bevin, 4. 4. 1947; Mark Turner, 8. 4. 1947; Makins an Hall-Patch, 9. 4. 1947). AMAE, Y 378, Bl. 140 (18. 1. 1947). NA, RG 59, 740.00119 Council/3-2447. Deighton, Impossible Peace, S. 155 (Playfair, 5. 4. 1947). 
russische Zone bis Ende 1947 eine große wirtschaftliche Belastung werden. “270 Eine Kompromißlösung wurde also nicht für ausgeschlossen gehalten, sie wurde aber für politisch als wenig realistisch bzw. nicht länger wünschenswert erachtet.

Mit einer faktischen Beendigung der Reparationen konnte Frankreich nicht einverstanden sein. Die erhofften Lieferungen waren bislang fast vollständig ausgeblieben, seit Clays Demontagestopp die Realisierung des Industrieniveauplans verhindert hatte. Alle Pläne für den Wiederaufbau waren damit beeinträchtigt, besonders der Monnet-Plan. Nachdem die USA und Großbritannien mit Gründung der Bizone die Löcher verstopft hatten, durch die Frankreich sich im Rahmen des Interzonenhandels indirekte Vorteile verschaffte, und nun Dollar-Zahlungen für die wichtigsten Güter verlangten, war das Problem noch dringlicher geworden. Im Vorfeld der Moskauer Außenministerkonferenz war Frankreich nicht abgeneigt, auf bilateraler Ebene mit der Sowjetunion einen Vorschlag für die Revision des Industrieniveauplans auszuarbeiten, der „die Verwirklichung eines Plans für Reparationen aus laufender Produktion“ zuließ, aber „ohne zu riskieren, die Sicherheit der Staaten zu gefährden, die Opfer der deutschen Aggression gewesen sind. Während es uns scheint, daß das Potential der Schlüsselindustrien wie der Eisen- und Stahlindustrie nicht ohne Gefahren ausgedehnt werden könnte, könnten gewisse verarbeitende Industrien leichter ausgebaut werden und zur Wiederherstellung unserer zerstörten Volkswirtschaften beitragen." ${ }^{271}$ Der bizonale Industrieniveauplan, der die vollständige Einstellung der Reparationen zuungunsten Frankreichs anzudrohen schien, machte ein Beharren auf laufenden Reparationen noch dringlicher. Aber: „Das Stadium der Wahl ist vorbei.“ Angesichts der Gefahr, „daß trotz der Bemühungen Frankreichs Deutschland eine Ausrüstung behalten wird, die viel höher als seine Bedürfnisse und moderner als die seiner Opfer sein wird, wird man diese Form der [laufenden] Reparationen energisch suchen müssen“. Ende November 1947 verlangte das Industrie- und Handelsministerium vom Quai d'Orsay, darauf hinzuwirken, daß ein Teil der deutschen Produktion schon aus Konkurrenz- und Sicherheitsgründen an die Reparationsgläubiger abgetreten werde, „ein Teil vielleicht auf Handelsbasis und der wichtigere Teil als Reparationen", vor allem Rohstoffe und Halbprodukte: Kohle, Mineralien, Baustoffe, chemische Produkte, Strom, Textilien und Häute, Werkzeug- und andere Spezialmaschinen ${ }^{272}$. Kurz: Es bestand die Gefahr, daß Frankreich leer ausging, weil man in Paris auf Aktienbeteiligungen an deutschen Firmen setzte ${ }^{273}$ oder die Revision des Industrieniveauplans in der

270 PRO, FO 800/Ger/47/14 und Eur/47/2; FO 944/761 (An Appreciation of the Economic Position in the Soviet Zone and the Effects which Fusion with it would have on the Western Zones). FRUS, 1947/II, S. 273 f., 309, 1137 ff.

271 AMAE, Y 291, Bl. 94 (Blum, 13. 1. 1947).

272 AMAE, Y 372, Bl. 56-63.

273 Bereits auf der Pariser Reparationskonferenz ging Frankreich den Weg, „to justify the acquisition of new interests in the German economy on a replacement rather than a reparation basis“. NA, RG 43/WWII\&PWConf, box 147, folder: State Department Briefs (Memorandum No. 5: Post-Surrender Acquisitions in Germany, ca. Anfang 1947). Frankreich wollte ausländische Beteiligungen am Management deutscher Firmen nicht ausschließen und die erbeuteten 1,120 Mrd. RM zum Ankauf von Beteiligungen an der Saar-Industrie nutzen. Hinzu kamen Beteiligungen von Bürgern aus Elsaß-Lothringen an deutschen Firmen im Werte von 54 Mio. RM. Zugleich wurde die Wiederbelebung alter Beteiligungen an deutschen Firmen gesucht, um die Rohstoffgewinnung beeinflussen oder den Technologietransfer einleiten zu können. AMAE, Y 653, B1. 174 ff. (CGAAA, 15. 10. 1946). Intern wurde diskutiert, ob man nach dem Muster der Sowjet AGs Beteiligung und Kontrolle suchen solle. Y 370, Bl. 390 ff. (GFCC an CGAAA, 23. 11. 1946). Als Frankreich 1947 eine 
Bizone nicht verhindern konnte. Ehe Frankreich in Nachteil gegenüber der deutschen Wirtschaft geriet, sollte es sich lieber unter Hinweis auf die europäischen Sicherheitsinteressen, zu denen ein Rekonstruktionsvorsprung gegenüber Deutschland gehörte, auch mit weniger attraktiven Reparationsleistungen begnügen ${ }^{274}$. Der MarshallPlan war der eine Ansatz, mit dessen Hilfe Frankreich versuchte, finanzielle und technologische Kompensation seitens der USA einzufordern, die europäische Integration der andere, das deutsche Potential mitbenutzen oder doch mitkontrollieren zu können.

\section{Arbeitskräfte als Reparationen}

Die Debatte des Jahres 1947 über die Reparationen aus laufender Produktion ließ indirekt eine Frage akut werden, die zuvor unter ganz anderen Gesichtspunkten diskutiert worden war: den Einsatz deutscher Arbeitskräfte zu Reparationszwecken. Sowohl vom amerikanischen Council on Foreign Relations als auch vom britischen MalkinKomitee waren seit den ersten Planungen zwei Möglichkeiten des Einsatzes ventiliert worden: Deutsche Arbeitskräfte konnten entweder in den kriegszerstörten Gebieten der Siegermächte zum Wiederaufbau eingesetzt werden, wie es später in unterschiedlichen Formen praktiziert wurde, oder zur Unterstützung ihrer Kriegsführung gegen Japan. Unter humanitären wie unter wirtschaftlichen Aspekten wäre die Alternative eleganter gewesen, die deutschen Arbeitskräfte in Deutschland selbst für Reparationsleistungen einzusetzen: durch Weiterverarbeitung alliierter Rohstoffe oder Halbfabrikate, also durch Veredelungsarbeiten ${ }^{275}$. Nach diesen Vorstellungen sollten die Reparationsgläubiger die Rohstoffe, auch die Energie für Menschen und Maschinen zur Weiterverarbeitung stellen, die Finanzierung der Arbeitsleistungen als solcher wäre den Deutschen anheimgefallen. Nachdem die Briten diese Vorschläge in ihrem Entwurf der Waffenstillstands-Urkunde vom 15. Januar 1944 der EAC vorgetragen hatten, betraten die Siegermächte mit dieser Diskussion völkerrechtliches Neuland.

Monopolgesellschaft für Öl in seiner Zone gründete, stieg der Druck der amerikanischen und britischen Ölindustrie. BA, Z 45 F/OMGUS, FINAD/2/166-1. Zwar kam es zur Aufweichung in der Frage des Re-Investments durch Rückkauf von Vorkriegsbesitz, aber Briten wie Amerikaner waren trotz aller Bereitschaft, die Ansprüche ihrer Industrie zu sichern, sehr restriktiv im Sinne einer älteren Vereinbarung über die Neu- bzw. Re-Investierung blockierter Markguthaben. Dafür hatten sie mit den Forderungen des Committee of British Industrial Interests in Germany bzw. der Association of Owners of British Property in Germany and Austria zu rechnen, dem von ICI und Unilever über Babcock, Dunlop und Cunard bis BAT, EMI und Anglo-Iranian Oil die Creme der Industrie angehörte. PRO, BT 211/83; FO 1049/251. Kindleberger, Letters, S. 9. Die Briten wollten ihren Firmen gestatten, Reichsmark-Guthaben in „new assets" anzulegen, ,in view of American proposals in the economic directorate in Berlin this might have to be done under the cover of making good war losses or damage“, z. B. durch Ankauf von Aktien. PRO, FO 371/65030/CE148 (Burrows, 7. 2. 1947). Für „approved purposes“ war das seit 1947 möglich. NA, RG 59, 740.00119 Council/4-747 und /4-1547. Im November 1947 legten die USA dem Koordinationskomitee ein Papier vor, in dem sie sich für einen weitgehend ungehinderten Handel aussprachen, aber darauf bestanden, „that full freedom of foreign investment is not possible in Germany at present", auch nicht für die eigene Ölindustrie. BA, Z 45 F/OMGUS, 2/118-3/10-21 (CORC/P(47)230, Appendix , $\left.A^{\circ}\right)$. Amerikanische Geschäftsleute wurden nur nach Deutschland gelassen, um ihren alten Besitz zu inspizieren, „component parts" für amerikanische Produkte gegen Dollars einzukaufen und Dollar-Einkäufe für die USA zu tätigen. PRO, 371/64425/C512 (6.1. 1947).

274 AMAE, Y 201, Bl. $101 \mathrm{f}$. Noch 1952 wollte Frankreich nicht prinzipiell auf laufende Reparationen verzichten, sondern nur auf deren Einforderung. Bonner Vertrag, S. 219 ff. Dies geschah erst 1954. FRUS, 1952-54/VII, S. 84 f., $91 \mathrm{f}$.

275 Nübel, Reparationspolitik, S. 57. Kettenacker, Krieg, S. 407. Cairncross, Price, S. 29 f. 
Die Sowjetunion, von der angesichts der verheerenden Kriegsschäden am ehesten die Forderung nach deutschen Arbeitskräften zu erwarten gewesen wäre, hielt sich zunächst zurück. Wenn sie, so die amerikanische Einschätzung, an Reparationen aus der laufenden Produktion interessiert war, konnte sie nicht für einen massiven Entzug der dafür erforderlichen Arbeitskräfte aus Deutschland plädieren. Diese hatte sich, wie Äußerungen Molotows und Maiskis in Yalta nahelegten, noch keineswegs festgelegt. Eugen Vargas frühere Forderung nach 10 Mio. deutschen Arbeitern, die in zehn Jahren die sowjetischen Eisenbahnen, Brücken, Städte und Fabriken wiederaufbauen sollten ${ }^{276}$, wurde zunächst auf $2-3$, später auf 4 Mio. Arbeitskräfte reduziert, aber weiterhin für einen Zeitraum von zehn Jahren. In erster Linie seien Nazis und Kriegsverbrecher heranzuziehen; sollten diese nicht ausreichen, kämen auch Arbeitslose in Frage. In der Moskauer Reparationskommission hatte sich die Position abermals geändert; erst wenn geklärt sei, welche Sachlieferungen, d. h. Reparationen aus der laufenden Produktion, Deutschland leisten müsse, ließen sich Umfang und Charakter der Arbeitsleistungen außerhalb des Reiches bestimmen. Daraus konnte man den Schluß ziehen, daß die Sowjetunion die Vorstellung einer radikalen De-Industrialisierung mit einem entsprechenden Überhang von Arbeitskräften aufgab und die diesbezüglichen Planungen ihrem in Yalta vorgetragenen Reparationsprogramm anpaßte, nämlich daß die Deutschen einmal Reparationen aus laufender Produktion zu liefern hatten und zum anderen die im Rahmen der einmaligen Kapitalgüterlieferungen demontierten Betriebe bei den Empfängerländern wiederaufbauen, vielleicht auch (anfangs) betreiben sollten. Sie machte keinen Hehl daraus, daß sie in erster Linie an Kriegsgefangenen interessiert war, um ,in Übereinstimmung mit den Prinzipien des Völkerrechts Militärpersonal in der Zeit des Waffenstillstands ausschließlich als Arbeitskräfte für Rekonstruktionsarbeiten einzusetzen“. Das Genfer Protokoll von 1929 war für sie, wie die Westmächte befürchteten, mehr Rechtsgrundlage für den Arbeitseinsatz von Kriegsgefangenen als Verpflichtung für deren Behandlung, zumal angesichts des Schicksals der sowjetischen Kriegsgefangenen in Deutschland während des Krieges. Da Moskau eine Anrechnung der Arbeitsleistungen auf die beanspruchte Reparationssumme von $\$ 10 \mathrm{Mrd}$. ablehnte, schloß das Protokoll von Yalta eine solche Verrechnung ausdrücklich nicht ein, auch wenn die Briten dieses Prinzip nachträglich doch noch zu verankern suchten, um die deutschen Gesamtleistungen in die Nähe ihrer deutlich niedrigeren Ansätze zu drücken ${ }^{277}$. Daß die Frage in Potsdam nicht zur Sprache kam, bedeutete keinen Verzicht seitens der Sowjetunion. Diese scheint das Problem bewußt ausge-

276 FRUS, 1944/I, S. 399 ff.

277 BA, Z 45 F/OMGUS, AGTS/88/1-9 (8. 5. 1944). FRUS, Malta and Yalta, S. 177, 630, 704, 707, 982 f. FRUS, 1945/III, S. 1189. Krim(Jalta)konferenz 1945, S. 64 f. NA, RG 59/Pauley Mission, box 11 (Memorandum No. 2). Keynes berechnete den Wert der Arbeitsreparationen auf der Basis von $£ 40$ bzw. $\$ 160$ pro Jahr. Das hätte bei 2-3 Mio. Arbeitskräften und einer Dauer von zehn Jahren ca. \$3,2-4,8 Mrd. ergeben. Um den sowjetischen Forderungen begegnen zu können, trug er Churchill am 11.6. 1945 andere Zahlen vor: „Four million slaves at 400 dollars a year is 16 billion dollars in ten years - far more than will ever be got in any other way. Indeed, this is the only way in which anything like the figure of 20 billion dollars which the Russians mentioned will ever be achieved“. Zitiert nach: Foschepoth, Britische Deutschlandpolitik, S. 704. Cairncross, Price, S. 193. Bereits am 8. 2. 1945 hatte das britische War Cabinet beschlossen, der Sowjetunion Arbeitsreparationen anzubieten, um deren Ansprüche ohne radikale De-Industrialisierung befriedigen zu können. Foschepoth, Britische Deutschlandpolitik, S. 681. Krim(Jalta)konferenz 1945, S. 64, 95 ff., 135, $139,164$. 
klammert zu haben, da sie ohnehin über ausreichend Kriegsgefangene (sowie andere deutsche Zwangsarbeitskräfte ${ }^{278}$ ) verfügte.

Trotz der Bedenken seiner Berater hatte Roosevelt sich im Oktober 1943 dem Votum des britischen Malkin-Reports zugunsten von Arbeitsreparationen angeschlossen, nachdem sich vor Beginn der Moskauer Außenministerkonferenz verschiedene europäische Staaten am 14. September für solche ausgesprochen hatten ${ }^{279}$. Die USA sahen ihre Überlegungen einmal durch das deutsche Angebot auf der Versailler Friedenskonferenz 1919 legitimiert, zum anderen durch den rücksichtslosen Einsatz von Kriegsgefangenen in der deutschen Kriegswirtschaft ${ }^{280}$. Die USGCC wollte derartige Maßnahmen auf die weitergefaßten Regelungen der Kapitulationsbedingungen begründen, die den unbegrenzten Zugriff der Alliierten auf alle deutschen Bürger und die Ausgestaltung der rechtlichen und sozialen Bedingungen eines solchen Einsatzes gestatteten. Obwohl sie selbst deutsche Arbeitskräfte nur zum Minenräumen einzusetzen beabsichtigten, hatten die USA zunächst Verständnis für die Bedürfnisse der stark zerstörten Staaten, besonders der Sowjetunion. Die Arbeitsleistung galt als „zweckmäßige und nützliche Form der Reparationen“, allerdings sei der Einsatz deutscher Arbeitskräfte an schützende Bedingungen zu binden: Eine internationale Organisation, etwa die Reparationskommission, sollte ihn anordnen und überwachen. Zudem müsse sichergestellt sein, daß er der europäischen Rekonstruktion mehr nutze als die direkte Produktion von Reparationsgütern in Deutschland, daß er zeitlich (vor allem für „politisch passive Deutsche") auf drei bis vier Jahre beschränkt bleibe und daß für angemessene Unterbringung und Entlohnung (inkl. der von Deutschland zu tragenden Sozialversicherung) gesorgt werde ${ }^{281}$. Der ökonomische Effekt wurde als gering eingeschätzt, der politische um so höher. Dabei stand weniger die Re-education als vielmehr die Überlegung im Vordergrund, die Entfernung der ,aktiven Nazis“ werde der inneren Stabilisierung der jungen Demokratie förderlich sein, zumal auf diesem Wege die Arbeitslosigkeit in Deutschland abgebaut, die europäische Rekonstruktion beschleunigt werde ${ }^{282}$. Trotz ihrer Vorbehalte sahen die USA „keinen zwingenden Grund", sich solchen Forderungen nach Arbeitsreparationen zu widersetzen, soweit sie sich ,in vertretbaren Grenzen“ hielten und die geforderten Rahmenbedingungen eingehalten wurden. Daher stimmten sie in Yalta den Arbeitsreparationen $\mathrm{zu}^{283}$.

Die Briten vertraten anfangs die Auffassung, Kriegsgefangene fielen im Falle einer bedingungslosen Kapitulation keineswegs automatisch unter den Schutz der Genfer

278 Seit 1941 hatte die Sowjetunion 700.000 Rußlanddeutsche nach Sibirien und Zentralasien verschleppt und zur Zwangsarbeit herangezogen, dazu Deutschstämmige aus den besetzten osteuropäischen Gebieten. Weitere 310.000 „Reparationsverschleppte“ folgten nach dem Krieg. Von den 1 Mio. Zwangstransferierten kehrten bis 1950 nur 30\% zurück. Reichling, Vertriebene, Teil I, S. $17 \mathrm{ff}$.

279 Nübel, Reparationspolitik, S. 60, 63, $77 \mathrm{f}$.

280 NA, RG 59/EAC, box 25 (Report of the Interdivisional Committee on Reparation, Restitution and Property Rights, PWC-226, Part IV: Comments, 10. 6. 1944, S. 45 ff.). Vgl. zur Rechtsdiskussion die Stellungnahme der Legal Division der USGCC vom 15. 4., die Clay sich am 1./14. 5. 1945 zu eigen machte. BA, Z 45 F/OMGUS, POLAD-TS/32/55.

281 BA, Z 45 F/OMGUS, POLAD-TS/34/1-3 (16. 1. 1945). NA, RG 59, 740.00119 EAC/3-1745.

282 BA, Z 45 F/OMGUS, POLAD-TS/32/55; 34/1-3. NA, RG 107/McCloy, box 30 (27. 4. 1945).

283 FRUS, Malta and Yalta, S. 158, 885, 979, 983. Die Arbeitsreparationen waren nicht einseitig von den Sowjets in das Protokoll hineingeschrieben worden (Nübel, Reparationspolitik, S. 125). Das Thema war zweimal von den USA aufgeworfen, aber als „schwierig“ zurückgestellt und an die Reparationskommission in Moskau überwiesen worden. Vgl. FRUS, 1945/III, S. 1224 (18. 5. 1945). 
Konvention. Die Alliierten könnten von Deutschland verlangen, alle diese Personen zu bezahlen, zu kleiden oder zu ernähren, die von den Siegermächten im Sinne der russischen Formel zu Kriegsgefangenen „erklärt“ worden seien, auch wenn sie im Ausland eingesetzt würden; „es gibt keine geographischen Begrenzungen für diese Verpflichtung“. Innerhalb Deutschlands sollten derartige Arbeitskräfte vor allem Dienst bei den alliierten militärischen Dienststellen leisten; für den Auslandseinsatz standen vorrangig die Sowjetunion, aber auch die Kriegsgebiete um Japan zur Diskussion. Während die Briten im Inland einen zivilen Status für die „Zwangsarbeit“ vorsahen, bevorzugten sie aus Kosten- und Sicherheitsgründen beim Auslandseinsatz den Kriegsgefangenenstatus ${ }^{284}$. Die Arbeitsleistung der vorgesehenen 3 Mio. Arbeitskräfte sollte auf drei, später fünf Jahre beschränkt bleiben, deren Zahl jährlich um 1 Mio. reduziert werden. Um diese Zahlen erreichen zu können, gaben sie in den weiteren Debatten teilweise die Beschränkung auf Kriegsgefangene oder überzeugte Nationalsozialisten auf. Sie begründeten das u. a. damit, daß aufgrund der Kriegsfolgen und der Umsiedlungen aus dem Osten eine hohe strukturelle Arbeitslosigkeit in Deutschland zu erwarten sei, trotz „ausgleichender Faktoren, wie der Entsendung von vier Millionen deutschen Kriegsgefangenen zum Arbeitseinsatz in Rußland“285.

Die Briten trugen ihre präzisierten Vorstellungen im Februar 1945 in der EAC vor und forderten, keine „absolut starre Regel“ festzulegen, um sich ein Höchstmaß an Flexibilität zu erhalten. Die Zahl der von den EAC-Mächten wie von ihren Verbündeten voraussichtlich benötigten Arbeitskräfte sollte frühzeitig erhoben werden, damit der Kontrollrat tätig werden konnte, ehe die Demobilisierung begann. Da es vor der Kapitulation unmöglich sei, den genauen Bedarf an Arbeitskräften auch nur annähernd zu schätzen, müsse man die Demobilmachung hinausschieben; einmal entlassen, verlören die deutschen Soldaten ihren Status als Kriegsgefangene und müßten davor schreckten Briten wie Amerikaner zurück - als Zivilisten für Zwangsarbeiten erneut rekrutiert werden ${ }^{286}$. Noch bei der Vorbereitung für die Potsdamer Konferenz sahen die Briten „umfangreiche Aushebungen von Reparationsarbeitern“ vor: 250.000 deutsche Arbeitskräfte als Bau- und Landarbeiter zum Einsatz in England, dazu 160.000 im Mittleren Osten, in Ostafrika und „zur Unterstützung des Kriegs im Fernen Osten“. Doch seit Ende Mai 1945 hatten sie sich von ihren frühen Überlegungen zu distanzieren begonnen, den Arbeitseinsatz als Bestrafung von Nationalsozialisten und Kriegsverbrechern zu nutzen. Außer den Kriegsgefangenen sollten keine weiteren Bevölkerungsgruppen nach Ablauf einer Frist von etwa sechs Monaten herangezogen werden, um nicht - so ihre offizielle Begründung - die Ruhe in Deutschland zu gefährden oder die Entstehung von Widerstand zu provozieren. Die Dauer des Arbeitseinsatzes sollte drei Jahre nicht überschreiten; im Bedarfsfalle könne diese Begrenzung „überprüft“ werden. Um internationale Wettbewerbsverzerrungen auszuschließen, indem „die Arbeitskräfte in Betrieben eingesetzt würden, die mit britischen

284 FRUS, 1944/I, S. 130 f. (EAC(44)1, 15. 1. 1944). BA, Z 45 F/OMGUS, AGTS/88/1-9 (28. 3. 1944). PRO, FO 942/193 (APW(44)1 19, 24. 11. 1944). Cairncross, Price, S. 30, 76, 103.

285 PRO, FO 371/46827 (EIPS-Working Group on Employment and Unemployment, Januar 1945). FRUS, Potsdam II, S. 214, 221 (Attlee). Der britische Philips Report rechnete mit 1,8-3,6 Mio. Arbeitslosen, selbst wenn 500.000 Deutsche von den Alliierten im Ausland beschäftigt würden. Die französische Regierung erwartete bis zu 2,3 Mio. Arbeitslose, auch wenn sie 1,75 Mio. Reparationsarbeiter erhielte.

286 BA, Z 45 F/OMGUS, POLAD-TS/32/55 (EAC(45)15, 27. 2. 1945). 
konkurrieren“, sollten sich alle Länder, die deutsche Arbeitskräfte zu Reparationszwecken anforderten, in einer Art Sozialcharta auf Mindestgrundsätze für deren Behandlung verpflichten ${ }^{287}$.

Auch die USA rückten, obwohl sie selbst mit dem Arbeitseinsatz von Kriegsgefangenen im eigenen Land bis Mitte 1946 einen Netto-Gewinn von \$230 Mio. erzielten $^{288}$, zunehmend von einem Zwangseinsatz deutscher Arbeitskräfte (mit Ausnahme von Kriegsverbrechern) im Ausland ab, obwohl angesichts der katastrophalen Wirtschaftslage in Deutschland eine Umschichtung des Arbeitskräftepotentials ins Ausland auf freiwilliger Basis Vorteile zu bieten schien. Um „Sklavenarbeit“, wie es nun hieß, zu verhindern, wurden neue Hürden aufgebaut: Freiwillige und zwangsweise Arbeitsleistungen im Ausland sollten nur „zur Rekonstruktion und Reparatur von Kriegsschäden“ erlaubt sein, ausdrücklich „nicht für laufende Produktion, außer für Brennstoffe und Lebensmittel“. Und sie sollten als geldwerte Leistung auf das Reparationskonto angerechnet werden, um ihre Attraktivität zu mindern ${ }^{289}$. Angesichts der phantastischen Zahlen von bis zu 7 oder gar 9 Mio. Arbeitskräften, die in der Diskussion genannt wurden, erwartete die Regierung innenpolitische Widerstände in den USA selbst, besonders seitens der Gewerkschaften. Ihr war das Thema so brisant, daß sie durch Meinungsumfragen erkundete, ob die öffentliche Meinung eine derartige Dimension der Arbeitsreparationen politisch mittragen würde. Bei den Vorbereitungen für die Beratungen der Reparationskommission rückte die amerikanische Delegation zusätzlich die möglichen negativen Wirkungen für das amerikanisch-sowjetische Verhältnis in den Vordergrund. „Wenn nicht Sicherungen eingebaut werden, werden die Bedingungen, unter denen deutsche Arbeitskräfte in der UdSSR beschäftigt werden dürfen, und die Methoden der Rekrutierung von Gruppen aufgegriffen und ausgeschlachtet werden, die der Sowjetunion feindlich sind.“290 Diese (reale oder vorgebliche) bündnispolitische Rücksichtnahme wurde von der Sowjetunion als Distanzierung von den früheren Kompromissen interpretiert, als die amerikanische Delegation zahlenmäßige Begrenzungen und Versorgungsgarantien von ihr verlangte. Der eigenwillige Pauley, zusätzlich verunsichert durch Morgenthau, verhandelte in Moskau trotz verschiedener Korrekturen seitens des State Department derart unverbindlich, daß Briten wie Sowjets nicht mehr wußten, wie die amerikanische Position tatsächlich war, aber annehmen mußten, daß eine Anrechnung auf Reparationskonto nicht beabsichtigt war ${ }^{291}$. Letztlich spitzte sich die amerikanische Position darauf zu, die Arbeitsreparationen prinzipiell zu akzeptieren, sie aber gleichzeitig durch Auflagen und Anrechnung auf Reparationskonto wirtschaftlich unattraktiv zu machen. In dem Sinne gaben die USA am 12. August 1945 in der Reparationskommission für ihre Partner etwas überraschend zu Protokoll, daß sie „keinem unbegrenzten Programm für Zwangsarbeit zustimmen werden“. Es gelte abzuwarten, ob die interessierten Staaten direkt oder im Kontrollrat entsprechende Vorstöße unternähmen. Die

${ }^{287}$ FRUS, 1945/III, S. 1231 f. NA, RG 59/Pauley Mission, box 11 (Mai 1945). Vgl. PRO, FO 1051/494 (6. 3. 1946); FO $942 / 193$ (CCG, 12. 2. 1946).

288 Jung, Deutsche Kriegsgefangene, S. 155 ff., 170, 203 f. $91 \%$ der in den USA internierten Kriegsgefangenen wurden zu Arbeitsleistungen herangezogen, für insgesamt (von Anfang 1943 bis Mitte 1946) 125 Mio. Arbeitstage.

289 FRUS, 1945/III, S. 1224 (18. 5. 1945). NA, RG 59/EAC, box 3, folder: USGCC (Knapp an Murphy und Heath, 3. 6. 1945). Der Positionswandel wurde vor allem von Leo Crowley betrieben.

290 NA, RG 59/Pauley Mission, box 14 (28. 7. 1945).

291 DBPO, I, 1, S. 299. Morgenthau-Tagebuch, S. 331-75. FRUS, Potsdam I, S. 550, 553. 
Rückkehr zu dem Vorschlag, ausschließlich verurteilte Kriegsverbrecher heranzuziehen, war für die Briten „völlig unakzeptabel“, ganz zu schweigen für die Franzosen und Sowjets ${ }^{292}$.

Frankreich hatte ein erhebliches Interesse an Reparationsarbeitern: „Die Rekonstruktion Frankreichs wird von vier Faktoren bestimmt: Arbeitskräfte, Rohstoffe, Ausrüstung und Kredit." Die Provisorische Regierung ließ daher im November 1944 weitgefaßte Ansprüche erkennen. Da voraussichtlich 4 bis 5 Mio. französische Arbeitskräfte fehlten und die aus der Kriegsgefangenschaft Zurückgekehrten nur noch 60-80\% ihrer Leistungsfähigkeit besäßen, könne diese Lücke allein durch deutsche Arbeitskräfte geschlossen werden ${ }^{293}$. Obwohl das Land begründbaren Bedarf für den Einsatz von 4 Mio. Deutschen über fünf Jahre habe, werde es sich jedoch mit 1,5 bis 1,75 Mio. für zwei oder drei Jahre begnügen, da mehr nicht untergebracht und ernährt werden könnten. Da sie selbst nur über 570.000 verfügte, bat die Regierung SHAEF um die Zuweisung von 1 Mio. Kriegsgefangenen, die zu „Arbeitsbataillonen“ zusammengefaßt werden sollten. Sie war bereit, die Forderung der Genfer Konvention nach baldiger Entlassung zu erfüllen, erwartete aber im Gegenzug Ersatz durch junge Freiwillige, u. a. indem ,die öffentliche Meinung in Deutschland ledige junge Männer zwingen werde, verheiratete Kriegsgefangene auszulösen, vor allem wenn es verbreitete Arbeitslosigkeit in Deutschland gibt und die Jugendlichen müßig sind“. Die jungen Freiwilligen sollten die „schwereren und gefährlicheren Aufgaben“ übernehmen, z. B. das Minenräumen oder den Bergbau unter schwierigeren Bedingungen; dafür versprach Frankreich „anständige Arbeitsbedingungen“ und „angemessenen Lohn“, der „teilweise“ nach Deutschland überwiesen werden dürfe ${ }^{294}$. Im Juli 1945 präzisierten die französischen Ministerien für Arbeit und für Wiederaufbau diese Vorstellungen: Frankreich habe im Kriege nicht nur 720.000 Fremdarbeiter in Deutschland stellen müssen, sondern auch 1,5 Mio. Kriegsgefangene, von denen infolge der Zwangsarbeit 500.000 arbeitsunfähig zurückgekehrt seien. Ziel müsse es sein, bis zum Juli 1946 1,75 Mio. deutsche Kriegsgefangene (aus Wettbewerbsgründen bei gleichem Lohn wie die französischen Arbeiter!) einzusetzen: 1,4 Mio. für Rekonstruktion und Bergwerke, 150.000 für die Landwirtschaft und 80.000 für Forstarbeiten, 25.000 für Grubenholz, 20.000 für die Elektroindustrie und 10.000 für sonstige Arbeiten. Die Erfahrungen der Jahre 1916 bis 1919 [!] ließen erwarten, daß die deutschen Gefangenen bei guter Behandlung und Ernährung arbeitswillig seien. Die Bereitschaft, in Frankreich zu arbeiten, werde ohnehin steigen, ,wenn, wie wir hoffen, wir es schaffen, das Wirtschaftspotential Deutschlands zu verringern“"295. Am 22. September 1945 wurde mit den USA ein Abkommen „über die Lieferung von deutschen Kriegsgefangenen mit Arbeitskraftqualität nach Frankreich“ geschlossen ${ }^{296}$. Für SHAEF war die Kontrolle und Versorgung der fast 8 Mio. Kriegsgefangenen immer lästiger geworden, so daß Briten und Amerikaner rasch mit der Demobilisierung der in Deutschland gehal-

292 NA, RG 59/Pauley Mission, box 19 (IX. Decisions Reached, Second Draft, Gulick, 12. 9. 1945, S. 44). Cairncross, Price, S. 103.

293 AN, 457 (Bidault) AP 60/II (MAE, 22. 1. 1945); 61/I (November 1944). AN, 60/3034 (Document No. 4, 10.8. 1945).

294 NA, RG 59/Pauley Mission, box 14 (Ziegel an Calsoyas; Calsoyas, 18.6. 1945). AMAE, Y 363, Bl. $88 \mathrm{ff} .(19.11 .1945)$.

295 AO, Berlin/3273/3/2731, I (SGAAA, Document No. 4, 10. 8. 1945; GFCC, 11. 9. 1945).

296 AN, 60/3034 (25.9. 1945). 
tenen Kriegsgefangenen begannen und nicht ungern ihre Gefangenen in Westeuropa den jeweiligen Ländern überstellten. Die USA, die 266.000 Deutsche als Hilfskräfte bei den eigenen Dienststellen beschäftigten, ihre Kriegsgefangenen aber zunehmend nicht mehr angemessen versorgen konnten, übergaben bis Ende 1945740.000 Kriegsgefangene an Frankreich, 123.000 an Großbritannien, 30.000 an Belgien, 14.000 an die Niederlande und 5000 an Luxemburg ${ }^{297}$.

Die Briten suchten sich zumindest die Optionen offenzuhalten. Von den 209.000 Gefangenen, die im Sommer 1945 auf der Insel festgehalten wurden, war die Hälfte im Arbeitseinsatz, zumeist in der Landwirtschaft. Obwohl unter dem Druck der Sowjetunion und dann des Kontrollrats die Entlassung der Kriegsgefangenen aus britischem Gewahrsam in Deutschland beschleunigt werden mußte, verfügte Montgomery Anfang Dezember 1945 noch immer über 700.000 Gefangene in seiner Zone, weil er durch Befehl verpflichtet war, „225.000 als Reparationsarbeiter für das Vereinigte Königreich festzuhalten "298. Die Briten hatten die Hoffnung auf Arbeitsreparationen also keineswegs aufgegeben, obwohl sie selbst die Hürden für deren Einsatz hochgeschraubt hatten. Sie versuchten, sich neue Flexibilität zu verschaffen, indem sie auf Zwangsarbeiter zugunsten ziviler Arbeitskräfte verzichteten. Im Oktober 1945 regten sie gegenüber den USA eine Regelung an, daß jedes Land die Gefangenen nach eigenem Gutdünken einsetzen, bei Bedarf andere Alliierte um den Transfer zusätzlicher Kriegsgefangener bitten und bei anhaltendem Bedarf mit dem Kontrollrat über die Bedingungen einer Anwerbung von Zivilarbeitern verhandeln dürfe. Je mehr die Anwerbung von Zivilarbeitern in den Blickpunkt rückte, um so dringlicher wurde die Klärung der Arbeitsbedingungen, der Entlohnung, eventuell der internationalen Kontrolle der Lebens- und Arbeitsverhältnisse sowie die Definition des in Frage kommenden Personenkreises und der Einsatzmöglichkeiten. Wenn die (zivilen) Arbeitskräfte als Teil der deutschen Reparationsleistungen anzusehen waren, dann mußte, so die amerikanische Auffassung, das auf internationaler Ebene zwischen den Alliierten ausgehandelt und die Verrechnung auf Reparationskonto geregelt werden. Angesichts solcher technischer und rechtlicher Probleme war es nur natürlich, daß Überlegungen angestellt wurden, ob die Arbeitskräfte nicht sinnvoller in Deutschland selbst für Veredelungsarbeiten in Engpaßbereichen eingesetzt werden könnten bzw. für die Lieferung von Reparationen aus laufender Produktion ${ }^{299}$.

Aufgrund dieser vielfältigen Unsicherheiten und der erheblichen Inkonstanz der jeweiligen Positionen war weder in der Reparationskommission der vier Besatzungsmächte noch auf der Pariser Reparationskonferenz der westlichen Gläubigernationen eine Einigung möglich. In der Reparationskommission war die Frage nach scharfen russischen und französischen Protesten für eine „spätere Diskussion“ zurückgestellt worden. Frankreich strebte die Verlagerung der Verhandlungen in den Kontrollrat an, um die Aufrechnung gegen andere Reparationsansprüche zu verhindern, wollte aber prinzipiell an einer Vier-Mächte-Regelung festhalten ${ }^{300}$. Mangels fehlender Beschlüsse

297 Smith, Heimkehr, S. 27.

298 PRO, FO 1051/494 (24. 5. 1945); FO 942/522 (CCG an Street/COGA, 1. 12. 1945). Vgl. oben S. $167 \mathrm{f}$.

299 FRUS, 1945/III, S. 1338 f. PRO, FO 942/498 (Board of Trade, German Division, 21. 2. 1946).

300 AMAE, Y 363, Bl. 129 ff. Auch Clay verlangte eine Verlagerung in den Kontrollrat. „Manifestly such a decision will materially affect allocations of industrial equipment.“ Angesichts der großen Zahl von Kriegsgefangenen aus den Westzonen sei zu überlegen, ob der sowjetische Anteil an den 
hatte nun jede Siegermacht das Recht, nach eigenem Gutdünken vorzugehen. Insofern ist nicht auszuschließen, daß die Briten im Kontrollrat erneut die Anrechnung der Arbeitsleistungen auf Reparationskonto vorschlugen, um eine solche Situation zu provozieren. Denn auf der Pariser Reparationskonferenz unterstützten sie (in vollständiger Umkehrung ihrer früheren Vorstellungen) die Position der Franzosen, es werde kaum praktikabel sein, Arbeitsleistungen zu bewerten und auf Reparationskonto zu verrechnen. Letztlich ging es den Briten nur um eine Formel, die es ihnen erlaubte, „bei der Verwendung von Reparationsarbeitern alles zu tun, was wir wollen“, ohne die USA zu verprellen ${ }^{301}$. Gegen eine Anrechnung auf Reparationskonto wehrten sich auf der Pariser Reparationskonferenz besonders hartnäckig die Franzosen, die beim Einsatz von über 1 Mio. Kriegsgefangenen eine erhebliche Reduktion ihrer sonstigen Ansprüche befürchten mußten. Mit dem Hinweis, ohne die Beteiligung der Sowjetunion könne diese Frage nicht abschließend geregelt werden, versuchten sie, einem Beschluß auszuweichen. Doch die USA, wie die Briten, lehnten jede Einbeziehung der Sowjetunion mit dem aufschlußreichen Argument ab, dieser sei lediglich ein Anteil an den Kapitalgüterreparationen aus den Westzonen zugestanden worden; in der Arbeitskräftefrage sei sie auf ihre eigene Zone beschränkt. Die USA versuchten zunächst, durch diplomatische Pressionen die französische Hinhaltetaktik zu überwinden, indem sie damit drohten, die Kriegsgefangenen in amerikanischer Obhut stünden nicht unbegrenzt zur Verfügung, „,wenn die Franzosen nicht bereit seien, die ihnen daraus entstehenden Vorteile anzuerkennen“. Doch die amerikanischen Vertreter erkannten frühzeitig, daß eine Einigung mit Frankreich nur möglich war, wenn der Reparationswert der Arbeitsleistungen extrem niedrig angesetzt wurde; sie erhielten Anweisung von Byrnes, einen „vernünftigen“ Ansatz zu akzeptieren. Nachdem der französische Reparationsanteil bei gewissen Sachlieferungen zugunsten der kleineren Gläubigernationen reduziert worden war, sahen sich die USA nicht länger zu einer harten Haltung in der Lage, wollten sie nicht das Gesamtpaket in Frage stellen. Die Franzosen nutzten das aus, indem sie nun jegliche Verpflichtung zur Bezahlung der Arbeitskräfte oder Verrechnung auf Reparationskonto zurückwiesen. Die USA hätten die Kriegsgefangenen abgetreten, um Kosten zu sparen; diese könnten daher „nicht als ein Reparationsgut betrachtet werden“. Schließlich gaben die Amerikaner sich mit Formelkompromissen zufrieden $^{302}$.

Trotz mangelnder Einigung auf der internationalen Ebene verstanden es die Mächte, ihre Ansprüche in die Kontrollratsdirektive Nr. 18 vom 12. November 1945 einfließen zu lassen. Die Forderung nach „Entlassung und Auflösung der deutschen bewaffneten Kräfte“ war aus den sowjetischen Forderungen nach Auflösung der Internierungslager in der britischen Zone entstanden. Ein Entwurf des Militärdirektorats vom 27. September 1945 hatte keinen direkten Hinweis auf die Problematik enthal-

Sachlieferungen gekürzt werde. Gegenüber den westlichen Reparationsgläubigern sollte das Argument nicht gelten; Clay und Murphy hätten es vorgezogen, mit diesen bilaterale Verträge für genau spezifizierte Einsätze abzuschließen. CP, S. 124 ff. (28. 11. 1945). Das State Department gestand zu, daß die Festlegung des Zeitpunktes, bis zu dem die Kriegsgefangenen zurückzugeben seien, die $\operatorname{Re}-$ krutierung von zivilen Arbeitskräften und deren Einrechnung in das Reparationskonto dem Kontrollrat zukomme, nicht aber die Anrechnung der Arbeitsleistung von Kriegsgefangenen, die auf bis zu 500 Mio. RM anzusetzen sei. FRUS, 1945/III, S. 1420.

301 PRO, FO 1051/494 (6. 3. 1946).

302 FRUS, 1945/III, S. 1381-85, 1390, 1414 ff., 1448. 
ten, sondern nur in einer Anlage erklärt, daß keine der Bestimmungen „den Einsatz deutscher Kriegsgefangener als Arbeitskräfte für Rehabilitations- und Reparationszwecke seitens der vier Mächte beeinträchtigen“ solle. Erst nachdem die Sowjetunion und, in geringerem Maße, auch Frankreich Änderungswünsche hinsichtlich des Status von Berlin und des Zeitpunkts der Entlassung angemeldet hatten, wurde der Passus in die Direktive selbst aufgenommen. Die Direktive enthielt keine Verpflichtung, alle Kriegsgefangenen umgehend zu entlassen, wenn dem „die Anforderungen von deutschen Arbeitskräften durch die alliierten Nationen“ entgegenstanden. Ausdrücklich wurde die „Verschiebung“ von Gefangenen, die sich außerhalb Deutschlands befanden, von der einseitigen Willenserklärung der Obhutsmacht abhängig gemacht: „Diese Verschiebungen werden von der betreffenden Macht zu einem ihr passenden Zeitpunkt vorgenommen, vorausgesetzt, daß kein von den Alliierten getroffenes Abkommen über zu leistende Reparationsarbeiten dazu in Widerspruch steht.“ Damit war auch das „Ausleihen“ von Kriegsgefangenen an Drittländer gedeckt. Die Alliierten, die nicht Besatzungsmacht waren, sollten bilateral auf verbindliche Regeln für diese „Verschiebungen“ verpflichtet werden ${ }^{303}$.

Die Frage der Arbeitsreparationen gewann eine neue Qualität, als einige der Besatzungsmächte 1946 dazu übergingen, Zwangsmaßnahmen zur Sicherstellung ihres Arbeitskräftebedarfs zu praktizieren. Wieder machten die Briten den Anfang. Angesichts ihrer wirtschaftlichen Krise waren sie immer weniger gewillt, sich durch internationale Verpflichtungen die Hände binden zu lassen. Das Kabinett beschloß am 14. Februar 1946, zur Deckung des inländischen Arbeitskräftebedarfs zusätzlich zu den bereits im Lande befindlichen 195.000 Gefangenen weitere 118.000 deutsche Kriegsgefangene aus Kanada bzw. den USA sowie bis zu 185.000 aus Deutschland zu „importieren“304. Damit sollte in erster Linie der extreme Bedarf bei „schwerer und aufreibender ungelernter Arbeit" abgedeckt werden. Vorrang wurde dem Wohnungsbau, der Erntearbeit und der Lebensmittelproduktion eingeräumt; der Einsatz zu militärischen Aufräumarbeiten im Zuge der Demobilmachung blieb erhalten. Die CCG wurde angewiesen, 165.000 Reparationsarbeiter in das Mutterland zu überweisen, von denen 50.000 aus den „Dienstgruppen“ und weitere 50.000 aus ehemaligen, inzwischen aufgrund sowjetischer Proteste entlassenen Wehrmachtsangehörigen zu rekrutieren seien. Letztere Gruppe schien Robertson problematisch, nachdem die Entsendung von Kriegsgefangenen zur Bergwerksarbeit in Frankreich Proteste in der deutschen Bevölkerung ausgelöst hatte. Zum einen hatten die Entlassenen inzwischen einen zivilen Status, zum anderen blieben durch die Beschränkung auf (ehemalige) Kriegsgefangene die internierten Nationalsozialisten von Arbeitsleistungen verschont. Die Hoffnung der CCG vom Mai 1946, bis zum November 125.000 Kriegsgefangene, davon 50.000 aus den USA und 30.000 aus den eigenen „Reserven“, bereitzustellen, konnte nicht erfüllt werden ${ }^{305}$. Die Briten überlegten im Som-

303 BA, Z 45 F/OMGUS, 2/118-1/5-16 (CORC/P(45)114). Im Spätsommer 1948 verfügte Polen über 45.000, Jugoslawien über 90.000, die Tschechoslowakei über 12.000 deutsche Kriegsgefangene. Smith, Heimkehr, S. 162.

304 Wolff, Kriegsgefangene, S. $51 \mathrm{ff}$. Von 362.000 Kriegsgefangenen waren $80 \%$ im Arbeitseinsatz, 212.000 in der Landwirtschaft. Bis Mitte 1948 wurden 154 Mio. Arbeitstage geleistet, doch erzielte England nach eigenen Angaben keinen Gewinn.

305 PRO, FO 1051/494; FO 942/193; FO 942/522. DBPO, I, 5, S. 417. 
mer 1946 daher, ob sie eine Vereinbarung in der IARA und/oder im Kontrollrat herbeiführen sollten, um zur Demontage einen „Arbeitsdienst“ einführen und deutsche Techniker zur Wiedererrichtung von Reparationsbetrieben im Ausland einsetzen zu können; im Oktober oder November sollten die ersten Rekrutierungen erfolgen ${ }^{306}$. Angesichts ihrer Bedenken, daß durch eine ungeregelte Rekrutierung der Arbeitsmarkt der eigenen Zone zu sehr belastet würde, sahen die Briten Ende 1946 keinen anderen Ausweg, als bei den USA vorzufühlen, ob man nicht doch zu Zwangsrekrutierungen übergehen solle ${ }^{307}$.

Mit diesem Ansinnen stießen sie auf den erbitterten Widerstand von OMGUS, nachdem die Westmächte gerade im Kontrollrat gegen den zwangsweisen Transfer deutscher Arbeitskräfte in die Sowjetunion protestiert hatten ${ }^{308}$. Ausgangspunkt der sowjetischen Zwangsmaßnahmen war das Scheitern ihrer bisherigen Reparationspolitik. Schon der Betrieb der amerikanischen Lend-lease-Fabriken hatte der Sowjetunion erhebliche Probleme bereitet, deren Produktivität bei 10-20\% lag. Wenn der Transfer deutscher Reparationsbetriebe in die Sowjetunion nicht in einem ähnlichen Fiasko enden sollte, bot sich die Lösung an, deutsche Facharbeiter und Spezialisten (auf Zeit) in die Sowjetunion zu holen, um das eigene Arbeitskräftepotential anzuleiten ${ }^{309}$. In der „Aktion Ossawakim“ verpflichtete die SMAD, für die die Anordnung selbst als „totale Überraschung“ kam und die die Abmilderung bzw. Verschiebung zu bewirken versuchte ${ }^{310}$, am 21. und 22. Oktober - am Tage nach den Berliner Wahlen! - eine größere Zahl von Arbeitern, inkl. ihrer Familien, für eine Arbeitsleistung von zwei bis fünf Jahren in die Sowjetunion. Die Westmächte sahen keine rechtliche Grundlage, gegen die Maßnahme als solche zu protestieren! Sie nutzten aber die Gelegenheit, daß einige der Betroffenen im britischen Sektor wohnten, um den Gesamtkomplex am 25. Oktober Kommandantur und Koordinationskomitee vorzulegen ${ }^{311}$. Pikant war die Koinzidenz, daß nur wenige Tage zuvor Fritz Sauckel, verantwortlich für die deutschen Zwangsdeportationen während des Krieges, hingerichtet worden war. Als Clay im Koordinationskomitee auf Sauckel verwies und dabei den sowjetischen Chefankläger in Nürnberg, Rudenko, zitierte, drohte Sokolowski verbittert mit Revanche, sollte die öffentliche Kritik in den Westzonen an den sowjetischen Maßnahmen nicht eingestellt werden. Allerdings hatte sich die SMAD inzwischen beeilt, mit den Betroffenen Arbeitsverträge abzuschließen; nach eigenen Angaben vor dem Abtransport, nach westlichen Informationen erst nachträglich. Der Vorstoß der Westmächte sei als Versuch zu werten, „die Kontrolle ausschließlich auf die Maßnahmen seitens der Sowjets

306 PRO, FO 943/28 (Dakin/Knight, Report, Juli 1946, S. 7, 13).

307 NA, RG 59, 740.00119 Control(Germany)/12-2446.

308 NA, RG 59, 740.00119 Control(Germany)/10-3146. Berlin: Behauptung 1946-1948, S. 57 ff. Zank, Wirtschaft, S. 65.

309 PRO, FO 800/466/Ger/46/33 (3. 10. 1946); FO 371/64305 (An Appreciation of the Economic Situation in the Soviet Zone, ca. Januar/Februar 1947). Da die amerikanische Regierung sich frühzeitig damit abgefunden hatte, daß die Sowjetunion ihre Gefangenen nicht nach westlichen Maßstäben behandeln werde, hatte sie im Sommer 1945 auf Proteste gegen den Abzug deutscher Arbeiter und Techniker mit den demontierten Betrieben in die Sowjetunion - und nach Frankreich! - noch verzichtet. FRUS, Potsdam II, S. 889, 891. Zu Frankreich vgl. NA, RG 59/Pauley Mission, box 14, folder: France (OSS-Report L-123, 8. 6. 1945).

310 NA, RG 59, 740.00119 Control(Germany)/10-2646, /11-1446. Ciesla, Spezialistentransfer. Karlsch, Reparationsleistungen, S. $153 \mathrm{ff}$.

31 FRUS, 1946/V, S. 736 ff. 
auszudehnen und der Kontrolle über ihre eigenen Handlungen auszuweichen“. Selbst wenn deutsche Techniker und Wissenschaftler freiwillig nach England oder in die USA gegangen seien, müsse doch angesichts der geringen Kriegsschäden in diesen Ländern davon ausgegangen werden, „daß diese deutschen gelernten Arbeiter für andere Gründe als den Wiederaufbau in diese Länder gebracht worden seien“. Doch konnten Briten und Amerikaner die Gesamtproblematik auf die Frage reduzieren, daß nicht der Abschluß eines Vertrages, sondern dessen Freiwilligkeit der entscheidende Punkt war. Aber die Sowjets fanden unerwartete Hilfestellung bei den Franzosen, die selbst von den angeforderten Arbeitskräften eine Weigerung, die Arbeit im Ausland aufzunehmen, nicht akzeptierten. Zum Ärger der Amerikaner verwies der französische Vertreter darauf, gemäß Proklamation Nr. 2 des Kontrollrats vom 20. September 1945 sei Deutschland verpflichtet, „Arbeitskräfte, Personal und Spezialisten und andere Dienstleistungen zum Einsatz in Deutschland oder anderweitig bereitzustellen, wie es die alliierten Vertreter anordnen mögen“312.

Damit war zwar den britischen und amerikanischen Attacken der Wind aus den Segeln genommen, doch angesichts dieser wechselseitigen Verdächtigungen und Beschuldigungen ließ sich ein Einvernehmen nicht erzielen, da die Anglo-Amerikaner zu offenkundig auf einen Grundsatzbeschluß aus waren, der zumindest indirekt das Vorgehen der Sowjets verurteilte. Nachdem das Koordinationskomitee sich nicht einmal auf eine Absichtserklärung für zukünftige Fälle einigen konnte, mußte der Kontrollrat entscheiden. Dort verbuchten die Anglo-Amerikaner am 20. November 1946 einen Teilerfolg, da Sokolowski erklärte, seine Regierung werde in Zukunft nur noch Spezialisten auf freiwilliger Basis für spezifische Zwecke in der Sowjetunion einsetzen. Er verweigerte aber jede von den Westmächten geforderte Fixierung dieses Ergebnisses in einem Kommuniqué oder gar Gesetzentwurf mit dem Argument, daß angesichts seines Verzichts auf zukünftige Wiederholung eine rechtliche Regelung nicht erforderlich sei, da begrenzte Auslandsaufenthalte als eine Art „Besuch“ geschäftlicher Usus seien. Aus dem Wunsch nach Fixierung müsse er schließen, daß die Westmächte ihrerseits - wie diese bejahten - an derartigen Praktiken interessiert seien. McNarney behielt sich indirekt freie Hand vor, indem er auf sein Notstandsrecht verwies. Erst recht machten die Franzosen deutlich, daß sie gesetzliche Regelungen für den Einsatz von Deutschen im In- und Ausland anstrebten, vor allem im Zusammenhang mit den Demontagen und dem Wiederaufbau der gelieferten Fabriken. Sie zielten auf eine indirekte Zulassung von $Z$ wangsmaßnahmen gegenüber zivilen Arbeitskräften und drängten auf die Ausarbeitung gemeinsamer Regeln durch das Arbeitsdirektorat. Selbst wenn diese auf dem Prinzip der Freiwilligkeit und des Vertragsrechts beruhten, wäre der von ihnen geübten Praxis der Arbeiteranwerbung alliierte Zustimmung verliehen worden. „Das ist der Grund“, bekannte Koenig, ,warum mir sehr daran liegt, daß gewisse rechtliche Regeln zur Anwendung der Proklamation Nr. 2 festgelegt werden, damit den Deutschen nicht der Eindruck gegeben wird, daß die Versetzung von Arbeitskräften mit Gewalt geschieht. ${ }^{\text {"“13 }}$ Sokolowski hatte sein Zugeständnis in einen politischen Erfolg umgemünzt.

312 BA, Z 45 F/OMGUS, 2/118-2/1-7 (CORC, 29. 10.-16. 11. 1946).

313 Als ein Antrag Jugoslawiens bei der IARA, deutsche Techniker zum Wiederaufbau der Reparationsbetriebe (auf Zeit) zwangszuverpflichten, von dieser am 18.10. 1946 befürwortend an den Kontrollrat weitergeleitet wurde, mußte eine Entscheidung getroffen werden. Das Arbeitsdirektorat 
Es war Clay daher sehr unangenehm, daß ausgerechnet zu diesem Zeitpunkt die Briten im Kontrollrat die Einführung einer Arbeitspflicht im Kohlebergbau forderten $^{314}$, obwohl die USA im Herbst 1946 selbst derartige Maßnahmen unter Bezug auf den Kontrollratsbefehl Nr. 3 vom 17. Januar 1946 unterstützt hatten, der die Registrierung jedes Erwerbstätigen bzw. Erwerbsfähigen anordnete, die Zuteilung von Lebensmittelkarten von dieser Registrierung abhängig machte und Zwangseinweisungen von Arbeitslosen zuließ ${ }^{315}$. Da es „Präzedenzien“ in allen Zonen für Zwangsarbeit wie Arbeitszwang gemäß Befehl Nr. 3 gebe ${ }^{316}$, lehnte OMGUS aus Rücksicht auf die Briten (und die Kohleförderung) eine solche Maßnahme nicht prinzipiell ab, soweit sie

konnte eine Einigung nicht erzielen. Im Koordinationskomitee wollten die drei Westmächte am 14. 4. 1947 dem Antrag stattgeben, wenn die Genehmigung des jeweiligen Zonenkommandeurs vorliege, wenn die Rekrutierung über deutsche Stellen erfolge und wenn den Betroffenen ein Exemplar des Arbeitsvertrags vor der Abreise ausgehändigt werde. Die Sowjetunion war bereit, diesen Klauseln zuzustimmen, wollte die Grundsätze aber nicht durch Beschluß als „politische Richtlinie“ offiziell festgelegt, sondern nur als Einzelfallentscheidung behandelt wissen. Die Anglo-Amerikaner verlangten zusätzlich, deutsche Arbeitskräfte seien als „Export“ anzusehen und ihre Entlohnung dem jeweiligen Zonenkommandeur zu erstatten. Daran waren schon die Verhandlungen der drei Westmächte in Paris über den französischen Wunsch gescheitert, Arbeitskräfte in der Bizone anwerben zu dürfen. Das State Department grenzte seine Zustimmung weiter ein, indem es die Rekrutierung von Zivilisten prinzipiell nur zulassen wollte, soweit diese als Ersatz für Kriegsgefangene herangezogen würden. NA, RG 59, 740.00119 Council/4-1247. FRUS, 1947/II, S. 1104 ff. BA, Z 45 F/OMGUS, 2/118-3/10-21 (CORC/P(47)93, 10. 4. 1947). Trotz geringer Unterschiede in den Positionen war eine Einigung nicht möglich.

314 Gegen deutsche Proteste drängten die Briten im Mai 1946 in ihrer Zone auf die „zwangsweise Arbeiterrekrutierung“, vor allem eine „Arbeitsdienstpflicht von Jugendlichen“ im Ruhrbergbau, da der Altersdurchschnitt der Bergleute auf 43 Jahre gestiegen und kein Nachwuchs in Sicht war. Die Maßnahmen blieben unwirksam; 1946 schieden $73 \%$ der neu angelegten Bergleute wieder aus. AVBRD, Bd. 1, S. 453, 1081.

315 BA, Z 45 F/OMGUS, 2/118-1/17-21 (CORC/P(45)59, Revise und 2nd Revise). Das Koordinationskomitee hatte die Vorschläge des Arbeitsdirektorats vom September 1945 ohne Debatte akzeptiert. Wenn sich die Verkündung des Befehls Nr. 3 bis zum Januar 1946 hinzog, so lag das an bürokratischen Reibungsverlusten, nicht an inhaltlichen Differenzen. Die Einführung eines „Arbeitsbuchs“ kam nicht zustande, doch war im Prinzip die Einführung der Registrierung der gesamten arbeitsfähigen Bevölkerung im Arbeitsdirektorat unumstritten, die auch den Westmächten als Grundlage für die zwangsweise Heranziehung der Deutschen dienen sollte. Die CCG lehnte das „Arbeitsbuch“ als NS-Einrichtung ab, während deutsche Stellen, auch die Gewerkschaften, bei entsprechender Veränderung keine Einwände hatten. Aber im Koordinationskomitee und im Rechtsdirektorat war eine Einigung nicht möglich. 2/126-1/7-14 (DMAN/P(45)50, 57, 62).

316 In Berlin begann die SMAD kurz nach der Kapitulation, Bäcker oder Köche für den Bedarf der Besatzungsbehörden zu rekrutieren. Befehl Nr. 43 vom August 1945 drohte allen, die sich vor der zugewiesenen Arbeit „drückten“, mit Ausschluß von der Lebensmittelversorgung. Befehl Nr. 153 vom 29. 11. 1945 ordnete die Vermittlung Arbeitsloser ohne Rücksicht auf den erlernten Beruf an. Gemäß Befehl Nr. 178 vom 22. 12. 1945 mußte die Zentralverwaltung für Arbeit den sowjetischen Kriegsbeute-Abteilungen 218.000 Arbeitskräfte zur Verfügung stellen. Den Sowjet AGs wurden zunächst 13\% (290.000 Personen), später 17\% aller Beschäftigten „zugewiesen“; dabei „mußte zeitweise zu Zwangsmaßnahmen gegriffen werden, indem Leute von der Straße weggeholt werden mußten“. Der interregionale Ausgleich von Arbeitskräften erfolgte ebenfalls durch Zwangsverpflichtungen, die zu 90\% auf Anordnung der SMAD zurückgingen. Angesichts der volkswirtschaftlichen Folgen protestierten im Mai/Juni 1946 SED-Vertreter vergeblich bei den sowjetischen Behörden. SAPMO, ZPA, Nl 182/1189, Bl. 21. Im Januar 1947 protestierte die SED-Thüringen in Berlin, daß die SMA-Thüringen eine „rigorose Beitreibung von Arbeitskräften“ (,aus Kinos, Gaststätten, von Tanzsälen und von der Straße weg") betreibe und diese einer ,unwürdigen Behandlung“ aussetze, indem sie "geschlagen und bedroht“ würden. ZPA, Nl 90/314, Bl. 38. Befehl Nr. 234 vom Oktober 1947 ordnete nach deutschen Protesten eine Einschränkung der Zwangsmobilisierung an, da in den Betrieben der Widerstand wuchs. Mit dem Ende der Demontagen konnten die deutschen Behörden die Zwangsverpflichtungen auf $1-2 \%$ der Beschäftigten drücken. Zank, Wirtschaft, S. 58 ff., 104 ff. BAP, C-15/231, 510, 657, 659; L-1/190, Bl. 17. 
auf Notsituationen begrenzt blieb ${ }^{317}$. Das Arbeitsdirektorat hatte den Zwangseinsatz von Arbeitskräften innerhalb Deutschlands, einschließlich ihrer geographischen und beruflichen Umsetzung, im Sommer 1946 diskutiert. Damals hatte nur die Sowjetunion solches als „undemokratisch“ abgelehnt, da der Befehl Nr. 3 lediglich für Arbeitslose gedacht sei und da die Wohnungsfrage, die Entschädigung während des Transports sowie die Versorgung der Familien ungeklärt seien. Dagegen hatten die Briten im Hinblick auf die Notsituation im Kohlebergbau auf rasche Maßnahmen gedrängt; die USA hatten den deutschen Behörden die Möglichkeit für Zwangsmaßnahmen eröffnen wollen ${ }^{318}$; Frankreich war für eine vorsorgliche gesetzliche Regelung eingetreten. Noch im September waren sich die drei Westmächte einig, daß eine solche rechtliche Grundlage „wünschenswert“ sei, während die Sowjetunion auf ihren prinzipiellen Bedenken beharrte, aber gleichwohl das Zugeständnis machte, den Zwangseinsatz im Kohlebergbau „prüfen“ zu wollen ${ }^{319}$. Anders als auf der Ebene des Arbeitsdirektorats wandten sich Franzosen und Sowjets im Koordinationskomitee vehement gegen die Einführung von „Sklavenarbeit“ im Ruhrbergbau, die der Bericht der Kohle-Experten als letzte mögliche Maßnahme vorgesehen hatte. Sie verlangten wirtschaftliche Anreize zur Leistungssteigerung der Bergleute, während sie gleichzeitig alles taten, um eine Finanzierung entsprechender Maßnahmen durch Erhöhung des Kohlepreises zu verhindern. Grund dafür war die Passage im anglo-amerikanischen Entwurf, der die Zwangsumsetzung von Arbeitskräften ,notfalls auf interzonaler Basis“ vorsah, d. h. dem Kontrollrat ein weitreichendes Zugriffsrecht eröffnet hätte ${ }^{320}$.

Diese Debatte wurde weiter dadurch kompliziert, daß die USA Frankreich im Sommer 1946 gemahnt hatten, die Kriegsgefangenen nach Deutschland zurückzusenden, vor allem jene, die sie selbst überstellt hatten. Angesichts der wirtschaftlichen Probleme des Landes hatten sie auf Drängen Bidaults dieser Forderung lange Zeit keinen Nachdruck verliehen. Doch im November sahen sie Handlungsbedarf, nicht nur weil die eigene Öffentlichkeit es forderte oder weil die Sowjetunion die Repatriierung einer größeren Zahl von Kriegsgefangenen angekündigt hatte. Hinzu kam die Überlegung, daß die Rückkehr der „vielen Hochqualifizierten und Techniker [...] Deutschland in die Lage versetzen würde, einen größeren Beitrag zur europäischen Wiederherstellung zu leisten“; d. h. die Kräfte sollten zum Wiederaufbau Deutschlands eingesetzt werden, dem zumindest in dieser Hinsicht ein zeitlicher Vorrang vor der Rekonstruktion Westeuropas eingeräumt wurde. Bis zum 1. Oktober 1947 sollte Frankreich (ebenso Belgien, die Niederlande und Luxemburg) die Repatriierung abgeschlossen haben; zunächst wollten die USA nicht einmal die Umwandlung der Gefangenenarbeit in "freie“ Arbeit zulassen" ${ }^{321}$. Taktische Zwänge machten aber ein Nachgeben unausweichlich. Denn Frankreich hatte im Monnet-Plan vorgesehen, daß für 500.000 deut-

\footnotetext{
317 NA, RG 43/WWII\&PWConf, box 94, folder: Germany II (Acheson an Murphy, 2. 12. 1946).

318 Angesichts des Arbeitskräftemangels in Schlüsselbereichen drängten auch westdeutsche Stellen auf die Einführung einer Arbeitspflicht. Im Länderrat der amerikanischen Zone scheiterte im Mai 1947 ein Zonengesetz am Widerstand Bayerns. Ein Arbeitspflichtgesetz, das der hessische Landtag in Ausführung des Kontrollratsbefehls Nr. 3 am 26.6. 1947 erlassen hatte, wurde von Clay zunächst suspendiert und trat erst am 19. 8. in Kraft. AVBRD, Bd. 2, S. 303, 401; Bd. 3, S. 155. BA, Z 1/197.

$319 \mathrm{BA}, \mathrm{Z} 45 \mathrm{~F} / \mathrm{OMGUS}, 2 / 126-1 / 7-14$ (DMAN/P(46)69 und 129).

320 BA, Z 45 F/OMGUS, 2/118-3/10-21 (CORC/P(47)11 mit Appendix ,A').

321 FRUS, 1947/II, S. 980. FRUS, 1947/III, S. 621 ff. NA, RG 59/ASSOA, box 5, folder: 230.14
} 
sche Kriegsgefangene Ersatzkräfte erforderlich seien: deutsche Zivilarbeiter oder Displaced Persons. Die volkswirtschaftliche Bedeutung des Einsatzes von Kriegsgefangenen läßt sich daran ablesen, daß im Januar 1947 20\% der Bergleute in Frankreich deutsche Kriegsgefangene waren, die ein Drittel der französischen Steinkohle förderten ${ }^{322}$. Angesichts der schlechten Förderleistung der Ruhr und der Anforderungen des Kohle-Plans der Expertenkommission sahen die Briten jedoch keine andere Möglichkeit, als von Frankreich die deutschen Bergarbeiter zurückzufordern, die als Kriegsgefangene in den französischen Minen arbeiteten. Um die französische Wirtschaft nicht zu beeinträchtigen, sollte der Transfer schrittweise vorgenommen werden; gleichzeitig mußte, notfalls durch Zwangsmaßnahmen, sichergestellt werden, daß die Bergleute nicht anderweitig Beschäftigung aufnahmen ${ }^{323}$.

Die Franzosen antworteten mit der Forderung nach deutschen Ersatzkräften, waren aber nicht bereit, entsprechende Konditionen anzubieten. Sie wollten nur die Arbeitskräfte selbst, nicht aber deren Familien übernehmen; die Briten wollten dagegen die unproduktiven Esser nicht behalten, zumal die Franzosen sich weigerten, den Verdienst der deutschen Arbeitskräfte nach Deutschland zu überweisen, sondern sogar ein „Kopfgeld“ anboten, falls die Familienangehörigen nicht übernommen werden mußten. Auch die Bezahlung der Ersatzkräfte aus erbeuteten Reichsmark-Beständen, d. h. ohne Eigenbelastung, war für die CCG nicht akzeptabel. Im nächsten Schritt verlangten die Franzosen, die Entlohnung mit den deutschen Altschulden aus Dawesund Young-Plan verrechnen zu dürfen! Die Angelsachsen forderten demgegenüber, die Gelder - nach amerikanischen Schätzungen ein Betrag von \$9-10 Mio. - müßten als Devisenkredit zur Bezahlung von Importen verwendet werden. Die Franzosen antworteten mit dem Angebot, die Familien der Freiwilligen nicht nach Frankreich, sondern nur in ihre Zone zu übernehmen, um dem Überweisungsproblem auszuweichen $^{324}$. Erst im September 1947 kam ein Abkommen zustande, das Frankreich die Anwerbung von 25.000 deutschen Arbeitern, inkl. ihrer (genau definierten) Familienangehörigen, erlaubte, es mußte aber 25.000 Displaced Persons und „Volksdeutsche“ aus der britischen Zone in Österreich sowie Exil-Polen aus Großbritannien, ebenfalls inkl. der Familien, mit übernehmen ${ }^{325}$.

Mit den USA hatten ähnliche Verhandlungen im März 1947 stattgefunden. Da Frankreich nicht über die Dollarreserven verfügte, um beim weiteren Sinken der eigenen Kohleproduktion und beim Ausbleiben von Lieferungen aus dem Ruhrgebiet Ersatzkäufe in den USA zu bezahlen, durfte Frankreich den Gefangenen anbieten, sich

322 Böhme, Kriegsgefangene, S. 141 ff., 219 ff. In 383 Mio. Arbeitstagen erwirtschafteten die Kriegsgefangenen in Frankreich 6,2 Mrd. Francs (1938), das waren 1,9\% des Bruttosozialprodukts; 42,7\% waren in der Landwirtschaft eingesetzt. PRO, FO 1049/136. AMAE, Y 651, Bl. 142, 182. In Belgien waren $24 \%$ der Bergleute deutsche Kriegsgefangene.

323 PRO, FO 371/64362/C407 (7. 1. 1947); 64603/C9424 (12.6. 1947); 64602/C6688, C6877, C7498. NA, RG 59, 740.00119 Control(Germany)/12-246.

324 NA, RG 59/ASSOA, box 5, folder: 230.14. CP, S. 322 f. (12.3. 1947). PRO, FO 371/64603/C9424 (12. 6. 1947); 64602/C7497. BA, Z 45 F/OMGUS, 2/118-3/10-21 (CORC/P(48)2, 2. 1. 1948).

325 BA, Z 1/972, Bl. 2 ff. Trotz der Widerstände der französischen Gewerkschaften gegen den Einsatz von Fremdarbeitern wurden 10.000 polnische Kriegsgefangene bzw. Displaced Persons für die Kohlebergwerke angeworben, denen nach fünfjähriger Tätigkeit die französische Staatsbürgerschaft in Aussicht gestellt wurde. Die Übernahme von 36.000 baltischen Displaced Persons wurde abgelehnt, um Verwicklungen mit der Sowjetunion zu vermeiden. PRO, FO 943/342. FRUS, 1947/III, S. 624 . 
freiwillig weiter zu verdingen. Bis zum Juli hatten sich wider Erwarten 62.000 zum Bleiben entschlossen; schließlich waren es weit über 100.000 , nachdem die USA im November 1947 in Verträgen mit Frankreich und Belgien dieser Aktion zugestimmt hatten $^{326}$. Die übrigen Kriegsgefangenen sollten repatriiert werden, der Transfer der Löhne der ,freien Arbeiter“ nach Deutschland wurde geregelt, und die USA erklärten sich bereit, die französischen Bemühungen zur Rekrutierung freiwilliger Arbeitskräfte in ihrer Zone zu unterstützen ${ }^{327}$. Clay hatte erhebliche Vorbehalte gegen diese Regelung und behielt sich als Zonenkommandeur vor, die Rekrutierung zu steuern. In erster Linie sollten Displaced Persons oder Arbeitslose abgeschoben werden, um die zum Wiederaufbau der eigenen bzw. der Bizone benötigten Arbeitskräfte halten zu können. In den USA waren die Meinungen geteilt, ob nach den westlichen Protesten gegen die sowjetischen $Z$ wangsverpflichtungen die Anwerbung von Freiwilligen in die Zuständigkeit des Kontrollrats fiele; zumindest sollte dort die Frage der Geldüberweisungen geregelt werden, damit Frankreich auch in der SBZ bzw. in Berlin werben konnte und um eine zusätzliche Devisenquelle für Importe zu erschließen ${ }^{328}$. Dieser Punkt wurde erst Anfang Januar 1948 „gelöst“, als der Kontrollrat den französischen Vorschlag akzeptierte, daß jede Besatzungsmacht die Umtauschrate ihrer Landeswährung in Reichsmark selbst festlegte, ohne damit die umstrittene Tauschrelation bei Ex- und Importen zu präjudizieren. Die in ausländischer Währung bezahlten Löhne verblieben im Besitz des „verwahrenden“ Landes, während die auszuzahlenden Reichsmarkbeträge faktisch als zusätzliche Reparationsleistung von der jeweiligen Zone aufzubringen waren.

Vor dem Hintergrund dieser Debatten beschloß die Moskauer Außenministerkonferenz, bis Ende 1948 alle Kriegsgefangenen zurückzusenden ${ }^{329}$. Das Schicksal der deutschen Kriegsgefangenen in sowjetischer (und osteuropäischer) Hand hat überdeckt, daß die Westmächte ebenfalls solche als Reparationsarbeiter einsetzten und daß die Sowjetunion bis Ende 1948 im prinzipiellen Einklang mit den gemeinsamen Beschlüssen der Alliierten und des Kontrollrats handelte.

326 PRO, FO 371/64603/C9424, C9954, C9903, C12516. AMAE, Y 363, Bl. 129 ff. Piettre, Economie, S. 125. Böhme, Kriegsgefangene, S. 232, 251. Von dem Maximum der 720.000 Kriegsgefangenen im November 1945 arbeiteten nur $60 \%$; durch gezielte Entlassungen wurde der Anteil der Arbeitsfähigen $1946 / 47$ auf $80 \%$ erhöht. Von den 116.000 Gefangenen, die sich in zivile Arbeitskräfte umwandeln ließen, lebten 1949 noch 75.000 in Frankreich. Die Briten behielten 194820.000 Kriegsgefangene als Zivilarbeiter zurück. BA, Z 2/87, Bl. 131.

327 BA, Z 1/972, Bl. 6 ff. In einem Briefwechsel vom 25. 10. 1947 wurde Frankreich gestattet, in der amerikanischen Zone 20.000 Freiwillige anzuwerben: in erster Linie Facharbeiter, aber auch Ungelernte für den Einsatz im Kohlebergbau, bevorzugt im Alter von 18 bis 35 Jahren. Dafür verlangten die USA eine schnellere Entlassung der Gefangenen. Doch wurden die Zusagen nicht eingehalten, da OMGUS Verständnis für den Arbeitskräftebedarf Frankreichs zeigte. BA, Z 1/159, Bl. $121 \mathrm{f}$.

328 NA, RG 43/WWII\&PWConf, box 94, folder: Germany II (Caffery, 3. 12. 1946); RG 59, 740.00119 Council/4-1247. FRUS, 1947/III, S. 629-39. CP, S. 322 f. PRO, FO 371/64603 (CCG an FO, 1. 8. 1947).

329 FRUS, 1947/II, S. 382. Nach eigenen Angaben verfügten Mitte des Jahres 1947 die Briten über 372.000 Kriegsgefangene außerhalb Deutschlands, Frankreich über 535.000 (bei 500.000 bereits Entlassenen), die Sowjetunion über 890.532 (bei 1 Mio. Entlassenen), die USA über 13.633. BA, Z 45 F/OMGUS, 2/118-3/10-21 (CORC/P(47)238, 25. 11. 1947). 


\section{Sowjetische Gegenlieferungen}

Nachdem die Gebiete östlich von Oder und Neiße am 23. Juli 1945 durch die Außenminister aus dem Reparationsgebiet ausgeklammert worden waren, hatten Clayton und Pauley im Zuge des Potsdamer Reparationskompromisses die Vorstellung entwickelt, zum Ausgleich für die aus den Westzonen an die Sowjetunion zu liefernden Reparationen eine teilweise Kompensation durch Gegenlieferungen von Agrarprodukten und Rohstoffen vorzusehen ${ }^{330}$. Nach einem Entwurf vom 25. Juli sollten diese Güter, „einschließlich flüssigem und festem Brennstoff, Holz und Kali“, „für Westeuropa (einschließlich der Westzonen Deutschlands) aus Osteuropa (einschließlich der Ostzone Vorkriegs-Deutschlands)“, also inkl. der an Polen überstellten Gebiete, bereitgestellt werden. In verschiedenen Äußerungen von Byrnes und in weiteren Diskussionspapieren dieser Tage wurde, das sollte in den späteren Auseinandersetzungen wichtig werden, das Liefergebiet auf die sowjetische Besatzungszone begrenzt. Diese territoriale Regelung bezog sich eindeutig nur auf die Reparationen und nicht auf den Interzonenhandel: Ausrüstungsgegenstände im Werte von $\$ 2 \mathrm{Mrd}$. aus der britischen Zone, d. h. aus dem Ruhrgebiet, sollten gegen „Waren aus der sowjetischen Zone“ getauscht werden, „um so weit wie möglich die Notwendigkeit für Einfuhren nach Westdeutschland zu reduzieren und dazu beizutragen, den Bedürfnissen anderer alliierter Nationen entgegenzukommen. Diese Lieferungen werden den effektiveren Einsatz der europäischen Bestände ermöglichen und dazu beitragen, die Belastungen für Nachschub und Lieferungen aus Übersee zu verringern. “ Dagegen war der amerikanische Vorschlag vom 30. Juli sehr viel unpräziser, daß nämlich die Gegenlieferungen „uns von der sowjetischen Seite zur Verfügung zu stellen sind“331. In den letzten Entwürfen, nach mündlicher Übereinkunft zwischen Byrnes und Molotow, ging es nur noch um die Festlegung der zeitlichen Begrenzung, nach der diese Gegenlieferungen innerhalb von fünf Jahren abgeschlossen sein sollten ${ }^{332}$. Vergeblich blieben die Bemühungen der Briten, die schlesischen Gebiete reparationspolitisch dem Zugriff des Kontrollrats doch noch offenzuhalten: Polen sollte nach ihren Erwartungen 5 Mio. $t$ Kohle und Weizen für \$1 Mio. pro Jahr kostenlos liefern; darüber hinausgehende Mengen seien entsprechend zu vergüten ${ }^{333}$. Stalins und Molotows Feststellung, es handele sich „eigentlich um ein[en] Austausch von Reparationen“, blieb unwidersprochen, so daß die Sowjetunion davon ausgehen durfte, daß die Gegenlieferungen nicht von ihr, sondern von der SBZ, weniger den deutschen Ostgebieten aufzubringen waren ${ }^{334}$.

Nachdem die USA im Interesse des Kompromisses in Potsdam die Präzisierung der Liefergebiete aufgegeben hatten, suchten sie das nachträglich wieder zu revidieren.

330 DBPO, I, 1, S. 579 f., 617 f.

331 FRUS, Potsdam II, S. 868 (Anm. 2), 883, 885, 900, 912 f. DBPO, I, 1, S. 618. Potsdamer (Berliner) Konferenz 1945, S. 182 ff., 198, 202, 206, 222, 345. Hinter der Potsdamer Formel, nach der die Sowjetunion Reparationen aus den Westzonen erhalten sollte, stand sowohl das ökonomische Ziel, daß die Westzonen im Gegenzug Lebensmittel oder Kali beziehen konnten, als auch das politische Ziel, zu verhindern, daß die sowjetische Zone als "separate wirtschaftliche Einheit" behandelt werde. DBPO, I, 1, S. 920 f., 948 f., 1050-54, 1070 f., 1257 ff. DBPO, I, 5, S. 519 ff.

332 FRUS, Potsdam II, S. 449 ff., 513, 921 f., 926 f., 930 ff., 1593 f. DBPO, I, 1, S. 947 f., 1000.

333 DBPO, I, 1, S. 941 ff. Den Briten war bewußt, daß diese Position „not strictly logical“ war, da politisch weder durchsetzbar noch wünschenswert, indem Polen quasi als fünfte Kontrollratsmacht aufgewertet wurde. Dennoch trugen sie sie offiziell vor; ebenda, S. 1020.

334 Potsdamer Abkommen, S. 178. Potsdamer (Berliner) Konferenz 1945, S. 202. 
Truman erklärte Anfang August, die Gegenlieferungen dienten einer „ausgewogenen Wirtschaft“ in Deutschland, ,den üblichen Austausch von Gütern zwischen dem östlichen und dem westlichen Teil vorausgesetzt“. In seinem Bericht an den Präsidenten vom 20. September 1945 vertrat Pauley die Auffassung, daß zwar die Herkunft der Gegenlieferungen nicht spezifiziert sei, daß aber wegen des Zusammenhangs mit der Abtrennung der Gebiete östlich von Oder und Neiße „die Lieferverpflichtung der Sowjetunion auferlegt sei - nicht der Ostzone Deutschlands“. Dieses Prinzip hatte Pauley durch den Einschluß von „Öl und Ölprodukten“ unter den Gegenlieferungen zu verankern gesucht, um den Anspruch auf Erdöllieferungen aus Österreich, Ungarn und Rumänien zu wahren. Das war nach Forderung Wischinskis auf „Ölprodukte“ reduziert worden, die auch die SBZ zu liefern vermochte, so daß am Ende „Nahrungsmittel, Kohle, Holz, Kali, Zink, Ölprodukte und andere eventuell zu vereinbarende Waren“ ins Abschlußprotokoll aufgenommen worden waren ${ }^{335}$.

Insofern war das State Department unsicher: Der entsprechende Passus sei „zweideutig“; er widerspreche der sowjetischen Auffassung, die Gegenlieferungen sollten „ausschließlich“ aus der SBZ kommen, die weder über Zink noch über Kohle verfüge, doch schließe er keineswegs aus, daß ein Teil dieser Lieferungen aus der sowjetischen Zone kommen könne. Gegen die (inzwischen revidierten) Vorstellungen der Briten ${ }^{336}$, die Wirtschaftseinheit schließe die Entnahme der Gegenlieferungen aus der SBZ aus, weil das den Importbedarf erhöht hätte, schien dem State Department die rigide Festlegung auf Liefergebiete außerhalb Deutschlands weder gerechtfertigt noch durchsetzbar. Allerdings wurde die restriktive Interpretation Ende Oktober 1945 von Briten und State Department deutlich drängender vorgetragen, auch wenn man wußte, daß die Sowjetunion wohl kaum dazu bewegt werden konnte, diese ,in ihrer Gänze“ zu akzeptieren. Im Dezember versuchte Murphy das State Department darauf festzulegen, daß die Lieferungen ,von außerhalb der Grenzen Deutschlands, wie es vom Kontrollrat verwaltet wird, kommen werden“, um auf diesem Umweg die Gebiete östlich von Oder und Neiße doch noch dem Einfluß des Kontrollrats zu öffnen. Während Pauley sich der britischen Auffassung anschloß, akzeptierte Clay, daß das Potsdamer Protokoll der sowjetischen Position nicht ausdrücklich widerspreche. Noch hatte das ökonomische Argument Vorrang. Die USA hofften, daß mit der baldigen Aufnahme der Vorab-Reparationen auch die sowjetischen Gegenlieferungen beginnen würden, die sie - wie die Briten - für die Versorgung ihrer Zone bzw. Berlins einzusetzen gedachten. Die Gegenlieferungen sollten daher nicht als Importe, sondern als Reparationen betrachtet und bei der IARA reklamiert werden, um sie gegen die Kosten für Importe bzw. die eigenen Belastungen bei deren Vorfinanzierung aufzurechnen. Clay wurde aufgefordert zu erkunden, welche Güter die Sowjets zu liefern beabsichtigten. Im Dezember war anerkannt, daß im Falle einer Bewertung der Gegenlieferungen als Reparationen die IARA in diese Beratungen mit einzuschalten war $^{337}$.

Nachdem die Sowjetunion Anfang Dezember 1945 im Reparationsdirektorat auf die Angabe der gewünschten Güter gedrängt und Frankreich eine erste Liste eingereicht hatte, mußte eine Entscheidung getroffen werden. Doch das Direktorat erzielte keinen Konsens, so daß am 25. Februar 1946 das Koordinationskomitee eingeschaltet

335 FRUS, Potsdam II, S. 944 ff., 1506. FRUS, 1945/III, S. 1371 f.

336 FRUS, 1945/III, S. 1327.

337 FRUS, 1945/III, S. 1331, 1337, 1352, 1378 f., 1480 f., 1496 f. CP, S. 87. 
wurde. Wieder waren es die Briten, die auf Klärung der Frage bestanden, ob die Waren ,entweder von der UdSSR ohne Rückgriff auf die deutschen Ressourcen geliefert werden sollen oder, wenn sie aus Deutschland genommen werden, in einem Umfang und in einer Art geschehen sollen, die keine zusätzlichen Einfuhren auf der Grundlage des vereinbarten deutschen Mindestbedarfs erforderlich machen“. Sokolowski lehnte jede Festlegung der Liefergebiete ab; das Potsdamer Abkommen verpflichte die Sowjetunion lediglich, innerhalb von fünf Jahren zu liefern. Clay stimmte prinzipiell zu, daß „Rohstoffe und Produkte der Ostzone selbstverständlich [...] als Bezahlung akzeptiert werden sollten“, sofern - damit griff er den britischen Vorbehalt auf die Bedürfnisse der „deutschen Minimalwirtschaft“ berücksichtigt seien. Diesen Standpunkt erhielten die Angelsachsen auch im Kontrollratsbericht für die Moskauer Außenministerkonferenz aufrecht: „Sie könnten weder Güter als Reparationen gewähren noch im Austausch akzeptieren, die für die deutsche Minimalwirtschaft nötig seien, d. h. für die Wirtschaft Deutschlands als Ganzem." OMGUS arbeitete an einer restriktiveren „Interpretation von Potsdam“, nach der „die Verschiebung von Gütern innerhalb Deutschlands nicht als Bezahlung seitens der Sowjetunion für Industrieausrüstung aus den Westzonen angesehen werden könne“. Im Mai 1947 erhielt OMGUS aus Washington die Billigung für diesen Kurs, der die SBZ als Liefergebiet nicht ausschloß, aber unter Bedingungen, die eben das auf Umwegen erreichen sollten ${ }^{338}$.

Ähnlich wie bei den Restitutionen und den Vorab-Reparationen versuchten die Angelsachsen, auf der Ebene der materiellen Interessen die Sowjetunion zur Herstellung der wirtschaftlichen Einheit zu zwingen, die sie auf der institutionellen Ebene der Zentralverwaltungen nicht hatten durchsetzen können. Denn zweifellos war der sowjetische Rechtsstandpunkt legitim. Gerade die USA hatten in Potsdam dafür plädiert, die Wirtschaftseinheit auf dem Gebiet der Reparationen auszusetzen. Die Briten hatten dem trotz ihrer Bedenken ${ }^{39}$ zugestimmt, so daß die Rückkehr zu ihrer ursprünglichen Position eine Revision des Potsdamer Abkommens implizierte. Indem beide diesen Punkt zur Prinzipienfrage machten, schoben sie unter Hintansetzung der Bedürfnisse ihrer Zonen die Gesamtproblematik auf die lange Bank. Insgesamt hatten die Westmächte wenig Mühe, aus taktischen Erwägungen die Diskussion (vorübergehend) von der ökonomischen auf die politische Ebene zu verlagern, etwa um ihren Verzicht auf die Gegenlieferungen gegen den (teilweisen) sowjetischen Verzicht auf Reparationen aus laufender Produktion aus den Westzonen eintauschen zu können. Dies fiel ihnen um so leichter, da realistischerweise ohnehin „nie sehr viel Wahrscheinlichkeit“ bestand, daß die Gegenlieferungen „aus Gebieten außerhalb der deutschen Grenzen geliefert würden“340.

Der Grundsatzkonflikt konnte bis 1948 nicht gelöst werden ${ }^{341}$. Wirtschafts- und Reparationsdirektorat benötigten das ganze Jahr 1946, um sich unter Ausklammerung der politischen Dimension auf technische Rahmenentscheidungen zu einigen, die sie dem Koordinationskomitee im Januar 1947 vorlegten: wann und in welchem Umfang die sowjetische Verpflichtung zur Gegenlieferung eintreten sollte, ob bei Demontage,

339 DBPO, I, 1, S. 1052 ff., 1070.

340 NA, RG 59, 740.00119 Control(Germany)/9-1546 (Report, S. 34).

341 BA, Z 45 F/OMGUS, 2/102-3/1 (CORC/P(47)45, Tab: US-Brief, 20. 2. 1947). Eine Übersicht über die Verhandlungen in: 17/8235/5 (DRDR/PSEC(47)14, Appendix , $A^{*}$ ). 
Verladung, Grenzübertritt oder nach Empfang der IARA-Wunschliste; nach welchen Kriterien die Wertbestimmung vorzunehmen sei; wie die Transportkosten abgedeckt würden u.ä.m. ${ }^{342}$ Weitere sechs Monate vergingen, bis sich die Alliierten gegen den anfänglichen Widerstand der Briten über die Zuständigkeiten innerhalb des Kontrollrats geeinigt und das Reparationsdirektorat beauftragt hatten, dem Koordinationskomitee zwei Vorschläge zu unterbreiten: hinsichtlich der Herkunftsgebiete der Gegenlieferungen zum einen, der Preisfestsetzung und Bewertung dieser Güter zum anderen. Nach allen Erfahrungen im Kontrollrat genügte allein der zweite Bereich, neue zeitliche Verzögerungen zu bewirken. Obwohl die Sowjetunion immer wieder anbot, auch ohne die Klärung der prinzipiellen Probleme mit der Lieferung zu beginnen, und obwohl die IARA sich bis zum Januar 1947 endlich über die erste Liste der zu beantragenden Güter im Gesamtwert von 10 Mio. RM geeinigt hatte, war eine pragmatische Lösung nicht in Sicht, zumal die westlichen Besatzungsmächte den Warenkatalog der IARA nicht akzeptierten. Die Briten wollten Weizen, weniger für ihre Zone als für sich selbst, der auf dem Weltmarkt knapp war, während die USA und Frankreich Holz und Kali bevorzugt hätten. Ohnehin war die westliche Verhandlungsposition nicht günstig, nachdem z. B. die Briten bereits für 17,7 Mio. RM (1938) Vorab-Lieferungen geleistet hatten und im Grunde hätten akzeptieren müssen, was ihnen angeboten wurde. Indirekt betraf der Streit auch die Frage der Liefergebiete. Nachdem der Versuch, die Wirtschaftseinheit zu erzwingen, gescheitert war und die westzonale bzw. westeuropäische Rekonstruktion Vorrang gewonnen hatte, trat das ökonomische Argument wieder vor das politische. Clay plädierte daher für ein pragmatisches Vorgehen und empfahl, die Waren unabhängig von ihrer Herkunft zu akzeptieren, um sie einmal für den Aufbau im Westen einsetzen und zum anderen der Sowjetunion vorenthalten zu können ${ }^{343}$. Ähnlich dachten inzwischen auch die Briten. „Als die Warenliste des Potsdamer Abkommens zusammengestellt wurde, war es die Absicht, möglichst viele Waren zu benennen, die die Russen voraussichtlich außerhalb Deutschlands besorgen müßten. Wenn das Ergebnis der Moskauer Konferenz die anhaltende Trennung Ostdeutschlands von Westdeutschland ist, ist es für uns fast belanglos, woher die Lieferungen tatsächlich kommen. Aber wenn Deutschland als wirtschaftliche Einheit behandelt werden soll, dann ist es äußerst wichtig sicherzustellen, wenn wir können, daß diese Lieferungen von außerhalb der deutschen Grenzen kommen. "344 Nachdem sich die Außenminister auf ihrer Moskauer Ratstagung nicht über die politische und wirtschaftliche Einheit Deutschlands hatten einigen können, ließen sich die Gegenlieferungen erneut als politische Waffe im Reparationspoker verwenden.

Gleichwohl dienten die Debatten keineswegs nur der Verhinderung von Lösungen, auch wenn sich Anfang August 1947 die Verhandlungen im Reparationsdirektorat erneut festgefahren hatten. Die Sowjetunion behielt sich weiterhin die Entscheidung über die Liefergebiete vor, während ebenso unnachgiebig die USA auf ihrer Auffassung beharrten, die Gegenlieferungen müßten aus nicht-deutschen Gebieten kommen, „es sei denn, sie gehen über die Bedürfnisse der vereinbarten Minimalwirtschaft

342 Eine Ubbersicht in: BA, Z 45 F/OMGUS, 2/128-3/20 (DRDR/Misc(47)14, 17. 7. 1947); 2/118-2/ 8-20 (CORC/P(46)403, 403/1, 403/2 und 403/3).

343 CP, S. 349 f. (3. 5. 1947).

314 PRO, FO 371/65001/CE 1031. 
von ganz Deutschland hinaus und sind nicht exportierbar, um Gelder für die Erstattung der Besatzungskosten bereitzustellen“. Die Briten legten sich zunächst nicht fest; die Franzosen schlossen sich dagegen prinzipiell den USA an, griffen aber - da die Frage nur eine theoretische sei, solange die Wirtschaftseinheit nicht realisiert werde pragmatisch im Interesse baldiger Lieferungen den Vorschlag der Sowjetunion auf, die politischen Grundsatzfragen zurückzustellen ${ }^{345}$. Im Koordinationskomitee wiederholten am 12. September alle Mächte ihre Positionen. Robertson bezeichnete es (zu Unrecht) als „offensichtlich“, daß die Potsdamer Bestimmungen keine Lieferungen aus Deutschland meinten; die Produkte, die sie aus der SBZ zu liefern anbot, „gehören unter den Bedingungen der Wirtschaftseinheit nicht der Sowjetunion, sondern den vier Besatzungsmächten als der Regierung Deutschlands“. Aber, das war die überraschende Wende, da die Wirtschaftseinheit nicht bestehe, verdiene der französische Vorschlag „als eine praktische Lösung“ Beachtung. Clay drohte mit der neuerlichen Einstellung der Reparationslieferungen, wenn die Frage der Gegenlieferungen nicht geklärt sei, doch lenkte auch er schließlich ein. Nach längerer Debatte kam auf Vorschlag Noirets eine Kompromißformel zustande, die die Frage der Herkunftsgebiete bis zur Herstellung der Wirtschaftseinheit zurückstellte; die Sowjetunion verpflichtete sich dafür, über die Herkunft der Lieferungen Buch zu führen, so daß im Falle einer späteren Einigung eine Verrechnung erfolgen könne. Zögernd empfahl Clay seiner Regierung die Annahme „als eine vorläufige Maßnahme bis zur Einigung über die Vereinigung Deutschlands“. Nachdem sie von ihren Regierungen grünes Licht erhalten hatten, akzeptierten Clay und Robertson auch offiziell diesen Kompromiß ${ }^{346}$.

Allerdings waren noch immer drei Fragen zu klären: die Definition der Gegenlieferungen, ob sie „Teil der Reparationen“ seien und „auf Reparationskonto“ gingen; ob Verpackung und Transport in den Wertstellungspreis einzuschließen seien; ob Deutschland die Kosten ab Lieferort oder ab Grenze zu tragen habe. Es brauchte den ganzen Oktober, bis die Fragen pragmatisch ausgeklammert oder vertagt wurden, auch wenn Frankreich keine Lieferung akzeptieren wollte, deren Preis es nicht kannte. Der November verstrich, weil die IARA nicht in der Lage war, sich über die Verteilung der ersten Tranche zu einigen, weil keine Lieferorte benannt wurden und keine Experten zur Verfügung standen, die Qualitätskontrollen vor dem Versand durchführten. Im Dezember weigerte sich Großbritannien, die offerierten $1000 \mathrm{t}$ synthetisches Gummi zu akzeptieren, obwohl nach sowjetischen Angaben das Angebot schriftlich bestätigt worden war ${ }^{347}$. Nachdem das Reparationsdirektorat Ende November einen Einigungsvorschlag erarbeitet hatte, billigte das Koordinationskomitee am 15. Dezember 1947 das Tableau. Gemäß IARA-Beschluß vom November wurden auch Jugoslawien, die Niederlande, die Tschechoslowakei, Belgien, Griechenland, Indien und Ägypten zu Lasten des französischen und amerikanischen Anteils bedacht. Die Lieferungen sollten am 20. Dezember einsetzen ${ }^{348}$.

345 BA, Z 45 F/OMGUS, 2/118-2/8-20 (CORC/P(46)403/3, 7. 8. 1947; 403/4, 5. 9. 1947). FRUS, $1947 / \mathrm{II}, \mathrm{S} .1121 \mathrm{f}$.

346 BA, Z 45 F/OMGUS, 2/118-2/8-20 (CORC/P(46)403/5, 29. 9. 1947). CP, S. 433 f. (21. 9. 1947).

347 BA, Z 45 F/OMGUS, 2/118-2/8-20 (CORC/P(46)403/6, 14. 11. 1947). Die Sowjets boten im November 1947 an: $10.000 \mathrm{t}$ Weizen, $15.000 \mathrm{cbm}$ Grubenholz, $25.000 \mathrm{cbm}$ Nadelholz, $3000 \mathrm{t}$ Benzin, 1000 t synthetisches Gummi, 5000 t Gasolin. FRUS, 1948/II, S. 706.

348 BA, Z 45 F/OMGUS, 2/118-3/10-21 (CORC/P(47)250, 10. 12. 1947). NA, RG 335, box 45, folder: 387.6 Germany (OMGUS, Wilkinson, 23. 1. 1948). AO, Berlin/3276/2/2009. 
Zwischenzeitlich hatte der Marshall-Plan erneut die Parameter verändert. Der amerikanische Kongreß sprach sich im Interesse des raschen Wiederaufbaus ausdrücklich gegen weitere Demontagen in Deutschland aus, während das State Department mit Rücksicht auf den Marshall-Plan im Gegenteil die Wiederaufnahme von Kapitalgüterlieferungen ins Auge faßte, „um den frühestmöglichen Maximalbeitrag zur Wiederherstellung Europas durch ein Reparationsprogramm sicherzustellen“. Doch wenn - das war innerhalb der Regierung umstritten - Reparationen an Westeuropa geliefert wurden, um Ressentiments gegen den bizonalen Industrieniveauplan abzubauen und Forderungen nach laufenden Reparationen zuvorzukommen, dann mußte dies auch zur Wiederaufnahme der Lieferungen nicht nur an die „Satelliten“-Staaten, sondern ebenso an die Sowjetunion führen. In dem Falle war es sinnvoll, die sowjetischen Gegenlieferungen zur Beförderung der westeuropäischen, weniger der deutschen Rekonstruktion einzusetzen, obwohl das politisch die endgültige Einstellung des gesamten Reparationsprogramms erschweren mußte ${ }^{349}$. Auch die Briten drängten mit ähnlichen Argumenten auf eine Wiederaufnahme der Kapitalgüterlieferungen. Deren Einstellung müsse von der Sowjetunion als „endgültiger Bruch“ und als „Abschied von den Potsdamer Beschlüssen“ interpretiert werden. Die dann zu erwartende Einstellung der Gegenlieferungen werde die kleineren IARA-Länder um ihren ohnehin geringen Reparationsanteil betrügen, „deren wohlwollende Kooperation für den Erfolg des Marshall-Plans als Ganzem sehr wichtig ist“. Für die Besatzungsmächte werde die Einstellung dieser Lieferungen eine zusätzliche Belastung durch höhere Kosten in Deutschland bedeuten. Angesichts des geringen Umfanges der noch ausstehenden Lieferungen an die Sowjetunion sei es nicht zu verantworten, ein Ende des Interzonenhandels in Deutschland, wachsenden Widerstand der Kommunisten gegen die Demontagen in den Westzonen und gegen die „Aufrechterhaltung des Vier-MächteApparats" in Berlin zu provozieren ${ }^{350}$. Weniger im Interesse eines koordinierten Wiederaufbaus, der Deutschland zumindest als Planungs- und Bezugsgröße einschloß, sondern mehr noch im Hinblick auf die Durchsetzung der eigenen Reparationsinteressen gegenüber dem amerikanischen Kongreß, schien es vorteilhafter, unter Zurückstellung der alten prinzipiellen Positionen pragmatische Sofortlösungen zu erzielen.

Nachdem fast parallel auch die IARA-Länder selbst ihre entsprechenden Forderungen nachdrücklich geäußert hatten, war eine Einstellung der Reparationslieferungen an die Sowjetunion nicht mehr möglich. Auch Clay schloß sich den Argumenten der Briten an und wies darauf hin, daß ,die Verzögerung bei der Bezahlung von Gegenlieferungen nicht die Schuld der Sowjets war, sondern Folge der langen Verzögerungen, bis die Anforderungen der IARA eingingen. Die Sowjets erfüllen ihre Verpflichtungen." Im übrigen sei die Herkunft der Lieferungen aus der SBZ unerheblich, da es im Interesse des Westens liege, „so viel wie möglich von diesen ,Reparationen“ aus der Ostzone Deutschlands zu erhalten, die sonst in die UdSSR gehen“. Ein Abbruch aller Reparationslieferungen und damit wohl auch der Gegenlieferungen sei nicht nur mit Rücksicht auf die westeuropäischen Regierungen ausgeschlossen, sondern beide seien Teil eines Abkommens, „das wir in voller Kenntnis der Weigerung der Sowjetunion eingegangen sind, die anderen Bestimmungen des Potsdamer Abkommens auszufüh-

349 FRUS, 1947/II, S. 1116-26, Zitat S. 1120. Zu den Forderungen des Kongresses und den Diskussionen innerhalb der Regierung vgl. FRUS, 1948/III, S. $717 \mathrm{ff}$.

350 FRUS, 1947/II, S. 1139 f. (Bevin, 27. 12. 1947). 
ren“. Das State Department machte sich aus bündnispolitischen Rücksichten diese Argumente zu eigen, indem es - mit Zielrichtung Kongreß - darauf hinwies, daß eine Einstellung der Gegenlieferungen einen Nettoverlust in Höhe von 150 Mio. RM (1938) für Westeuropa bedeuten würde, daß andererseits diese Summe es nicht rechtfertige, ein Aufbrechen der westlichen Front im Kontrollrat zu provozieren. „Kurzfristig werden die von der Sowjetunion lieferbaren Waren in Westeuropa viel dringender benötigt als Kapitalgüter und würden direkt die finanzielle Bürde der Vereinigten Staaten im Rahmen des Marshall-Plans erleichtern." ${ }^{351}$ Mit anderen Worten: Die Gegenlieferungen wurden als Ersatz für die ausgebliebenen deutschen Reparationen aus laufender Produktion den Westeuropäern als Trostpflaster angeboten.

Daher hielten die Westmächte auch nach dem Ende des Kontrollrats an diesen Vereinbarungen fest ${ }^{352}$. Obwohl die Preisberechnung noch nicht geklärt war, schätzte OMGUS den Wert der sowjetischen Verpflichtungen auf etwa 60 Mio. RM (1938); im Februar 1948 legte der Kontrollrat diese auf 37,1 Mio. RM fest. Nach französischen Angaben hatten die Sowjets durch den Kontrollrat Vorab-Lieferungen im Werte von 86,3 Mio. RM (1938) erhalten (IARA: 358,3 Mio. RM), von denen insgesamt $60 \%$ (51,8 Mio. RM) durch Gegenlieferungen zu honorieren waren ${ }^{353}$. In der ersten Tranche waren bis zum 30. April 1948 Lieferungen im Wert von 8,2 Mio. RM fällig. Die tatsächlichen Lieferungen, die seit Februar 1948 pünktlich geleistet wurden (auf Wunsch der drei Westmächte fast ausschließlich nach Berlin), hatten dagegen nur einen Wert von 6,2 Mio. RM (1938), da die Sowjetunion für das verweigerte synthetische Gummi keine Kompensation anzubieten bereit war. Die sowjetische Anfrage nach den westlichen Wünschen für die zweite Tranche erfolgte nach Sokolowskis Auszug aus dem Kontrollrat am 20. März. Trotz anfänglicher französischer Zweifel konnten im Mai 1948, als die IARA ihre Wünsche mitgeteilt hatte, Verhandlungen mit der Sowjetunion aufgenommen werden, die $10.000 \mathrm{t}$ Weizen, $20.000 \mathrm{t}$ Roggen, 10.000 t Dieselöl, 20.000 t Braunkohlebriketts, 25.000 cbm Bauholz, 2300 cbm Grubenholz und einige kleinere Posten im Werte von insgesamt 10 Mio. RM ankündigte, von denen die USA sich Getreide und Braunkohle für die Versorgung Berlins aussuchten. Die Verhandlungen, in denen die USA im Namen aller Westmächte auftraten, wurden trotz der beginnenden Blockade Berlins am 10. Juni erfolgreich abgeschlossen ${ }^{354}$. Grundsätzlich widersprach ein solches Arrangement, das die uneingeschränkte Gültigkeit des Potsdamer Abkommens anerkannte (und in diesem Punkt gar die sowjetische Interpretation desselben), den Bedenken Clays, die Sowjetunion könne dies zum Anlaß nehmen, den Kontrollrat wiederzubeleben ${ }^{355}$. Doch auch ohne Kontrollrat waren beide Seiten bereit und in der Lage, ihre nationalen Interessen durch pragmatische Lösungen zu Lasten Deutschlands zu wahren, das aus seiner Verpflichtung, Reparationen zu zahlen, noch keineswegs entlassen war.

351 FRUS, 1948/II, S. 706-16.

352 FRUS, 1948/II, S. 754 (2.6. 1948), 758 f. (4. 6. 1948). CP, S. 665 f. (4. 6. 1948).

353 BA, Z 45 F/OMGUS, 2/97-3/1 (DRDR/CRD/P(48)2, 6. 2. 1948). Die USA gaben Lieferungen an die Sowjetunion von ca. 90 Mio. RM bis zum März 1947 an; 17/8235/5.

354 NA, RG 335, box 45, folder: 387.6 Germany (OMGUS, 19. 5. 1948). AO, Berlin/3282/6/2137A. Piettre, Economie, S. 123.

355 Vgl. unten S. 474. 


\section{Die deutschen Reparationsleistungen}

Die Höhe der deutschen Reparationsleistungen ist exakt nicht zu berechnen. Einzelne Dienstleistungen und Sachlieferungen bzw. personale wie dingliche Leistungen wurden nicht erfaßt, wie die Arbeitsleistung der Kriegsgefangenen oder der Zivilarbeiter, ganz zu schweigen von der „Kriegsbeute“356. Exporte wurden bewußt niedrig bewertet oder nur teilweise bezahlt, durch Manipulation der Umtauschraten zuungunsten Deutschlands verrechnet oder nicht in die Bilanz eingestellt ${ }^{357}$. „Unsichtbare“ Leistungen wie die direkten und indirekten Besatzungskosten oder die Bezahlung von Waren und Leistungen mit Beutemark, Militärmark oder „Zigarettenwährung“ wurden nicht als Reparationen gewertet ${ }^{358}$, ebenso Preissubventionen, Baumaßnahmen oder Versorgungsleistungen ${ }^{359}$. Die Verluste durch die willkürliche Festlegung von Amortisationswerten, Wertminderungen, Altschulden usw., die zu astronomischen Differenzen in der Kalkulation der Kosten führten, wurden von deutscher Seite „geradezu als eine Vergewaltigung" bezeichnet. Der Transfer von Know-how und technischen Fertigkeiten oder der Verlust bzw. die Wiedergewinnung von Drittmärkten, die für die Westmächte ungleich wertvoller waren als für die Sowjetunion, lassen sich nicht annähernd schätzen; schon gar nicht die Einnahmeausfälle. „Wenn eine Besatzungszeit von nur 10 Jahren zu Grunde gelegt wird“, so das Thüringer Wirtschaftsministerium, „so gehen bei den einzelnen Betrieben die gesteigerten Umsätze [auf russische Reparationsrechnung] in die Hunderte von Millionen. Der Ausfall an Steuern würde weitere Millionenbeträge ausmachen." Während die SMAD durch Beschlagnahmungen unter dem Titel „Kriegsbeute“ und Demontagen als Maßnahme der „Entmilitarisierung“ bis 1946/47 kostenlose Entnahmen im großen Stil praktizierte, wurden die Sowjet AGs zwar auf das Reparationskonto angerechnet, aber nur zu (geschätzten) $20 \%$ ihres Wertes ${ }^{360}$.

356 Bis zum 30. 9. 1945 entnahm Frankreich „Kriegsbeute“ im Wert von 30 Mio. RM, vor allem für die eigene Rüstungsindustrie, Luftwaffe und Marine. Manz, Stagnation, S. 30. Zur Sowjetunion vgl. Karlsch, Reparationsleistungen, S. 55.

357 Durch die Differenz von Inlands- und Weltmarktpreis erzielten die Bizonen-Mächte bei Kohle bis Ende 1947 einen Gewinn von \$202 Mio., bei Holz in ähnlicher Größenordnung, bei Strom von $\$ 50$ Mio., beim Export der Bizone von 1945 bis 1948 \$180 Mio. Die Verluste für die Exportwirtschaft der amerikanischen Zone durch Zwangslieferungen für die PX-Läden werden auf jährlich $\$ 10 \mathrm{Mrd}$. (sic) geschätzt. Abelshauser, Wirtschaftsgeschichte, S. 30 ff. Balabkins, Germany, S. 124, 132. Die Idee, deutsche Reparationslieferungen unter Weltmarktpreis zu kaufen, hatten die Briten Anfang 1945 entwickelt. PRO, FO 942/226 (APW(45)13, 26. 1. 1945).

358 Die Käufe mit alliierten Militärmark wurden vom Institut für Besatzungsfragen als Quasi-Requisitionen angesehen. Vgl. oben S. $284 \mathrm{ff}$. Die Schmuggel- und Schwarzmarktgewinne der Besatzungstruppen waren noch 1952 Gegenstand des Truppenvertrags. AAPD, Bd. 2, S. 88 ff.

359 BA, B 120/vorl. 272, S. 1-6. Frankreich setzte \$70 Mio. Besatzungskosten pro Jahr an, davon $\$ 40$ Mio. für Lebensmittel und \$30 Mio. für Verbrauchsgüter. AO, Berlin/3276/5/2019D (24. 11. 1947). Nach Art. 52 der Haager Landkriegsordnung ist ein besetztes Gebiet verpflichtet, im Rahmen seiner Möglichkeiten Leistungen für die Besatzungsmacht zu erbringen. Dabei sind die Besatzungs- von den Besatzungsfolgekosten zu trennen. Ersteres meint Zahlungen für die Befriedigung von Bedürfnissen der Besatzungstruppen im besetzten Land, also Dienst- und Nutzungsleistungen, Sach- und Werkleistungen, Bau- und Transportkosten, Entschädigungsleistungen für unerlaubte Handlungen von Besatzungsangehörigen u.a..m.; letzteres die Nebenkosten bei der Durchführung von Demontagen, Restitutionen und Entmilitarisierungsmaßnahmen, vor allem Löhne, die bei Abbau, Verpackung und Transport entstehen.

360 ThHStA, MWA/420, Bl. 67 (August 1946). Die Sowjetunion erkannte bei der Übernahme deutscher Betriebe durch die Sowjet AGs die Altschulden nicht an und überließ sie den Gläubigern. BAP, G-2/1044, Bl. 71 ff. Im Januar 1947 klagte die SED-Thüringen, die regionale SMA sei mit 
Die vorliegenden Berechnungen bzw. Schätzungen sind insofern nur „Mindest-Tabellierungen", die im Ost-West-Vergleich oft politischen Zwecken dienten und für die eigene Seite schöngerechnet wurden, indem z. B. die Kriegsbeute oder die Besatzungskosten nur für die SBZ, nicht aber für die Westzonen berücksichtigt wurden. Die „Reparationskartei“ des Bundeswirtschaftsministeriums berechnete für die drei Westzonen Gesamtentnahmen der Besatzungsmächte (ohne bezahlte Requisitionen und Dienstleistungen) in Höhe von 6,1 Mrd. RM Neu- bzw. 4 Mrd. RM Zeitwert (1938) bis $1958^{361}$. Die Besatzungs- und Besatzungsfolgekosten lagen allein in den Jahren bis 1948/49 dreimal so hoch wie die (von gleicher Stelle benannten) Repara-

Tab. 6: Die Besatzungslasten der drei Westzonen 1945-1948 (in Mio. RM/DM ${ }^{362}$ )

\begin{tabular}{lrrrr}
\hline & BBZ & USZ & FBZ & Gesamt \\
\hline I. Besatzungskosten & & & & \\
1. Arbeitskräfte (Inland) & 2502,6 & 2053,2 & 257,7 & 4813,6 \\
2. Nutzungsleistungen & 508,1 & 666,6 & 336,1 & 1510,6 \\
3. Sach-, Werkleistungen & 2413,4 & 1595,7 & 262,1 & 4271,3 \\
4. Bahn & 341,7 & 663,4 & - & 1005,1 \\
5. Post & 138,2 & 32,4 & - & 170,5 \\
6. Entschädigungen & 7,0 & 39,8 & 0,1 & 46,9 \\
7. Pauschzahlungen & - & - & 1237,1 & 1237,1 \\
8. Soldzahlungen & 370,1 & - & - & 370,1 \\
Summe von I. & 6281,0 & 5051,1 & 2093,2 & 13425,3 \\
II. Besatzungsfolgekosten & & & & \\
1. Displaced Persons & 1029,9 & 791,4 & 138,1 & 1959,2 \\
2. Kriegsgefangene & 715,5 & 88,1 & 32,7 & 836,4 \\
3. Haft, Internierung & - & 46,5 & 17,9 & 64,4 \\
4. Reparationen & 271,7 & 91,5 & 17,2 & 380,4 \\
5. Restitutionen & 13,5 & 13,9 & 9,0 & 36,5 \\
6. Entmilitarisierung & 192,5 & 38,3 & 53,5 & 284,5 \\
7. Sonstiges & 55,6 & 99,2 & 66,3 & 221,0 \\
Summe von II. & 2278,7 & 1169,0 & 334,8 & 3782,4 \\
Summe von I. + II. & 8559,8 & 6220,0 & 2427,9 & 17207,7 \\
\hline
\end{tabular}

Lohnzahlungen in Höhe von 1,5 Mio. RM bei Demontagearbeiten im Rückstand, Sozialbeiträge würden nicht abgeführt u.ä.m. SAPMO, ZPA, Nl 90/314, Bl. 38.

${ }^{361}$ BA, B 102/56573: Demontagen (4,2 Mrd. RM Neuwert bzw. 2,7 Mrd. RM Zeitwert), unbelegte Entnahmen (0,5 bzw. 0,37 Mrd. RM), Entmilitarisierung (0,67 bzw. 0,43 Mrd. RM) und Restitutionen (0,73 bzw. 0,5 Mrd. RM). Am stärksten betroffen war die britische Zone mit 4,3 bzw. 4 Mrd. RM, am geringsten die französische. Kramer (British Dismantling Politics, S. 150 f.) bewertet den Aussagewert dieser Angaben ,as most realistic estimate“, Buchheim (Wiedereingliederung, S. 79 f., 85, 95) dagegen als zu niedrig und schätzt die „einseitigen Belastungen Westdeutschlands durch die Besatzungsmächte" von 1945 bis 1948 auf $\$ 6,069$ bzw. $\$ 7,619$ Mrd. von 1945 bis 1950 . Setten (Zehn Jahre, S. 25) setzt die Belastungen des Bundeshaushalts durch Reparationen und Demontagen 1945-1950 mit 33 Mrd. RM/DM an. Die Bundesregierung benannte die Reparations- und Restitutionsschäden (inkl. der Ostgebiete) 1963 auf 22 Mrd. DM. Röper (Reparationen, S. 818) berechnet bis Ende 1963 für die Bundesrepublik 300 Mrd. DM Kriegsfolgelasten (Kriegsopferversorgung, Gefangenenentschädigung, Leistungen im Rahmen des Lastenausgleichs, Verpflichtungen aus dem Londoner Schuldenabkommen und Besatzungskosten, globale und individuelle Wiedergutmachungsleistungen, inkl. an Israel, und sonstige Kapitalleistungen).

${ }^{362}$ BA, B 120/vorl. 273 (Anlage 1). Leicht abweichende Zahlen für die Besatzungskosten (I.) in einer Gesamthöhe von 14,9 Mrd. RM/DM für die Jahre 1945 bis 1948 bzw. von 59 Mrd. RM/DM für die Jahre 1945 bis 1955 bei Oeftering, Besatzungslasten, S. 35. 
tionsleistungen von 1945 bis 1958 . Bis zum 31. März 1949 waren in den Länderhaushalten 17,2 Mrd. RM/DM als Besatzungskosten ausgewiesen, die Berechnungen des Instituts für Besatzungsfragen setzten indes Kosten von 21,1 Mrd. RM/DM an, da auf Anordnung der Siegermächte gewisse Zahlungen nicht als Besatzungskosten verbucht werden durften. Real betrug der Anteil der Besatzungskosten an den Haushalten der westdeutschen Länder 1946 und 1947 etwa 31\% und lag auch nach der Währungsreform bei rund einem Drittel.

Während die Sowjetunion 1953 eine „Abschlußbilanz“ über Zahlungen von \$ 3,658 Mrd. bis 1950 und \$ 0,634 Mrd. in den Jahren 1950 bis 1953 sowie \$2,8 Mrd. Lieferungen aus der laufenden Produktion vorlegte, d.h. über ca. $\$ 7 \mathrm{Mrd}$. insgesamt $^{363}$, liegen die westlichen Berechnungen für die SBZ um ein Vielfaches höher.

Tab. 7: Sowjetische Reparationsentnahmen aus der SBZ 1945-1953 (in Mrd. RM/DM) ${ }^{364}$

\begin{tabular}{lr}
\hline 1. Kriegsbeute (Sach- und Kunstwerte) & 2,00 \\
2. Demontagen & 5,00 \\
3. Zahlungen mit erbeuteten Banknoten & 6,00 \\
4. Zahlungen mit Besatzungsgeld & 9,00 \\
5. Waren aus laufender Produktion & 34,70 \\
6. Nebenkosten Reparationen (Verpackung, Versand) & 2,85 \\
7. Preissubvention für Reparationslieferungen aus deutschen Betrieben und Sowjet AGs & 3,30 \\
8. Ausstattung und Kapitalentzug der Sowjet AGs & 1,00 \\
9. Rückkauf der Sowjet AGs & 2,55 \\
Summe & 66,40 \\
\hline
\end{tabular}

Die zuverlässigste Schätzung dürfte insgesamt die von Fisch sein, der für die SBZ wie für die Westzonen in den Jahren 1945 bis 1953 etwa gleich große Leistungen von $\$ 16,3$ bzw. 16,8 Mrd. (1938) annimmt. Letztlich habe Gesamtdeutschland bis 1988 rund $\$ 50$ Mrd. (1938) gezahlt. Angesichts der unterschiedlichen Größenordnung von Bevölkerung bzw. Wirtschaftspotential lag die relative Belastung in Ostdeutschland jedoch deutlich höher. Die Leistungen der Westzonen bzw. der Bundesrepublik übertrafen zwar relativ die der osteuropäischen Satellitenstaaten, blieben jedoch hinter denen der SBZ/DDR zurück. Die vermutlich höchste Reparationsleistung hat indes, trotz eines geschätzten Reparationsanteils von ca. $30 \%$ des Bruttosozialprodukts in der unmittelbaren Nachkriegszeit, nach Auffassung von Fisch nicht die SBZ, sondern die französische Zone erbracht ${ }^{365}$. Entsprechend dem Grad der Belastung unterschiedlich waren auch die strukturellen Folgewirkungen. Das Brutto-Anlagevermögen der Industrie sank in den Westzonen von 1945 bis 1948 um knapp 10\%, in der SBZ um ca. $17 \%$, es hatte aber infolge der kriegswirtschaftlichen Maßnahmen in Mitteldeutschland 1945 mit 143,4\% von 1936 deutlich höher gelegen als in den Westzonen

363 Karlsch, Reparationsleistungen, S. 229. Karlsch hält diese Angaben für realistisch aus sowjetischer Sicht, da diese den Wert der Bezüge berechnete, aber nicht Gestehungskosten, Nebenkosten, Subventionen usw., die für die Deutschen konkrete Kosten und damit Leistungen bedeuteten. Die von der SMAD festgelegten Preise der Reparationsgüter deckten nach ostdeutschen Angaben nur 50 bis $80 \%$ der Kosten. BAP, G-2/1044, Bl. 71 ff. (8.-11. 1. 1947). Zugleich mußten von 1946 bis 1949 aus Landes- bzw. Provinzialhaushalten ca. 19,6 Mrd. RM an die Finanzverwaltung der SMAD abgeführt werden; das waren zwischen 48 und $76 \%$ der Gesamteinnahmen. Karlsch, Selbmann-Memorandum, S. 91.

364 DDR-Handbuch, S. 726. Vgl. Piettre, Economie, S. 123, 566 f. Cairncross, Price, S. 219.

365 Fisch, Reparationen, S. 178-225. 
mit $120,6 \%^{366}$. Trotz eines Substanzverlustes von $20 \%$ durch Kriegszerstörung, Verschleiß u.ä.m., von 30\% durch Demontagen bis 1948 und trotz einer Belastung von $50 \%$ durch Besatzungsleistungen aller $\mathrm{Art}^{367}$, erreichte das industrielle Produktionsniveau in der SBZ bis zur Währungsreform 1948 ca. $60 \%$ von 1936 - im Gleichklang mit den Westzonen. Aber bereits 1948 dürfte der Gütegrad des industriellen Maschinenparks unter dem der Westzonen gelegen haben ${ }^{368}$. Mit anderen Worten: Die SBZ lebte - nicht zuletzt infolge der Reparationen aus der laufenden Produktion - von der Substanz. Zwar wurde auch in den Reparationsbranchen der SBZ neu investiert, seit 1947 vor allem in der Eisen- und Stahlindustrie, doch wurden die (wohl teilweise) sowjetisch finanzierten Investitionsleistungen nachträglich über Reparationen aus der laufenden Produktion wieder abgeschöpft ${ }^{369}$.

Nicht zuletzt aufgrund der Erfahrungen von 1918 hat Deutschland, vielen propagandistischen Behauptungen der Besatzungsmächte zum Trotz, damit nach dem Zweiten Weltkrieg weit mehr an Wiedergutmachung geleistet als nach dem Ersten (und als von dem Potsdamer Abkommen vorgesehen), auch wenn abermals nur ein Bruchteil von dem an Wiedergutmachung für das geleistet wurde, was allein an Sachwerten zerstört worden war, von anderen irreparablen Schädigungen an Leib, Seele und Gesundheit der Menschen ganz zu schweigen.

366 Abelshauser, Wirtschaftsgeschichte, S. 20, 60. Matschke, Entwicklung, S. 62, 98, 247, 280.

367 Karlsch, Reparationsleistungen, S. 232 ff. Allerdings erreichte der Reparationsanteil wohl allein in Sachsen die 30\%. BAP, G-2/8724, Bl. 177; C-15/231 (11. 12. 1947). Nach Sokolowski wurden im 1. Quartal 1946 „nur“ $15 \%$ als Reparationen entzogen. SAPMO, ZPA, IV/2/602/21, Bl. 30 (1.6. 1946). Für 1947 wurden intern „12-20\%“ angegeben. Badstübner/Loth, Pieck, S. 90 (25. 10. 1946). Der Anteil der Sowjet AGs an der industriellen Produktion lag 1947 in Sachsen-Anhalt bei 50\%, in Thüringen bei $20 \%$. SAPMO, ZPA, N1 36/687, Bl. $84 \mathrm{ff}$.

368 Matschke, Entwicklung, S. 251. Die Entwicklung der industriellen Produktion 1947 im Vergleich zu 1936 betrug nach einer internen Aufstellung 9,412 Mrd. gegen 14,844 Mrd. RM (in unbereinigten Zahlen), d. h. 63,41\%; in der Metallurgie 0,241 zu 9,18, im Maschinenbau 1,15 zu 3,25, in der Elektroindustrie 0,25 zu 0,54, in der Chemie 0,60 zu 1,66 Mrd. RM usw. Nur der Bergbau wies mit 0,875 zu 0,694 Mrd. RM eine Steigerung aut. SAPMO, ZPA, Nl 36/687, Bl. 93.

369 Spätestens seit Mitte 1946 führte die Sowjetunion Rohstoffe, z. B. Baumwolle, in die SBZ ein und trug „Milliarden Rubel“ der Besatzungskosten selbst. SAPMO, ZPA, IV/2/602/21, Bl. 28 ff. Im Oktober erging der Befehl, das demontierte Stahlwerk Riesa in sieben Monaten neu aufzubauen. Teile durften im Westen gegen Dollar und andere Devisen gekauft werden, die die SMAD zur Verfügung stellte. BAP, G-2/1044, Bl. 9, 18, 24, 26. SAPMO, ZPA, IV/2/602/70, Bl. 183. 